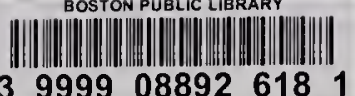




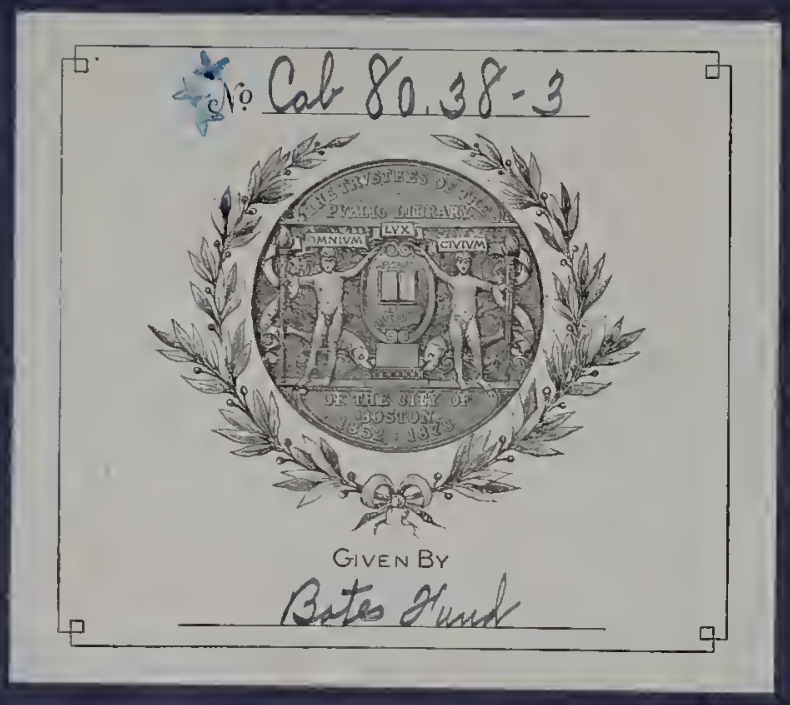



H.R.H. PRINCESS LOUISE, MARCHIONESS OF LORNE.

\title{
PLANT STUDIES
}

FOR ARTISTS, DESIGNERS, AND

ART STUDENTS.

\author{
CONTAINING \\ FIFTY FULL-PAGE PLATES, AND FIVE HUNDRED DESCRIPTIVE CUTS \\ ILLUSTRATIVE OF TEXT. \\ MUELIC LDIABY \\ एथ। \\ $\mathrm{BY}$ \\ GEORGE CHARLES HAITÉ.
}

LONDON :

BERNARD QUARITCH, I 5 PICCADILLY. 1886. 


\section{Hes.}

374.246

$796.17,1856$

II

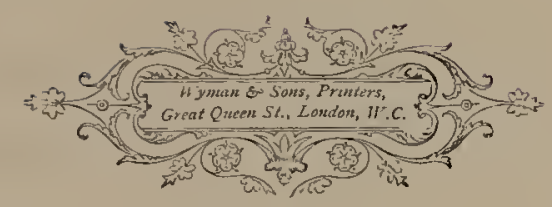

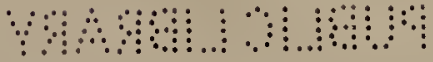

ॠ७ः

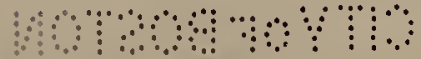

$x+606,50,38,3$ 


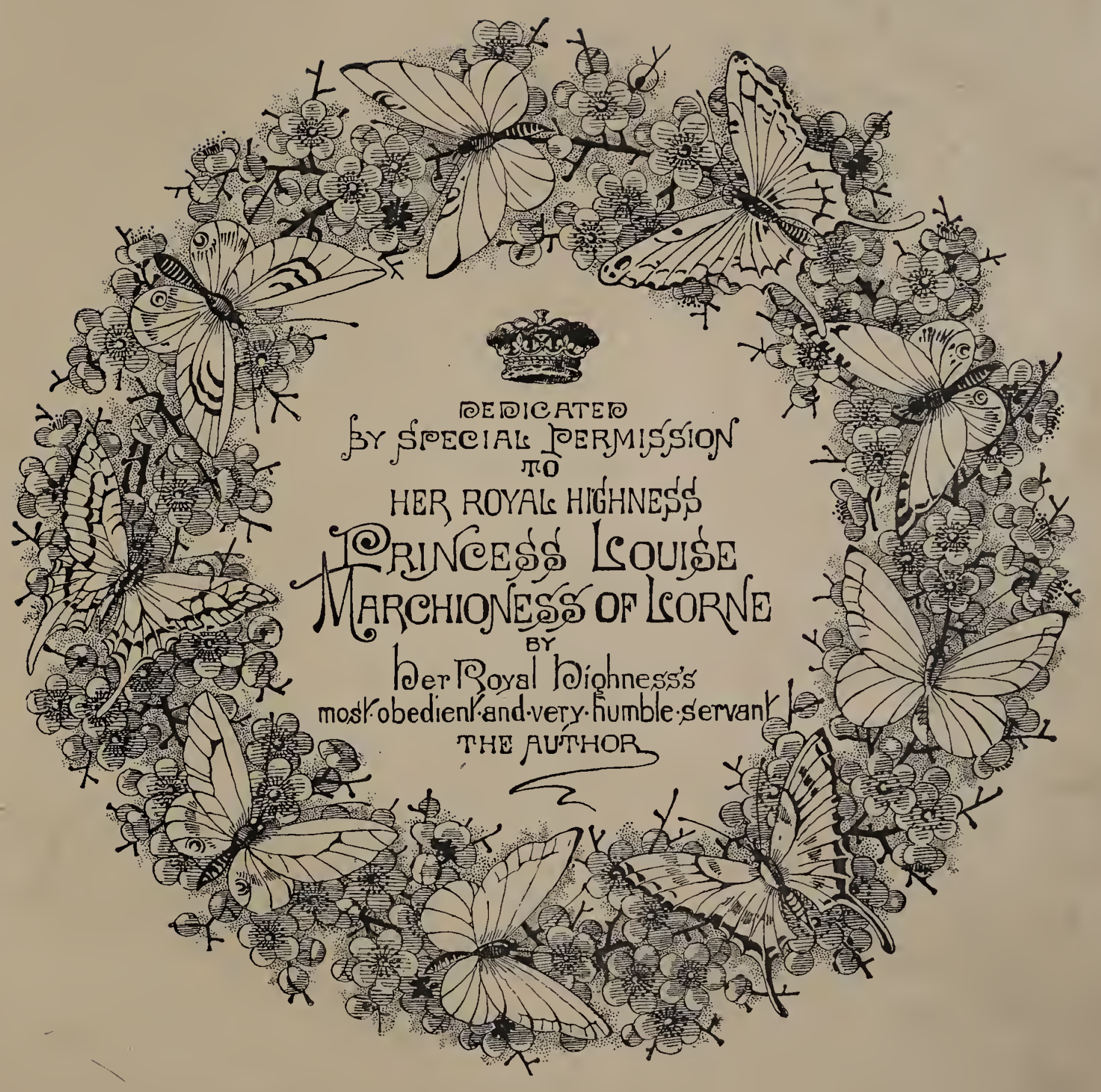




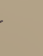

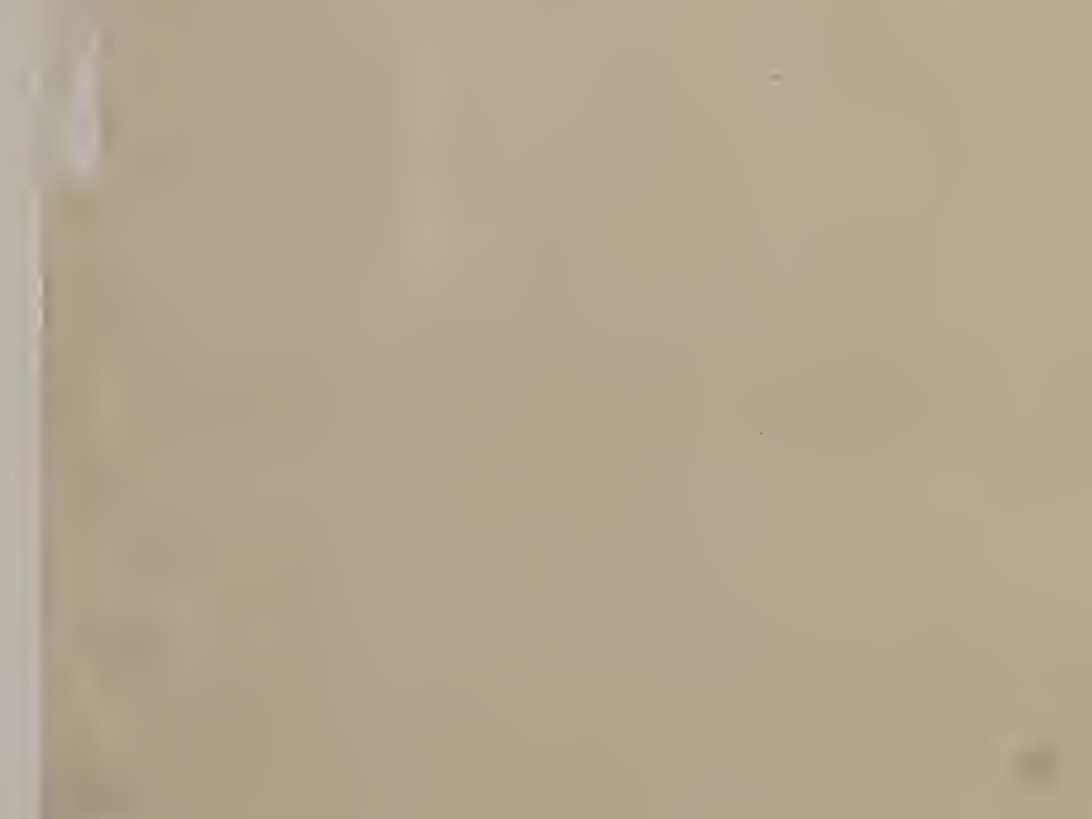




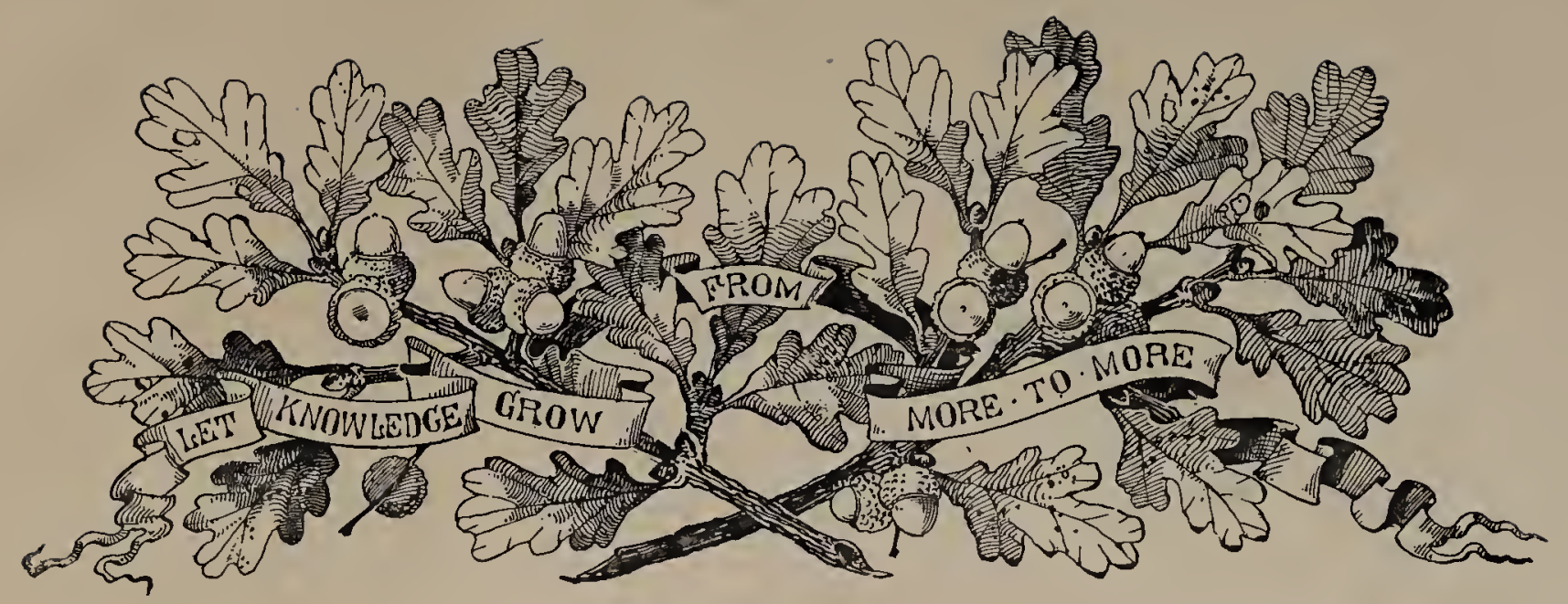

CONTENTS.

\begin{tabular}{|c|c|c|c|c|}
\hline & & & & bagc \\
\hline NTRODUCTORY REMARK & $\mathrm{kS}$ & $\ldots$ & $\ldots$ & $\ldots$ \\
\hline HE GARDEN PEA... & $\cdots$ & $\ldots$ & $\cdots$ &. \\
\hline HE NASTURTIUM ... & $\ldots$ & $\cdots$ & $\ldots$ & \\
\hline IE APPLE $\ldots$ & $\ldots$ & $\ldots$ & & \\
\hline HE CANTERBURY BELL & & $\ldots$ & $\cdots$ & $\ldots$ \\
\hline HE SUNFLOWER $\ldots$ & $\ldots$ & ... & ... & 8,13 \\
\hline HE BLACK BRYONY & $\ldots$ & $\cdots$ & $\cdots$ & $\cdots$ \\
\hline IIE CHRYSANTHEMUM & (PETER & R TIIE GP & REAT) & $\ldots$ \\
\hline HE BLACKBERRY ... & $\ldots$ & $\cdots$ & $\cdots$ & $\cdots$ \\
\hline HE MOUNTAIN ASH & $\ldots$ & ... & - & $\ldots$ \\
\hline HE CHRYSANTHEMUM & (MEG & MERRILI & (ES) & ... \\
\hline IIP OF THE WILD ROSI & $S E$ & ... & $\ldots$ & ... \\
\hline THE WHITE GRAPE & $\cdots$ & $\cdots$ & $\cdots$ & $\cdots$ \\
\hline HE POPPY $\quad \ldots \quad \ldots$ & $\cdots$ & $\ldots$ & $\cdots$ & \\
\hline rHe Mistletoe $\quad .$. & $\cdots$ & $\ldots$ & $\cdots$ & $\cdots$ \\
\hline HE QUINCE ... $\quad \ldots$ & $\cdots$ & $\cdots$ & $\cdots$ & $\cdots$ \\
\hline IIE VIRGINIAN CREEPE & & $\ldots$ & $\cdots$ & $\cdots$ \\
\hline HE CHRYSANTHEMUM & (MONS. & S. LEMC & E) & $\cdots$ \\
\hline HE YELLOW IRIS... & $\ldots$ & $\cdots$ & $\ldots$ & $\ldots$ \\
\hline THE DOUBLE POPPY & $\ldots$ & ... & $\cdots$ & $\ldots$ \\
\hline HE MEDLAR & $\cdots$ & ... & $\cdots$ & $\cdots$ \\
\hline HE WILD ROSE ... & .. & $\cdots$ & $\cdots$ & $\ldots$ \\
\hline HE OX-EYE DAISY & & $\cdots$ & $\cdots$ & $\cdots$ \\
\hline IE EVERLASTING PEA & & $\ldots$ & $\cdots$ & $\ldots$ \\
\hline
\end{tabular}

$\begin{array}{llllllll}\text { ASPARAGUS } & \ldots & \ldots & \ldots & \ldots & \ldots & . . & \text { bage } \\ 38\end{array}$ $\begin{array}{llllllll}\text { THE GOOSEBERRY } \ldots & \ldots & \ldots & \ldots & \ldots & \ldots & 39\end{array}$ $\begin{array}{llllllll}\text { THE HAWTHORN } & \ldots & \ldots & \ldots & . . & \ldots & \ldots & 40\end{array}$ $\begin{array}{llllllll}\text { THE WHITE } \operatorname{LILY} & \ldots & \ldots & \ldots & \ldots & \ldots & \ldots & 4 \mathrm{I}\end{array}$ $\begin{array}{lllllll}\text { THE SCARLET RUNNER } \ldots & \ldots & \ldots & \ldots & \ldots & 43\end{array}$ $\begin{array}{lllllll}\text { THE PASSION-FLOWER } & \ldots & \ldots & \ldots & \ldots & \ldots & 44\end{array}$ $\begin{array}{lllllllll}\text { THE HAZEL } & \ldots & \ldots & \ldots & \ldots & \ldots & \ldots & \ldots & 46\end{array}$ $\begin{array}{llllllll}\text { IRIS SEED PODS } & \ldots & \ldots & \ldots & \ldots & \ldots & \ldots & 47\end{array}$ $\begin{array}{llllllll}\text { THE FOXGLOVE } & \ldots & \ldots & \ldots & \ldots & \ldots & \ldots & 4^{8}\end{array}$

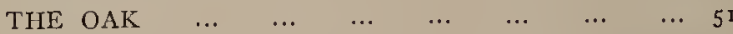
$\begin{array}{lllllll}\text { THE WILD CLEMATIS } & \ldots & \ldots & \ldots & \ldots & \ldots & 53\end{array}$ $\begin{array}{llllllll}\text { THE ALMOND } & \ldots & \ldots & \ldots & \ldots & \ldots & \ldots & 54\end{array}$ $\begin{array}{llllllll}\text { THE TOMATO } & \ldots & \ldots & \ldots & \ldots & \ldots & \ldots & 55\end{array}$ $\begin{array}{lllllllll}\text { THE IVY } & \ldots & \ldots & \ldots & \ldots & \ldots & \ldots & \ldots & 57\end{array}$ $\begin{array}{llllllll}\text { THE LABURNUM } & \ldots & \ldots & \ldots & \ldots & \ldots & \ldots & 59\end{array}$ $\begin{array}{lllllllll}\text { IHONESTY } & \ldots & \ldots & \ldots & \ldots & \ldots & \ldots & \ldots & 60\end{array}$ $\begin{array}{lllllll}\text { THE PYRUS JAPONICA } & \ldots & \ldots & \ldots & \ldots & \ldots & 6 \text { I }\end{array}$ $\begin{array}{llllllllll}\text { THE } & \text { HOP } & \ldots & \ldots & \ldots & \ldots & \ldots & \ldots & \ldots & 62\end{array}$ $\begin{array}{llllllll}\text { THE SYRINGA } & \ldots & \ldots & \ldots & \ldots & \ldots & \ldots & 6_{3}\end{array}$ $\begin{array}{llllllll}\text { THE HOLLYHOCK } & \ldots & \ldots & \ldots & \ldots & \ldots & \ldots & 65\end{array}$ $\begin{array}{llllllll}\text { THE GUELDER ROSE } & \ldots & \ldots & \ldots & \ldots & \ldots & 66\end{array}$ $\begin{array}{lllllll}\text { THE HORSE CHESTNUT } \ldots & \ldots & \ldots & \ldots & \ldots & 67\end{array}$ $\begin{array}{lllllll}\text { THE SYRIAN MALLOW } & \ldots & \ldots & \ldots & \ldots & \ldots & 69\end{array}$ $\begin{array}{llllllll}\text { THE RED BRYONY... } & \ldots & \ldots & \ldots & \ldots & \ldots & 70\end{array}$ 



\section{$-$}

$y$ 


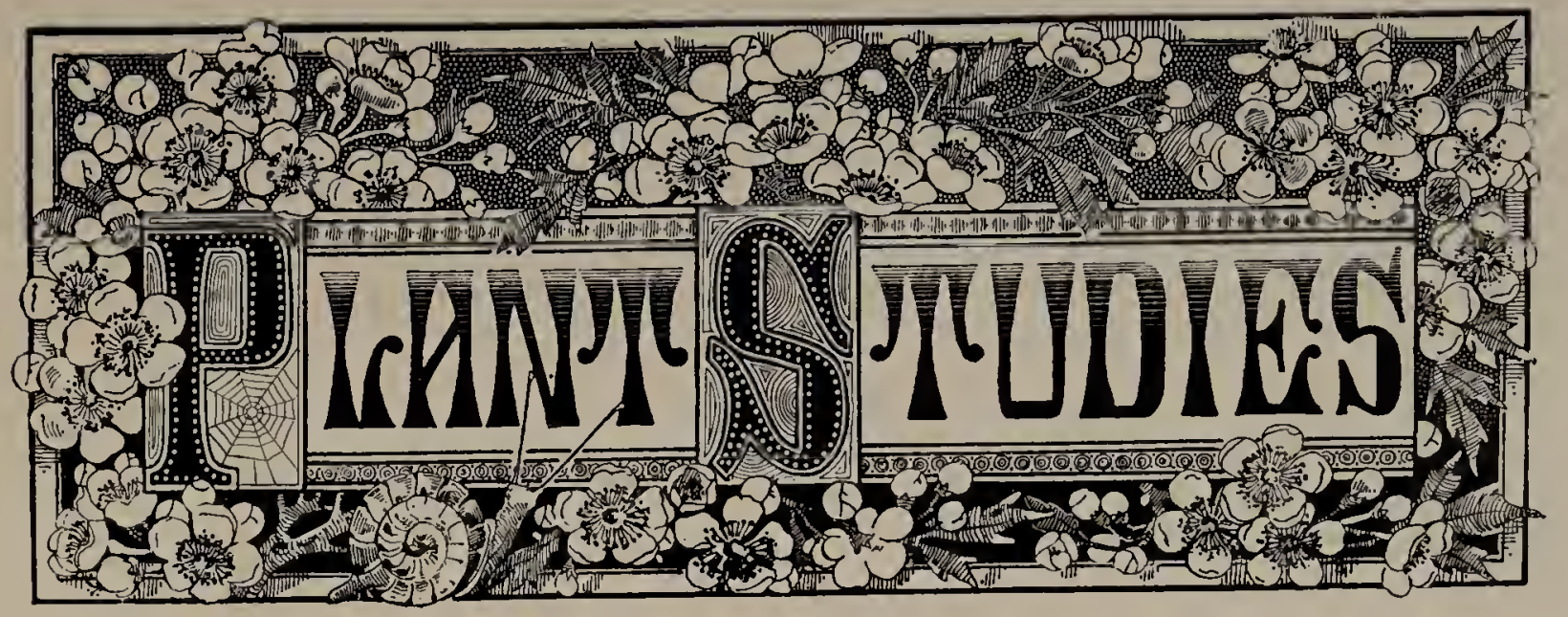

\section{INTRODUCTORY REMARKS.}

Oh, how much more doth bcauty bauteous scem,

By that swect ornament which truth doth give.-SHAKSPERE.

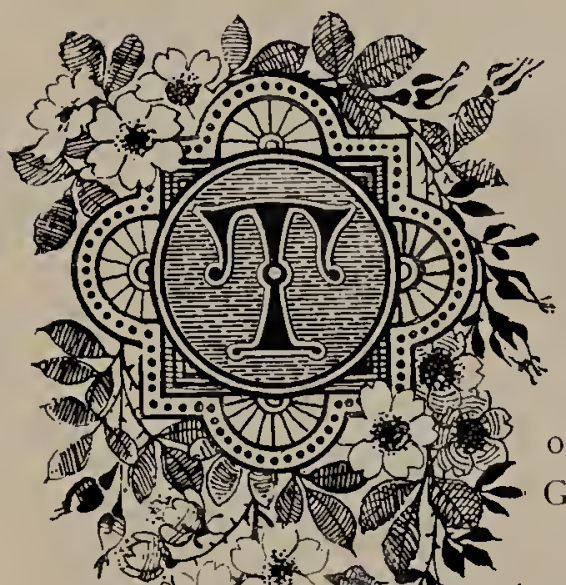

HERE would seem to most people little need for a new Series of Flower Illustrations, so many works of that kind, some of them of acknowledged excellence, having already appeared. Yet, numerous as they are, I am encouraged to enter the lists with the hope that my effort, intended, as it is, to be of a purely practical kind, may find favour. To most, if not all, Designers and Art-workers, and to no one more clearly than myself, the want of a Sketch-book or Portfolio of Plant Studies, for reference on the subject of Floral Growth and Form, is one that has made itself manifest.

Workers in the various branches of art-production have hitherto looked in vain for a collection of careful and accurate Studies from Nature, 2us ts affording examples upon which they could rely confidently in the execution of their own designs. There are, it is true, many publications professing to meet this very requirement; but I have found few examples in them of $1 \%$ conscientious study and the accuracy which the subject demands. Hulme's $-10.26$

Tis 30 20 "Plant Form" may be an exception, and it is certainly the most valuable work that has hitherto appeared; but, apart from the fact that it is now practically unobtainable, I think it often does not go deeply enough into the description
of the plants, while it certainly overlooks many of their most valuable and interesting features.

4. We meet with volumes of plates and illustrations, more or less truthfully drawn 10. and beautifully coloured, upon which a great deal of time and money have been i. expended, yet showing at most a spray from Nature or a very much curtailed botanical analysis. Such drawings, artistic as they may be, or such analyses, no matter how correct, fail to be of real practical use to the Artist; they either do not go far enough, or else not in the required direction, those salient points which appeal to and are most useful to the Designer receiving little if any attention. There is as a rule insufficient detail in these studies for a craftsman to utilise them in forming the design of the subject he has chosen, or to assure him that he comprehends the true growth and characteristics of a plant, its individuality, or anything of idiosyncrasy and caprice of Nature, the artistic value of which cannot well be overrated. The studies that are required, and that are of real practical value, are examples of Floral Growth such as an artist would himself select, drawn in the way that an artist himself would draw them with a view to utilising them at some future time. Moreover, the subjects should 
consist of such plants as most readily suggest features adaptable to the Dcsigner's requirements. Nany a flower may be quaint and rare, and yet lack those essential qualities which recommend it to the Artist, the true art of the Ornamentist lying more in the careful selection and application of his subject than in its quaintness or execution.

There would be little use in delineating a plant simply because it was eccentric in growth, novel in form, or rare in colour. I have on these grounds acted upon the safe plan of selecting only examples from which in my opinion good artistic results are obtainable. It is for the use of the Ornamentist, the Designer, the Wood-carvcr, the Metal and Stone Worker, the Painter of Pottery and Glass and the Student of every form of Art, that this Work is meant, it being, as far as possible, such a sketch-book as they might possibly have made for themselves. These black-and-white studies from Nature are not intended to look pretty, but to be faithful and serviceable working-drawings of the growth of flowers or shrubs and as sound a resource as may be had when the natural objects themselves are out of season or not within reach.

Suppose for instance an Artist requires something not in season, say a wild rose, and neither money nor glass-houses can procure him one. He must needs write to his professional friends, and, if fortunate, may after some trouble get a sketch of the plant, but that not a study at all, while as a working-drawing it is worse than useless. It may be either a beautifully-finished copy from Nature, manifesting the pains which the painter has taken to make a pretty little picture, or, on the other hand, it may be a slovenly and careless drawing. If he be compelled to utilise the drawing, trusting to memory for the growth and all that is wanting, it is only natural to expect that he will be at fault, giving wrong characteristics and a false growth. Work from well-considered studies never fails to impress with its trutll, even when the power of representation is far inferior to that shown in many productions less faithful to Nature. It is ever necessary for all work to impress us with its truth. Art is the delineation and embodiment of beauty and perfection, and must be true to be beautiful. If the drawing be untrue, although it may attract the eye, its greatest charm is lost and the right also of the production to the ennobling title of Art.

This fidelity does not necessarily restrict the Artist, for he can always invest his subject with interest and raise his work above the dull level of mere copyism, while still retaining the truth. His individuality should speak and assert itself, but never at the cxpense, of fidelity to Nature. The desire for originality, natural though it be and impatient of restraint, should not be allowed to lead him into the grave error of altering the fundamental structures of flowers. If his subject be the rose, the growth of the rose exclusively should be delineated. If his design be to represent the lily, let him exhibit the lily growth and none other. If, however, he wished to build upon an impression of his own, so to speak, selecting from the whole flora of Nature a foundation, taking all and every liberty with one or many growths, he would be justified in doing so, and might advantageously study the arts of India and Persia; but then his work must not be called a design in lilies, or what not, and must not appeal to others as a rendering of the rose or other flower he has utilised. The conventionalism must be at once apparent, avowed, and avowed boldly. There must not be natural flowers on a purely conventional growth. It is incxcusable in a Designer to delineate, for example, a bramble with a rose growth, although to the careless observer it may not appear incorrect.

It is not an uncommon thing for a tendril to be adapted as a standard growth; while in some cases unreality is carried to the extent of various plant-growths being engrafted upon a stem representing one particular flower, the Designer being plainly unconscious of the falseness and incongruity of his work. I cannot but admit there is some excuse for this frequent and apparent want of truth, since, apart from the difficulty of at all times procuring natural growths to study from, few can afford the time which the proper course of study demands. Before complete drawings or useful studies of a plant can be made much conscientious and careful work must be gone through, and this is a more expensive process than at first appears. In my own cxperience I have spent two days in studying a plant which I have had a commission to adapt, and which had not previously been used in the way prescribed.

Manufacturers and art-buyers, as a general rule, are loth to pay for this conscientious work; hence the great number of inferior productions. They lose sight of the additional value it would impart to their patterns and the healthy stimulus it would give to the art of designing, and are content to buy in a cheaper market from less scrupulous men, though their work be destitute of thought and devoid of artistic merit. 
These are my reasons for bclieving that there exists an absolute want of a Sketch-book, such as I have endeavoured to compile, of faithfully-drawn and well-described examples of Floral Form. I can only, in the interest of Art, regret that it has not becn undertaken by some one more gifted and competent than myself, both as Artist and Writer. I can promise however that the drawings shall be as carefully made and as truthful as it is possible for me to make them, and that the Work shall be as exhaustive as the means at my command will allow.

"Plant Studies," will form, when complete, a Portfolio, or Folio Volume, consisting of Fifty Plates of Photo-lithography, with descriptive letterpress and small illustrations to elucidate the text. The prominent characteristics and features most valuable to the Art-ivorker will receive due attention. The growth, nature, season of flowering, peculiarities and colour of each example will be described, and its merits for adaptation to various artistic purposes be pointed out.

In conclusion, I would impress upon all who may have occasion to use "Plant Studies," and I hope gain suggestions and assistance from it, the fact that, no matter how perfect the drawing may be, or how exhaustive the description, no other person's studies from Nature will or can be of such use to the true Artist as those he makes for himself. All the time and care he can bestow will be well repaid. In studying directly from Nature, features will strike his observant eye which would be undiscerned by other minds differently or less finely organised; and his sketch will, in after-years, although it may be at a time when he can afford to smile at the drawing, recall characteristics of growth, effects of colour, suggestions of adaptability and many points which no other drawings will enable him justly to appreciate.

Ornsiby Lodge, Bedrord Park, IV.

Nowember, 1883

GEO. C. HAITÉ.

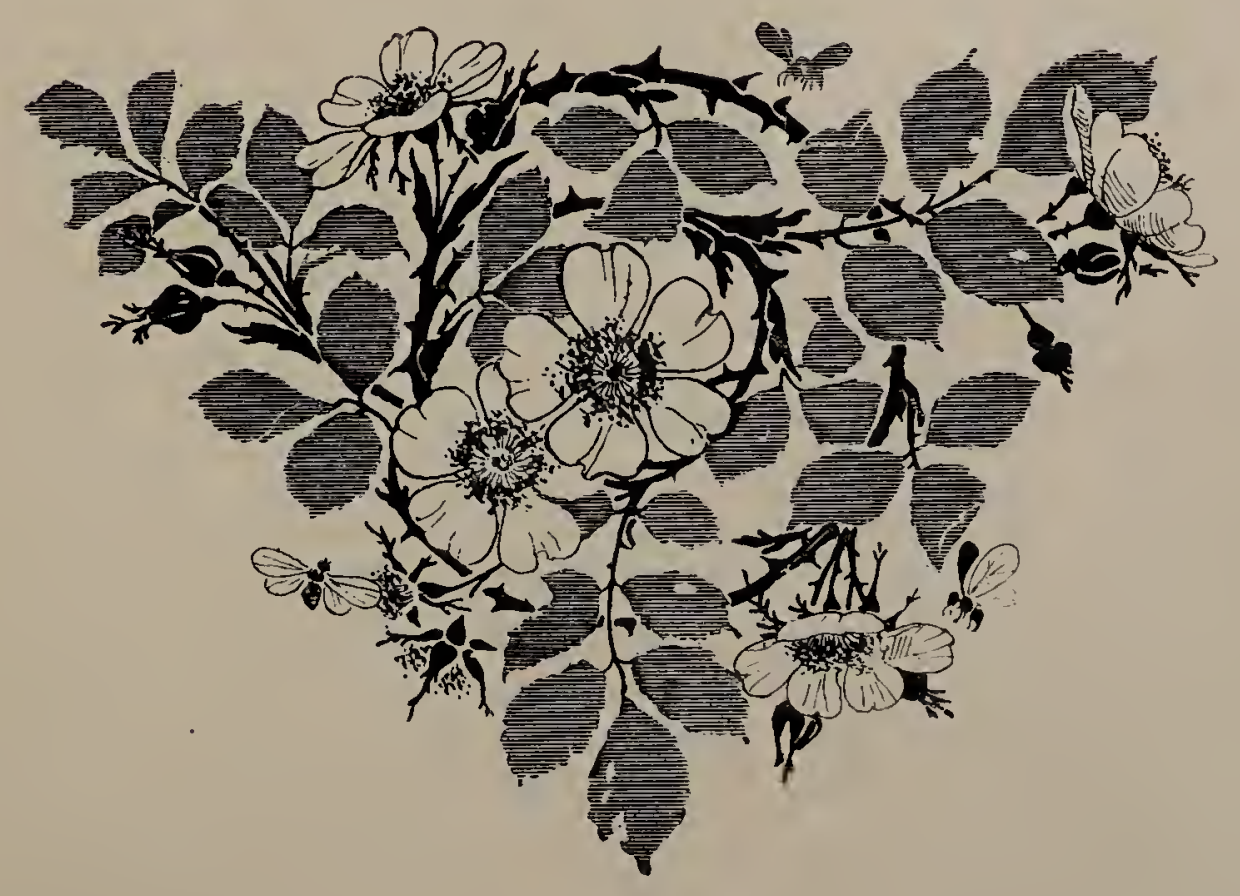





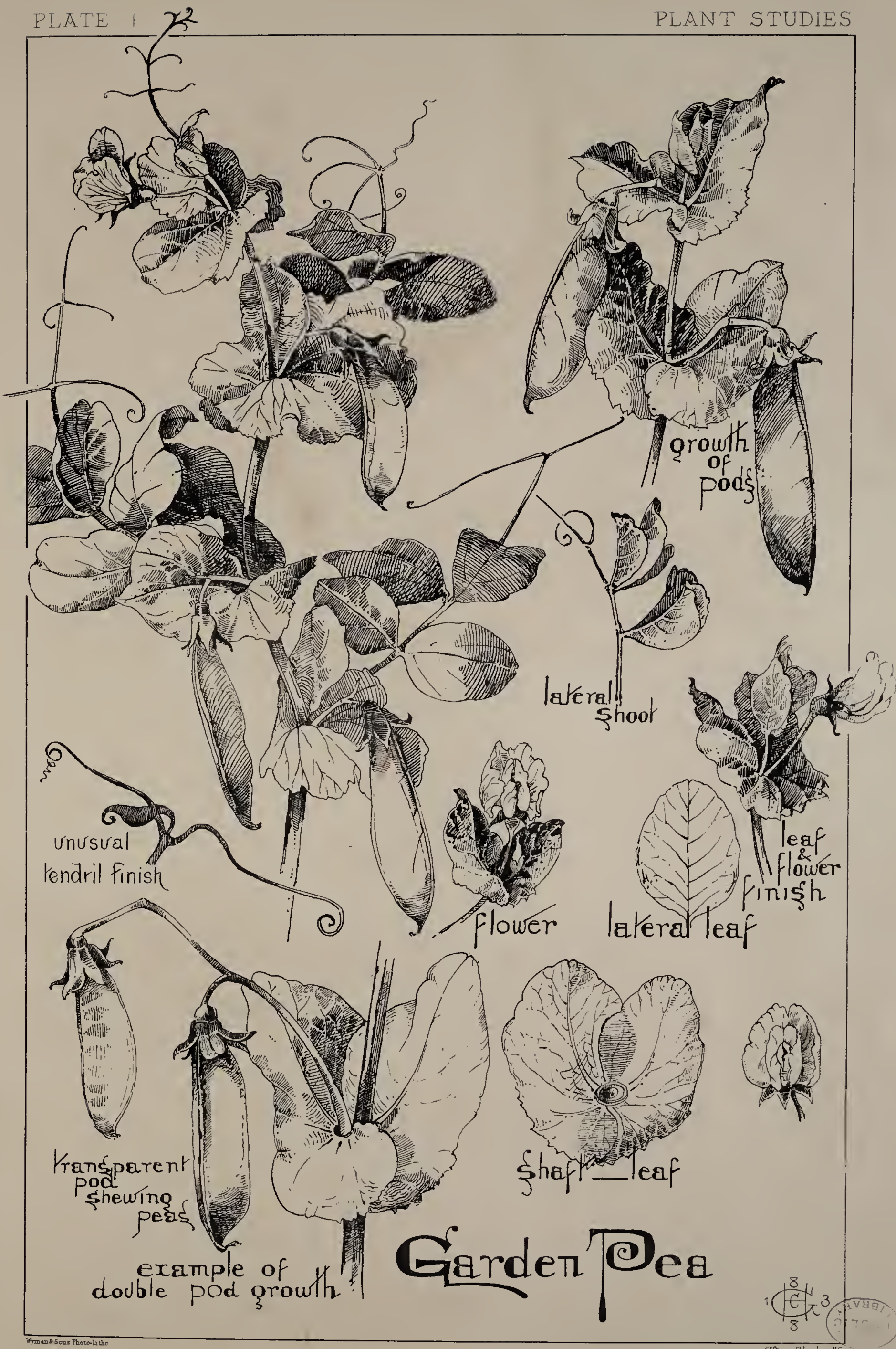





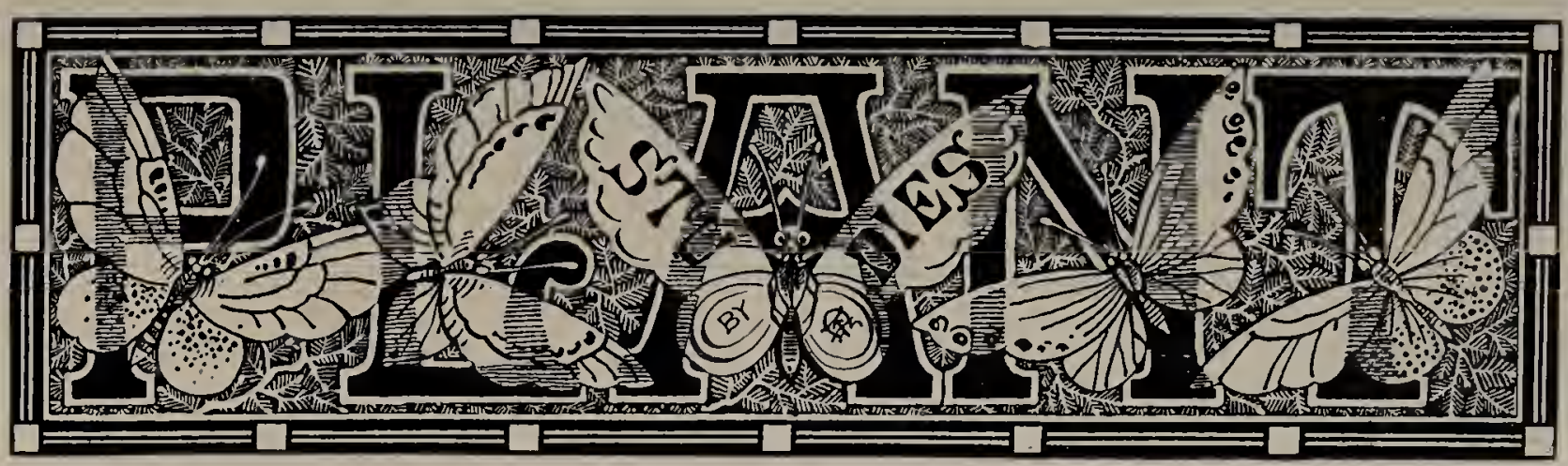

\section{Plate I.-THE GARDEN PEA.}

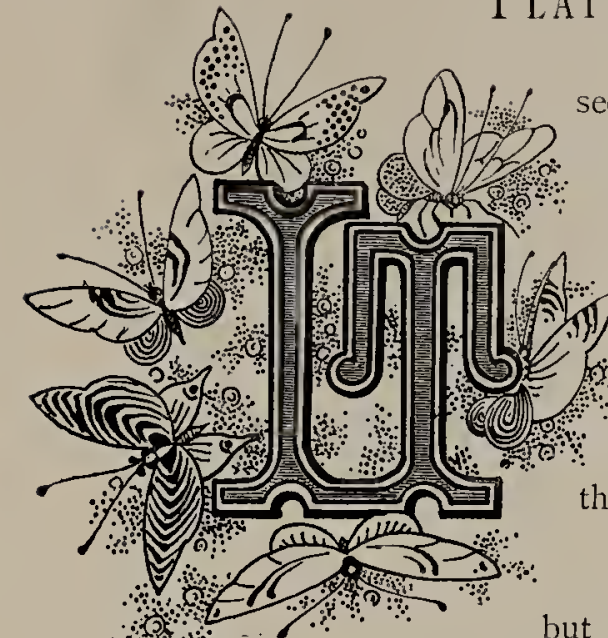

seems strange that vegetable growths are so little used for decorative purposes. This cannot be because they are lacking either in beauty or character. The grace of the scarlet-runner, of the sturdy-growing Garden Pea, or of the feather-like sprays and bright red berries of the asparagus, and the beauty of the ripening tomato, the potato flower, and many others which possess this qualification, are, I may say, quite neglected. Perhaps this may arise from the supposed inferiority of these plants and flowers to many others considered more decorative; but a little study will prove that they can well hold their own, for such purposes, against the more favoured flower forms.

I have heard it said that fruit in decoration becomes vulgar. but is this the fault of the fruit, or of the denied, as results testify W. It is much the same idea, accepted though unt which taboos the use of any as a merits as a design, or adaptability, but owing to the motif selected. I he opinion I hold as to the suitability of fruit and vegetables for decorative purposes, and I shall, therefore, show some of those above mentioned.

As my first illustration I take the common Garden Pea, which is severely decorative, and full of beauties, although, perhaps, it affords little opportunity for display of colour; yet, as a scheme of tender greens and greys, relieved by the milk white of the flowers, I do not know its equal, and its sturdy growth and beauty of form make ample amends for its limited colour
effect.

The growth is full of pleasing change, and yet rigidly severe in obedience to its fundamental laws. Being a climber, the tendrils are important and valuable as an artistic feature, twining, as they do, round the stalk and leaves in the most fantastic shapes. The single-hanging pods have their monotony relieved by an occasional couplet, as shown; while in some species the pods grow normally in couplets and triplets.

Notice the bold and decisive growth of the shaft-leaves from the main stem, and the lateral shoot branching off always from beneath (Fig. I). These shaft-leaves are distinct in shape from the lateral leaves, serrated, and grow in couplets, terminating The flower from the shaft-leaf, pea-pods, giving adthe plant, which is stages, from the

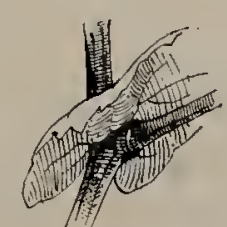

Fig. I. - Shinaft leaf,
showing tateral growth.

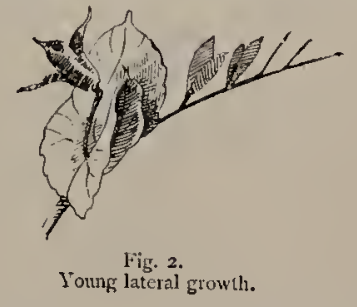
which are not pairs, always in two in a tendril (Fig. 2). stalks spring singly and develop into ditional beauty to then seen in all its young leaf and rower growth to the hanging pod, full ripe and sometimes half open, showing the symmetrical be useful in a design

fabric, flat decoration, suitable for adaptation to almost any material - stone, wood, brass, iron, every material or me inlay - its nature assisting the necessary treatment to suit each and perhaps for me greater for one more than another, it is grills, gates, \&c could Some really beautiful foliated work of this kind for brackets, lamp-pendants, valuable, and the imperially when on the pod, could be made very to the oval-shaped importance of the latter, either in a rounded form or beaten out flat, as a relief and habit of twining Haite's Plaut Sturcises. 
treated in an angular or flowing growth, fluted or round, while the tendrils at once offer themselves as the means of tying in.

In the illustration, I give an unusual example of tendril finish with a kind of leaf development; this in metal, copied direct from nature, would appear, even to the skilled, the outcome of careful adaptation.

\section{Plate II.-THE NASTURTIUM.}

$\mathrm{T}$

IIIS flower, remarkable both for the long spur of its calyx and its almost circular leaves, is very common and to be found in most gardens. From late spring until killed by the early frosts of winter this flower puts forth a succession of blossoms, and all stages of its growth may be seen at the same time, from the early bud-shoot to the ripening seed.

It displays, too, a great variety of colours, from the pale lemon to the deepest orange yellow, from delicate salmon to deep claret red. The species shown is of a rich golden yellow with deep dragon's-blood red markings. The blossoms are formed of five irregular petals, the three lower being fringed or bearded (Fig. 1), and having a smaller centre marking than the two top petals. The calyx develops into a most characteristic spur-like appendage, the local colour, which is of a paler shade than the flower, graduates into a delicate green at the tip (Fig. 2). Just as the bud bursts from its pale green sheath it is of a rich orange colour, or red, as the case may be; then, as it develops, it becomes somewhat paler, until it bursts forth in all the gorgeous colours of the full flower. The nature of the plant is to trail along the ground, throwing its leaves and flowers upward as is shown in the stem growth (see plate), but it is a good climber, and, moreover, an ambitious one, twining round and round its brother shoots if there be nothing else near. The stalks and branches adapt themselves to all manner of quaint and cramped positions in this desire to climb, and, having found suitable conditions, they sometimes reach to a considerable height, their glowing blossoms adding greatly to the beauty of the encumbered shrub or support. A wall covered with ivy, or many a shrub in itself flowerless or unassuming, sometimes becomes strangely beautiful through the intrusion of the gaily-coloured Nasturtium.
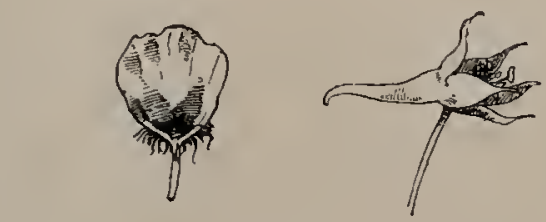

Fig. 1.- Lower bearded petal. Fig. 2,-Spur and calyx.

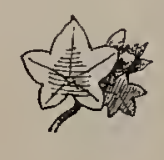

Fig. 3.-Joined leat.

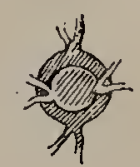

Fig. 4. -Section of stalk.

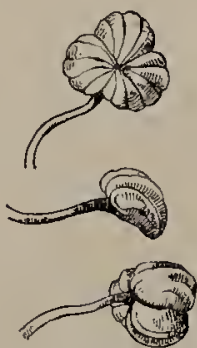

Fig. 5. - -Seed.

The flower stalks and lateral shoots grow from the stem joint of the leaf. The younger leaves are palmate (Fig. 3); but they lose the divisions as they develop, and the leaf gradually assumes a circular shape, with the stalk attached, not to the edge of the blade, but beneath it, a trifle out of the centre. The ribs, nine in number, spring from a point directly over the stalk, the body of the leaf is filled up with lacc-like traceries of a paler colour. Both the buds and leaves grow singly, and spring from the stem alternate (Fig. 4). The seed, very beautifully formed, is divided into three triangular lobes (Fig. 5). To the art-worker this plant is full of suggestions-for needlework (the leaves and flowers particularly lending themselves to appliqué work), for hand or machine-made lace, in which the leaves might be formed by an ornamental vein treatment, for painting on silk or ivory for fans, furniture coverings or fabrics, on vases and plates in pottery painting, and in flat decoration, with the aid of some standard or branching growth, while its running character at once suggests its adaptability to friezes and borders.

\section{Plate III.-The APPLE.}

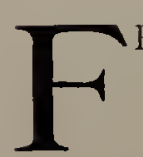

ROMI its early crimson buds and rosy-tipped wax-like blossoms in May to the ripened fruit of Autumn, few trees can vie in beauty with the Apple. Even when devoid of leaves, its gnarled branches and rugged lichen-covered trunk are full of picturesque beauties.

The source from whence we derived our cultivated Apple is somewhat obscure; but it has undoubtedly become the typical fruit of England, the climate and soil seeming to be specially adapted to it. The Apple is mentioned by the most ancient Greek writers. In Pliny's time it was grown in abundance in the villages around Rome, and it is probable that cultivated varieties were first introduced into our island by the Romans. 

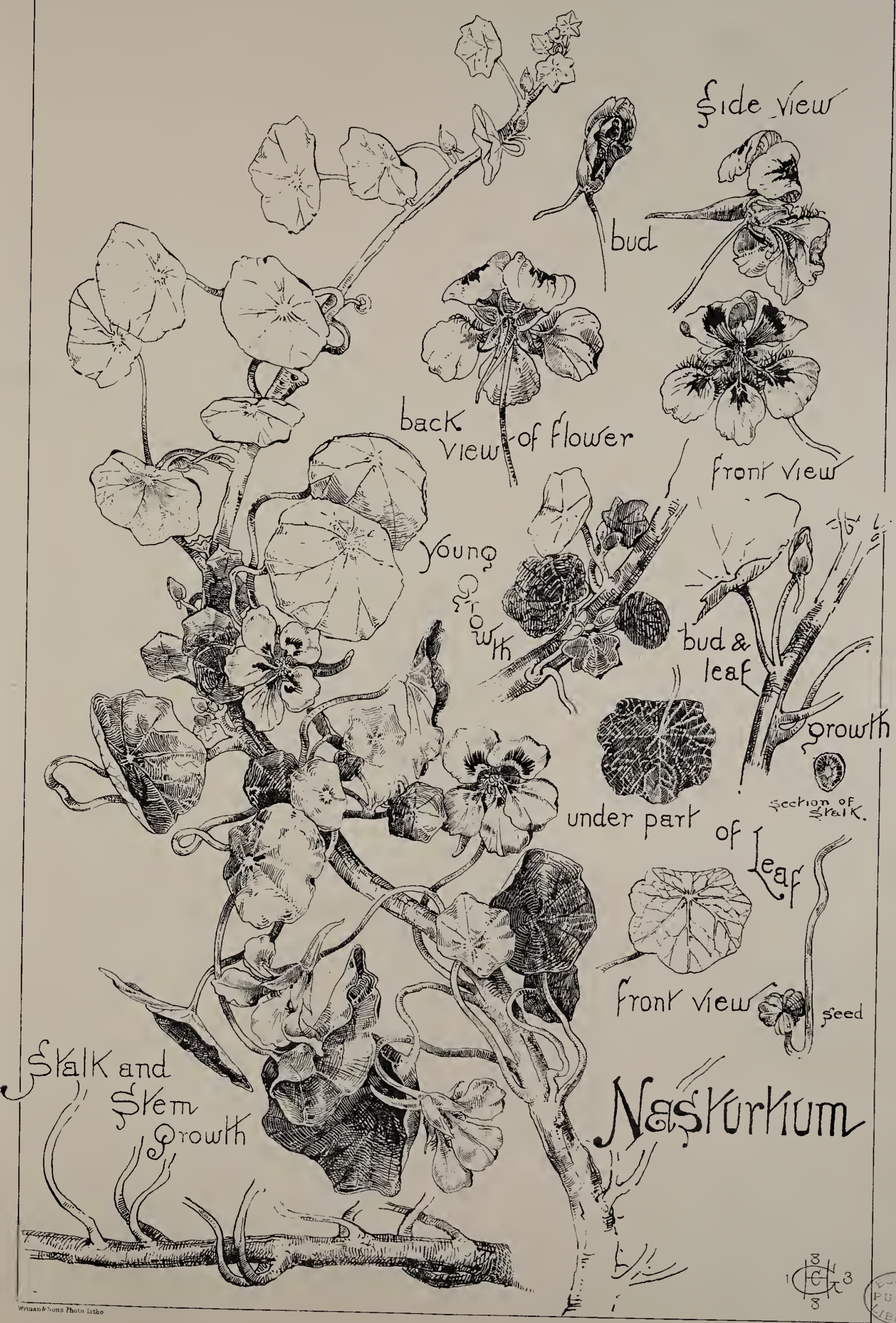



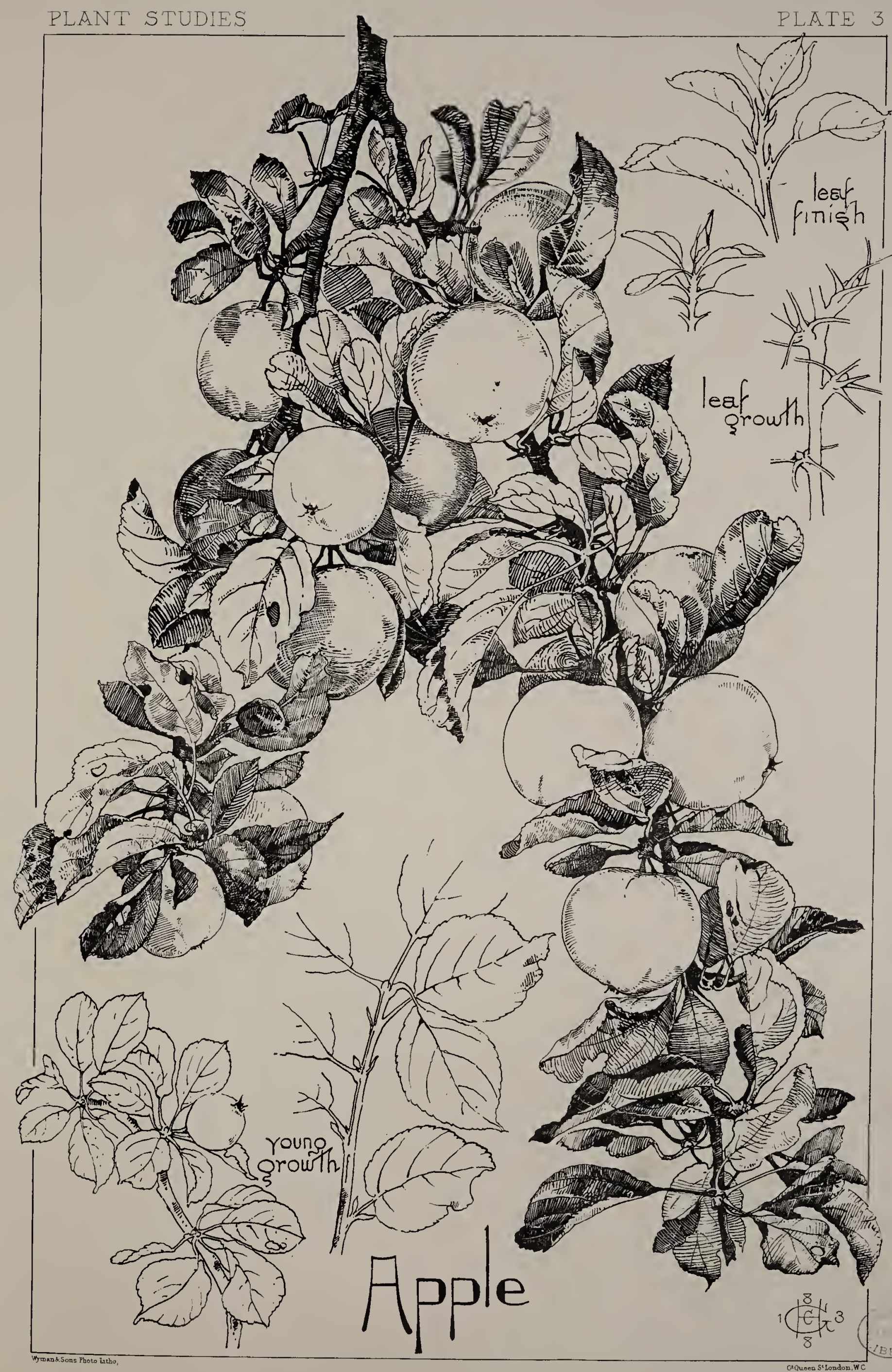





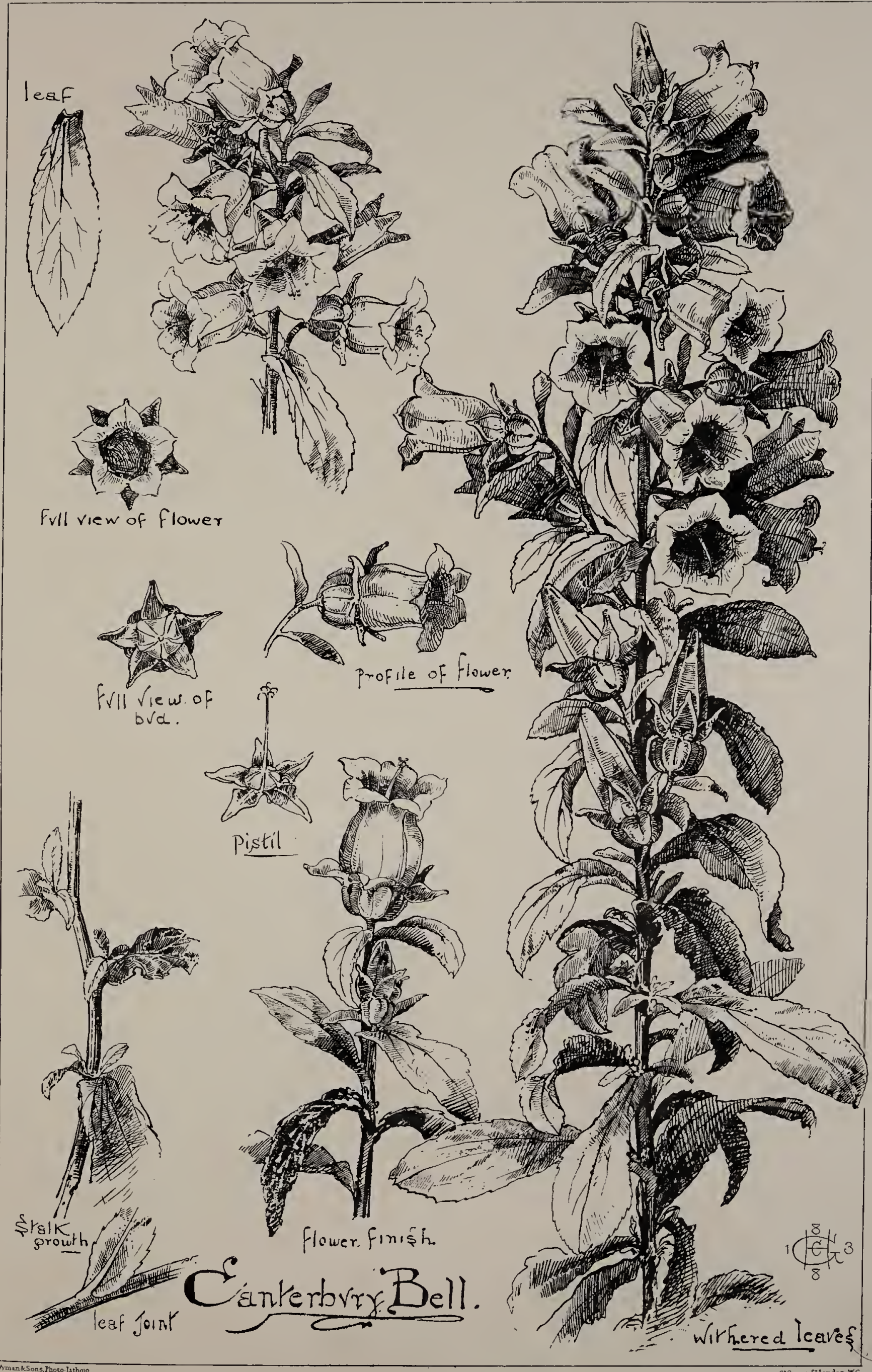



The Applc-tree frequently attains a great age, and screral now standing in this country must be nearly 300 years old. It is associated with our earliest religious impressions, and is also the trce which is distinguishcd by legends in the mythology of the Greeks, Scandinavians and Druids. The latter paid particular rcverence to the Apple-tree, because they supposed the mistletoe to grow only on it and the oak.

As at some futurc time I may show a platc of blossom, I shall at present confine my remarks to the fruit and foliage. The latter is of a morc or less rounded form, according to the variety, and is somewhat deeply serrated in tiee wild crab (which is possibly the common parent and origin of many cultivated kinds); which scrration, however, becomes lcss marked as the fruit is developed.

In the young growth the leaves grow alternate as shown in the Plate, from the base of which lateral shoots spring and form clusters of leaves, radiating round a centre (Figs. I and 2) from which the fruit hangs: examples of leaf finish are given, which, particularly in their early stages of growth, are exceedingly beautiful. The two miniature leaves at the base of the leaf stalk are especially valuable to the designer (Fig. 3), as are the rings surrounding the old wood (Fig. 4) at the joint of the new growth.
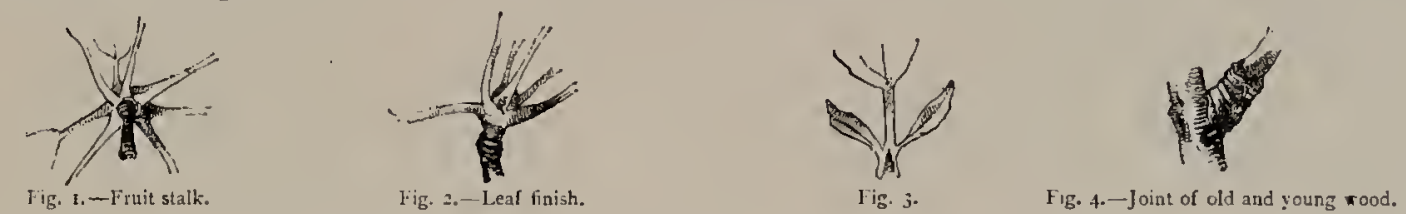

The various forms and colours of the fruit arc so familiar, that it would be superfluous to enter into any description. Suffice it to say that the latter range from greens through yellows to browns and reds so rich that cven pure carmine cannot portray them. The cxamplc I have given is of a cultivated kind, the Nonpareil, its fruit being green splashed with crimson. Although fruit is doubtless more difficult of treatment and less adaptablc than flowcrs and foliage, still, when it is treated successfully, it possesses a charm which is sufficient reward for the study expended upon it.

For carved stone or wood, inlaid panels for furniture, \&c., the Apple is capable of satisfactory treatment, and the young growth particularly will be found full of suggestive forms to the mctal-worker.

\section{Plate IV.-The CanterbURy Bell.}

$\mathrm{T}$

HIS beautiful standard flower, without which no country garden seems complete, is in bloom during the months of June, July, and far into August. It is a typc of the ordcr Campanula, the name signifying a littlc bcll, obviously applied with reference to the shape of the flower. The English name some botanists suppose to be in allusion to the bells carried by pilgrims to the shrinc of St. Thomas a Becket at Canterbury.

It sometimes grows to the height of four feet, and when in full bloom presents a pyramid of bell-shaped flowers, white, pale pink, or deep purple in colour, consisting of five petals, from the centres of which spring long divided pistils.

The calyx and buds are especially decorative, and the two small leaflets bencath form a beautiful feature (Fig. I), and seem to balance the flower, which might otherwise appear unsymmetrical. The first flowers on the parent stem are terminals, and the lateral shoots which spring from the leaf joints also develop into blossons, although seldom so fine. The same order of growth is continued, but, instead of the plant retaining its pyramidal form, it becomcs more bushy.

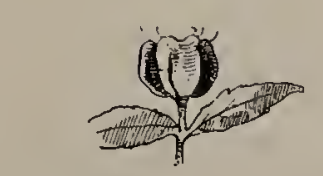

Fig. r. - Simall leaves at base of calyx.

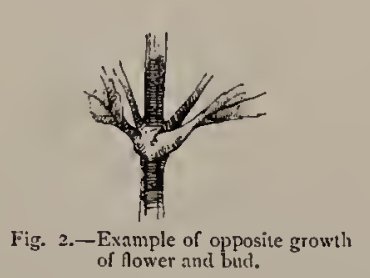

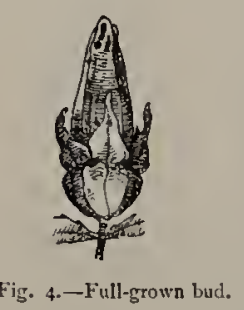

The leaves are of a deep bluc-green graduating to a yellow-grcen towards the top, and grow alternatc; an example of oppositc growth sometimes happening (Fig. 2).

The calyx is composed of five sheaths or husks, the base forming five cup-like receptacles for the seed (Fig. 3). The buds are of a whitish green, tipped with a dull purple, and are deeply fluted in five divisions (Fig. 4), and indented towards the top. While the plant is in its prime, the leaves at the base decay, and the browns thus formed are very valuable as a foil and contrast of colour to the healthy leaf, which is not much varied.

To the Ornamentist this flower, with its bold lines and striking detail, is of the greatest valuc in the decoration of upright Panels, Dados for Wall-papers, or in any position where it is desired to emplasise the fceling of height. 


\section{Plate Y.-THE SUNFLOWER.}

$\mathrm{T}$

HIS king of all flowers stands ercct and alone in all its gorgeous colour and completeness of form, disdaining companionship or comparison, neither seeking nor desiring support, breaking but not bending before the storm, conscious of its strength, the very embodiment of beauty, and worthy of its exalted name. I cannot refrain from quoting a passage I met with in a gardening book some 200 years old, which thus speaks of the Sunflower:"The corn marigold of Peru, which is that great monster we call the Flower of the Sun, of which there are two sorts, the one bearing round, and the other oval yellow flowers, heretofore admired, but now grown common, not at all respected." Thus, we see, two centuries ago fashion's dictates were as capricious as in our own day, when, owing to the false worship of the flower by the æsthetes, it has fallen into ridicule, but the beauty still remains; and nothing will ever detract from that, or rob the flower of its charm to the artistic eye.

In favourable situations it grows to a considerable height, not unfrequently attaining to ten or twelve feet, with leaves and flowers truly colossal in their proportions, so that it might almost lay claim to the title of tree or shrub. An example was brought to my notice this autumn of a grovth on which fifty-two full-blown flowers were to be seen at the same time.

The flower is of the Composite order, and is always a terminal either to the main, parent stem, or to the lateral shoots. It is composed of a double circle of yellow leaves forming the ray (a most appropriate name), and one of its features is the habit of constantly facing the sun. These yellow leaves are deeply ribbed, is formed by a number of small becoming developed as they approach are star-shaped (Fig. I), with stamens

The Sunflower is supported

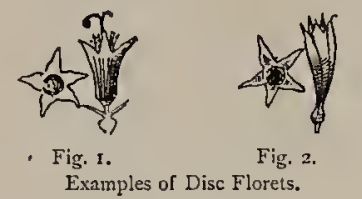
converging at the tip; the centre flowers in various stages of growth, the outer edge. These small florets and pistil.

upon a firm whorl of leaves or inin its proper place. The disc of volucre, which will receive attention the flower undergoes a continual series of beautiful changes and is full of variety, the almost
blackish purple of the young opening bud of the florets gradually merging into deep red, and thence into yellow; at the latter stage the pollen is carried away by bees and other insects, leaving the cavities of the flowers exposed, thereby giving the centre the effect of being formed of little brown circles with yellow depressions.

In another variety (the one mentioned in the quotation) the small florets of the disc are all yellow, with stamens and pistil hidden (Fig. 2), thus giving an appearance of the disc being formed of smaller leaves of the ray.

The pollen of the stamens immediately surrounding the unopened buds of the centre or disc appears as golden points or stars, when that of the outer florets has disappeared, thus forming a decorative circle at once beautiful and suggestive.

I need scarcely offer an apology for presenting three plates of such a plant, in illustration of the "Flower," "Back view of Flower" and "Bud, Leaf, and Stalk Growth." It would be impossible for me to do the Sunflower even scanty justice in fewer illustrations, and in devoting more than one plate to the delineation of such flowers as this, the Chrysanthemum and the Poppy, I am not altogether actuated by personal preference for these above others, but rather by my promise to give as much as I considered actually neccssary for the artist to possess, in order to make the plates as practically useful as possible.

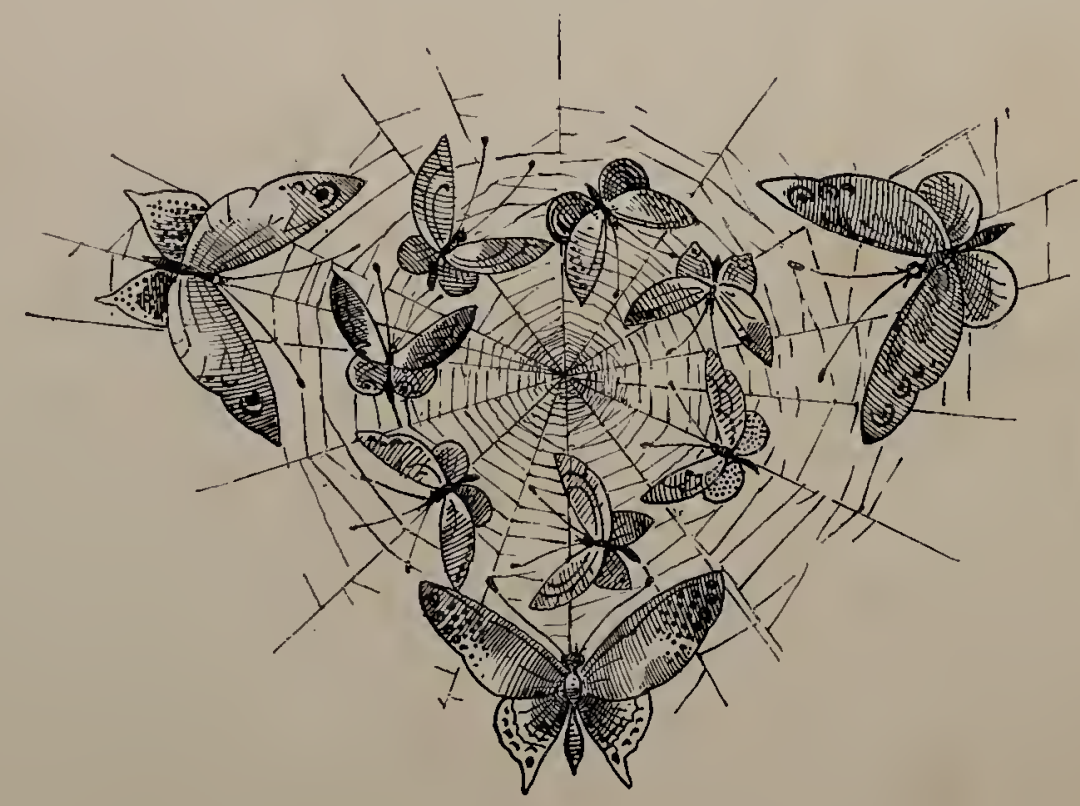




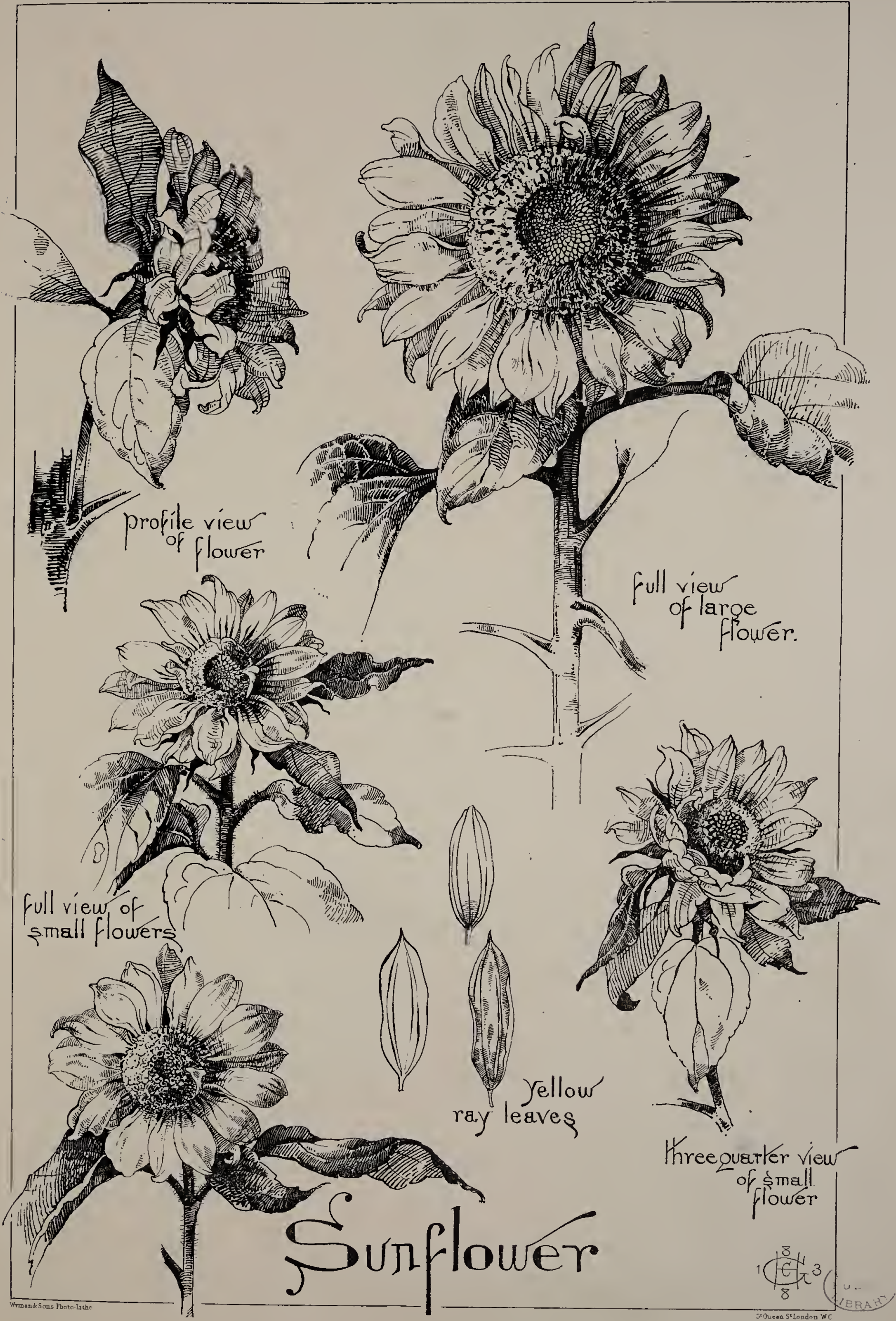





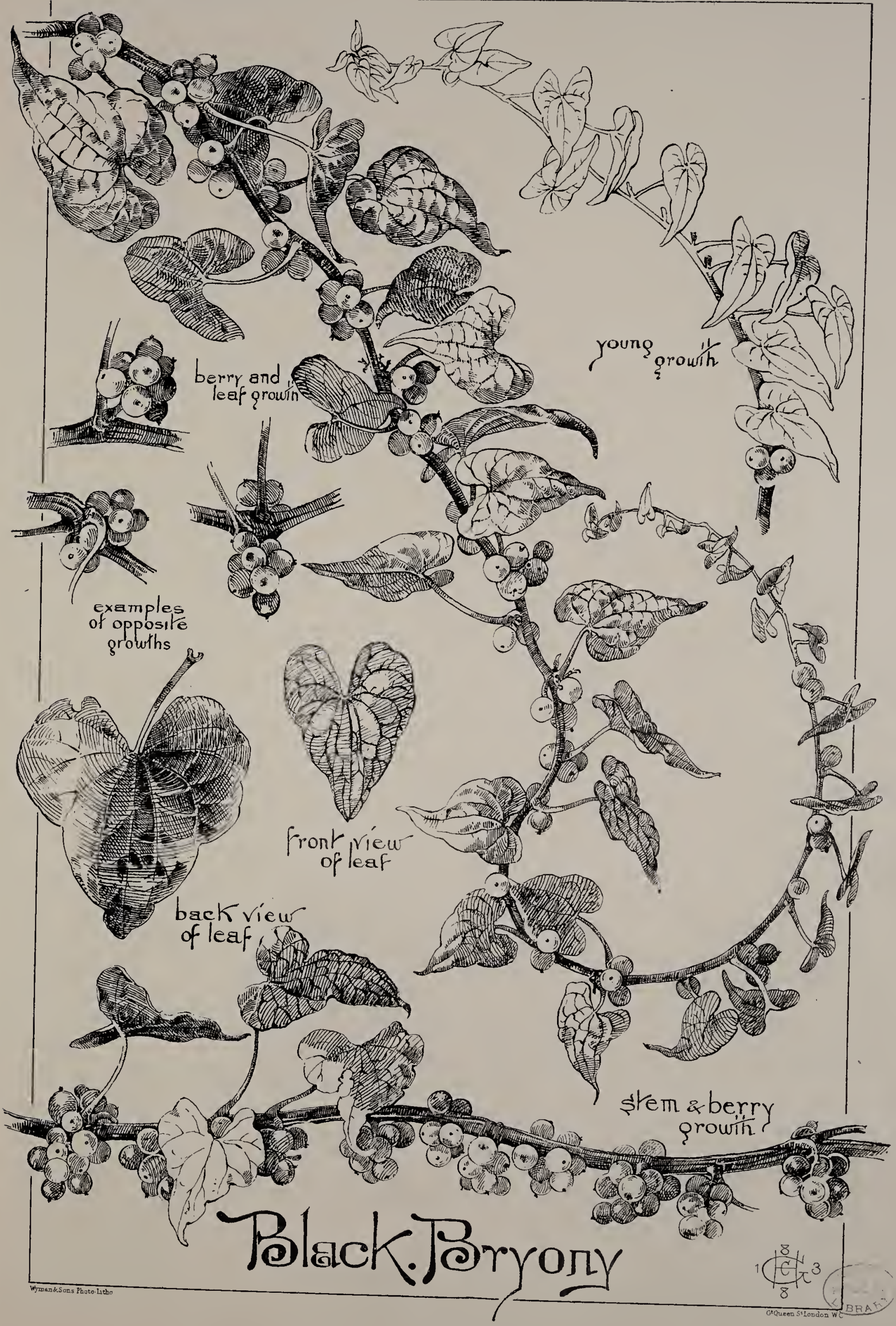





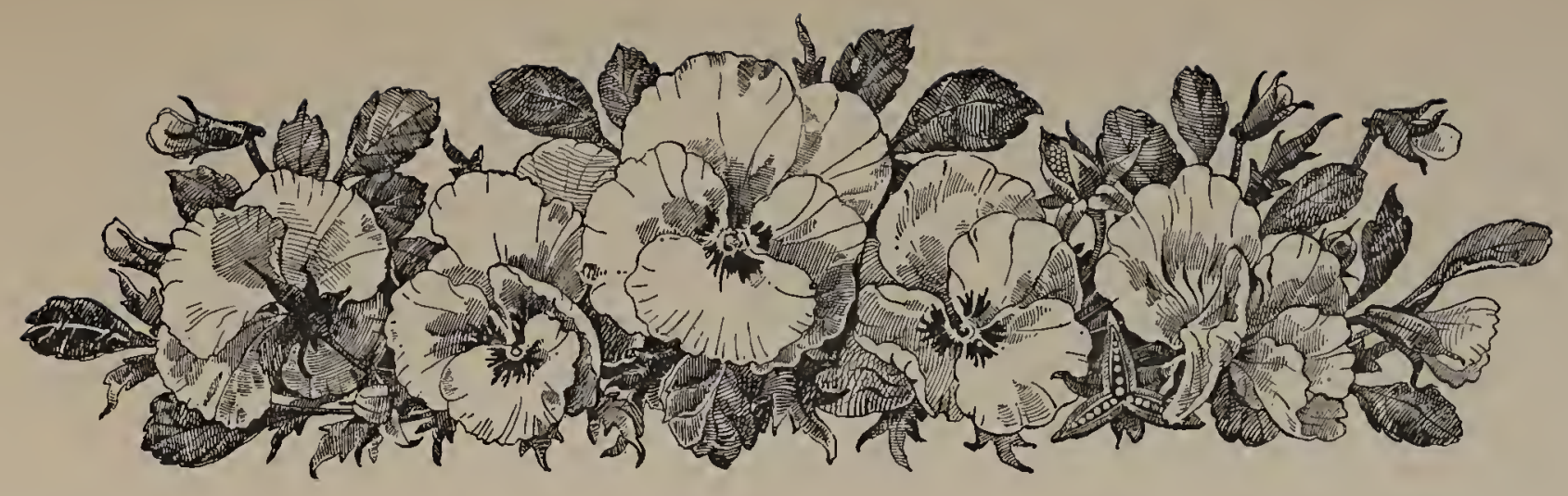

\section{Plate VI.-THE BLACK BRYONY.}

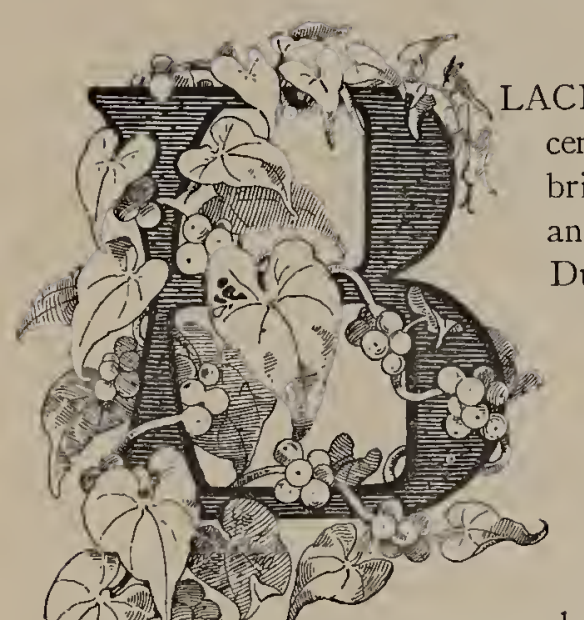

ACK BRYONY is the only British specimen of its kind, and is certainly one of our most luxuriant climbers, long garlands of its bright shining leaves, and equally polished scarlet berries, beautifying and adorning our hedges from spring until late into autumn. During May and June the racemes of its greenish-yellow florvers hang down from amongst its heart-shaped leaves (Fig. I); but the beauty in these months is not to be compared with its gorgeous appearance in autumn, when the leaves turn yellow, tinged with purple, and the brilliant red berries peep from beneath. Among the most charming characteristics of the autumnal period, are the numerous berries ripening on our hedges; but few of them can compete with the Bryony, which, even when the wintry winds have swept away all its leaves, still retains its

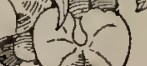

glowing berries, which might well be compared to strings of scarlet beads, so that its hardiness, apart even from its beauty, compels our admiration.

The stem is somewhat angular in section, of a twisted, ropelike appearance, and having no tendrils, it resembles the honey-suckle in its method of climbing (Fig. 2). Perennial in growth, its twining stem frequently attains great length, and is so thickly set with clusters of berries, that unless entwined round some sturdy growth it could not possibly support its own weight.

The flower of this plant is so small, and plays so unimportant a part in its general characteristics that its use, even if it be employed at all, is but limited, so far as the decorative
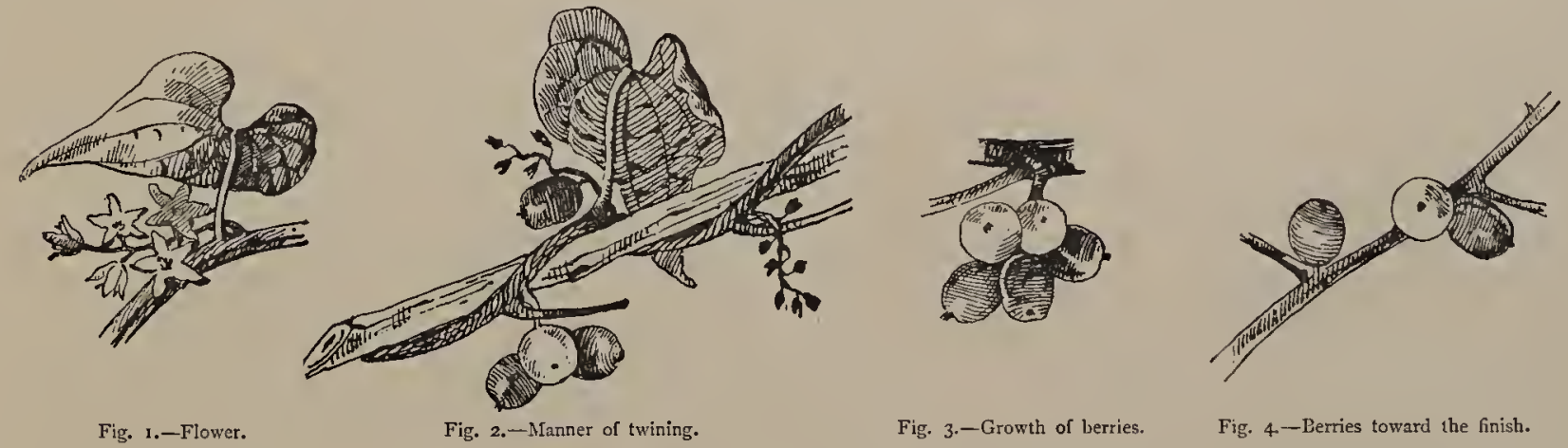

artist is concerned. The plant is remarkable for its leaves and berries, the former of which grow alternately on the stem, and are equally attractive in both form and colour. They are heart-shaped and very pointed, and have five, seven, or nine ribs, from which veins cross and divide up the surface into irregular forms, which, being convex, reflect the light. In colour they are bright green, semi-transparent, and so exceedingly glossy as to give the effect of being varnished. This bright green, splashed with purple, changes in the various stages of decay to yellows and browns, still showing the purple or brownish-black markings.

The berries, a conspicuous feature of this plant, grow abundantly, springing from the inside, though occasionally from the outside of the base, of the leaf-stalk. They are nearly the size of sloes, but more elongated in form (Fig. 3), and hang, like small bunches of grapes, in closely-packed clusters, which diminish to three, two, or even a single berry as they approach the terminal (Fig. 4). Although the true growth of the leaves, and in consequence the clusters of 
berries, are alternate, the latter are sometimes so abundant that an opposite growth is compelled (example shown in plate). They are bright and waxy in appearance, and on their glossy skins the high-light is distinctly marked, a point which should not be overlooked in any naturalesque treatment of the plant. They undergo many delicate colour changes during their gradual ripening; pale and deep greens, dull and brilliant yellows, may be found on the same bunch of berries, and the bright green in juxtaposition with the red of the ripe berries acts as a valuable foil, enhancing the beauty of each.

The bead-like berries and twisting growth of the Bryony form its chief recommendations to the artist, and niay be utilised by him for positions where a climbing plant is required, more especially as it affords the option of using it either with or without the foliage. To the mason or wood-carver, as an embellishment for columns, \&c.; to the painter, on silk or pottery; to the designer of borders, friezes, and many kinds of needlework, the Black Bryony will be found useful and effective.

\section{Plate Vil.-The Chrisanthemum.}

$\mathrm{I}$

$\mathrm{T}$ is in the dreary month of November, the melancholy season of decay, and of fogs, cold winds, and sometimes nipping frosts, that kind Nature gives us the Chrysanthemum, one of the most beautiful of flowers. It comes to cheer us when other flowers have departed with the dying breath of summer, and for its bravery in facing the tempests of winter, should be called the "Flower of Heroism." Although we cannot claim it as a native, it has taken kindly to our clinate, and thrives well even in our great cities; so that there are few flowershows more interesting or beautiful than that of the Chrysanthemum at the Temple Gardens, where the plant is cultivated to a high degree of perfection.

It was originally brought from China, about 1764 , under the name of "Chrysanthemum Sinecure," and since then has been developed into many varieties, the most beautiful of which are those known as the Incurved, the Reflexed, the Japanese, and the Anemone-flowered.

For several reasons I have selected for illustration the "Japanese" variety:--there being greater distinction in the formation of its flowers, and a wider range of colour, including, as it does, all except blue. It remains longer in bloom than most other varieties, and thus affords better opportunities of study.
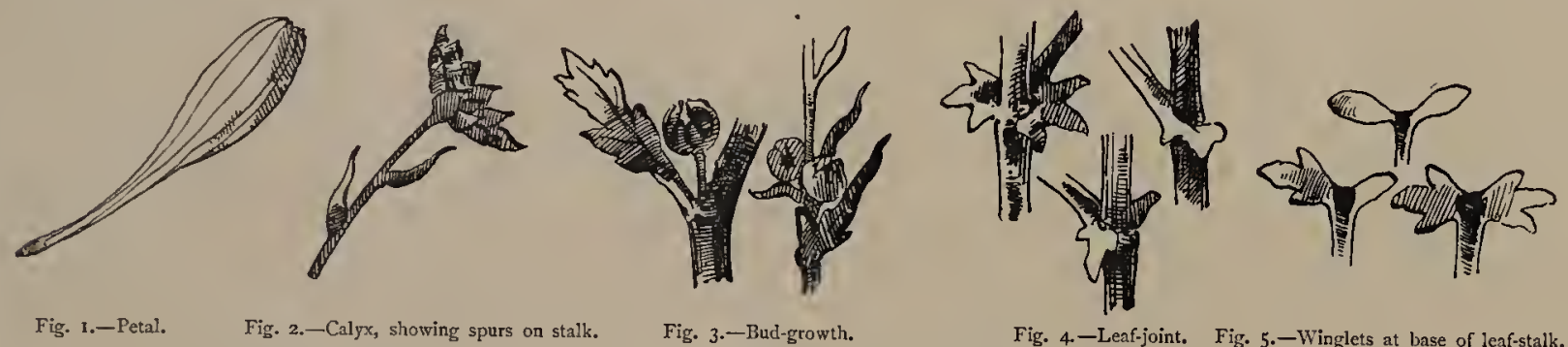

As the Chrysanthemum has such a wide range of form and colour, it is of inestimable value to the designer, and I offer no excuse for showing three plates of it, giving those known as "Peter the Great," "Meg Merrilies," and "Monsieur Lemoine," and possibly an additional sheet of various flower-heads, for the purpose of delineating their most useful and striking forms. "Peter the Great" is one of the finest specimens, frequently attaining the height of five or six feet, each of its stems terminating in an abundance of bright yellow blooms, some of which appear as double flowers, surrounded by single ones. The small spurs growing on the flowerstalks are invaluable to the artist, as serving to break a line which in composition might otherwise prove weak (see Fig. 2). The petals are long, and taper towards the base, widening at the tips, which are slightly serrated (Fig. I).

Some of the blossoms resemble the Marguerite Daisy; others are more spherical in form, and their numerous petals twist and curl over each other in their attraction to the centre. My illustration of "Peter the Great" defines the characteristics mentioned, and this marked diversity of form in the flower-heads growing on one plant cannot fail to be of much interest and utility to the artist. The calyx is, for so large a flower, somewhat small. It consists of numbers of overlapping pointed scales; in colour pale green, darker at the edges (Fig. 2). The buds spring from inside the leaf-joint (Fig. 3), and undergo a variety of exceedingly beautiful changes before expanding into flowers.

The stem is woody, and slightly grooved, and the leaf-stalks partly close round it (Fig. 4), and are of various forms, owing to the irregularity of the small winglets at their base (Fig. 5). This characteristic is valuable to the decorative artist, adding greater interest to his subject, and it may be emphasised in his work.

The leaf is deeply and boldly serrated, and in shape is somewhat like that of the oak; it 


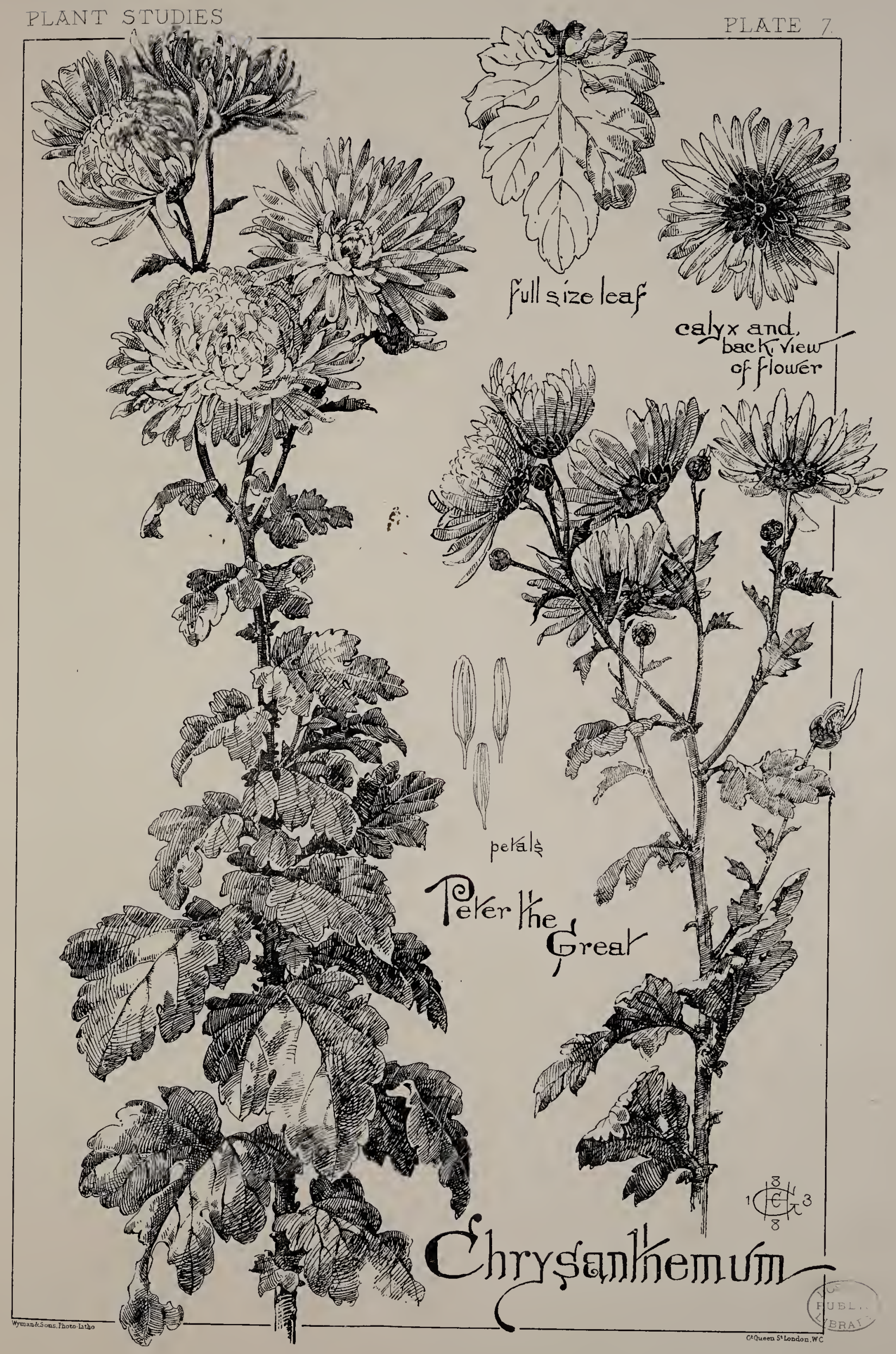





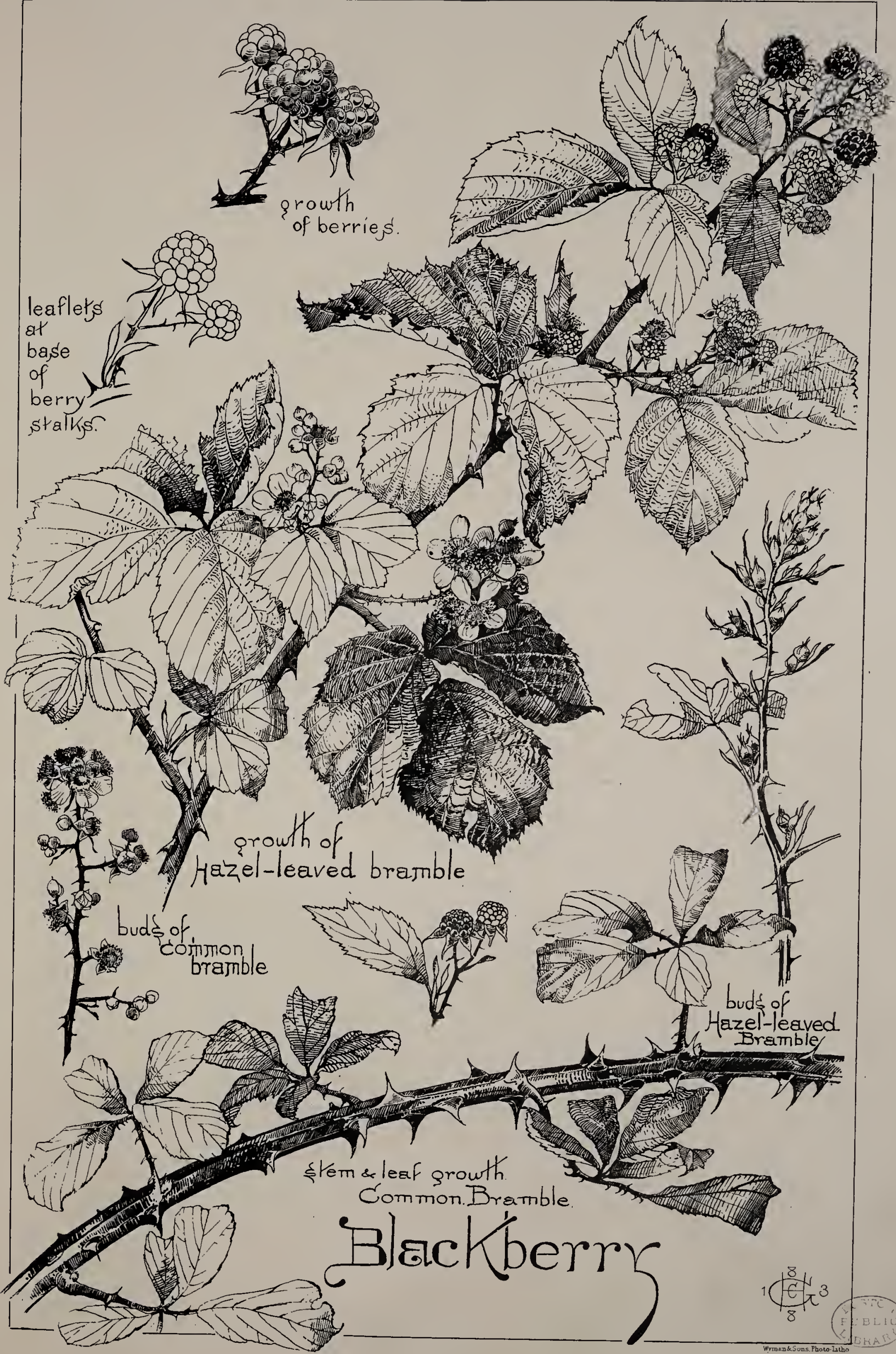



is a rich green in colour, which at the time of decay fades gradually through luminous yellows into brown. The veinings on the surface of the leaf form depressions, and the raised portions catch the light, and are therefore glossy in effect. The boldly-outlined leaf of "Peter the Great" may be considered the finest of the Chrysanthemum species.

The Chrysanthemum is the typical flower of Japan, as the Rose is of England, receiving, however, in that country much more attention. It would be difficult to imagine the decorative arts of the Japanese without it, for, with the exception, perhaps, of the Almond and Bamboo, it is that used most frequently, on their silks, and in every style of needlework; leather, paper, and lacquer work; and in brass, copper, silver ware, and pottery. It is also profusely carved in wood and ivory for the decoration of their temples.

\section{Plate VIII.-THE BLACKBERRY.}

$\mathrm{P}$ RHAPS no plant is more familiar to us than the Blackberry, flourishing as it does in every coppice, skirting every country roadside, trailing over every stone wall, growing freely on every common, the typical vagabond plant of England. There are numerous varieties of this plant, all having their origin in the common Bramble, but each showing some difference in detail, while still retaining the special characteristics of the parent. I have selected for illustration two varieties, which seem to me to be the Alpha and Omega of the species, - the common Bramble and that called the Hazel-leaved. The differences between these two varieties are very marked, though, as before observed, their laws of growth are the same. The long, trailing, and arched stems of the common Bramble are angular and fluted (Fig. I), and tinged with red, and they are much tougher than those of the Hazel-leaved, which are rounded (Fig. 2) and of a greenish hue. The Bramble stems are more thickly studded with prickles,

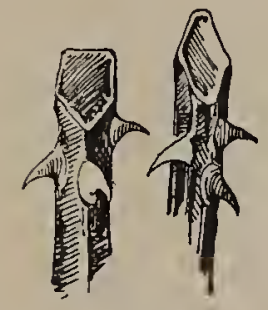

Fig. I. - Stem, Com
Bramble.

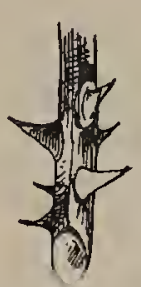

Fig. 2.-Stem, Hazel-leaved.

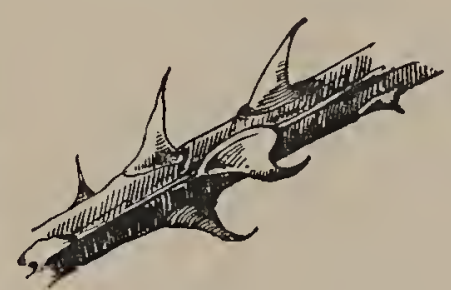

Fig. 3.-Prickles, Common Bramble.

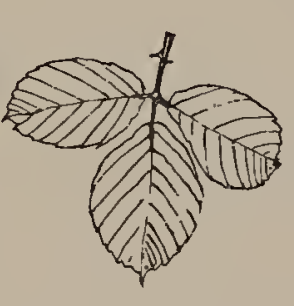

Fig. 4 Ordinary growth of leaves. Fig. 5 .

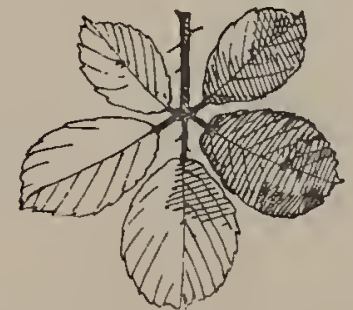

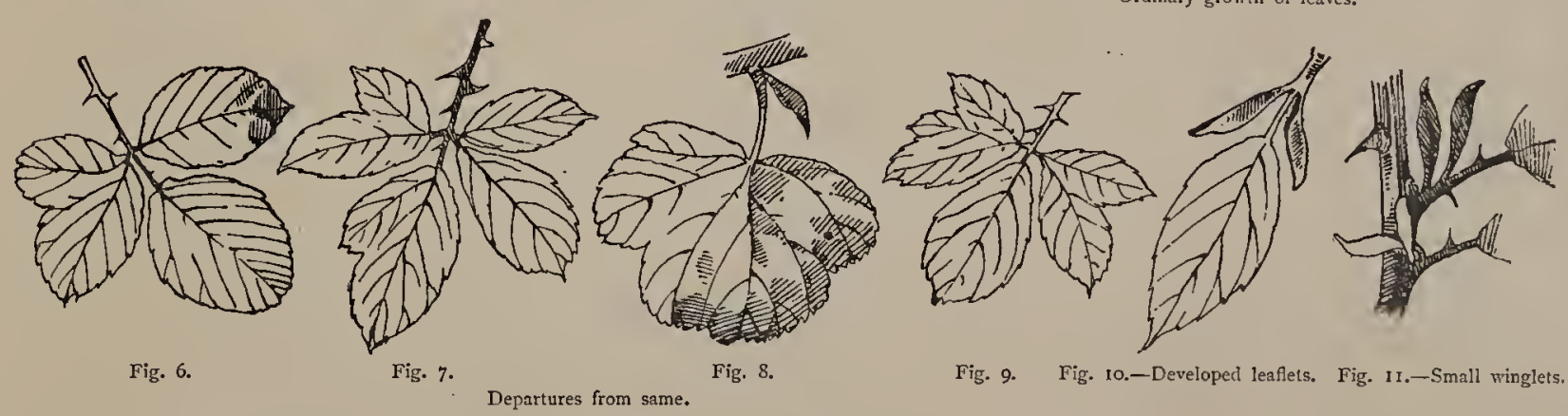

which (Fig. 3) are more hooked and much stronger than those of the Hazel-leaved plant. The upper surface of the leaves is of a dark, glossy green, splashed with purplish red, the under-side of a downy white, which, in consequence of the quaint manner in which they foreshorten and curl up, is constantly exposed to view; they are of an elliptical pointed form and doubly serrated. The leaves of the Hazel-leaved Blackberry are of a soft green on both surfaces, and very closely resemble those of the Hazel-nut tree in form, ribbing, and colour; they lie out flat and are less foreshortened and also rounder in shape than those of the common Bramble. Both species grow alike, the leaf-stalks alternating on the stem and the leaves springing in clusters of three or five, with all the leaf-stems meeting at one point. They have well-marked veinings, running from the centre rib to the edge of the leaf in severely straight lines. Figures 4 and 5 represent the ordinary growth, while Figures 6, 7, 8, and 9 show some very frequent departures from the same, the latter being of much value to the student.

The lateral shoots grow from the inside of the leaf-stalk joint, on the main stem, which is generally of a rich bronzy green, stained with crimson and purple hues on the side most exposed, the old wood presenting also many delicate grey and brown shades.

The flower of the common Bramble is creamy white, tinged with rosy pink, and is composed of five, or sometimes six or seven petals (thus justifying the occasional use of any of these numbers), with a downy reflexed calyx and a yellow centre, formed by the numerous stamens. 
The flowers of the Hazel-leaved variety open earlier, and differ also in colour, being of a pure white and larger. The fruit is finer, with fewer seed-pips, and of a browner purple colour.

Both these beautiful plants are to be seen in all stages of their growth at the same time, from the dull grey-green of the flower-buds to the purplish-blue fruit; the full glory of their effect is displayed in the autumn, when the green of their leaves changes into brilliant yellows and browns, mottled with such gorgeous scarlets and crimsons as words fail to portray.

The fruit grows in clusters, and during its ripening passes from green through varying reds, into the rich purple of the fully-ripe berry. From the base of the berry-stalks developed leaflets grow, unlike the true leaves in form (Fig. Io), presenting a feature of the plant worthy of close attention. Small winglets are also found at the base of the leaves, and occasionally attain a defined form (Fig. I I).

In favourable damp situations the Blackberry sometimes reaches a colossal size; and I have seen a hanging branch from fifteen to twenty feet in length, with leaves four inches in breadth.

This plant, as many examples prove, can be utilised for the decoration of almost any material, being admirably suited by the beauty of its form, growth, and colour to the requirements of ornamental art in all branches of its application.

\section{Plate IX. -THE MOUNTAin ASH.}

A THOUGH the Mountain Ash, or Rowan Tree, is most common in mountainous and northern districts, it is to be found in abundance in most parts of the kingdom. It is frequently grown in English parks and estates as an ornamental tree, and must be well known to all. The place of the Yew in England, is taken by the Mountain Ash in Wales, where few church-yards are to be found without it. At one time it was held in superstitious veneration, and associated with ideas of a mournful nature, and this feeling is not yet altogether extinct. The Welsh peasantry were accustomed to wear on certain days crosses made of its wood, and to illustrate how ancient and remote the origin of this superstition may be, we find Bishop Heber mentioning that he found in India a tree very similar in form to the Mountain Ash, which was regarded with the same superstitious reverence.
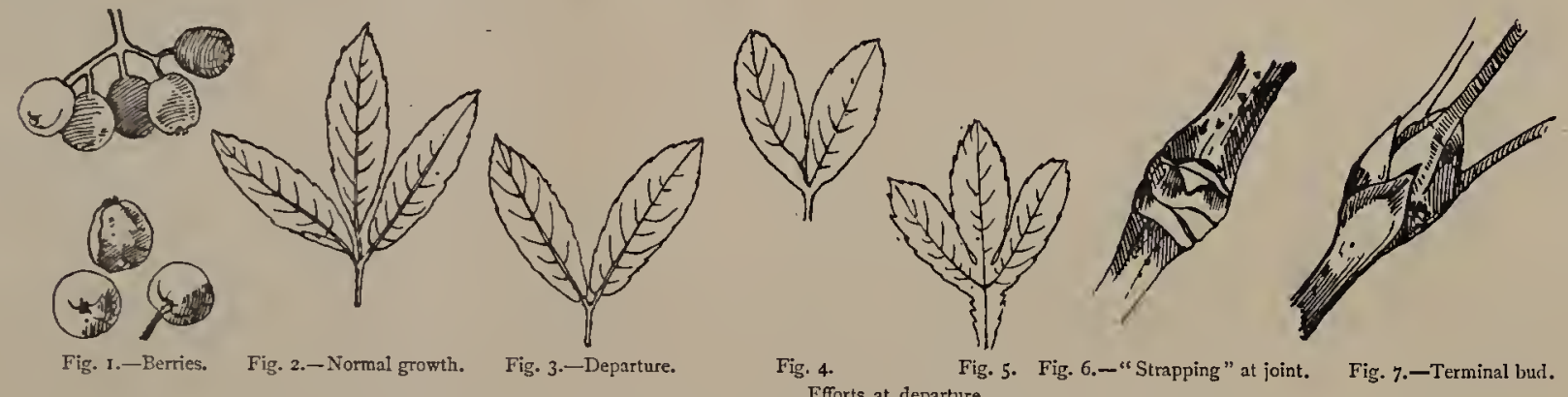

The flowers of this tree are white, and appear in May, the berries becoming ripe in September, and lasting, under favourable circumstances, until late in November. They form a favourite food of the feathered tribes, and are very juicy, but being of an acid, astringent taste, are scarcely palatable. The berries (Fig. I) hang in thickly-packed bunches from the ends of the branches, their weight being very considerable. A bunch picked without selection from a small tree not more than nine feet in height, contained, I found, no fewer than three hundred and ninety-two full-grown and ripe berries, and weighed over four ounces, quite sufficient to account for the characteristic drooping of the branches. During the ripening, the berries change in colour from a yellowish-bronze-green, through numerous gradations to a vivid scarlet.

The leaves are of a rich green colour, and frequently curl outwards, thus exposing some of the cooler grey-green of the under-sides, and by this means a change is obtained, relieving the monotony of their local colour. They are pinnate, and the leaflets serrated, of an oblong form, showing the rib-markings distinctly. The larger are from two to two and a half inches long, and grow in five, six, seven, eight, or nine couplets, finishing in a terminal (Fig. 2). Departures from this law are, however, of frequent occurrence, viz.,-midrib finishing as a couplet (Fig. 3); an effort to do so (Fig. 4); the terminal leaf unable to free itself from the encroachments of the last couplet (Fig. 5). Such interesting variations as these should be duly noted by the artist, and welcomed as affording legitimate opportunities for avoiding a dull and dreary uniformity of treatment, and imparting to his design a character of agreeable and truthful diversity. The stem is thick and firmly held at the joints, and is of a warm reddish-brown colour, speckled with little markings (see Illustration). Among the most beautiful and valuable of its characteristics is the strapping (if I may use the word to illustrate my meaning) of the joints (Fig. 6), and the exceedingly 


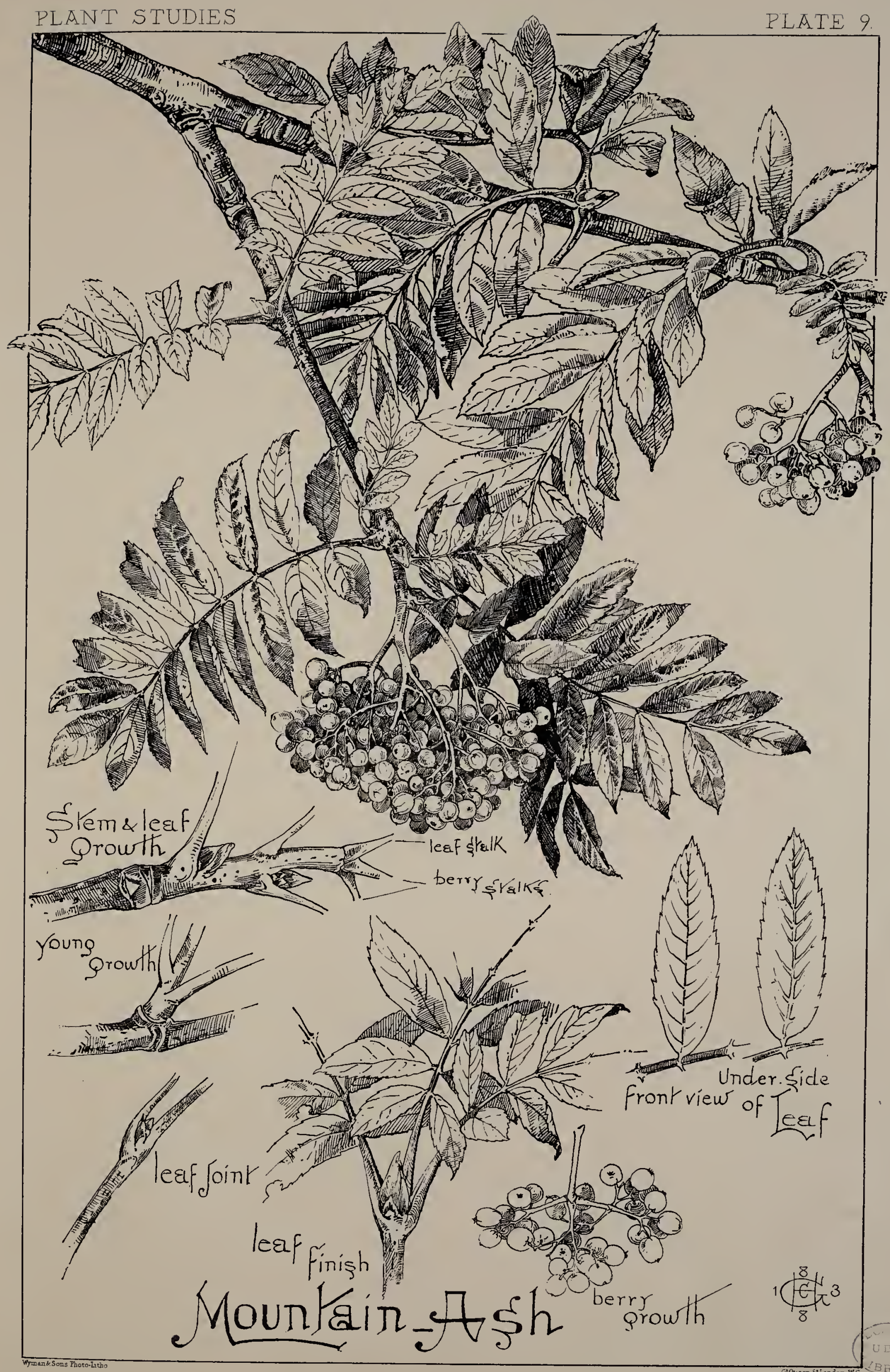





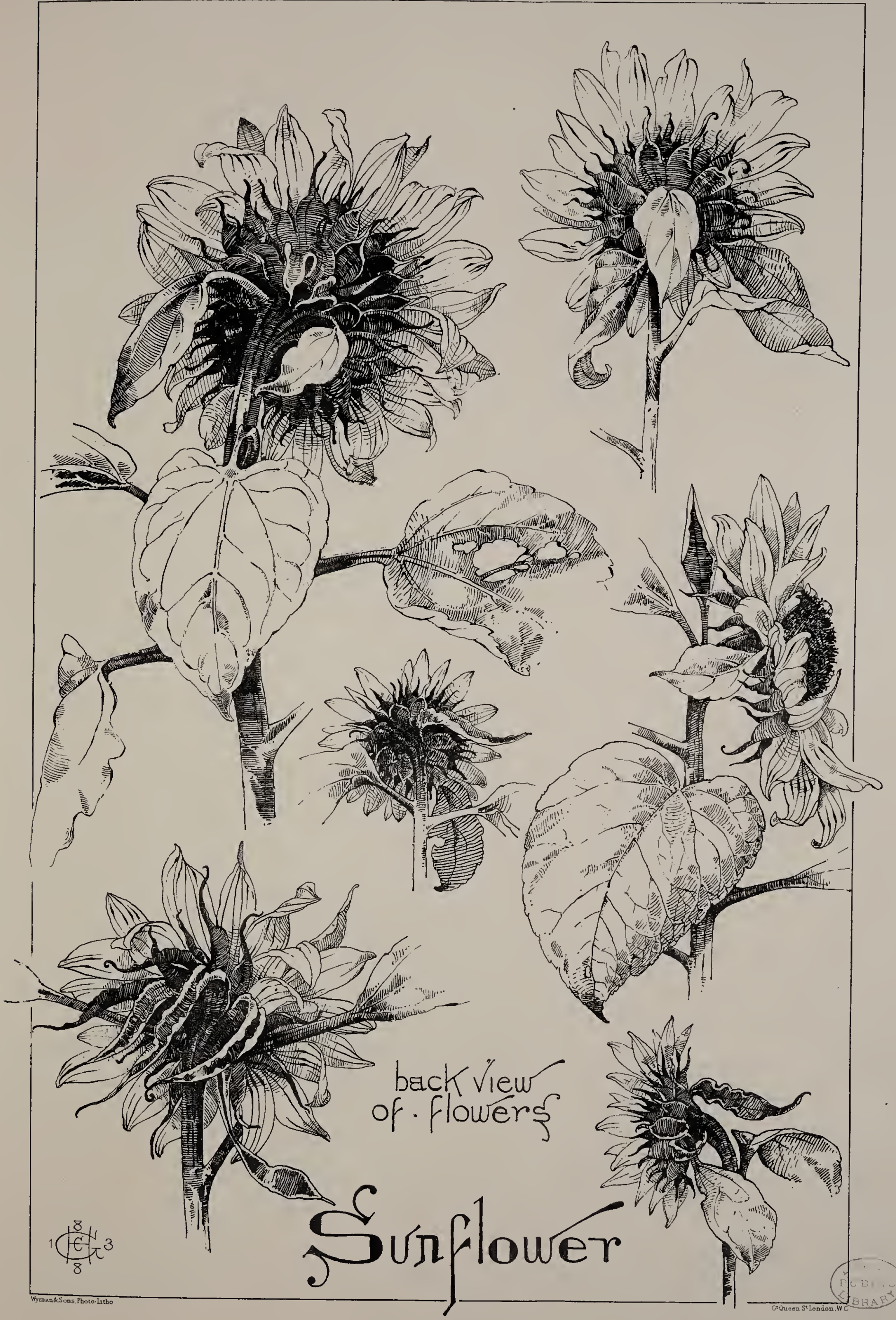



beautiful and decorative terminal bud to the branch (Fig. 7). The growth of the stem and leafstalk are full of beautiful and valuable features to the designer. Both in form and colour, the growth, foliage, and fruit of this tree are well adapted for various decorative purposes and mediums, either in flat treatment or relief. It might be used for carved wood and stone panels, \&c., and in flat decoration, for wall-papers or outlined panels; in woven stuffs for hangings, needle-work portières, screens, pottery, and many other purposes which will suggest themselves. For the reasons given above, as an accessory to any subject of a mournful nature, or in conjunction with birds, it would be most suitable.

\section{Plate X.-THE SUNFLOWER (continuer)}

I $\mathrm{N}$ the first Illustration devoted to this plant, examples of the flower were given, showing the full flower, the smaller blossoms in full view, in three-quarter, and in profile. This second plate I have reserved for the delineation of the back view of the flower, its involucre, and stalk-growth, and this aspect of the Sunflower will be found as interesting and beautiful as that first shown.

I have given several drawings of the involucre, which is cup-like in form, and composed of tiers of partly overlapping, sheath-like leaves, from which the yellow petals of the ray and florets grow, and are partially protected by them. A characteristic of the flower is the manner in which fully-formed leaves sprout out from the body of the involucre, which are those seen behind and

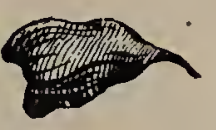

Fig. I.

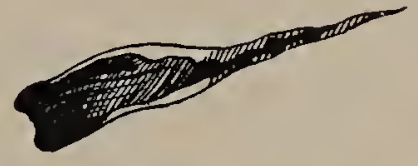

Fig. 2.

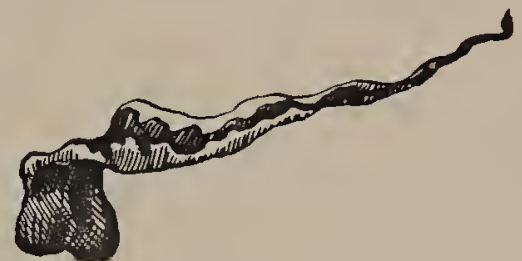

Fig. 3 .

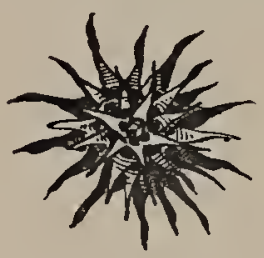

Fig. 4.

amidst the ray of the flower. The sheaths forming the involucre take different shapes, in some being short and thick (Fig. I); in others, tapering and folded (Fig. 2); and in some cases still larger, rougher, and also more curled and twisted (Fig. 3), the latter being, perhaps, the most beautiful. The involucre of the large flower on the plate is composed of sheaths formed like Fig. I ; the profile flower on the extreme right of Fig. 2, and Fig. 3 is taken from the flower in the left-hand corner. The colour of the involucre is rich green, deepening into a blackish tint, and when enveloping the young bud in its earliest stage has not unfrequently the appearance of a small black star (Fig. 4).

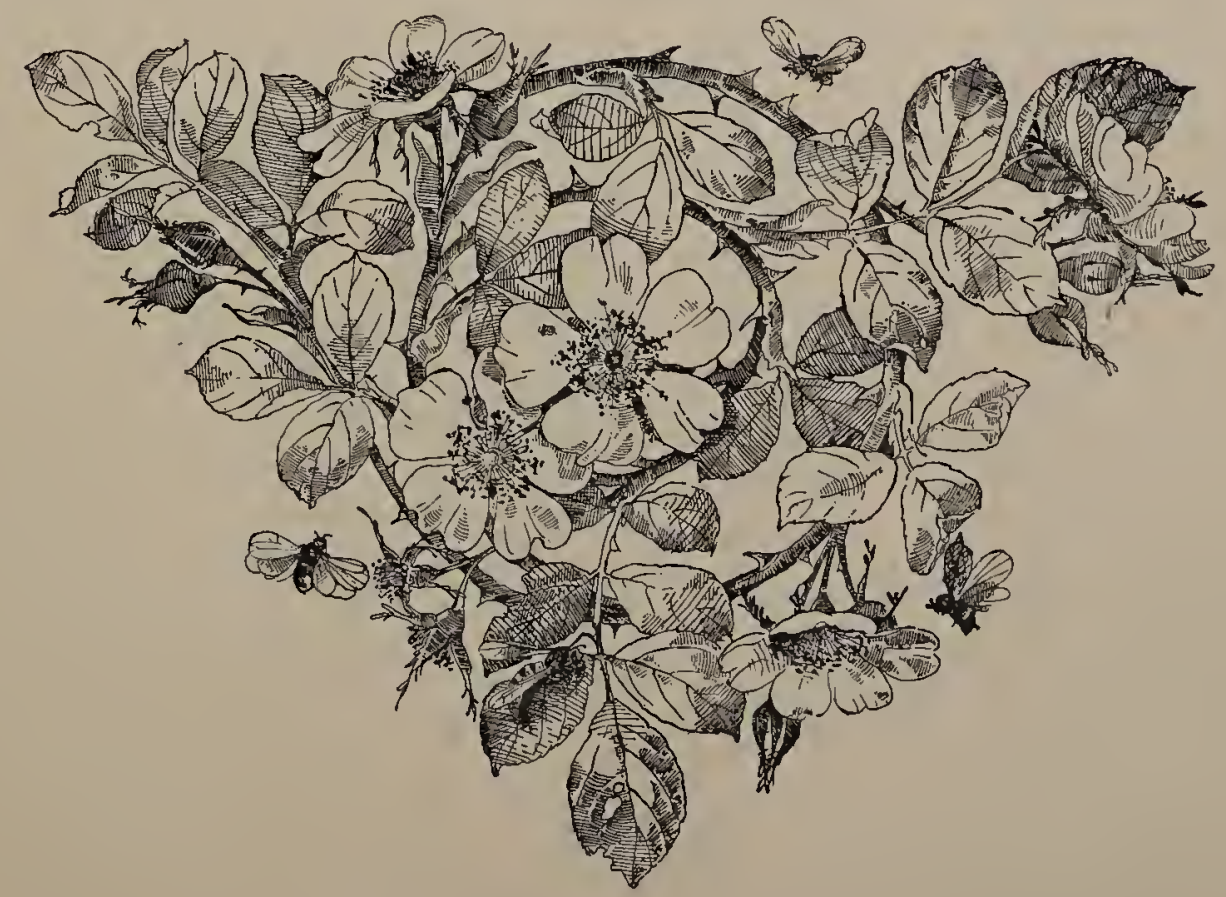





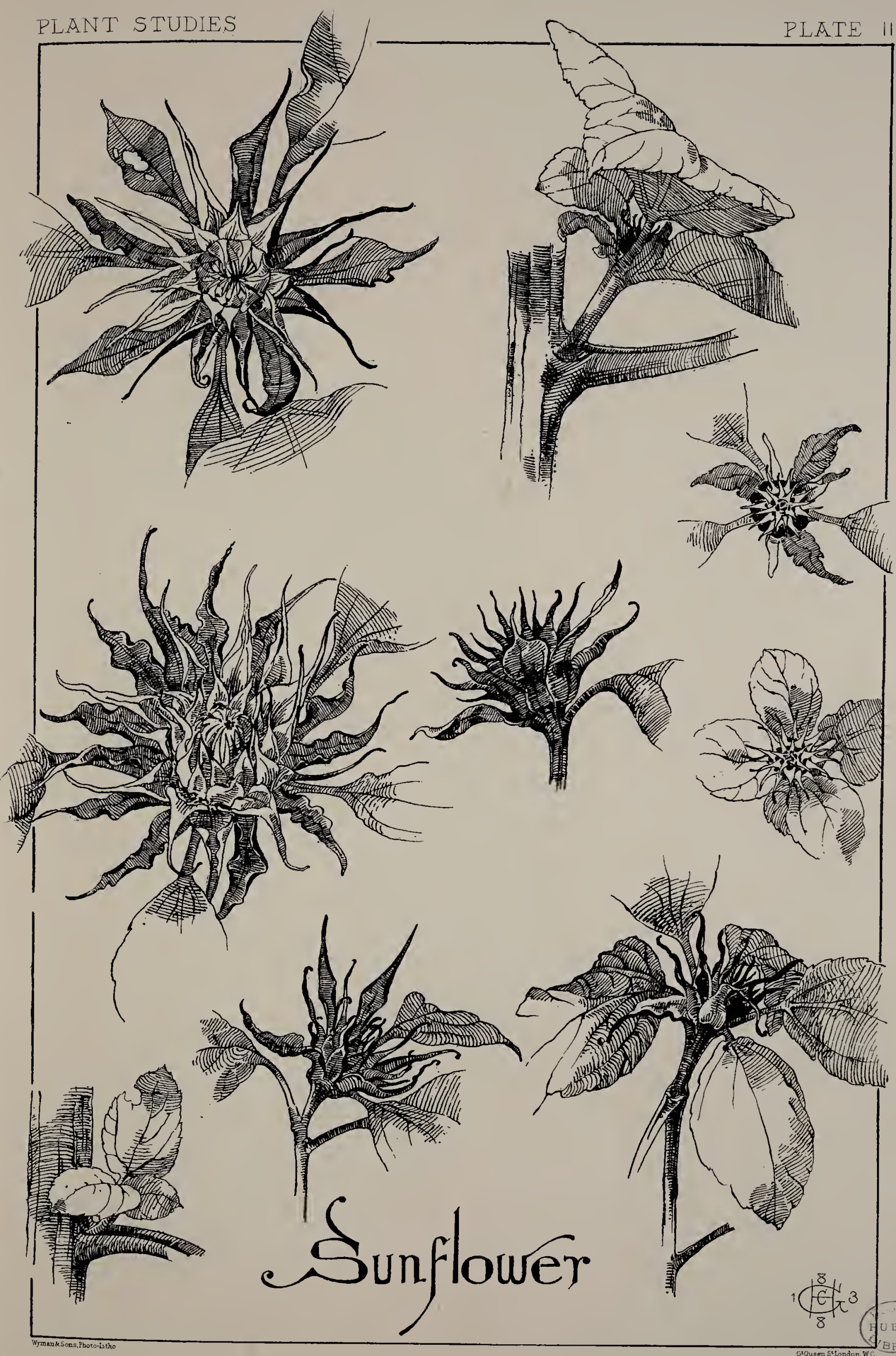




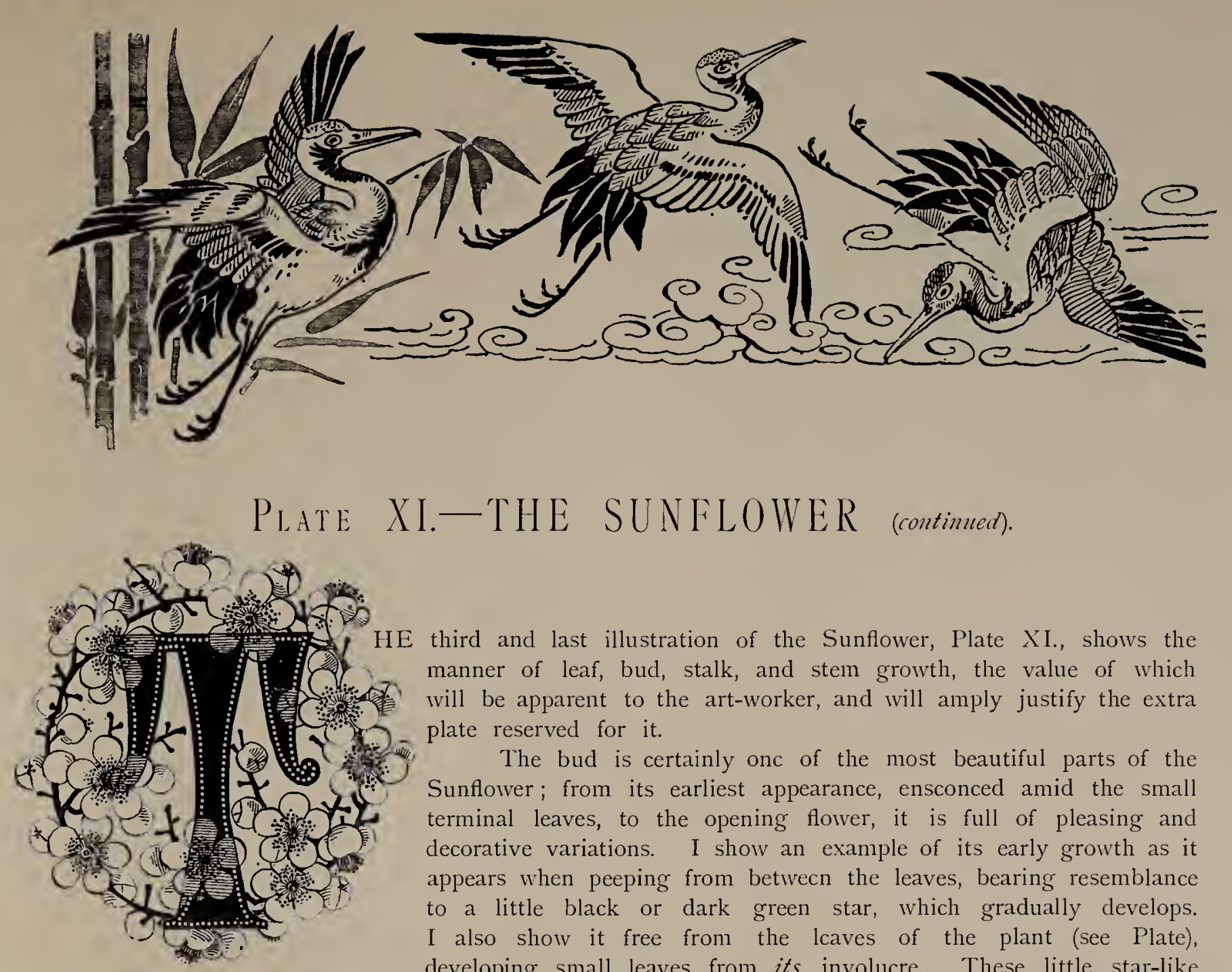

third and last illustration of the Sunflower, Plate XI., shows the manner of leaf, bud, stalk, and stem growth, the value of which will be apparent to the art-worker, and will amply justify the extra plate reserved for it.

The bud is certainly onc of the most beautiful parts of the Sunflower; from its earliest appearance, ensconced amid the small terminal leaves, to the opening flower, it is full of pleasing and decorative variations. I show an example of its early growth as it appears when peeping from betwecn the leaves, bearing resemblance to a little black or dark green star, which gradually develops. I also show it free from the lcaves of the plant (see Plate), developing small leaves from its involucre. These little star-like buds, appearing as terminals to the lateral shoots which spring from inside the sturdy leaf-joint, are exceedingly valuable in adaptation, and add to the interest of the flower. At the top left-hand cornes is illustratcd a fine example of involucre (a sheath of which is shown in description of Plate $\mathrm{X}$., Fig. 3), from the ccntre of which the ray leaves are just appearing in fine-pointed blades of rich golden yellow, while a still further development of the same is shown beneath. The stem is deeply fluted in perpendicular lines, and is sturdy, rigid, and straight in its growth, but sometimes zigzag towards the top; these deviations, however, generally straightening out as the plant develops. In colour the stem is pale green, and its younger parts are covered with short, soft hairs.

The leaf is exceedingly handsome, and of two distinct forms, almond-shaped in the young leaf (Fig. I), and heart-shaped when fully developed (Fig. 2). It has three principal ribs (Fig. 3), from which well-defined veins spring, and break up the body of the leaf into convex forms. The leaves are firmly connected to their stalks, and equally so to the stem (Figs. 4 and 5). The stalks

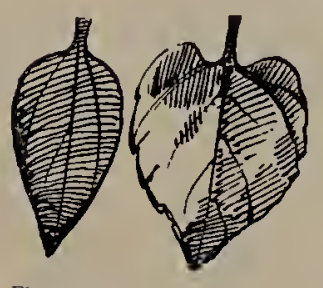

Figs. I and 2,-Forms of young

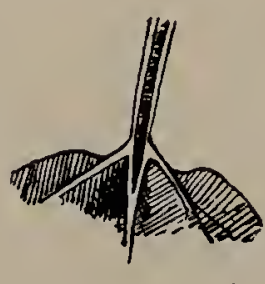

Fig. 3.-Vein-growth.

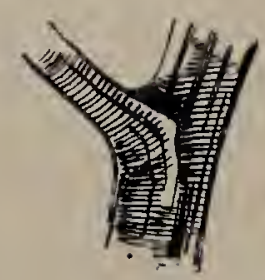

Fig. 4

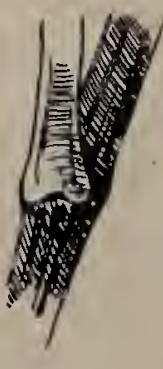

Fig. 5.

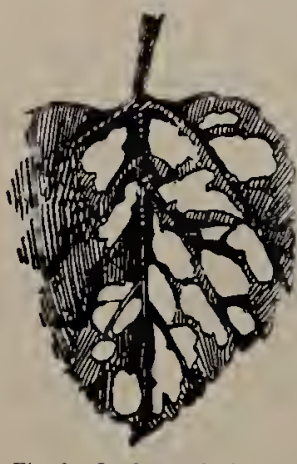

Fig. 6. - Leaf eaten by insects.

of the older leaves are deeply hollowed on the inner sides (see Plate). From the joints of the leafstalks, and protected by the grooves, the lateral shoots spring. The protection afforded by this groove is indeed needed, as the plant, standing alone, is much exposed to the violence of the wind. The leaves frequently attain gigantic size, and in colour are rich yellow-green, somewhat lighter and opaque on the undersides, where the ribs and veining show more prominently. An interesting feature is sometimes observed at the base of the plant, when the body of a leaf has been eaten away by slugs or snails, leaving only the ribs and veinings, which form a beautiful lace-like tracery (Fig. 6). The result of these insect depredations might occasionally be used by the artist as a means of relieving the somewhat monotonous surface of the leaf; and the valuable suggestions for lace and nccdlcwork to be obtained from a skcleton leaf, moreover, fully compensate for the mutilation. 
The purposes to which this beautiful flower is suited are, notably, appliqué work, in which its petals, leaves, and growth are all that could be desired; its recommendation for embossed velvets and plush, and working in crewels lies in its bold lines; its free modelling suggests its use for repoussé work in brass and other metals, for grills, gates, screen-standards gas-centres, brackets, Sc., for decorative panels in stone, brick, or wood; for raised leather, or the new Lincrusta Walton for walls, dados, and panels, and to many other purposes this flower, in the hands of a competent artist, may be successfully applied.

I make an exception in this instance, and show what really beautiful centres could be made from the florets of the Sunflower, without departing from nature in any particular. (Fig. 7)-Stamen

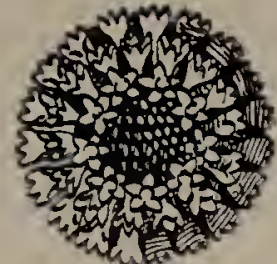

Fig. 7. -Centre, with stam and pistil gone.

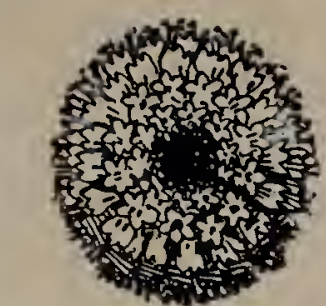

Fig. S.-Centre, with pollen of pistil gone.

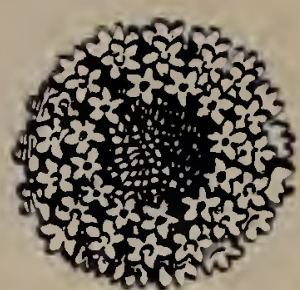

Fig. 9.-Centre, with pollen on pistil.

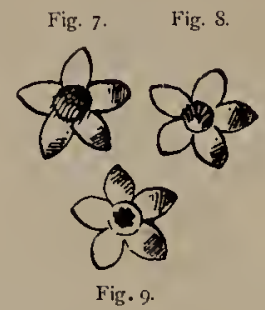

Small florets of which centres

are composed.

and pistil fallen off. (Fig. 8)-Stamen remaining, but pollen of pistil gone. (Fig. 9)-Pollen on pistil forming the golden star spoken of in description to Plate $V$. These illustrations of different aspects of the Sunflower's centre will serve to show how readily the plant will lend itself to severe and conventional treatment.

\section{Plate XII.-THE "MEG MERRILIES" Chrysanthemum.}

$\mathrm{O}$ F all the varied forms to be found in the flower-heads of the great Chrysanthemum family, I think the first place may be claimed for the specimen known as "Meg Merrilies," and that both for its beauty and decorative qualities. Even a slight acquaintance with the work of the Japanese - the most skilled of all modern decorative artworkers, and most observant of the truly beautiful-will testify to the right this flower has to such distinction. Such shrewd observers have not failed to recognise, and fully avail themselves of, the qualities of "Meg Merrilies," for they use it to enrich and decorate their productions more largely than any other variety of the great Chrysanthemum species.

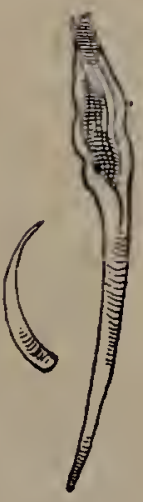

Fig. 1.-Petal.

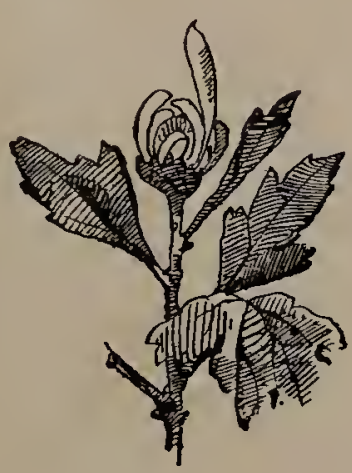

Fig. 2.-Bud-growth

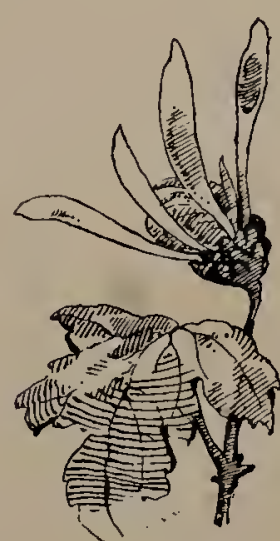

Fig. 3-Bud.growth

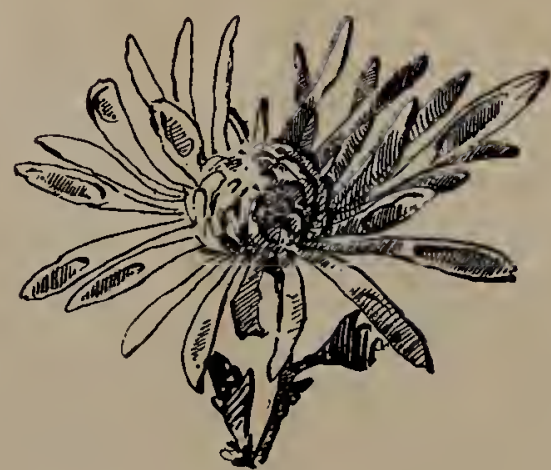

Fig. 4.-Bud-growth.

In the general characteristics of growth and foliage, the plant differs little from other varieties, but in the flower-heads the difference is at once apparent. They are large and elegantly shaped, the petals are gracefully curved, and, for the purity of their form, they might not inappropriately be termed classic. The flowers, and particularly the bud-growths, most forcibly recall the brush-work of the early Greek period, and are as readily represented by the same method of brush-" flicks."

There are two kinds of petals, the inner being small, and curving to the centre, and in colour bright gamboge. The outer and long petals are tubular for three quarters of their length, when they widen out towards the tips; in colour they are white, tinged at the base with pale green or yellow, and in form they somewhat resemble the flower of the Honeysuckle, without its lip-like 


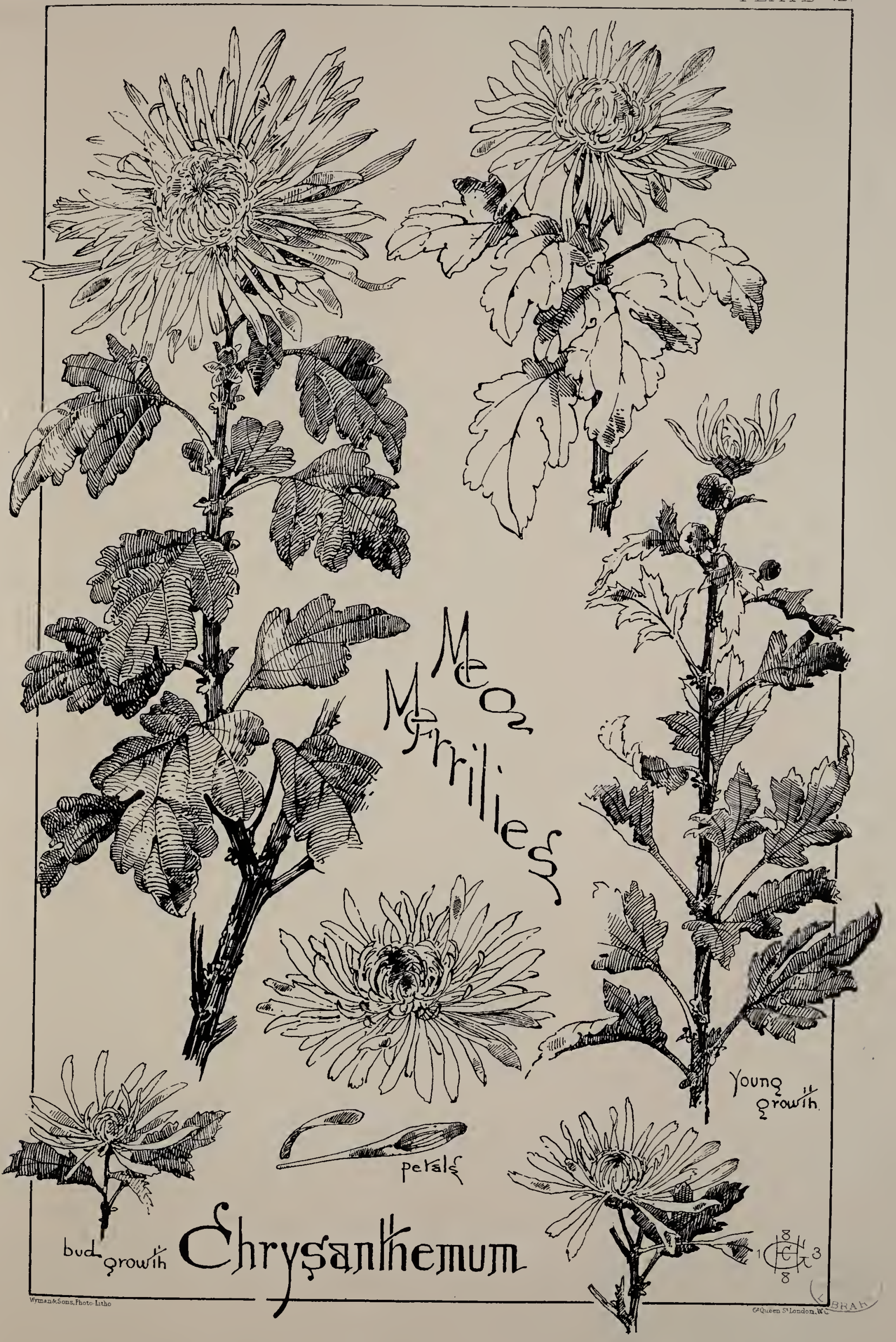





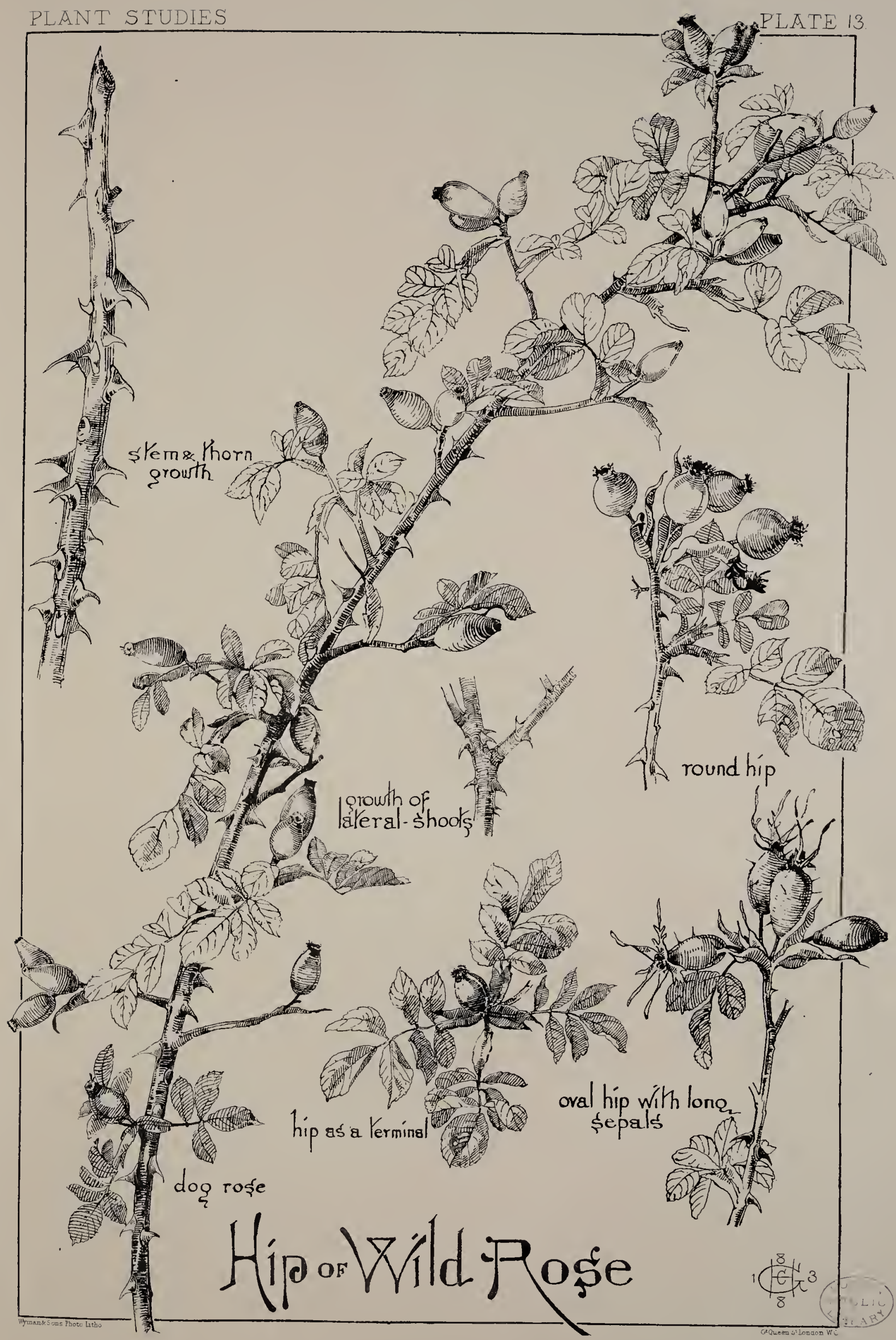



appendage (Fig. 1). The bud-growth abounds in beautiful and varied forms, full of suggestion and interest. In Figures 2, 3, and 4, I give some examples of these pleasing and valuable growths, and in Figures, 5, 6, and 7, a bud from different aspects. The leaves of "Meg Merrilies" differ from those of "Peter the Great" in being more pointed and toothed, with the serrations deeper and more numerous. The stalk is longer, and the winglets at the base larger. The stem differs little, if at all, from the general characteristics of the species.

The flower-stalks are furnished with the same spur-like appendages, and sheath-like leaves, commented upon in the description of "Peter the Great," which take niany interesting and valuable forms. Fig. 8 shows an example of a finc and peculiar growth in this direction.

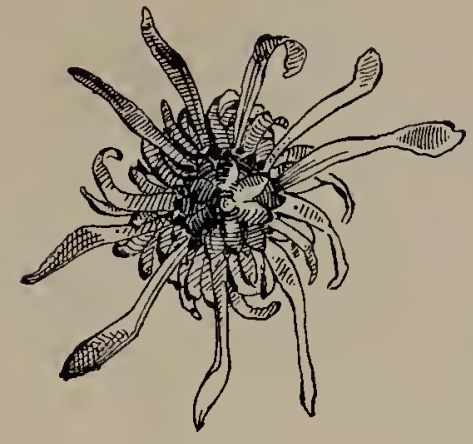

Fig. 5.-Back of bud.

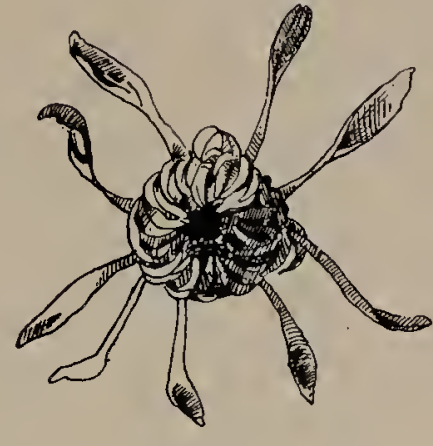

Fig. 6. - Front of bud.

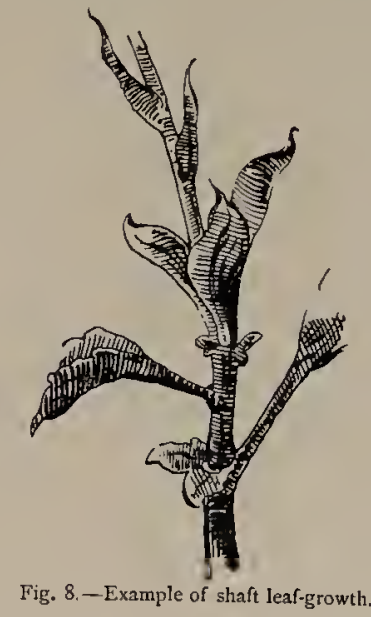

As to the usefulness of the Chrysanthemum to the ornamentist and designer, no comment is necessary; all I have said of "Peter the Great," and more, can be applied to this exceedingly beautiful variety of a lovely plant.

In the best examples of Japanese work, endless representations, and adaptations of the "Meg Merrilies" are to be found, in many cases showing little divergence from the purely natural forms and growth. Examples 2 and 3, although drawn direct from nature, are very suggestive of buds taken from Japanese work, which may illustrate how readily the flower lends itself to decorative requirements.

\section{Plate XIII.--HIP OF THE WILD ROSE.}

$\mathrm{O}$

all flowers the Wild Rose is perhaps the most typical of England's shady lanes and byways; nor could we possibly select one more beautiful. It is at once hardy and plentiful, generous in its wealth of blossom and delicate fragrance; and in all its stages of growth, from early spring till late autumn, it ever presents a host of beauties and progressive changes, each invested with a marked individuality. In the early summer days, its delicate pink shell-like buds and blossoms chequer the hedgerows with spots of radiant light; and in the sere and yellow leaf of autumn, its young leaves still remain a brilliant green, while its swaying boughs are decked

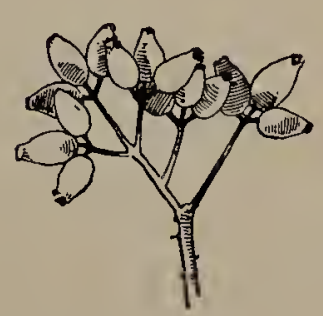

Fig. 1.-Example of cluster-growth.

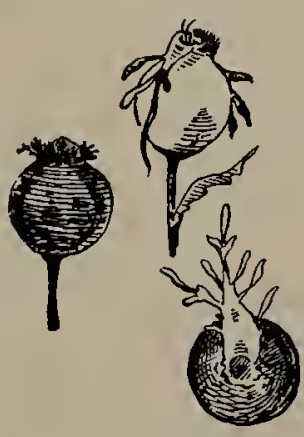

Fig. 2.--Round Hip.

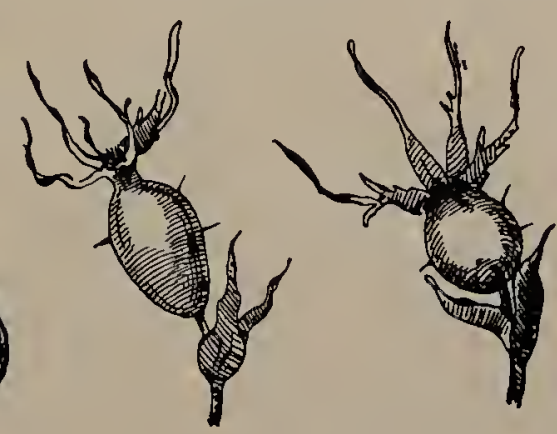

Fig. 3.-Ovate Hip, with long sepais and prickles

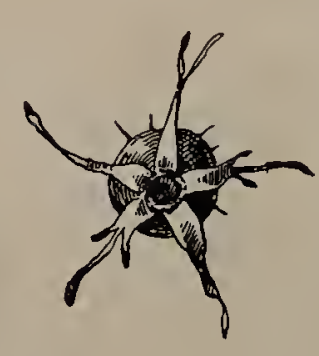

with a profusion of vivid scarlet berries, glistening like polished coral, as they nod before the wind and mirror thcmselves in the little rivulets and pools their arching branches overhang. Even at this season of the year an occasional late blossom is to be met with, looking doubly delicate and fragile beside the sturdy hip. A spray thus adorned is indeed invested with beauty that a poet alone could adequately describe.

I shall now speak of the autumnal appearance of the plant, reserving the spring and summer aspect of bud, flower, and leafage for future illustration. The most striking features of this period 
are the berries or hips, which grow as terminals to the lateral shoots, singly, or in couplets or triplets; and in some varieties in clusters (Fig. I).

Among examples shown on Plate is the "Hip of the Dog-Rose," which is of an inverted pear-shape, the "Round". (Fig. 2) and the "Ovate" hip (Fig. 3). The general growth of stem and leafage is the same in all; the dissimilarities are found in the growth and shape of the hip and sepals. Although the dried stamen and sepals sometimes remain, they usually fall away as the hip becomes fully ripe. In the Ovate hip (see Plate) the sepals are of great length and beauty, and this variety also possesses a characteristic I have not observed in any other, viz., small prickles growing from the body of the hip. The hip commences to form immediately the bud opens; and ripens from green through yellows and scarlets to the crimson of the dead-ripe stage.

The sepals are seen more perfectly on the green hip, because, as previously observed, they shrivel and curl up when the berry ripens; and while upon this feature (although I shall have to speak of the sepals again, when illustrating the bud and flower), I here take the opportunity of pointing out one most beautiful characteristic. It will be seen that two out of the five sepals
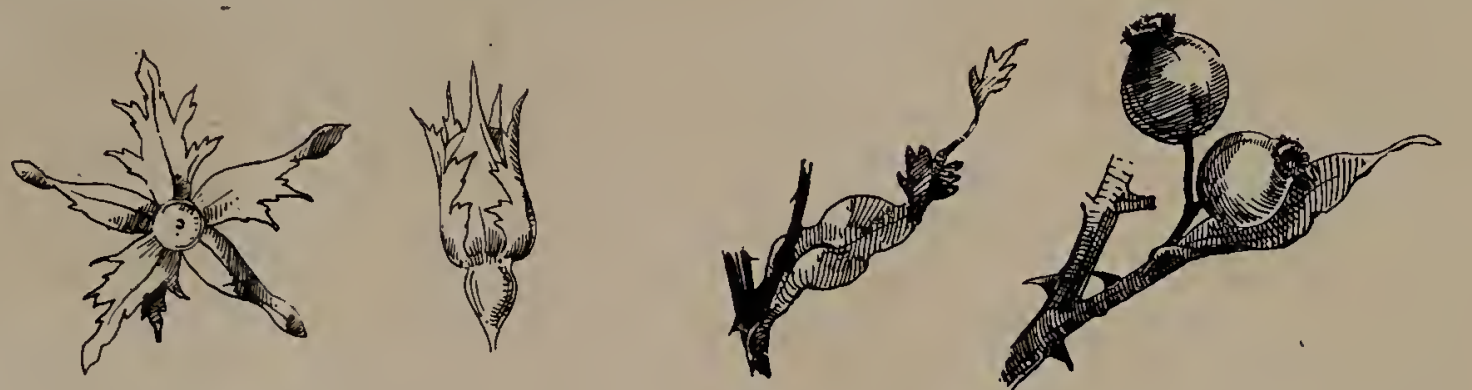

Fig. 4.-Formation of sepals. Fig. 5.-Sepals folding around bud. Fig. 6.-Example of sheath-growth.

Fig. 7. -Example of sheath-growth on Round Hip.

have small serrated portions on both sides, one having such appendages on one side only, the remaining two being perfectly plain: and this law is most obediently followed (Fig. 4). The reason of this irregular serration and departure from true geometrical symmetry is to be found on careful observation of the manner in which the sepals envelop the bud (Fig. 5). Each of the junctures is overlapped by these little phalanges, which serve to protect the tender bud from late frosts, sharp winds, and other dangers to which it would be exposed. Nothing better illustrates the wise provision Nature makes for the protection of her works than the wonderful formation of the sepals of the IVild Rose.

At the base of the berry-stalk small sheath-leaves develop into various forms (Fig. 6); while Fig. 7 illustrates a different development of the same feature on the round hip.

The foliage-growth of the Wild Rose will receive greater attention when I describe its summer aspect, than I purpose giving here; but as the leaf is to be seen in conjunction with

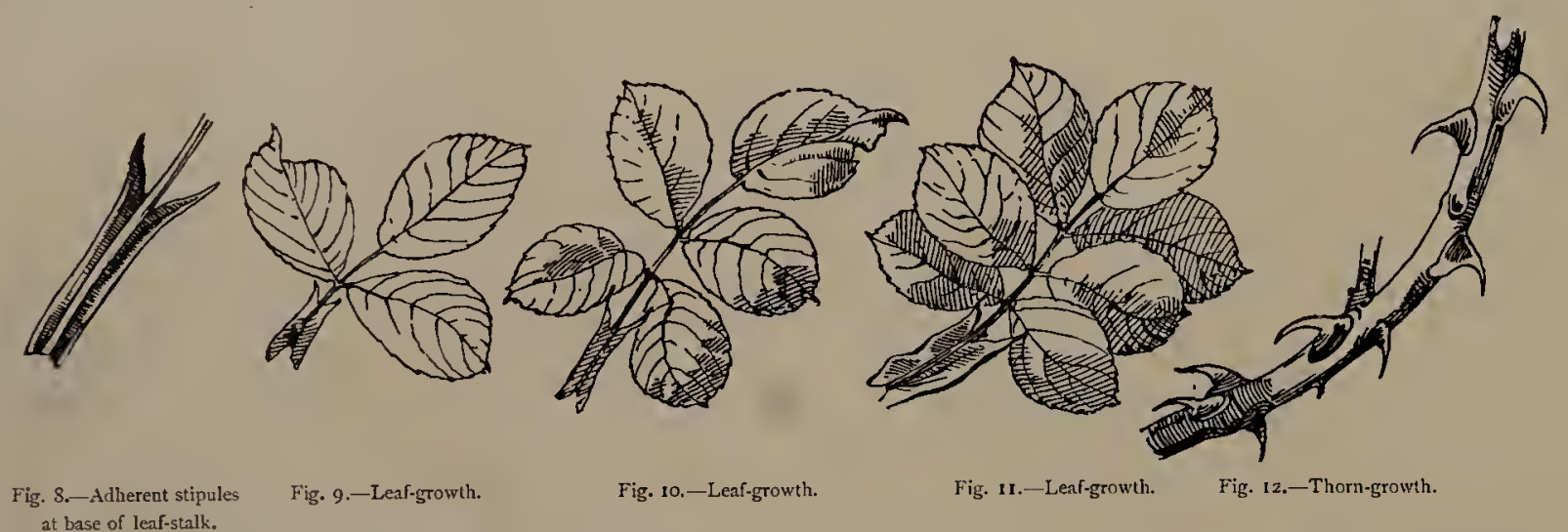

the hip, it may, however, be necessary to mention the leading characteristics. In all varieties the leaf is somewhat small, in comparison with the size of the hip or flower. The stalks spring alternately from the stem, having on either side adherent stipules (Fig. 8), and the leaves grow in sprays of three, five, or seven (Figs. 9, I0, II). The lateral shoots spring from the inside of the joint at the base of the mature leaf-stalks. The wood is rounded, and plentifully supplied with strong curved thorns (Fig. I2).

Extensive as the use of the Wild Rose has been in decorative arts, both past and present, the treatment of its autumnal aspect is yet rare. Its application would be judicious in perpendicular, arched or narrow spaces, for panels in either stone or wood, and inlay. On painted or stained glass, particularly where small portions of brilliant colour are required to be distributed, the hip stage of the IVild Rose will most readily offer itself. 


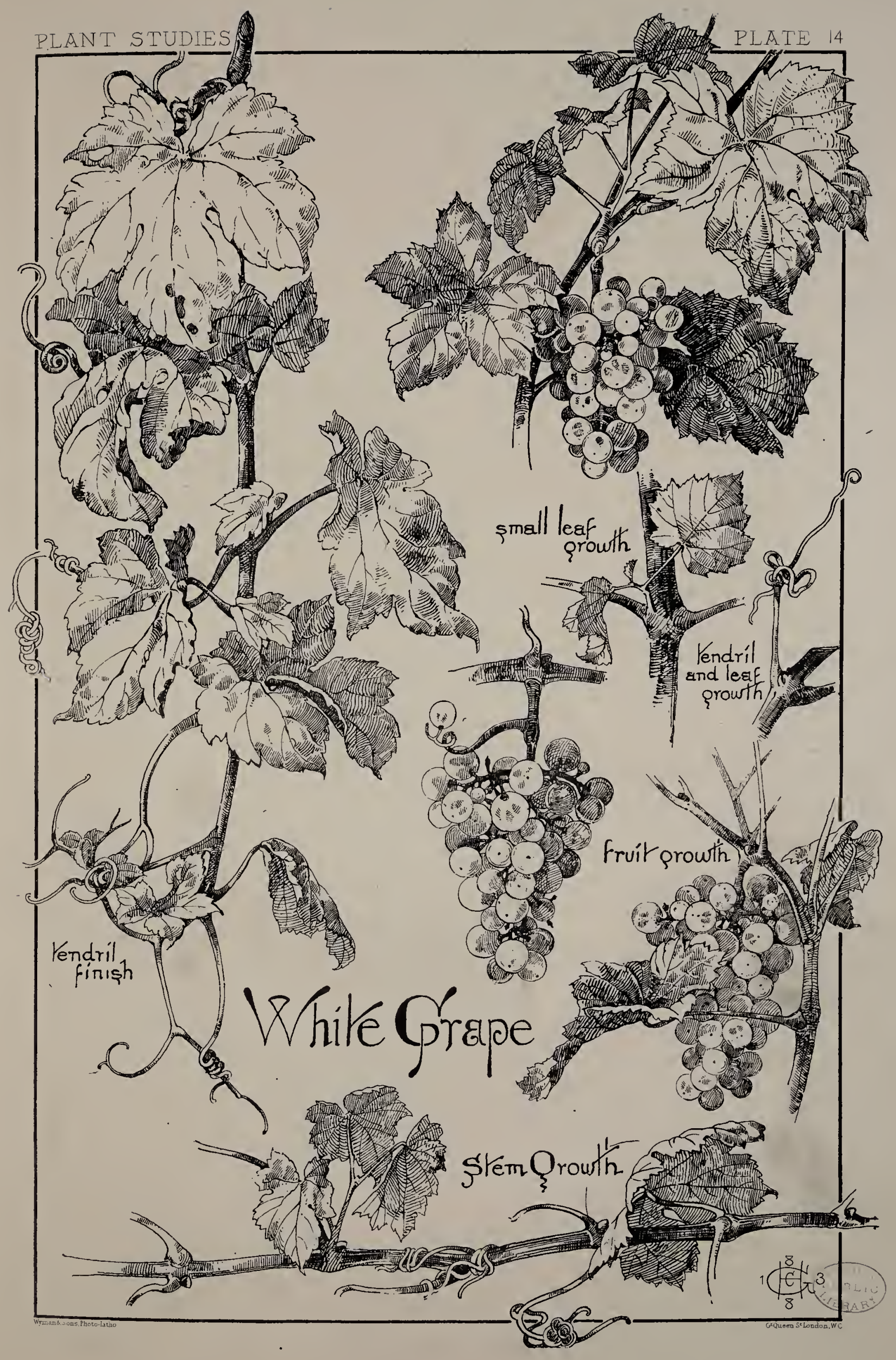





\section{Plate XIV.-THE WHITE GRAPE.}

$\mathrm{W}$

are all familiar with the eulogies bestowed upon the Vine's drooping branches as a place of shady rest from noonday heat, and for the refreshing juice of its generous fruit. It has been a favourite with poet and artist from the time when poetry and art first found cxpression in words and forms; whilè, apart from the beauty and utility of the plant, our Saviour's beautiful parable of the Vine, and the numerous references to it in Biblical history, invest it with a sacred interest certain to endure for all time.

There are numerous varieties of the Vine, differing in their manner of growth, in the forms of their leaves, and in the shape and colour of their berries. The Vine is a climber, plentifully supplied with tendrils by which it attaches itself to supports. It attains a great age, and the wood becomes gnarled and exceedingly tough.

I have selected for illustration the English White Grape, the old wood of which is a valuable and interesting study, twisting into fantastic and, at times, most grotesque forms. The Japanese frequently avail themselves of these contortions to carve humorous groups of figures, suggested by the natural growth of the wood. The predominant colours of the wood are browns and dusty grcys. In places the bark hangs in shreds of coarse fibre, and, where the branches have been pruned or torn away, cavities and irregular hollows are formed, breaking up the scarred surface. Neither the leaves nor grapes grow upon the old wood; and, although the bunches may hang over or against it, they will be found growing from the young wood of the lateral shoots.

The leafage appears about the end of April, and the flowers usually near Midsummer. The flower and early leaves are extremely beautiful; the latter pointed and elegant in form, and in colour rich bronzy yellows and greens. Although I have attempted to describe this characteristic colour of the early leaf-growth, it is really impossible to convey the tints intended.
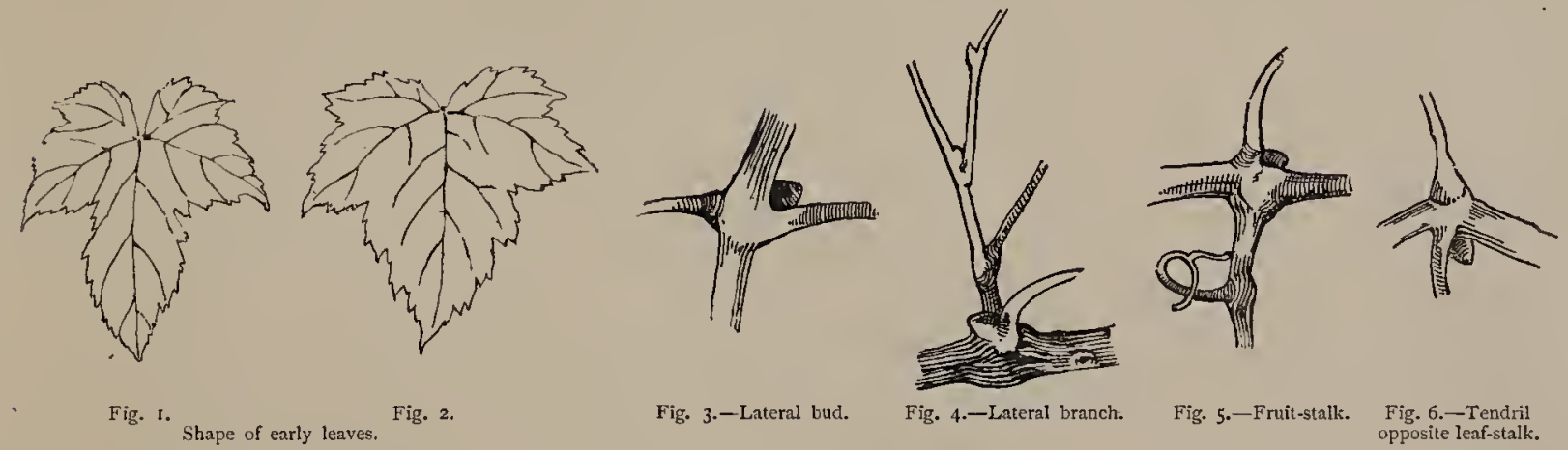

In the early growth of the leaf, which is five-pointed, two shapes are most common (Figs. I and 2), becoming broader as they develop. There are five principal veins always to be seen, even in the youngest leaflet, and smaller and more delicate traceries break up the body of the leaf. The leaves grow on rigid stalks alternately on the stem, and usually have a small brown bud at the inside of the joint (Figs. 3 and 4), from which the lateral branch springs.

The fruit-stalks invariably spring from opposite the leaf. Fig. 5 shows an example of this.

In colour the mature leaves are brilliant yellow-green, semi-transparent, and in the autumn, when the berries are ripcning, they change into endless varieties of golden yellow, orange and glowing bronzes. They arc often splashed with brilliant crimson markings, and die off from the cdges or centres in a variety of warm browns. At this, the most striking period of the leafgrowth, the grapes arc seen in their greatest beauty, the delicate silvery greens, greys, and yellows being enhanced by the rich tints of the fading leaves.

The tendrils of the Vine will be found of great importance and value to the artisan in adaptation. Thcy invariably grow, not as terminals, but opposite the leaf-stalk joint, or fruitbunch (Fig. 6). Examination of drawings of the Vine will prove that few are correct in this particular, so common is it for the tendril to be depicted independent of any order of growth. The tendrils frequently attain considerable length, and twist around their supports in pleasing forms, often tying themselves into most ornamental knots. Fig. 7 shows an example of tendril twining round a stick; Fig. 8, twining round its own wood, both illustrating the usefulness of such an appendage to the Vine. Fig. 9 shows various forms of tendril finish. In colour, the tendril-shoots are pale green, and, on the side exposed to the light, often tinged with crimson. In the plate I have given an example of tendril-knot, which is readily available for many decorative purposes. The grapes hang in heavy and thickly packed bunches; the skeleton form of which is shaped like a cross (Fig. Io), a fact that may have escaped the notice of many, and, when we 
remember the important part the Vine plays in the parables and teachings of Christ, it becomes invested with a deeper interest and meaning than we may, perhaps, have attached to it.

The stalk of the fruit-bunch always grows opposite a leaf or tendril (Fig. II). The berries are round, and become semi-transparent as they ripen, showing the seeds through their

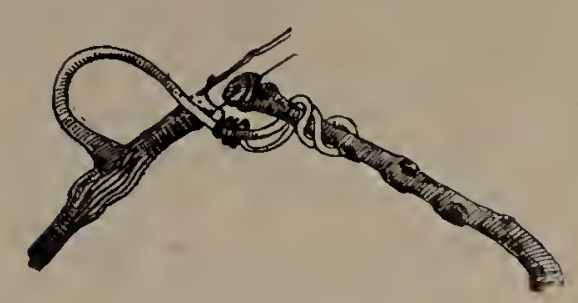

Fig. 7. - Tendril twining round $n$ stick.

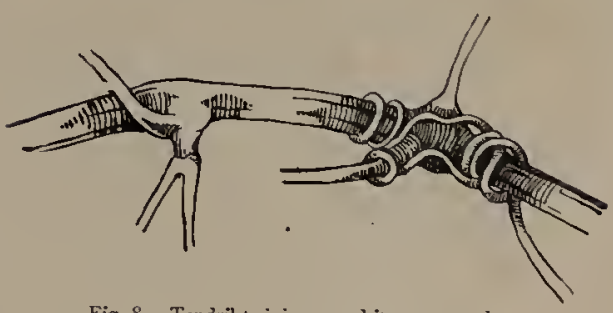

Fig. 8. - Tendril twining round its own wood
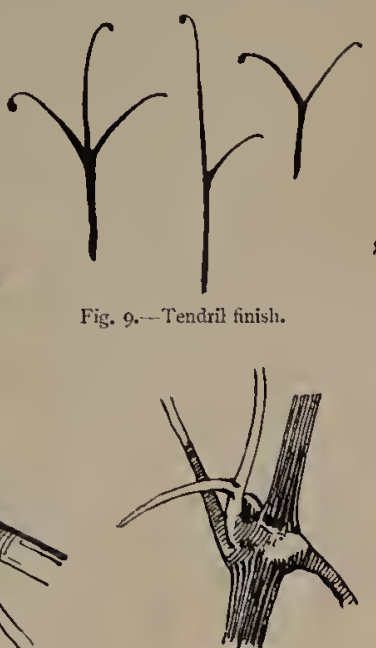

Fig. 11.-Stalk of the fruit-bunch. Fig. xo.-Skeleton form of fruit-bunch.

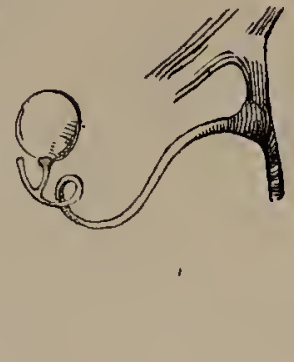

Fig. 12.-Grape ripened upon
a tendril.

delicate skins; they frequently remain hanging when all the foliage has fallen off, so that representations of the Vine in this stage of growth might be legitimately used with good effect. The fruit-bunches vary considerably long and narrow, others short would be as the stalk-structure want of light, or because too many mature but two or three berries. of a grape ripened upon a stalk ambition to become a tendril. get partly eaten by wasps and flies, exposing more of the stalky this frequent appearance, as it. of occasionally breaking the mass occur in the repetition of the

The Vine has been extensively many styles and methods of treathas been carved in stone and ivory and precious metals; empainted on glass, tiles, and pottery; decoration. The nature and freedom to almost any shape. The wide elegantly serrated leaf, globular stem, gives the Vine exceptional

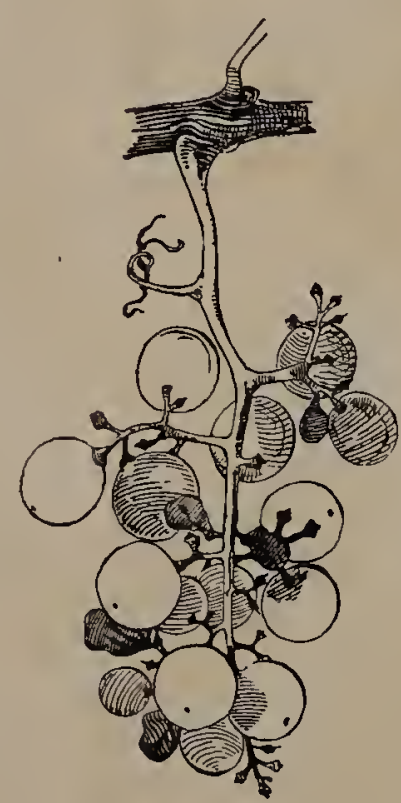

Fig. 13.-Stalky structure. in size and shape, some being and broad, though the true form suggests. Some bunches for the are allowed to remain on the plant, Fig. 12 shows a remarkable growth that apparently had an unworthy Occasionally some of the grapes or shrivel and fall off, thereby structure (Fig. I3). I illustrate affords the artist an opportunity of colour, which would of necessity fruit-bunches.

used as a motif for decoration in ment for almost every material. It wood; engraved and embossed on broidered and woven in rich stuffs; and stencilled and painted in flat of its growth allows for its adaptation difference to be found between the berries, and gnarled and rugged interest when used only for the sake of its form, in stone, wood, or metal; while, if selected to beautify glass, embroidery, mural or panel painting, the opportunities for display of delicate or gorgeous colour-effects, are unlimited.

\section{Plate XV.-THE POPPY.}

$\mathrm{T}$

HOSE who have examined the Poppy, either in its wild or cultivated state, must not only have been struck with its beauties, but have been led to the conclusion that it is one of the most wonderfully formed and interesting of flowers. The familiar name will doubtless recall the brilliant little scarlet flower, studding the fields and road-sides, and many a field of waving golden corn; indeed, so natural is the association of ideas, that a corn-field would seem strangely incomplete without the scarlet flowers of the common Poppy.

It is not this variety I illustrate, but the Wild White Poppy, which in some counties,notably Kent,-is very abundantly found in waste lands, and often, like its scarlet relative, grows amidst the corn.

There is a generally received opinion that the White Poppy, which is largely.cultivated for the sake of its opium, is the origin of all the garden varieties. Be that as it may, the general 


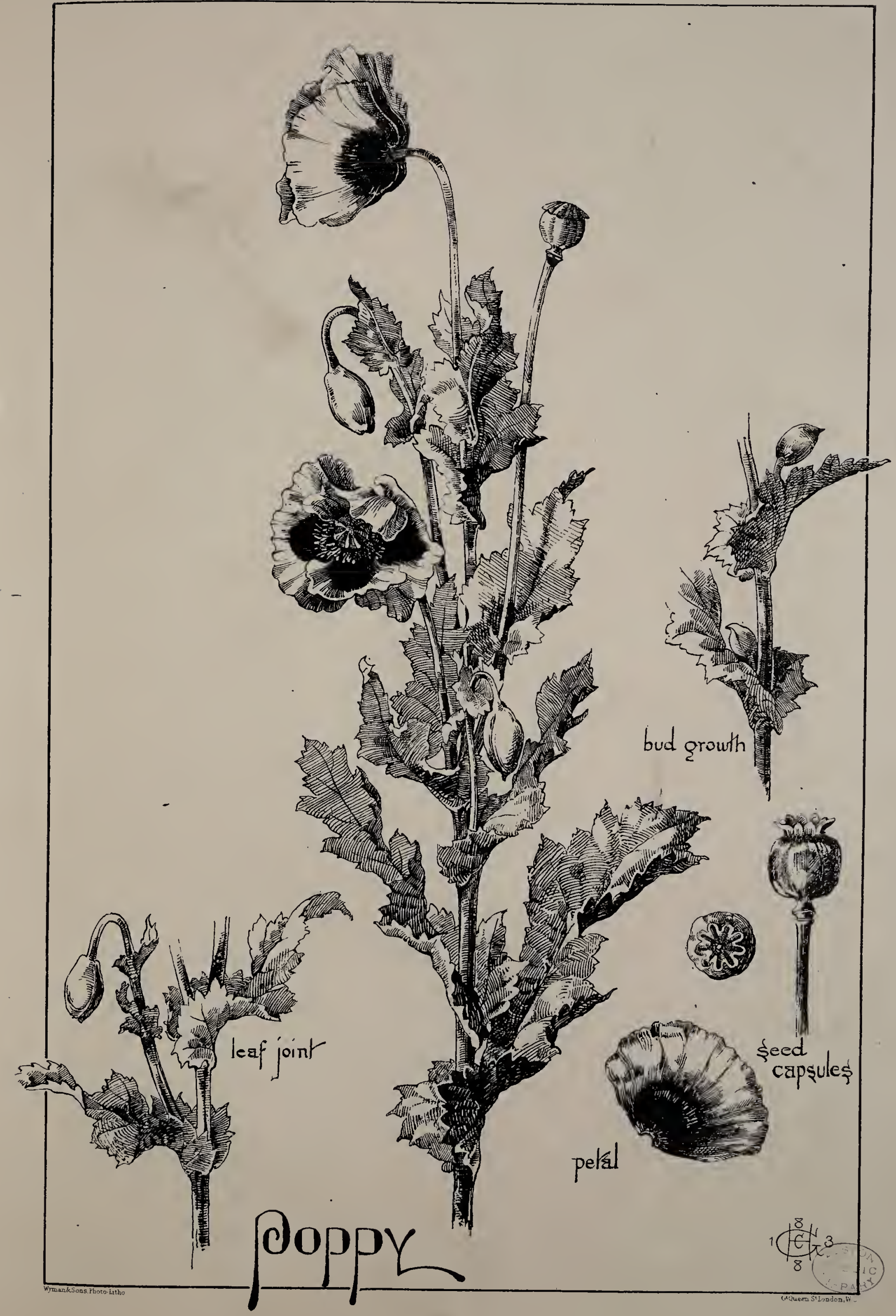



characteristics of the whole genus agree, the only difference lying in the colour and form of the single and double flowers. The characteristics of the bud-stalk and leaf-growth agree in the single and double species (which latter will be illustrated), therefore my remarks upon these points will apply equally to both.

The single White Poppy is in full bloom during the months of July and August; the plant growing to a height varying from eighteen inches to three feet, and sometimes four, in fine specimens becoming branched and bushy with finely developed foliage. The flowers stand erect and solitary upon long straight stalks which are often slightly curved just beneath the flower-heads.
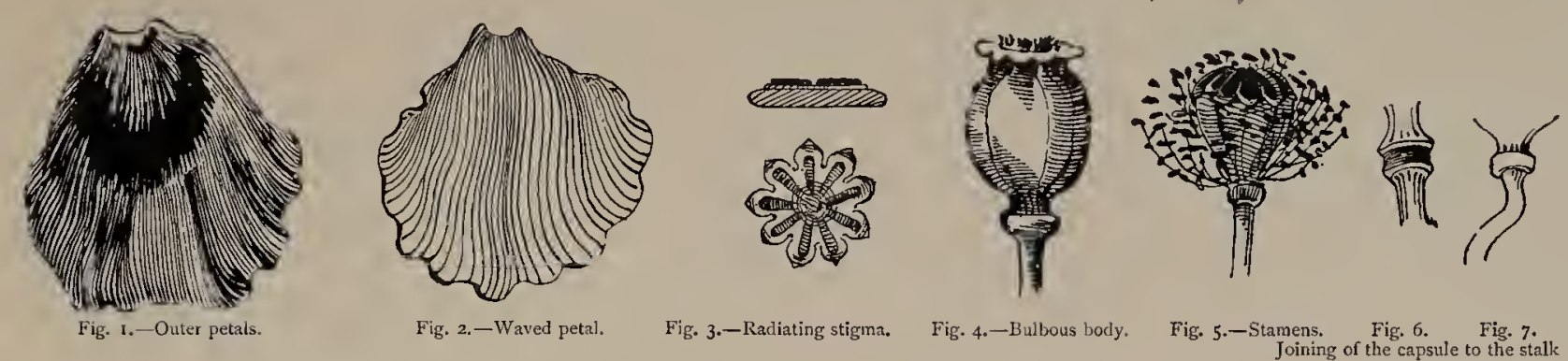

The petals, four in number, overlap each other (Fig. I), the two outer ones being the largest; this is a leading characteristic of the flower. The petals are waved at their edges, and very delicately veined, as indicated in Fig. 2, which, however, suffices to draw attention only to this feature, the lines being far more numerous. In colour it is milky white, tinged with a delicate lilac, and marked at the base with deep rich purples; and only under cultivation does the range of colours become extensive, so as ultimately to comprise salmon colour, claret, scarlet, red, and purple.

The flowers measure three to four inches across, and sometimes attain even a larger size. In the centre is the bright green seed-pod or capsule, with a radiating stigma of eight, nine, or ten divisions (Fig. 3); the bulbous body of the pod is indented perpendicularly, and is surrounded by numerous stamens (Figs. 4 and 5). The joining of the capsule to the stalk (Figs. 6 and 7) is firm, and suggestive of the strength it requires to withstand the storms and exposure during the period of its ripening, as, standing erect and solitary, it receives little, if any, shelter from the foliage.

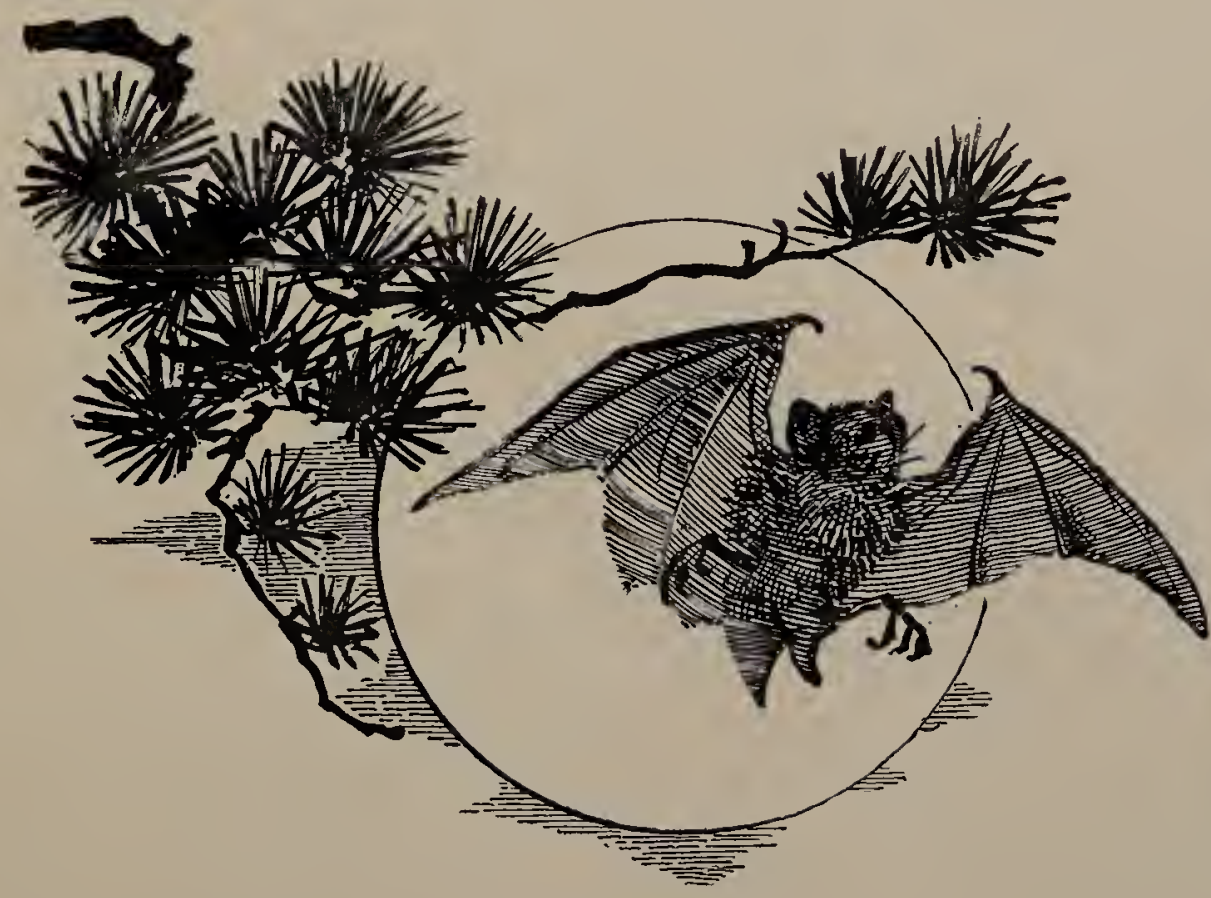





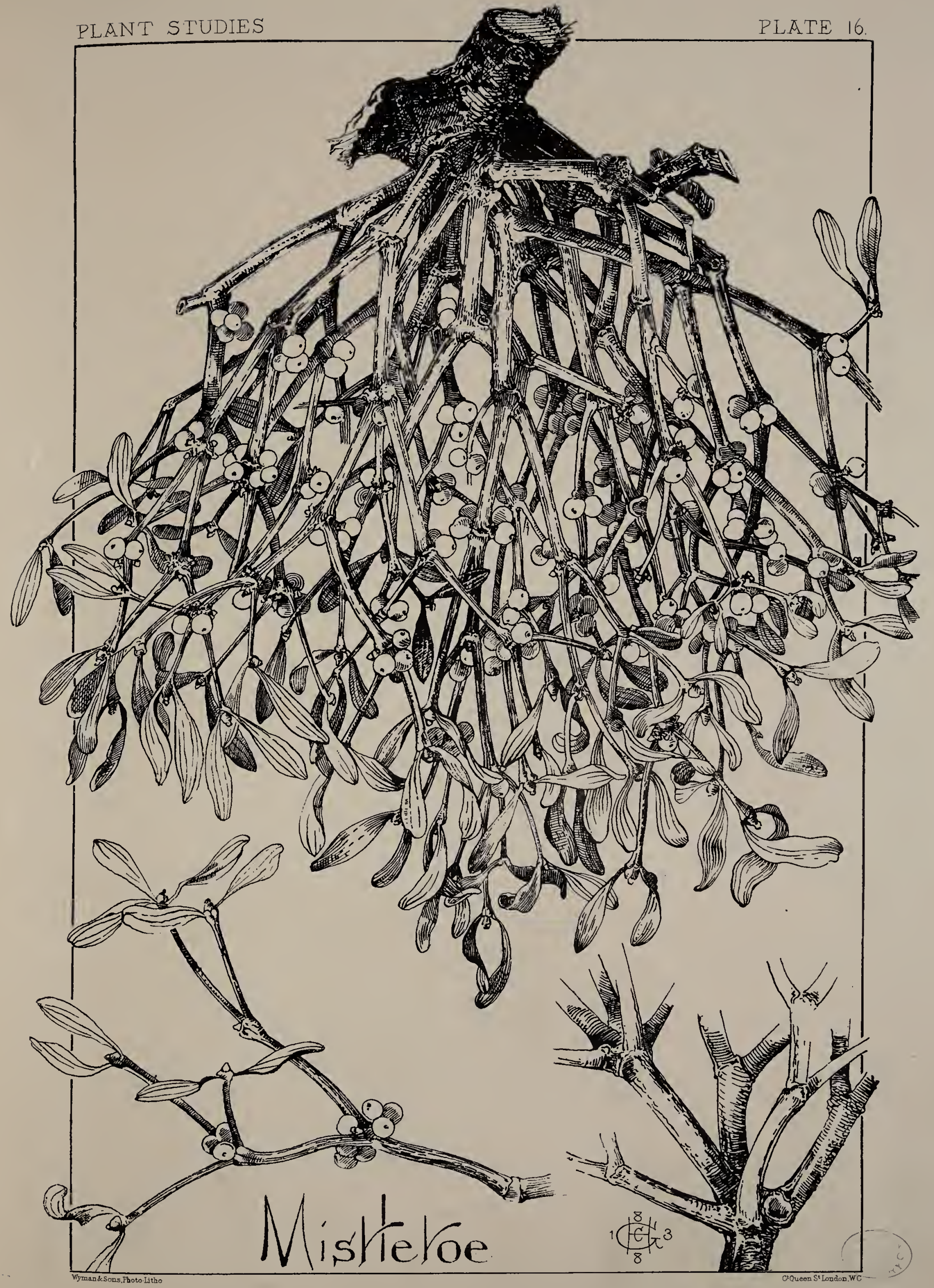





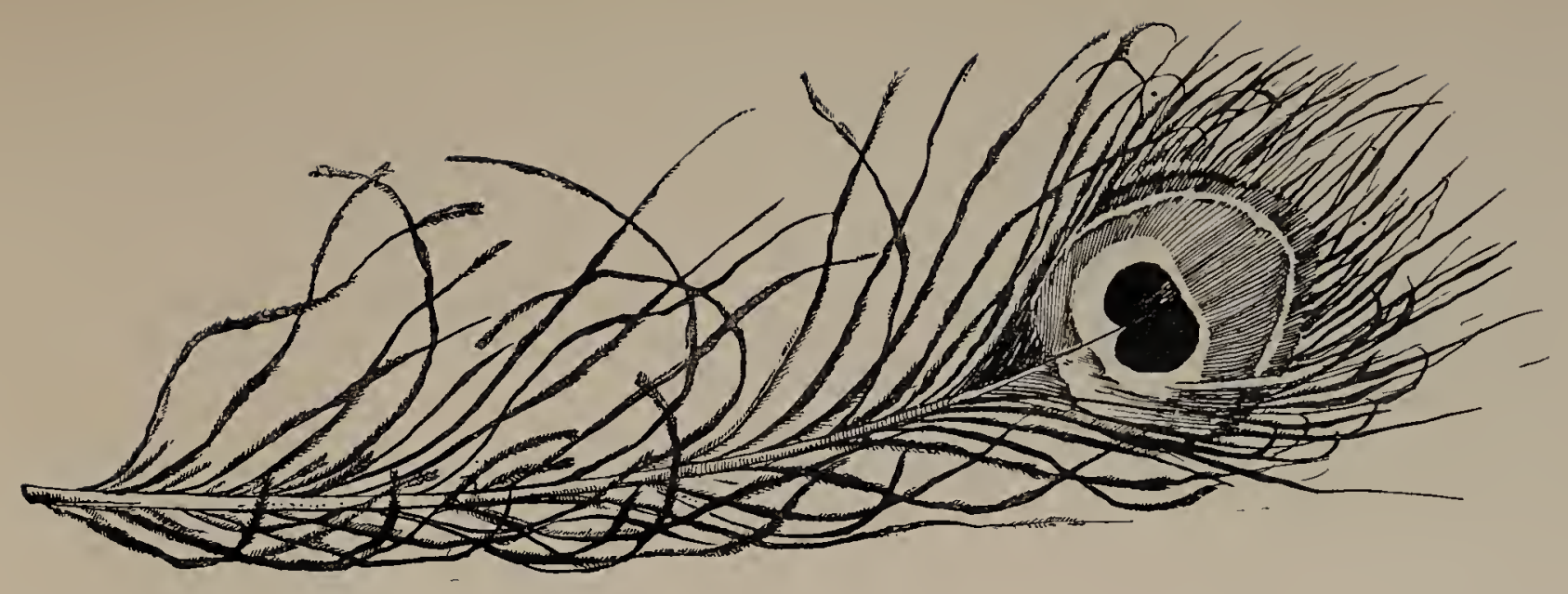

Plate XVI.-THE MiSTLETOE.

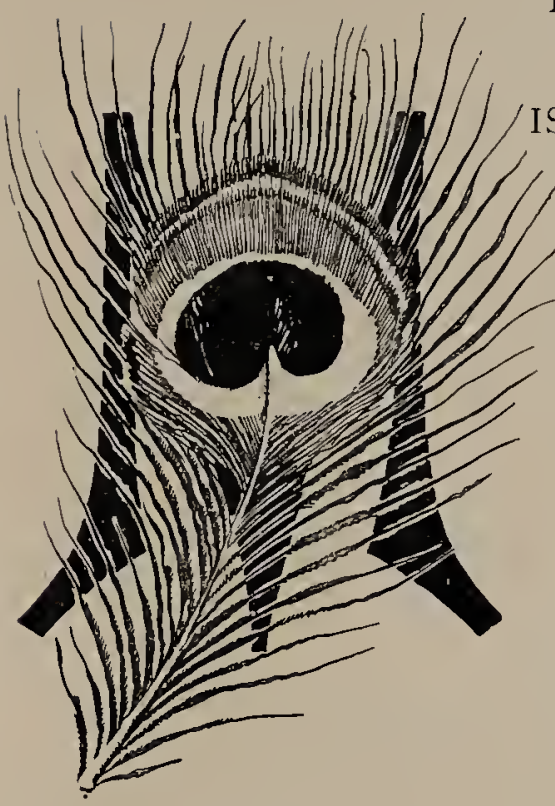

ISTLETOE is the only green parasite to be found in England, and is, in its singular growth and curious historical and legendary associations, full of interest to the botanist, antiquarian, and artist alike. It has so striking and strange an appearance when seen in winter, growing on the leafless branches of the trees, that there is little wonder that both Celt and Saxon should have hung about it religious and mystic legends.

The Mistletoe is found most frequently growing upon either the Apple or the Thorn, or the Black Poplar; less commonly upon the Acacia, American Oak, Chestnut, Mountain Ash, Nut, Fir, and Sycamore. It is generally supposed to grow most plentifully upon the English Oak, but, as a point of fact, it is found very rarely indeed, only fifteen instances of this being at present known in England. This extreme rarity probably increased the veneration with which the Druids regarded the Mistletoe when finding it so placed.

The plant is a smooth evergreen shrub, much branched, and of an angular growth. The wood is rounded and lined, and readily breaks at the joints (Fig. 1). The leaves are thick, dull green, and leathery in texture, oblong-shapcd, and rounded off at the tips (Fig. 2). When young, they are of a yellow-green colour, which darkens with age. In

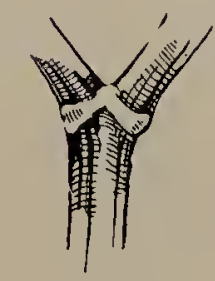

Fig. I.-Juint of Stem.

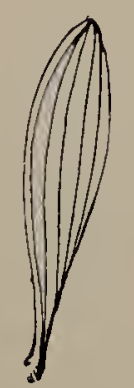

Fig. 2. -Leal.
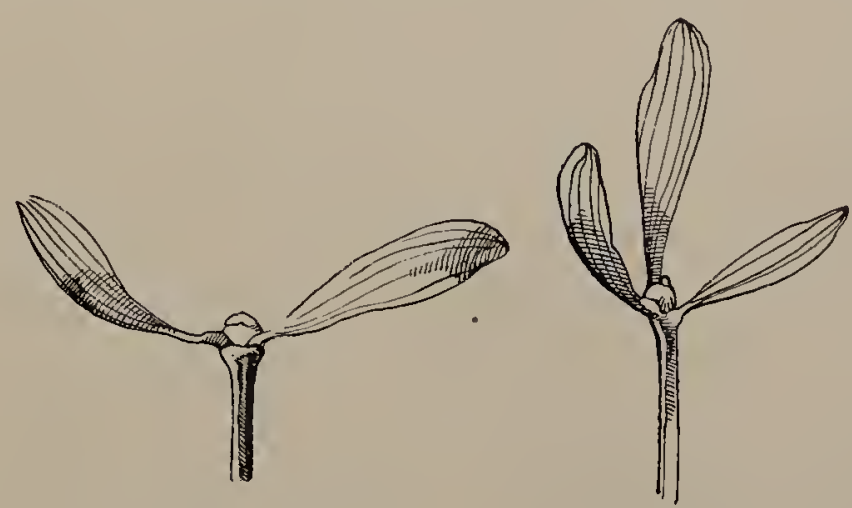
Fig. 4.-Departure from usual growh.
A whorl of three.

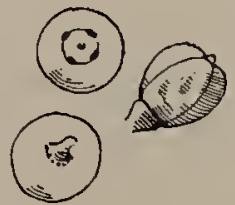

ig. 5.-Front, back, and

maturity they measure from two inches to three inches in length. They grow in pairs, directly opposite one another (Fig. 3), and more rarely in groups of three (Fig. 4). The leaf is divided by five longitudinal ribs.

The berries are the size of a large pea (Fig. 5), and vary in colour from a pale transparent grecn to a silvery yellowish shade. They grow, usually, in triplets, in the terminal forks of the branches (Fig. 6), or in the axils of the leaves, where they are generally solitary (Fig. 7). Sometimes the bcrries are numcrous, and form in largc clusters, as in Fig. 8. A bud and budgrowth is shown in Fig. 9.

The neglect this beautiful plant has suffercd by the early craftsmen is unfortunately continued to this day. It is seldom or never to be met with cxcept upon Christmas cards and Yule-tide illustrations, where a perverted imagination degrades it into evcry possiblc growth but the right. 
It is thus shorn of those very qualities which constitute its charm. $A$ noticeable instance of this lies before me, in an American prize Christmas card,-a very triumph of ignorance and carelessness. Stalk, leaf, and berry-growth are all wrong: and so hopelessly wrong that not a single feature of the plant is correct, even by accident. This inartistic neglect extends still further. The holly, yew, laurel, and ivy are used freely in our church decorations, but the Mistletoe never. It might be argued from this neglect that the plant is lacking in the qualities most suitable for ornamentation. On the contrary: in growth, form, and colour it is full of characteristics most directly amenable to the laws which govern decorative art.

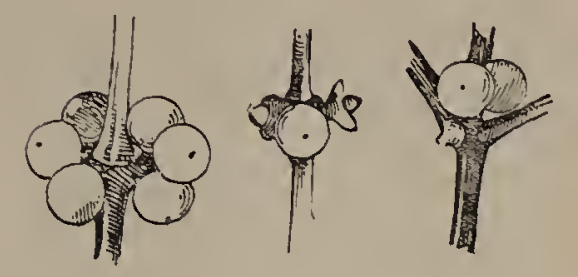

Fig. 6. -Growth of berries in the terminal forks of the branches.

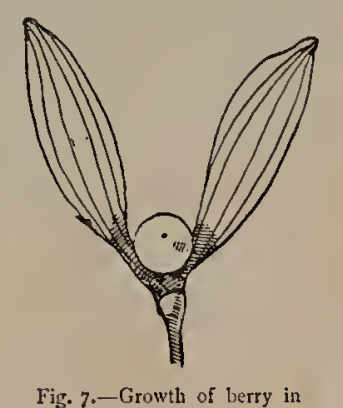

the axil of the leares.

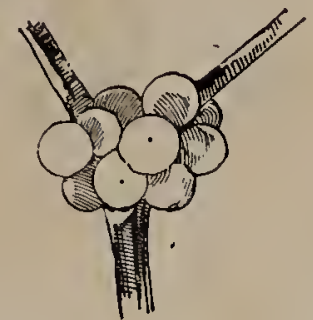

Fig. S. - A cluster of berries.

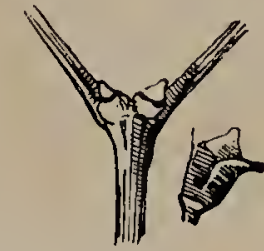

Fig. 9. - Bud and bud-growill.

The Mistletoe can be advantageously used in frieze, diaper, panel, or border, in wall-paper and fabric manufactures. It could also be introduced as a diaper background, or border, on stained glass. 'It may be easily adapted for arched spaces, and panels of furniture, doors, or boxes; for inlay-work, the mother-of-pearl and ivory representing the berries; for stone and brick-carving in pilasters, panels, \&c.; tile and pottery-painting; repoussé work, and the various methods of needlework. Its growth particularly recommends it for stencil-work, and, indeed, its possible use is almost endless.

\section{Plate XVII.-THE QUINCE.}

$\mathrm{T}$

HE Quince is one of the most elegant and beautiful of our fruit-trees, and was at one time esteened and well known as a valuable preserve and as a medium for flavouring.

Strange to say, it has fallen into an undeserved neglect in modern gardening; it is now anything but common, and, indeed, is seldom met with except in old-fashioned gardens, where it is sometimes to be found thriving in out-of-the-way corners; and yet, if it were once more given the place it deserves in our gardens, it would well repay the trouble of cultivation and the space it occupied.

Not only as a fruit is the Quince of value, but it is a form of vegetation exceedingly ornamental. It is a matter of some surprise to me that the Quince has been hitherto neglected
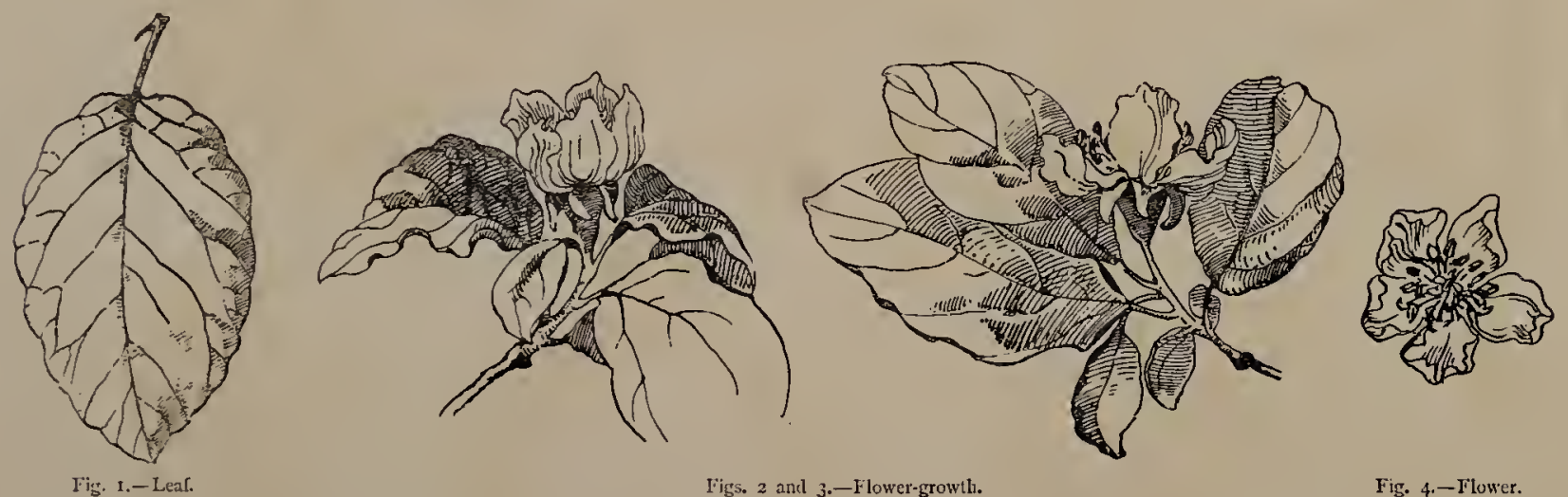

Fig. 4.-Fluwer.

by the ornamentists of past and present days; indeed, we very rarely see it used as a motif in decorative art. Yet not only the form of the fruit, by its very quaintness and unusual shape, but the whole growth, also, lends itself most kindly to a severe decorative treatment. We have become so wedded to a few accepted forms, that we hesitate to attempt anything in an entirely new direction, and thereby leave in comparative obscurity not a few of the most beautiful of nature's works. The apple, pear, and plum have all been utilised, but the Quince has, perhaps, more original characteristics than any, and can quite hold its own against them in a point of beauty.

Its use would be at once an agreeable change, and also express a desire to portray fresh beauties, as great as those selected and immortalised in ornament by the leading minds of anticuity. 


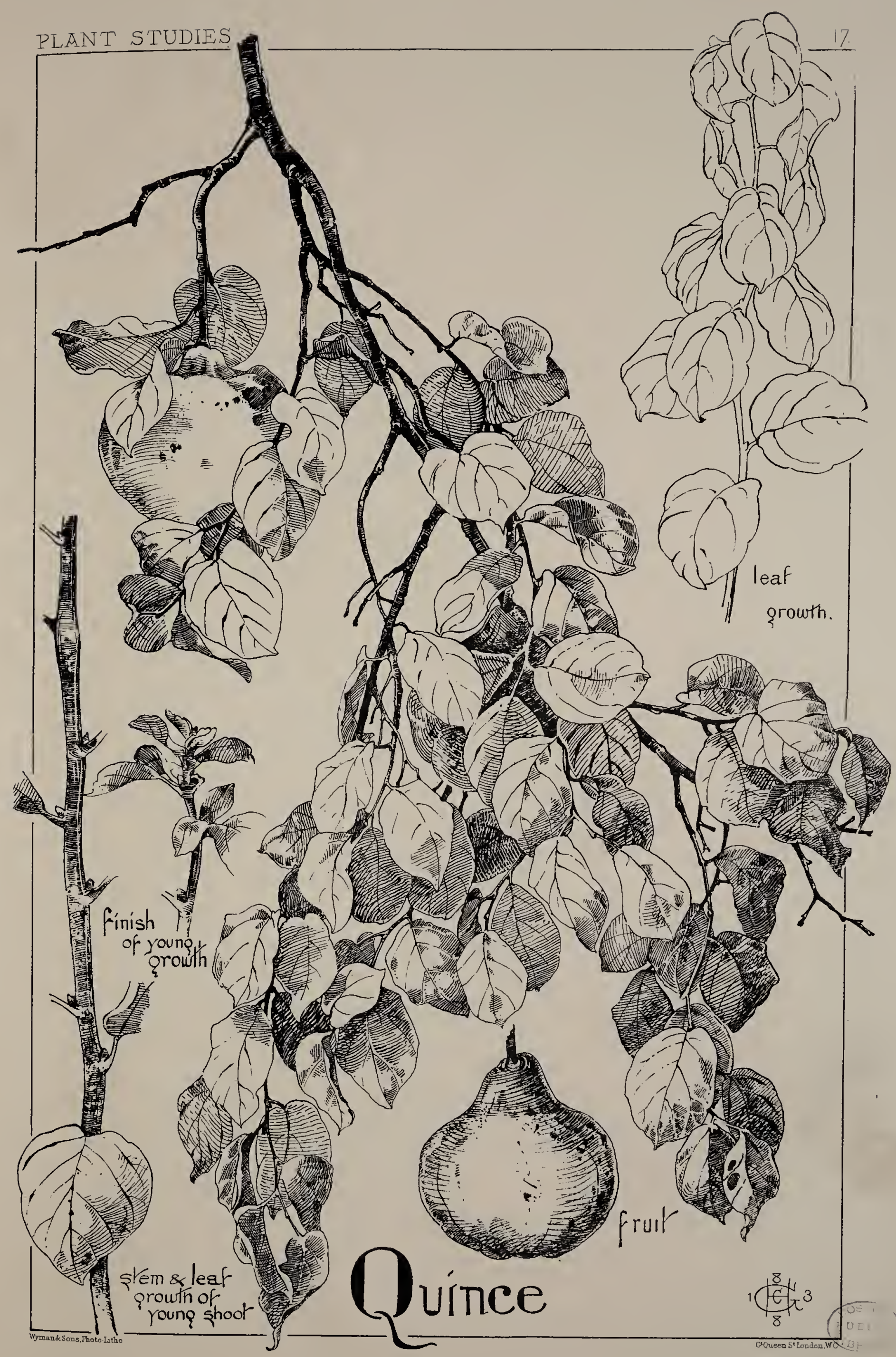





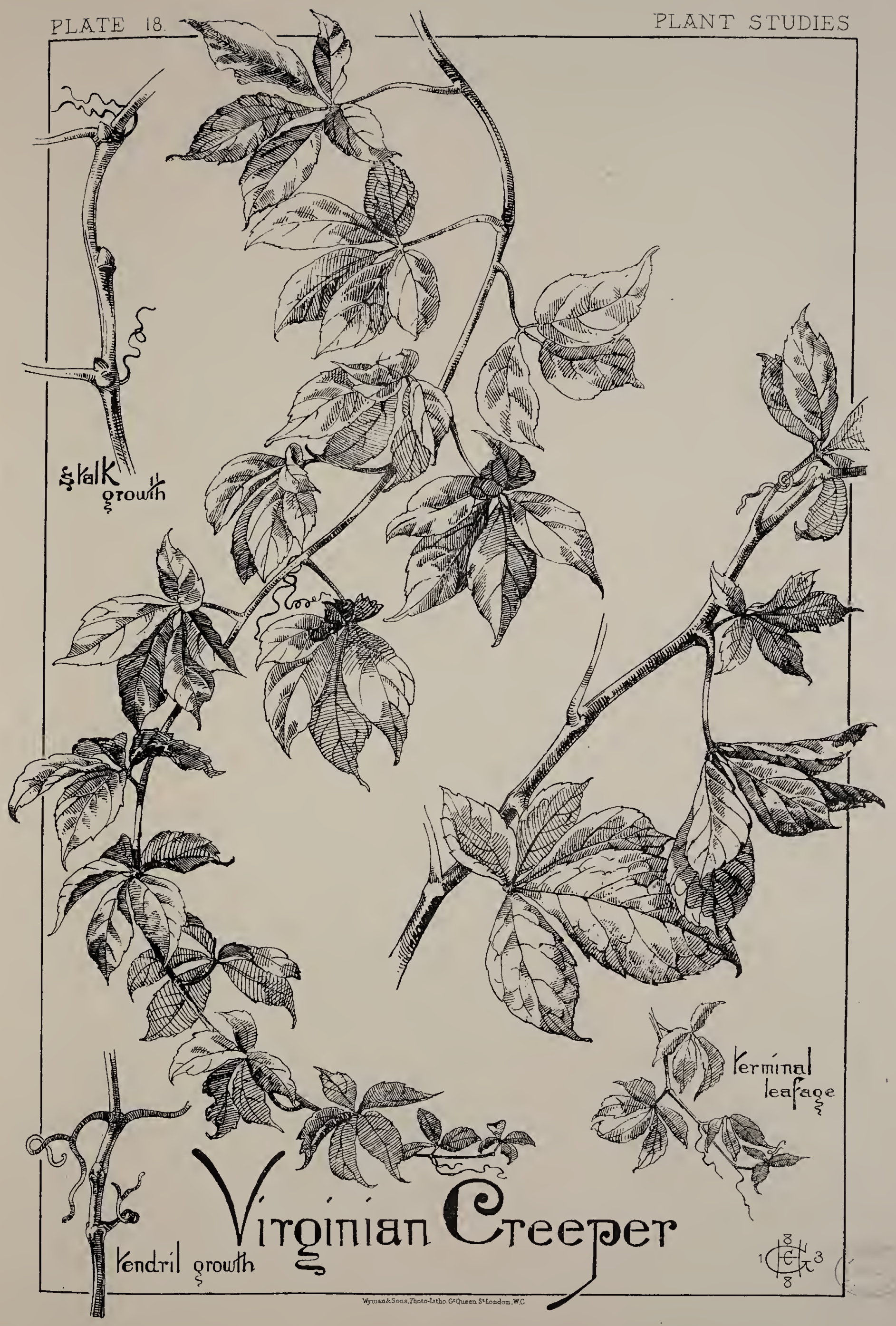



Several varieties of the Quince are known, differing from each other chiefly in the colour of their flowers, some being pure white, others tinged with a delicate flesh colour, or a deep scarlet or crimson, while some are striped with scarlet or crimson in a most charming and effective manner. The common English Quince is the subject of my remarks and illustrations, the flower of which is white, tinged with a delicate pink.

The tree is woody, and gracefully shaped, with long, drooping branches. The leaves are beautifully formed, and attached to the stem by delicate stalks. The wood is of a rich brown and bronzy-green, and is knotted at the joints. The young shoots are upright and sturdy, with a finer leaf-development. The sprays grow laterally from the branches, and take a zig-zag shape, a leaf springing from each of the alternating joints.

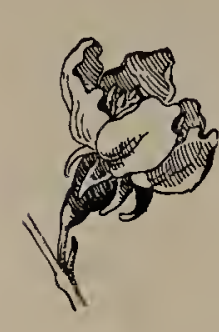

Fig. 5-Flower.

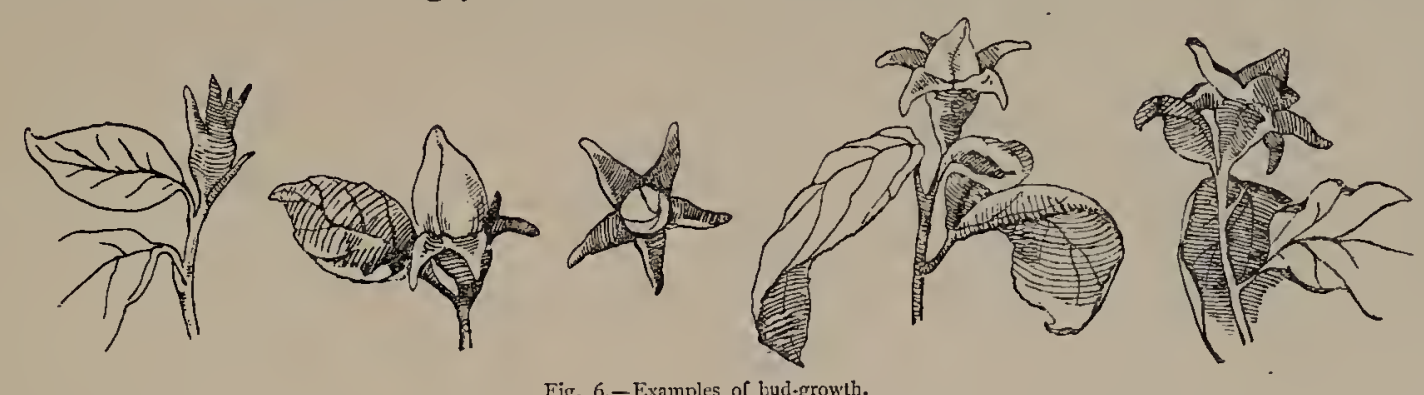

The leaf is rounded in form, with smooth edges (Fig. I), beautifully veined, and delicate in colour, the centre vein being crimson. The body of the leaf is pale green; on the under side, of a pale leaden-gray hue.

The flowers grow solitary, as a terminal to the small lateral shoots (Figs. 2 and 3), and are composed of five crinkled and delicate wax-like petals, with an indefinite number of pale, yellowish-white stamens (Figs. 4 and 5). It is supported in a five-petaled, dark-green calyx, which gives a beautiful feature to the varied bud-growth (Fig. 6). The leaf-terminals are also interesting (Fig. 7).

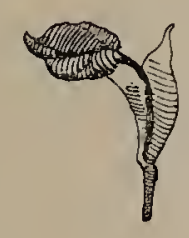

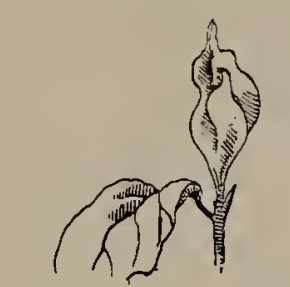

Fig. 7.-Examples of leaf-finishes.
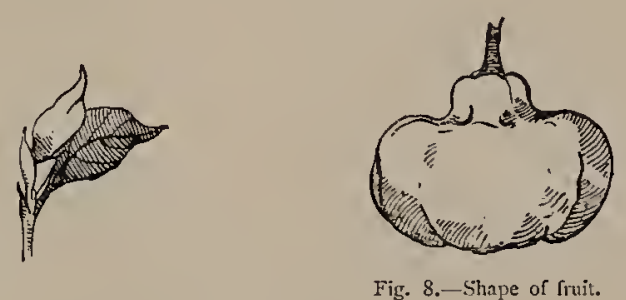

In the autumn, when the fruit hangs ripening, the leaves change to a golden yellow and bronze, and curl inwards. The fruit, which is the chief feature of this beautiful tree, is fully ripe in October, and hangs as a terminal on a light stalk. It is exceedingly heavy,-far more so than any other fruit of its size that I am acquainted with, -and invariably bends the branches down, which, being delicate, are swayed by the wind; thus, the fruit is beaten against the branches, and is usually much bruised, with marks of a more or less deep brown colour. The form of the Quince is most characteristic; though it frequently assumes a simple pear-shape, its true form is distinctly peculiar to itself (Fig. 8).

\section{Plate XVIII.-THE VIRGINIAN CREEPER.}

A

THOUGH the Virginian Creeper is not indigenous to our soil, yet it has taken so kindly to its new home, and flourishes as few exotics do, that we have come to look upon it as one of our commonest creepers. It has found favour with all classes of society, and what is always a mark of affection, has been dubbed with a popular name, "the Jenny."

We find it on every hand-now twining over the portico of some great house, or covering some ruined castle. Over hall or cottage alike it sheds its lustre ungrudgingly. We find it in the country, throwing its thick and graceful veil over a roadside bridge, or hanging like a magic robe from a withered tree, and in towns it may be seen struggling, against all difficulties, to climb some house or church, and clothe the hideousness of human invention with its divine natural beauty.

Wherever it is found it is always an object of admiration, whether stunted and small and half suffocated in English towns, or spreading in its full gigantic vigour over immense rocks and trees in the wilds of its own country. From spring, when it is of a delicate bronzygreen, until the autumn, when it flames with a wealth of ruby fire, it is always lavish with 
its unstinted varieties of colour. I can indeed recall no foliage at all common in England, where anything like this rich number of gorgeous shades can be parallcled, much less equalled; while in its native country it is even more splendid, both in colour and size. It will there rise to the height of fifty to a hundred feet from the ground, and is plentiful in the berries, which in England hardly ever come to maturity.
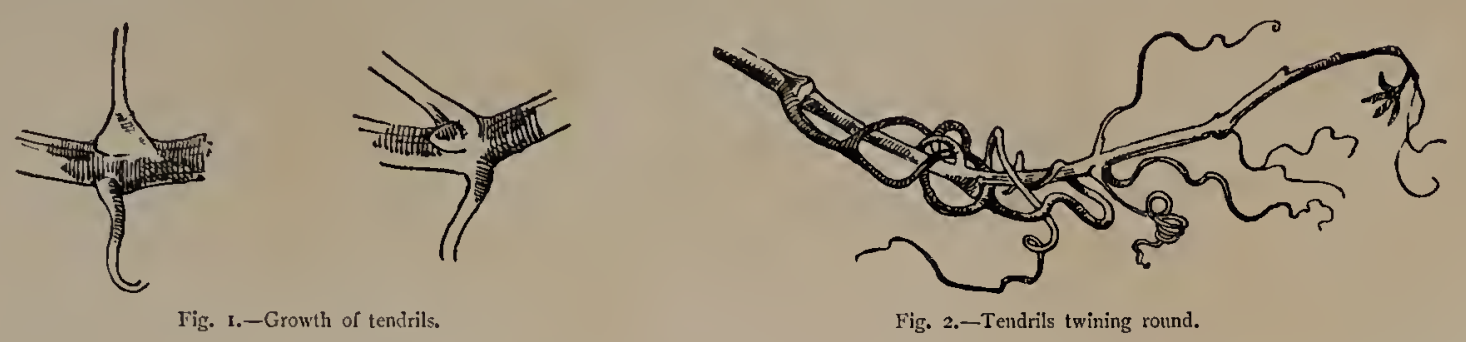

The Virginian Creeper puts forth its leaves early in May, and by June the branches are thickly covered with delicate leaves of a rich bronzy-green shade, which shine with a metallic and polished lustre. As autumn draws on they change into such a variety of brilliant orange, scarlet, crimson, and purple-greys that they beggar verbal description, and dim the brightest colours of our palette.

The plant, as a climber, either winds its stem and branches around its supporting object, or attaches itself by tendrils. These tendrils are numerous, and grow, as in the case of the

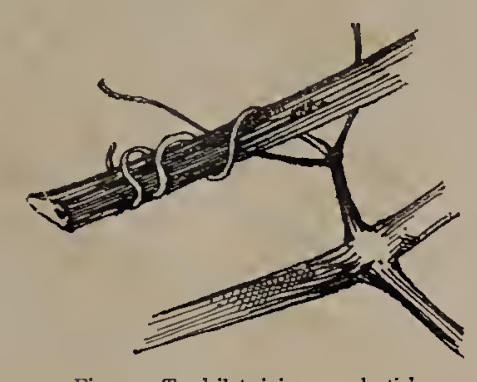

Fig. 2.-Tendril twining round stick.

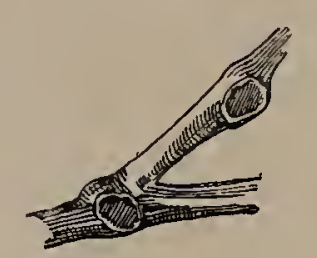

Fig. 3.-Joints of old leaf-stalls.

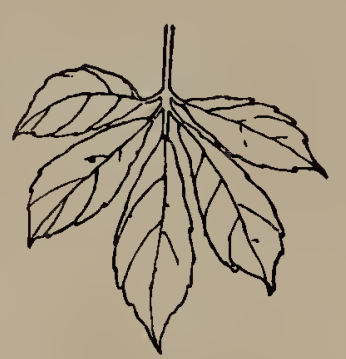

Fig. 4.--Normal growtin of lear.

vine, from opposite a leaf-joint (Fig. 1), and act either as suckers against a flat surface such as brick, wood, or stone, or else grasp and twine around the support (Fig. 2). The old wood is brown in colour, and marked with little cup-like depressions, where the stalks of former leaves once grew (Fig. 3). The normal leaf-growth is cinque-partite (Fig. 4), although there are frequent departures into the sexpartite and septempartite, and more rarely into the tripartite and quadripartite forms (Figs. 5 and 6).

The leaf is of an elegant shape, deeply serrated, and is centrally ribbed and most delicately veined. The young shoots and earlier leaves are especially graceful (Fig. 7).
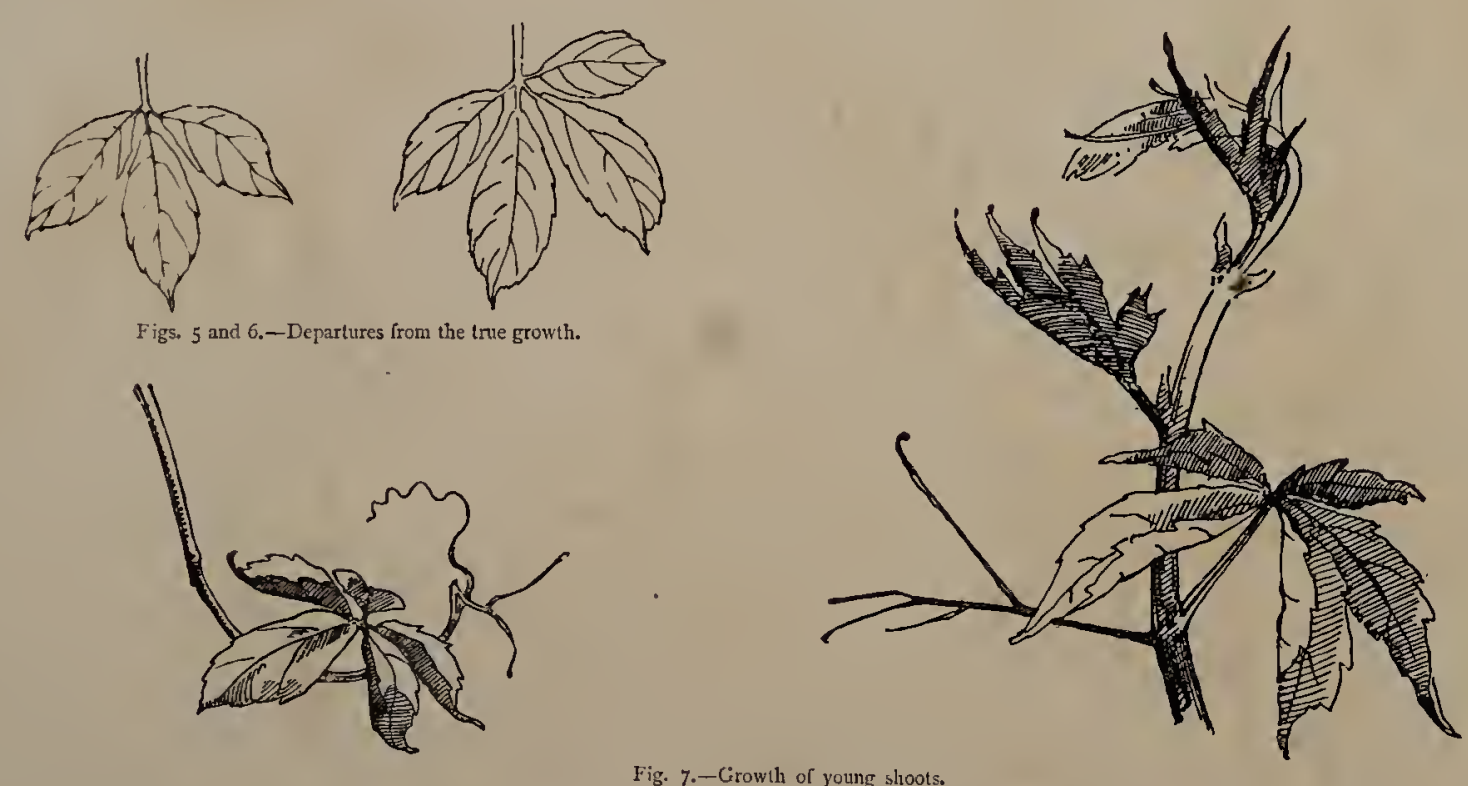

The Virginian Creepcr is esteemed highly by the ornamentist, but not more so than it deserves. There is no reason why it should not flourish as extensively in art as it does in nature. Its adaptability to all methods of applied art is well understood, so we may pass lightly over this portion of the subject. Instances of and opportunities for its use might be multiplied almost indefinitely, but I note particularly its suitability as a background for stained glass, when an opportunity occurs for using a mass of ruby colours. 


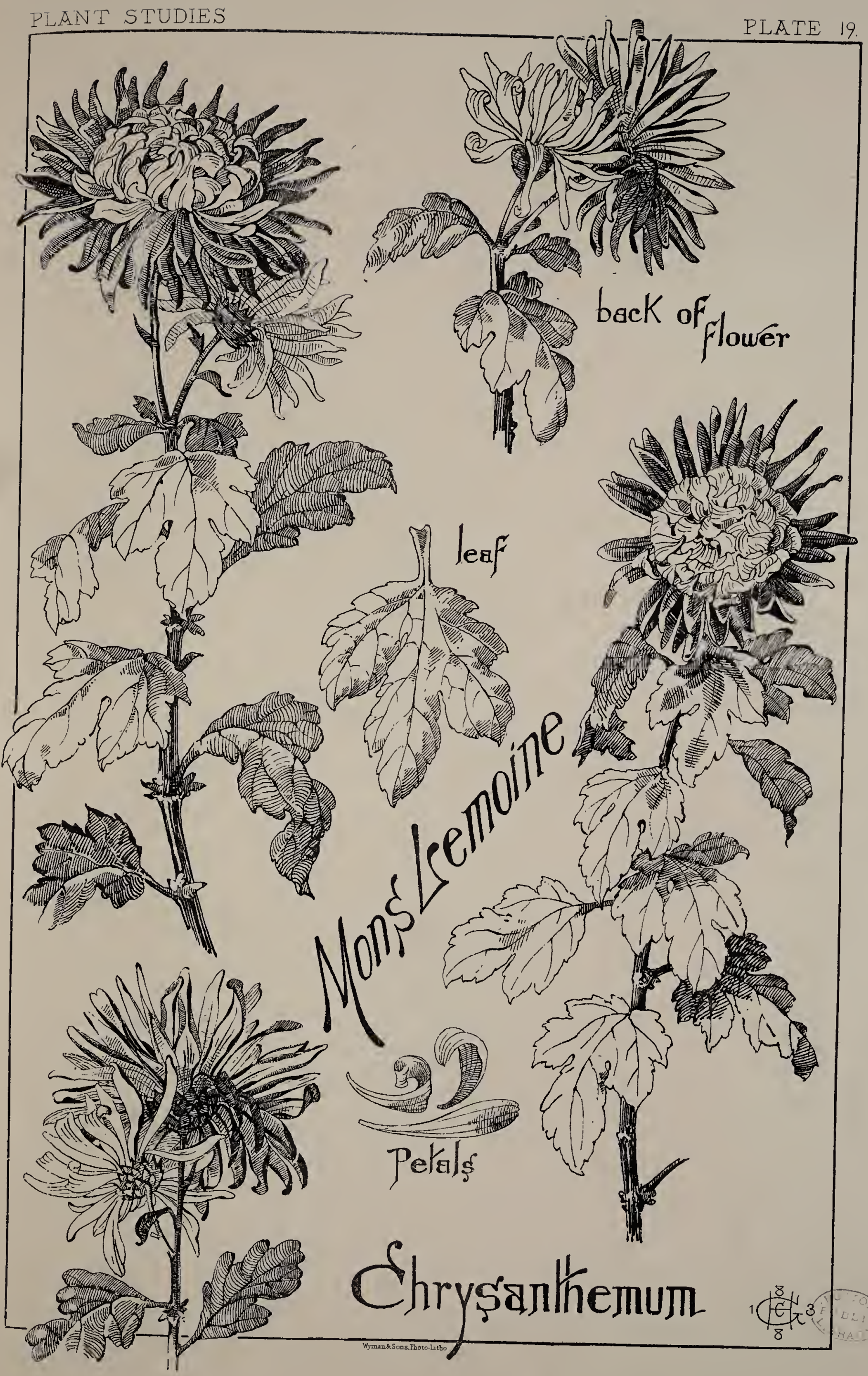





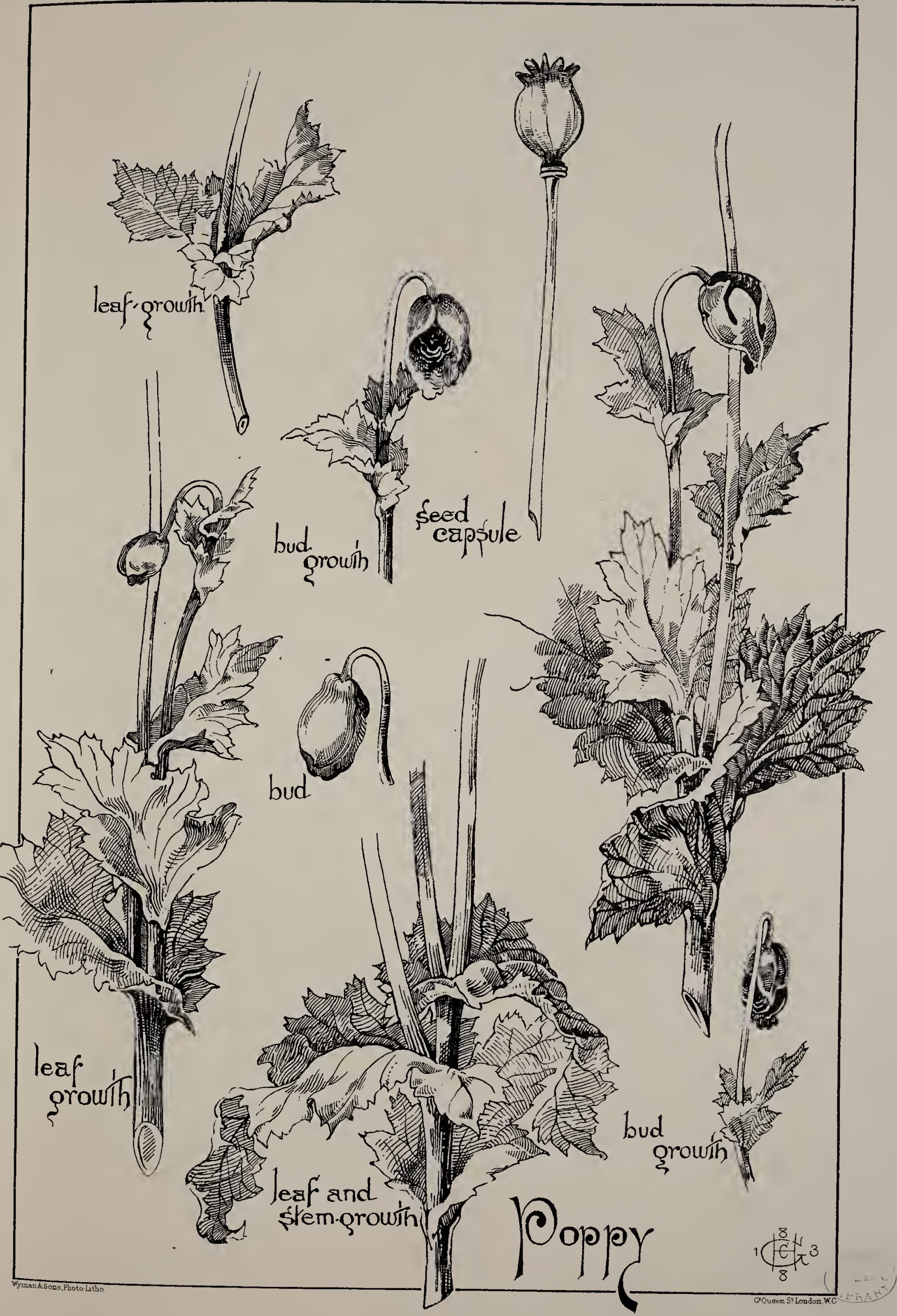





\section{Plate XIX.-THE “MONS. Lemoine” Chrysanthemum.}

$\mathrm{M}$ third illustration of the Chrysanthemum is again a Japanese variety, "Monsieur Lemoine," which, like the species already shown, possesses peculiar qualities in both form and colour. It differs little in the characteristics of its foliage, but greatly in the form of its blossoms.

The colour of the flower is deep dragon's-blood red, with a centre of yellow. The petals (Fig. I) widen out at their tips, the under sides of all being of a yellow colour, and those in the centre curving over and inwards (Fig. 2) expose this under surface, and give the flower its beautiful yellow centre. From the back view, it appears as a yellow bloom, striped with narrow lines of bright red; - this is caused by the petals folding outwards, and exposing their inner colour, red (Fig. 3). The young blooms are often entirely yellow, and act as a beautiful foil to the rich red of the fully-grown flower. The calyx is small, and the buds round and sturdy, with yellow petals.
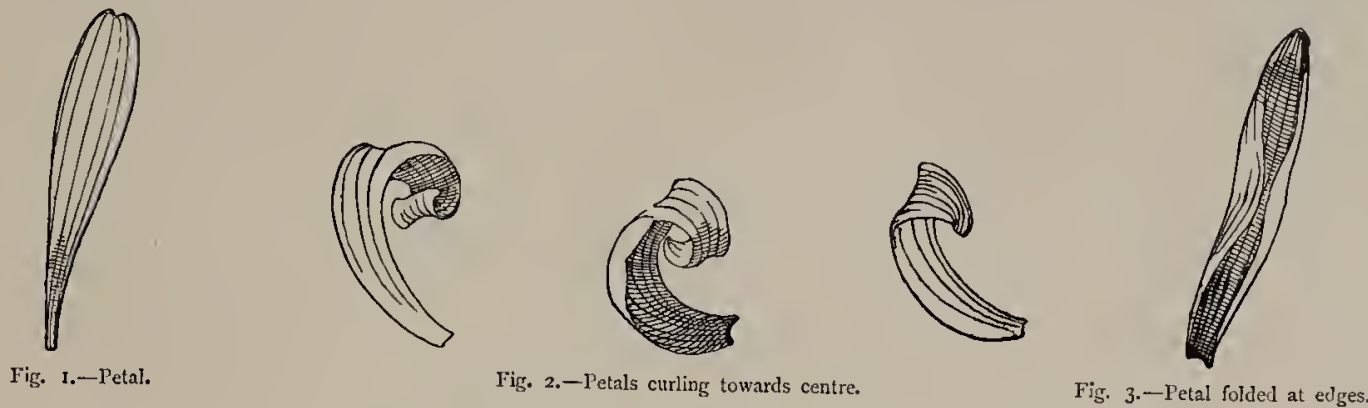

The leaf of "Mons. Lemoine" is brighter in colour than those of "Peter the Great" and "Meg Merrilies," and somewhat smaller, and less rounded in form, but the divisions and serrations are deeper and more numerous. The winglets at the base of the leaf-stalks are not so well developed as in the other species.

My illustration gives examples of the full-view, back-view, and profile of the flower.

My remarks upon the adaptability of "Peter the Great" and "Meg Merrilies" equally apply to "Mons. Lemoine." If a decided effect of contrast in colour is desired, the specimen now referred to would be found more useful than either the plain yellow of the former or the combined white and yellow of the latter.

The peculiar habit and formation of the petals of this variety will particularly recommend it to metal-workers and wood-carvers, by whom it might be made most serviceable.

\section{Plate XX.-THE POPPY (continucer).}

7 HE Poppy bud-growth possesses many beautiful features. They generally hang down (Figs. I and 2), gradually raising themselves as they develop, until they stand erect as full-blown flowers. Reference to the drawings will illustrate this peculiarity, which, in adaptation of the plant, should be observed.
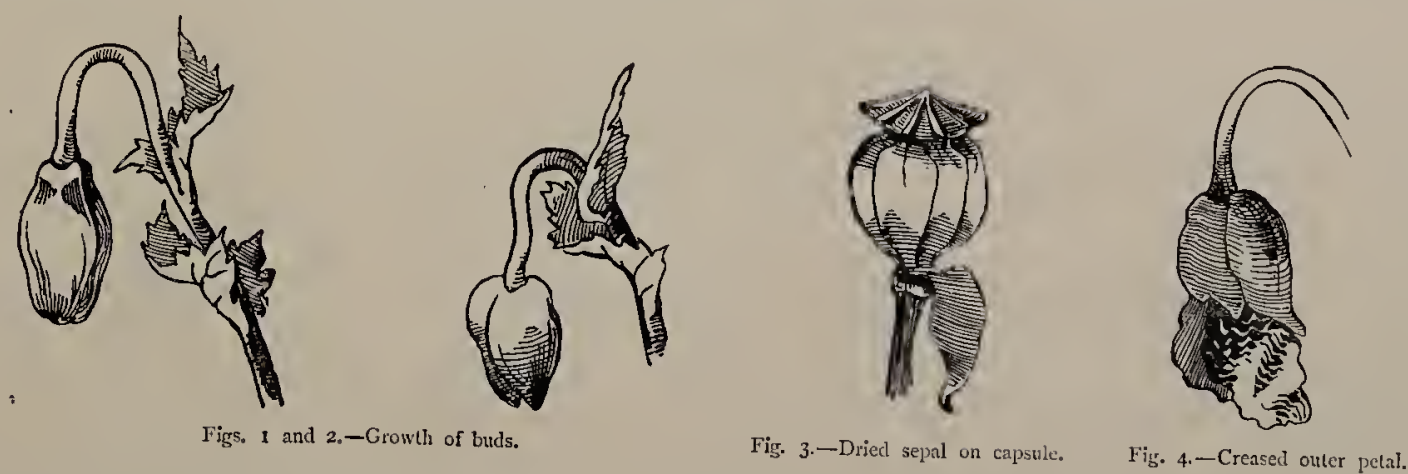

In their earlier stages, the buds are enveloped in two pale-green sepals, which fall off is, more the flower is fully developed; this is a distinctive characteristic of the plant, and is, moreover, common to the genus; occasionally, however, a dried sepal is found still adhering
to the capsule (Fig. 3).

Normally, the buds open at the tip; but frequently they burst their sepals at the sides and base, thus disciosing the gorgeously-coloured petals tightly foldcd. and, in many cases, creased
Hais's Plantsuntics. 
in waving lines (Fig. 4). Figs. 5 and 6 show some of the methods of opening, manifesting how valuable these peculiarities are in giving character to applied representation.

The foliage is remarkable, and worthy of so striking a flower. The leaf is elongated, finely veined, and deeply and irregularly toothed, growing alternately from, and partly closing round, the stem (Fig. 7), which is round and smootl. The leaves fold over, and fore-shorten

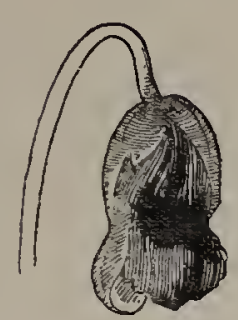

Figs. 5 and 6. - Hethods of opening.

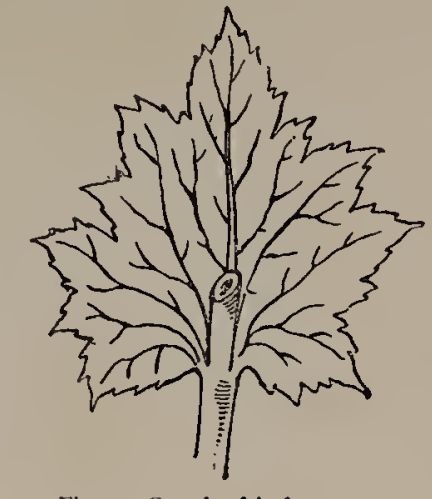

Fig. 7.-Growth of leal to stem.

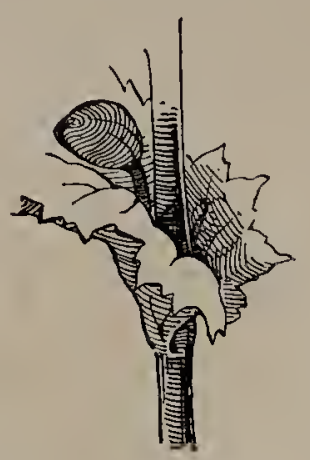

Fig. 8.-Growth of lateral bud.

into varied and most elegant forms. They are semi-transparent, and of a greenish-yellow colour when seen against the light. The general colour-effect of the leaf, bud, and stalk is a pale whitish-green, the whole being subdued by a bluish-white bloom. This opaque-looking bloom pervades the whole plant, and gives it a somewhat flat appearance.

From the inside of the leaf-joint the lateral shoots spring (Fig. 8), terminating in drooping buds, flower-heads, or capsules, according to the stage of growth.

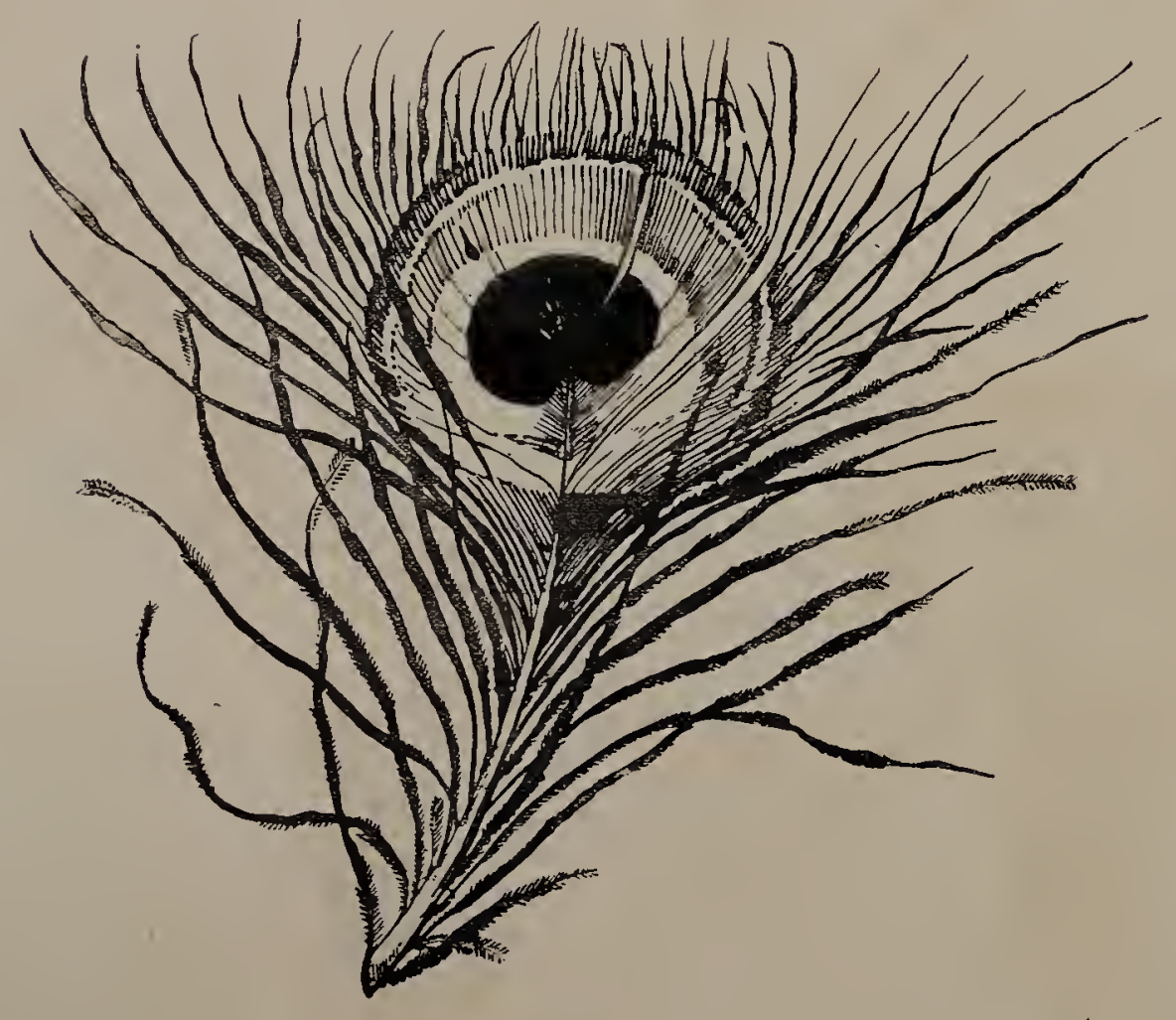



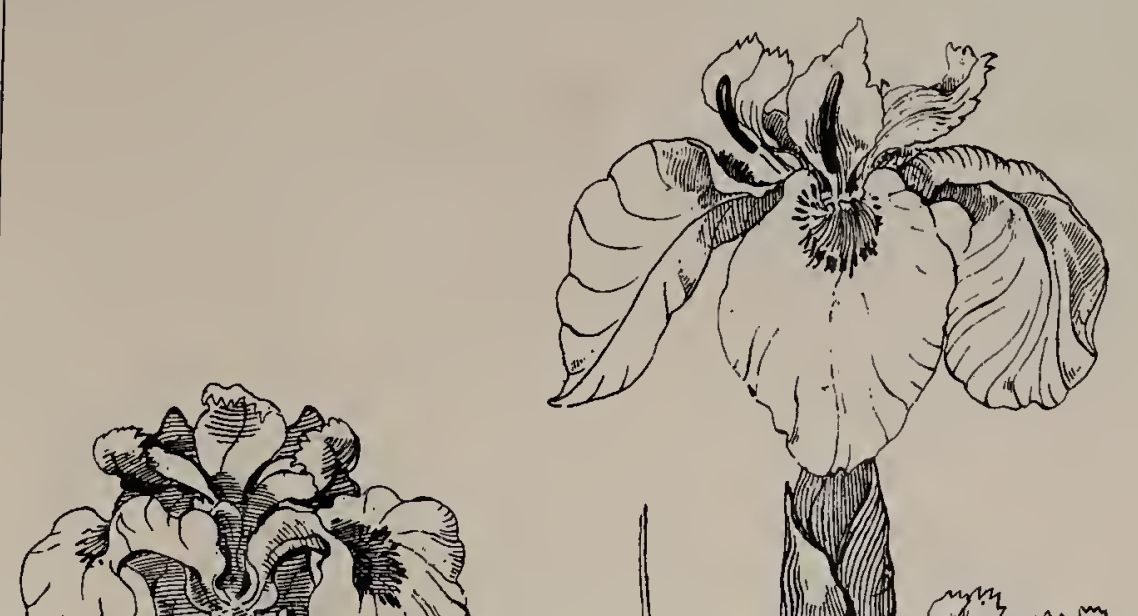

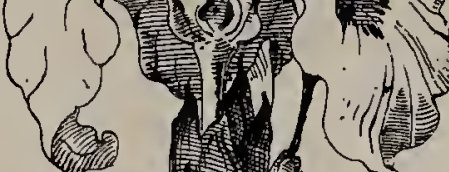

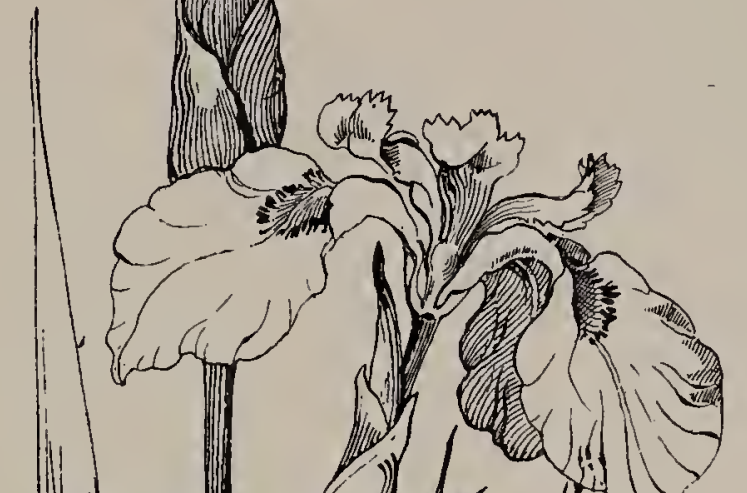

(1)

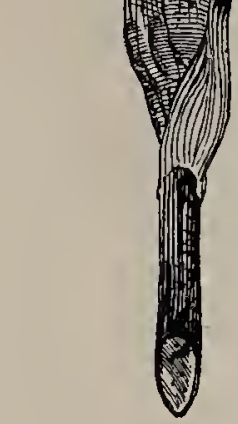

.

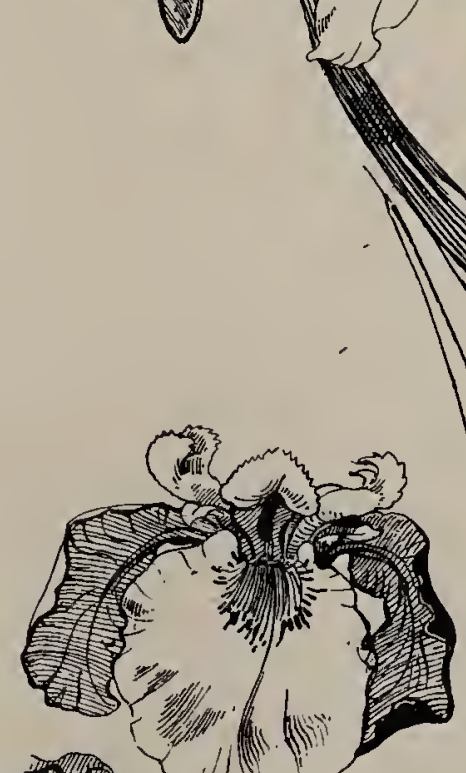

cium
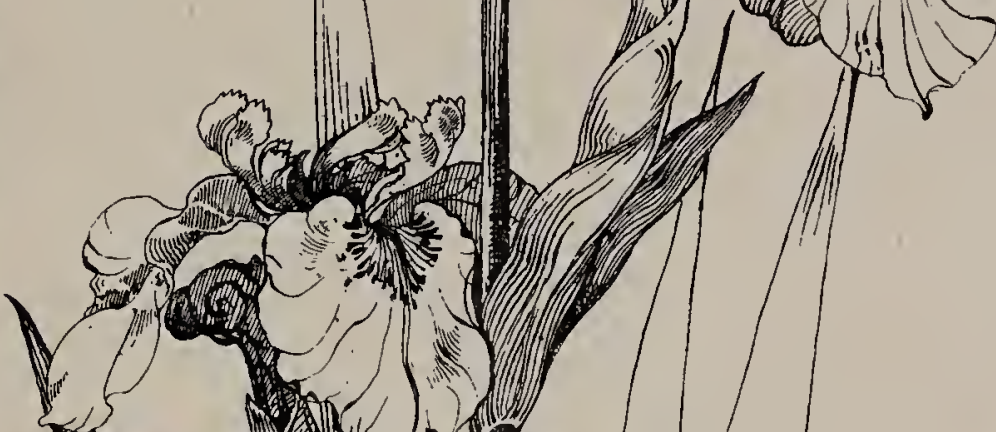

Thellout
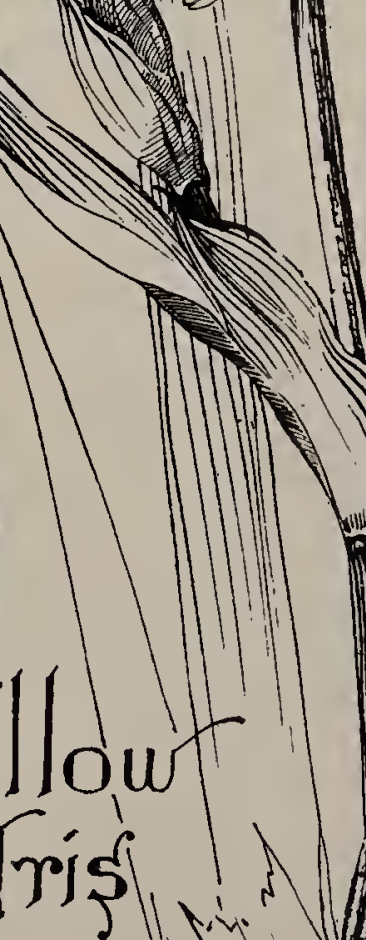

wain
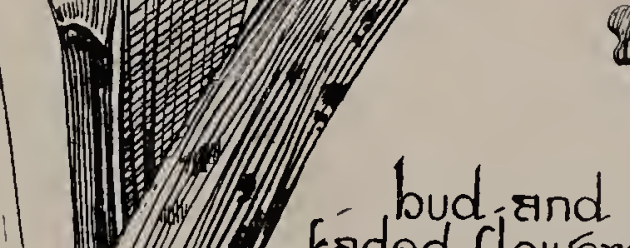
faded-flowers
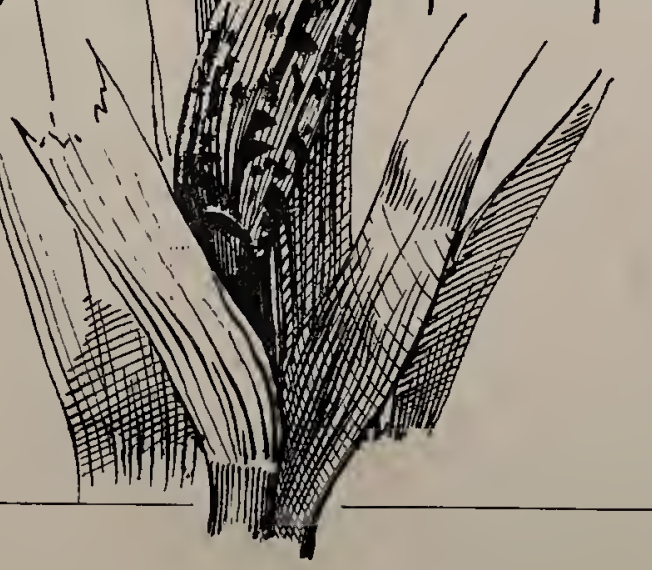


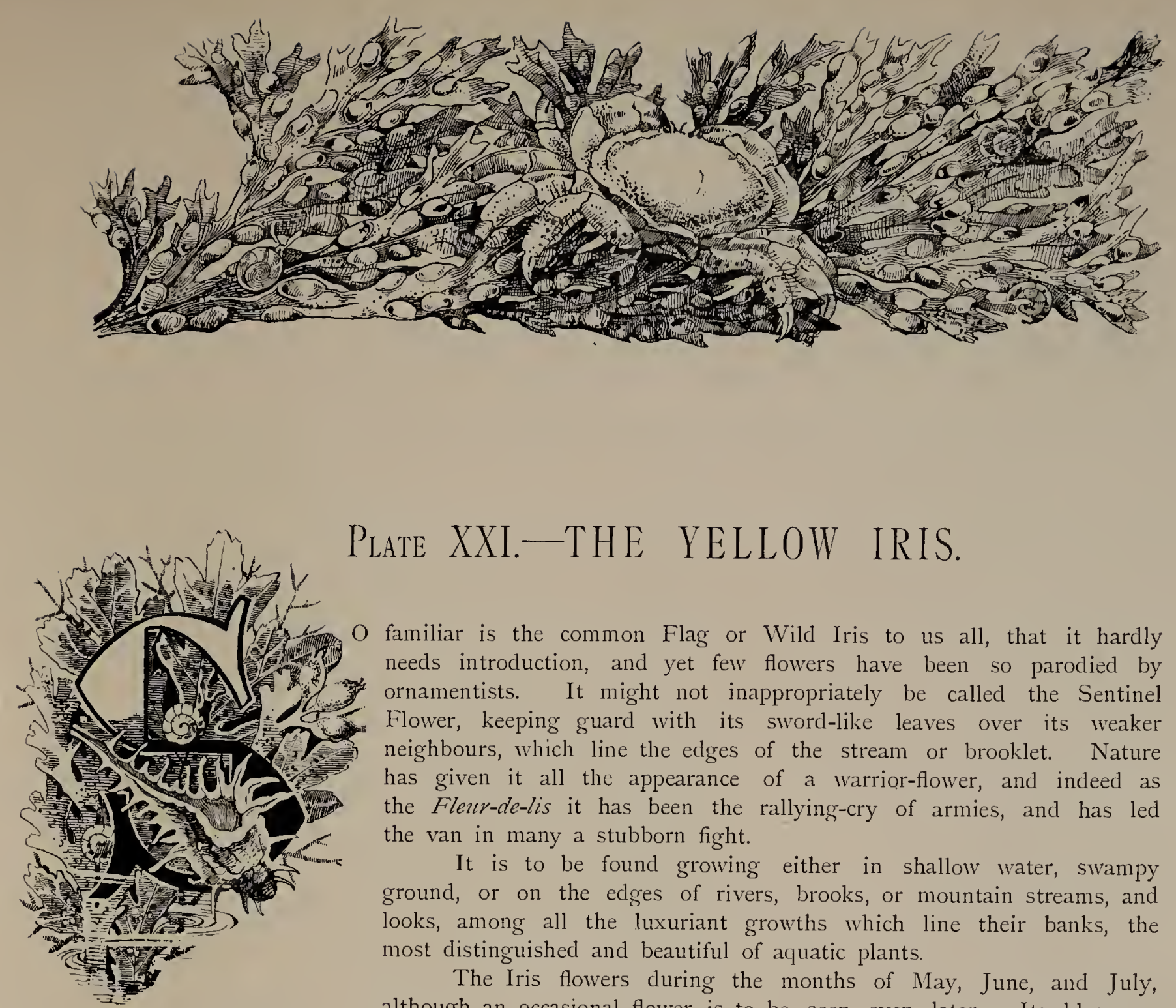

Plate XXI.-THE YELLOW IRIS.

O familiar is the common Flag or Wild Iris to us all, that it hardly needs introduction, and yet few flowers have been so parodied by ornamentists. It might not inappropriately be called the Sentinel Flower, keeping guard with its sword-like leaves over its weaker neighbours, which line the edges of the stream or brooklet. Nature has given it all the appearance of a warrior-flower, and indeed as the Fleur-de-lis it has been the rallying-cry of armies, and has led the van in many a stubborn fight.

It is to be found growing either in shallow water, swampy ground, or on the edges of rivers, brooks, or mountain streams, and looks, among all the luxuriant growths which line their banks, the most distinguished and beautiful of aquatic plants.

The Iris flowers during the months of May, June, and July, although an occasional flower is to be seen even later. Its blossoms are peculiar and characteristic in form, and either of a pale or deep yellow colour, with delicate brown and green veinings. Several flower-heads group upon the same stem, which sometimes grows to the height of four feet.
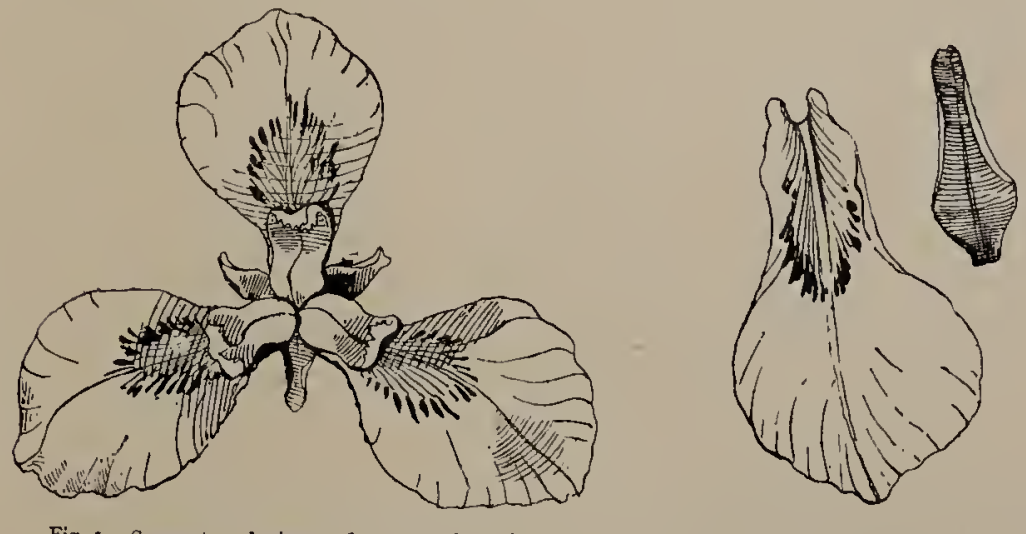

Fig. 2.-Large bearded petal. Fig. 3.-Segment.
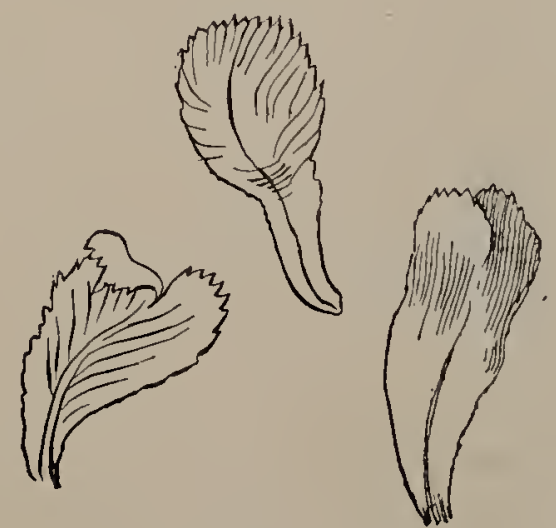

Fig. 4,-Stigmas.

The flower is composed of three whorls (Fig. 1), two of which are formed by the three largest and three smallest segments, all of which are narrowed at the base (Figs. 2 and 3). The former are bearded, and fall whorl of three stigmas, which are edges (Fig. 4). These three stigmas retaining the pollen.

In the autumn the stems still seed-capsules, which are divided into and disclose rows of tightly-packed This seed-period of the plant is so a plate to its delineation.

The buds are pointed and surrounded by the faded blossoms

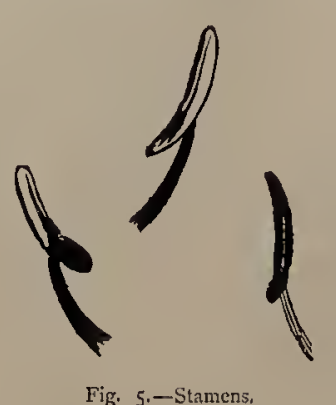
over, thus exposing the remaining cleft at the top and fringed at the arch over the stamen (Fig. 5), thus

remain erect, bearing aloft the dried three cavities. These, when ripe, open, and most brilliant scarlet berries. decorative that I may possibly devote exquisitely marked, and are often (Fig. 6), which curl up and change of the bud and flower. 
The leaf is straight, rigid, and pointed at the tip, and bears resemblance to the blade of a sword. It is parallel-veined, and folds around the stem (Fig. 7). The lateral flower-stalks spring from inside the base of the leaf (Fig. 8), which is deep blue-green in colour, fading to yellow and brown, during which process they are not infrequently marked with brown, red, and purple spots. The leaves in this stage serve as a valuable foil to the somewhat monotonous colour and rigidity of form natural to such vigorous growth.

Whether this yellow variety or the wild Purple Iris was selected for ornamentation and the badge of France is uncertain. The characteristics of the two species are similar, but from the treatment I am inclined to accept the Yellow Iris as the chosen flower. In "The Flowering Plants of Great Britain" we are told that "a Fleur-de-lis, exactly like that of the emblem of the French Monarchy, was found surrounding a sceptre (still the ornament worthy of kings), on a monument of highest antiquity at Dendera, in the heart of Egypt." The Iris, moreover, was placed on the brow of the Sphinx,-rather a paradoxical emblem perhaps, as the Ancients regarded the

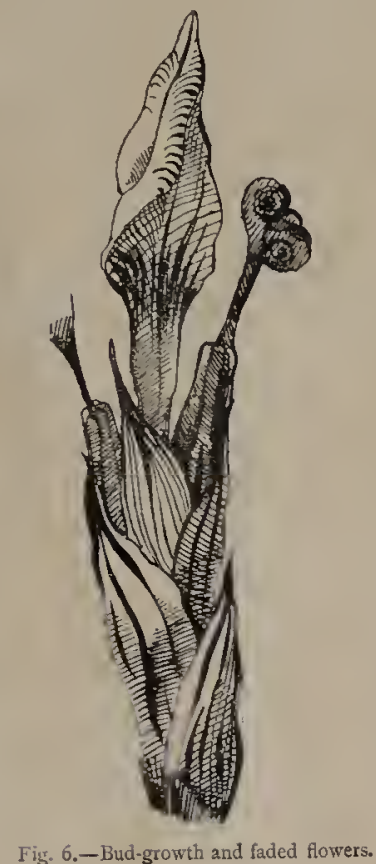

Fir. 6. - Bud-growth and faded flowers.

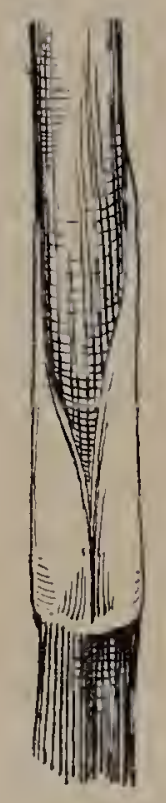

Fig. 7.-Leaf-growth.

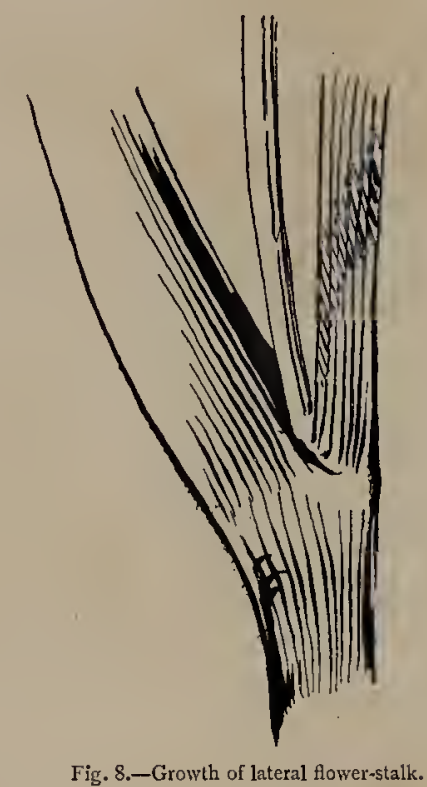

Fig. 8.-Growth of lateral flower-stalk.

plant as emblematic of eloquence. In Persian art the Iris stands, on account of the tongue-like leaves, as interpreter to God for the expression of the wishes and thoughts of other flowers.

Of all the aquatic plants common to Britain the Iris has taken the greatest part in ornamentation, and is to European art what the Lotus was to Ancient Egyptian art. In ecclesiastical work especially, its use has been most extensive. It has always been a great favourite with the ornamentist; in the familiar Fleur-de-lis form we find it carved in stone and wood, wrought in metal, painted on glass, and used for rich embroideries of every kind.

Of late years it has been greatly used in a more naturalesque form for painted, stencil, and printed decorations; for panels, needlework, china and pottery painting, and repoussé work, in all of which it can be readily and satisfactorily adapted.

\section{Plate XXII.THE DOUBLE POPPY.}

$\mathrm{T}$

HE Double Poppy is composed of four large outer petals (Fig. I) -like the single variety already described-and an indefinite number of smaller petals (Fig. 2), which curl and twist into an apparently tangled centre: all are marked with a deep, rich colour, and delicately veined. In the white variety the markings are purple; in the salmon-coloured, scarlet; in the scarlet, crimson; and in the claret-coloured, almost black.

The seed-capsule (Figs. 3, 4, 5) is not so frequently seen in the double variety, owing to the small centre petals completely surrounding it, but in full-blown flowers, or when the wind has scattered some of the petals, it stands out conspicuously, adding greatly to the beauty of the flower.

The plant often attains a height of nearly four feet, and the flowers, in some specimens, are exceedingly fine, while the variety of colouring is almost endless. In proceeding to speak of the usefulness of the Poppy to artisans, I may remark, it seems hitherto to have been left almost wholly to the designers of gaudy chintzes and French paper-hangings, who have sought 


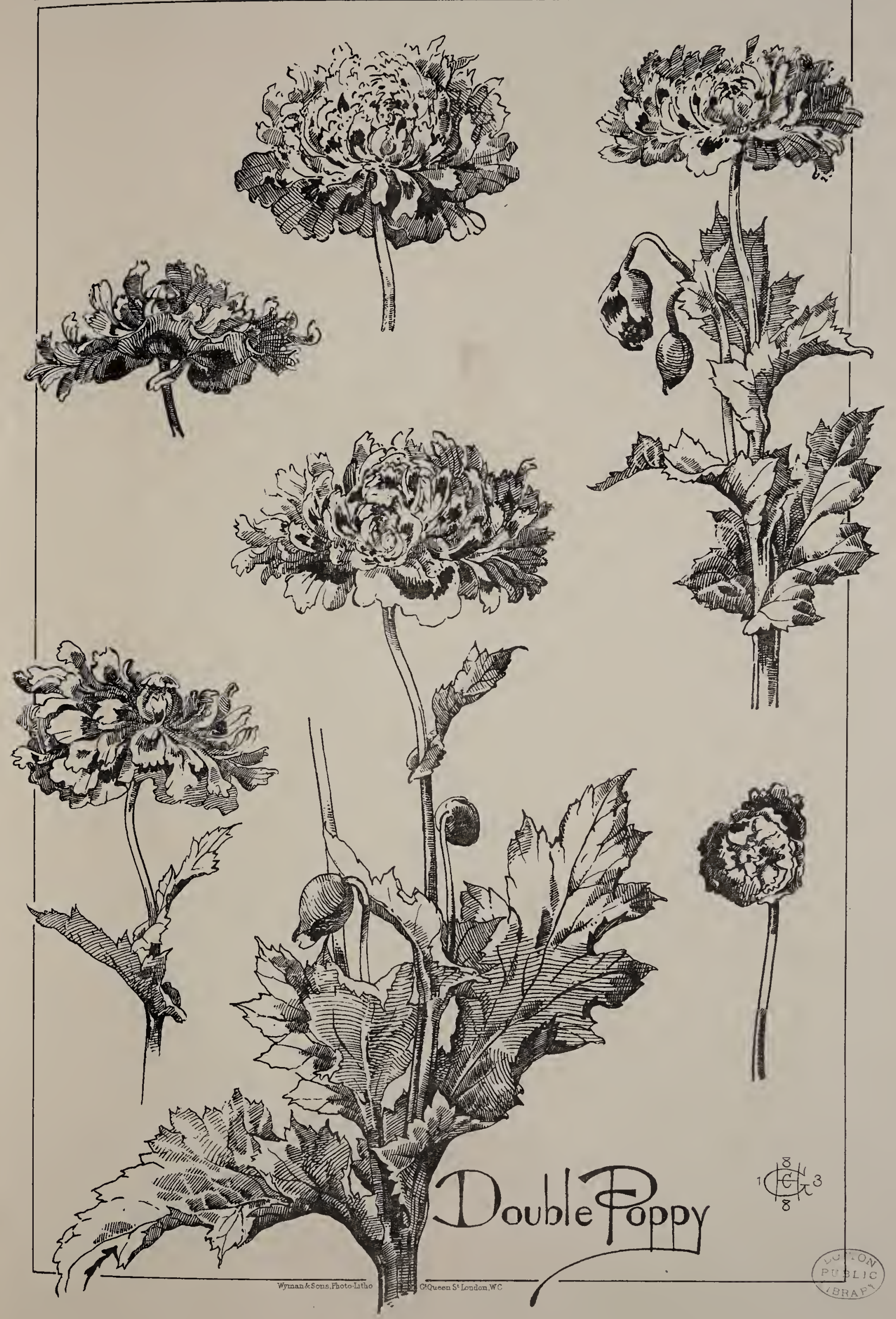





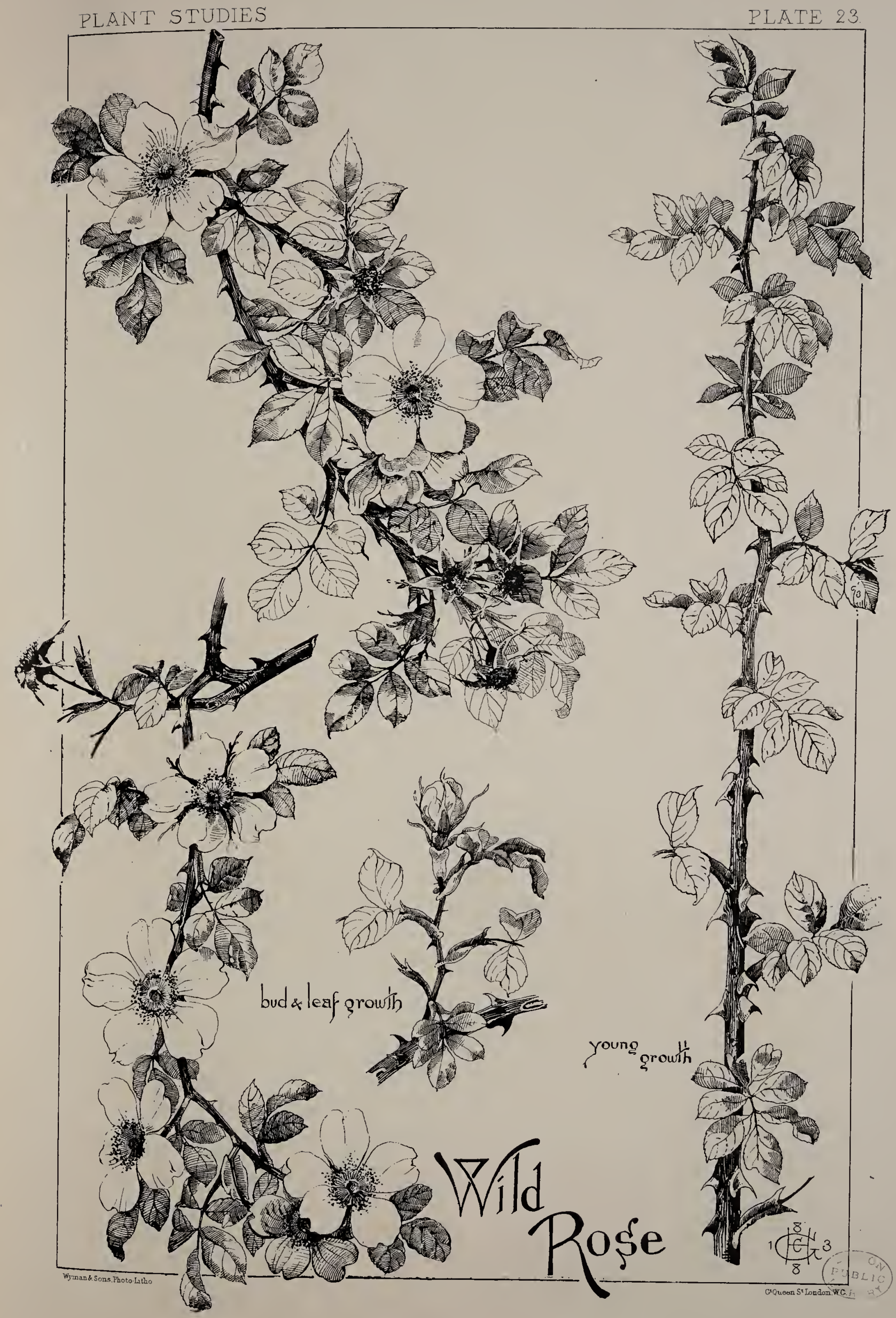



to delineate it in all the subtle gradations of its endless tints and reflected lights, and has received little of the serious attention due to a plant so beautiful. The lines shown on the outside petal in Fig. 2, Part III., might be made the feature in a decorative treatment; the stalks might be twisted and curved to break the rigidity of line; and to suit various conditions the leaves could be made broad or narrow, folding over in almost any position required.

For needlework, the Poppy readily suggests its own suitableness, especially in applique, where the petals could be formed of various velvets and silks, and the beautiful form of the leaf should be of great value.

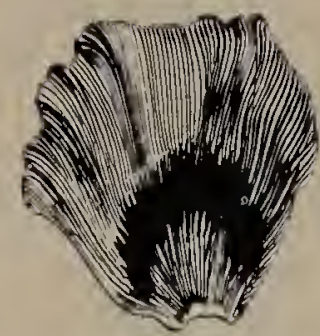

Fig. 1.-Large outer petal.

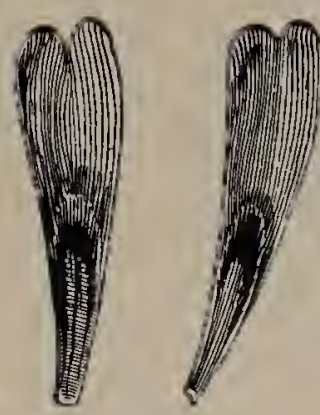

Fig. 2. - Snall petals.
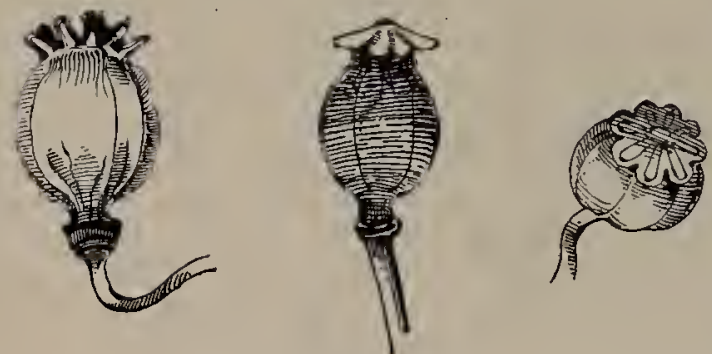

Figs. 3, 4, and 5. -Seed-capsules

A boldly-drawn border for wood-carving or inlay would come out extremely well; or a flat colour-decoration for door or furniture. panels. In plaques, tiles, vase or stained-glass painting, the Poppy could be made most useful, and could also be employed as an accessory to any subject bearing on sleep, its soporific properties, drooping buds, and dreamy foliage amply justifying this symbolic use of the Poppy in design.

\section{PLATE XXIII. -THE MEDLAR.}

$\mathrm{T}$

HE Medlar is of great antiquity, and we learn from the poets that it has long been held in great respect. Gower, Chaucer, and Shakespeare mention it as a tree evidently held in high estimation. It is in nowise a common tree, but it is to be found in old gardens, grown to a goodly size and spreading its quaintly-twisted branches in most picturesque confusion. Its remarkable peculiarity lies in the fact that the fruit is not eatable in its green state, but when ripe to rottenness it is much esteemed. The blossoms appear in May and June, and the tree then presents a most ornamental appearance. The flowers, milky white in colour, grow solitary at the terminal of the branches, and are composed of five crinkle-edged petals, from whose centre a somewhat limited number of twisted stamens, tipped with salmon-colour, surround a small green pistil (Figs. 1, 2, and 3).
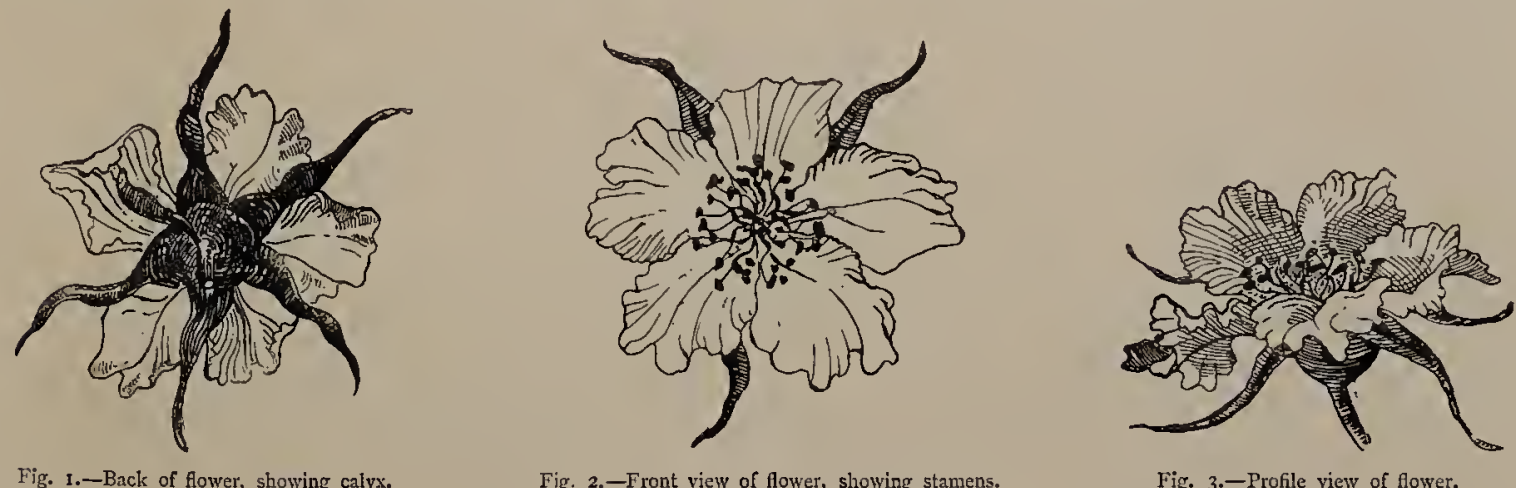

The bud-growths are particularly worthy of attention. In the early stages their small points of brilliant white, surrounded by the dark green of the downy calyx, present a most characteristic appearance (Figs. 4 and 5). The sepals, which remain on permanently, are very long, projecting from behind the flower.

The leaves are pleasing in form and sometimes very large. They are centre-ribbed, serrated at the edge, with the body of leaf broken up by veinings which alternately depress or raise the surface (Fig. 6). I believe there is a variety of which the leaves are doubly serrated, but I have not yet seen it.

The leaves grow on short, thick stalks alternately round the stem, and cluster about the flower or fruit, which grows as a terminal (Fig. 7). The colours to be seen in the 
Nedlar leaf, especially in the autumn, are almost innumerable. All manner of dull and bright greens, yellows, greys, and browns, frequently marked or splashed with blotches of deep rich brown, purple-red, and black. The colours on the underside of the leaves are subdued, partaking more of delicate mauve and grey shades. The leaves are found in their best period
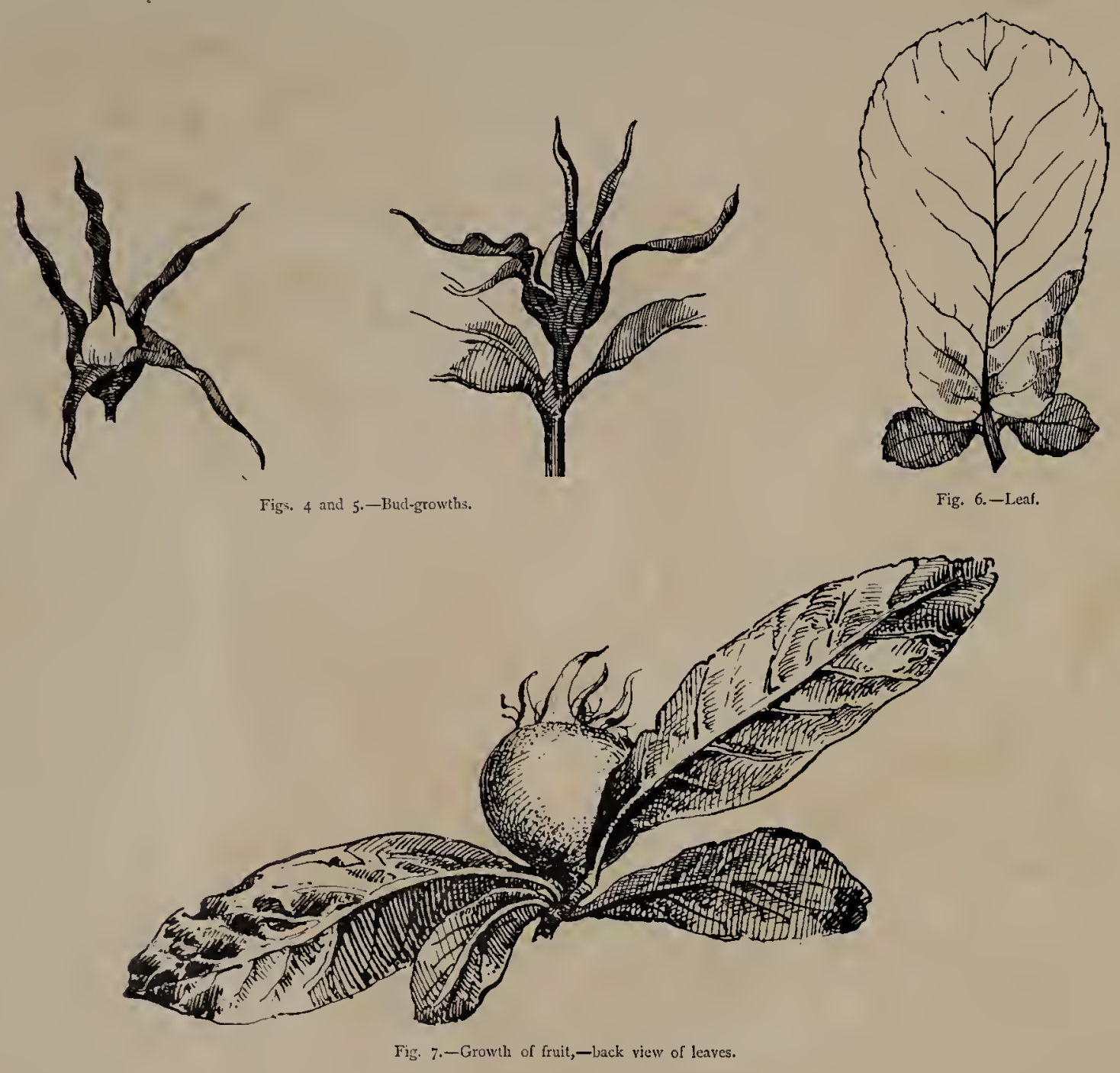

of colour-effect in the autumn, when the fruit is fully developed. Some of them have two smaller leaflets growing at the base of the leaf-stalk (Fig. 6). This beautiful growth would be of much value in adaptation. The stem and branches are gnarled and woody (Fig. 8), in the young wood green (Fig. 9), and in the old, various shades of brown. This twisting habit of the stem and boughs would frequently prove of value in the management of the Medlar for applied design.

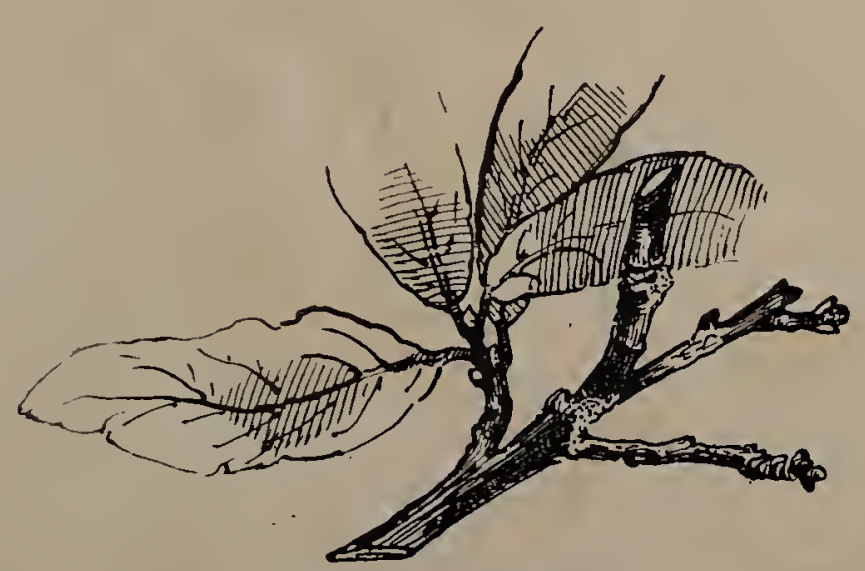

Fig. 8. - Leaf and stalk-growth.

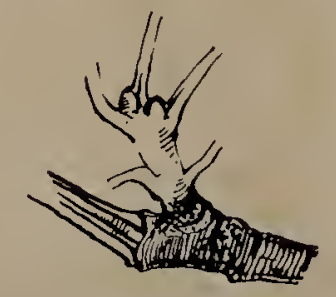

Fig. 9. - Growth of young wood and leaves.

The chief attraction is, of course, centred in the strange nature of its peculiar fruit. Figs. IO, II, and 12 show back, front, and profile views of the fruit, the distinctive characteristics of which will be readily'seen. The sepals remain, as do some of the stamens, which dry off in little fibrous curls. The fruit ripens from dull and rich greens to yellows and golden bronzes. It has a rough texture, and is so firmly fixed upon its stalk that it will often hang and rot upon the tree. 


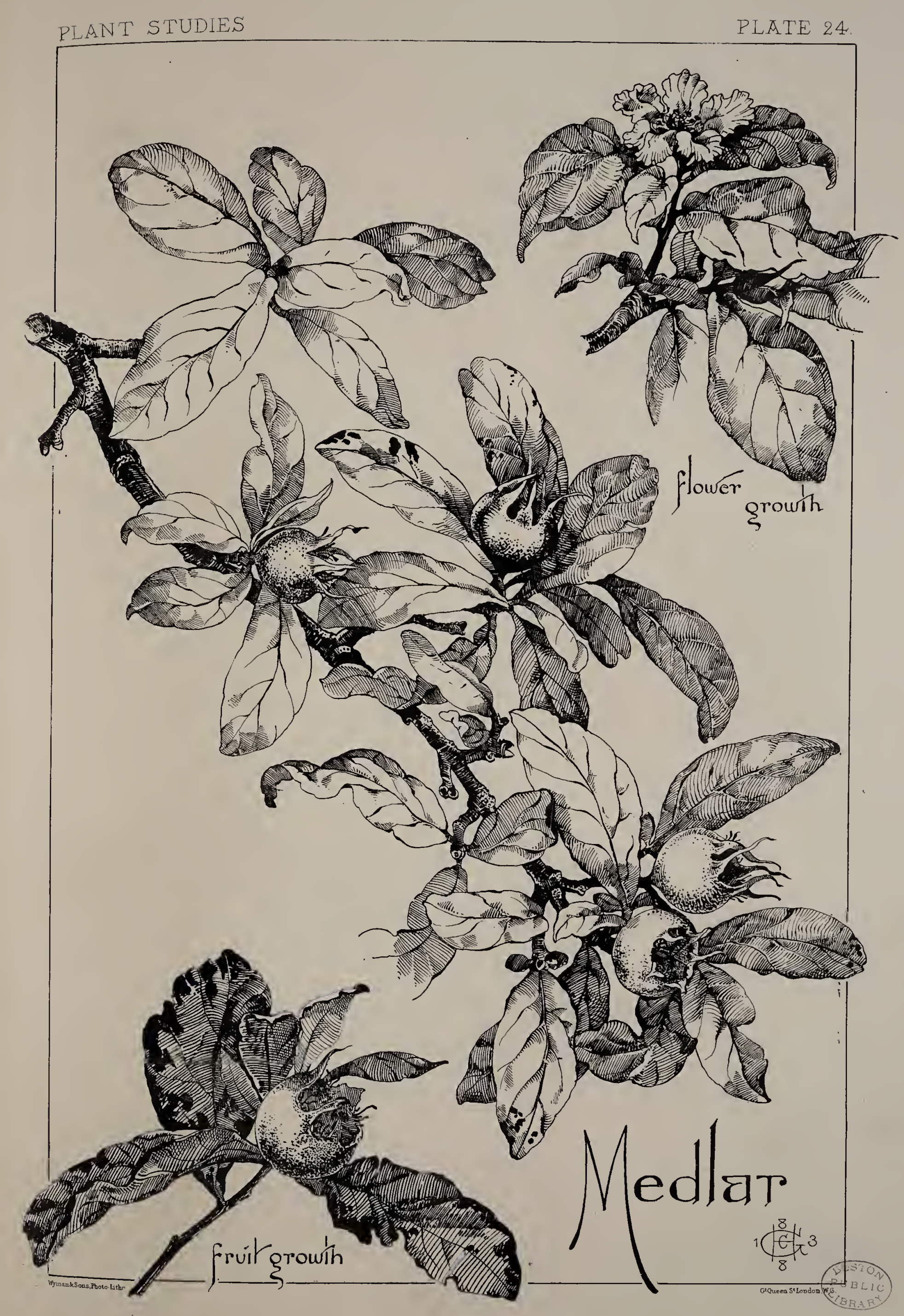



The Medlar, either in its most ornamental flower period of growth or later as a fruit subject, offers many recommendations to the designer. The notched nature of the flower petals and the exceptional length of the sepals require little if any accentuation, while the growth of the lcaf, with or without the small leaflets hitherto mentioncd, is all that could be desired. For most of the art-industries the beauty and formation of the Medlar might be utilised, and

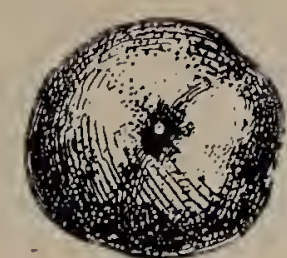

Fig. 10.-Back view of fruit

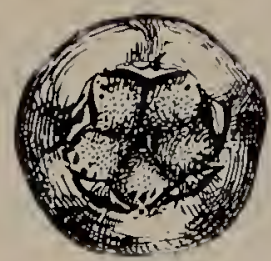

Fig. 11.-Front view of fruit.

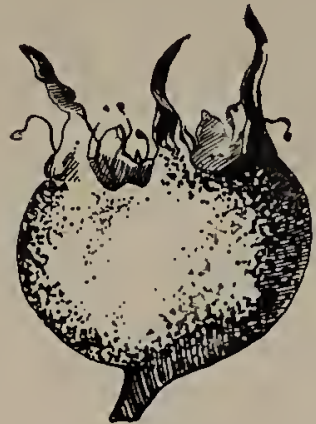

Fig. 12.-Side view of fruit.

claim attention in an equal degree with that bestowed on the Apple, Pear, or Plum. This seems to $\mathrm{mc}$ another instance of unwarranted neglect by the artisan, who is content to select the more familiar forms, with little chance or desire of investing these with any new feeling or interest.

\section{Plate XXIV. - THE WILD ROSE.}

$\triangle \mathrm{S}$ promised in my description of the Hip of the Wild Rose, I now give a Plate showing

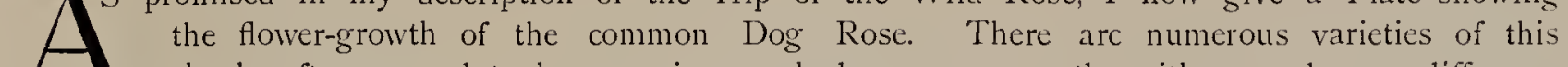
1 shrub, often several to be seen in one hedgerow, apparently with scarcely any difference between them; but on careful examination they will all prove to be distinct, so much so that many writers have described them as distinct species.

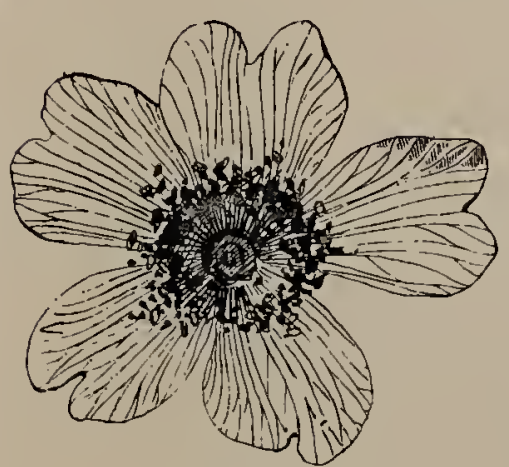

Fig, 1,-Flower.

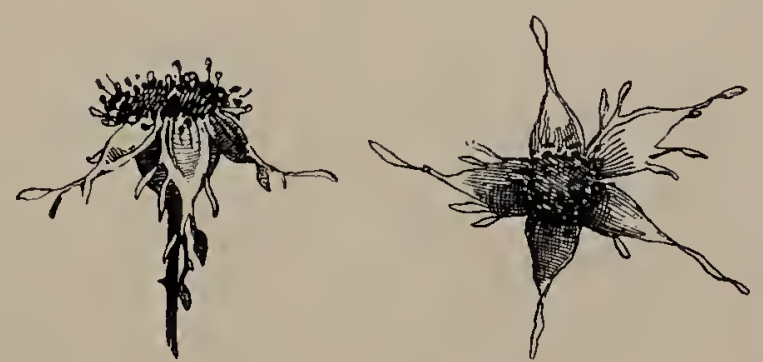

Fig. 2.--Stamens and calyx.

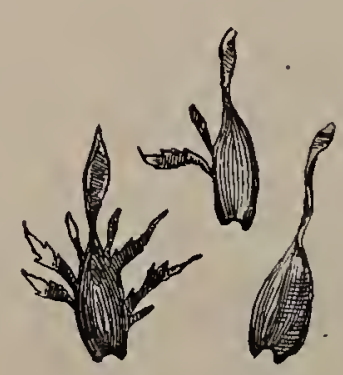

liig. 4.-Formation of sepals

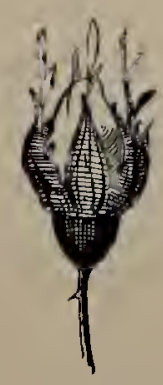

Fig 5.-Bud.

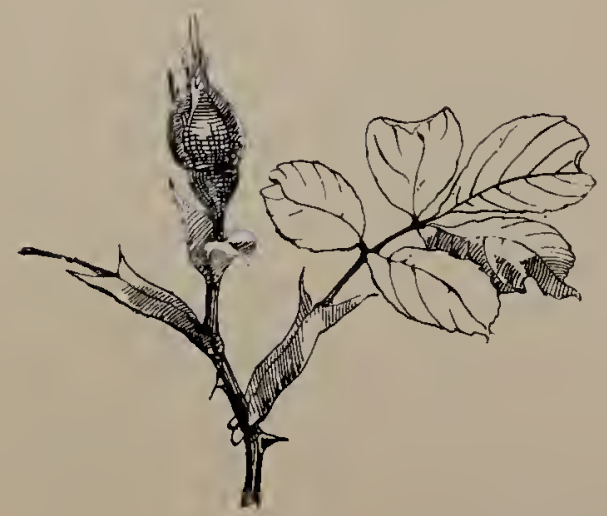

Figs, 6 and 7.-Bud-growths.

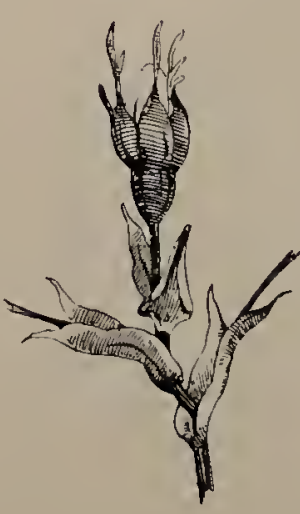

The Dog Rose, above all others, is the true Wild Rose of England; vigorous and sturdy, and found growing plentifully almost everywhere, decking the hedges with sprays of delicate blossoms, and breathing an odour of roscs. In many cascs, when hidden from view, its fragrance betrays its neighbourhood. 
Its buds are deep pink, fading as they expand into a delicate blush colour, and ultimately become almost white. The blossoms are very ephemeral, the petals falling soon after the flower is plucked. It must be seen hanging from the hedges with the chequered sunlight upon the blossoms for its true beauty and elegance to be adequately appreciated, even if that be possible.

Among the characteristics peculiar to the shrub is the growth of mossy balls and tufts of a delicate green colour, changing in autumn to a bright crimson. These excrescences, which are formed by a small worm, might often be advantageously used in the adaptation of the plant.

The flower, which usually grows solitary, is composed of five heart-shaped petals, delicately veined (Fig. 1). The centre is formed of an indefinite number of stamens of a bright yellow colour, springing from a pale green pistil. The petals frequently turn inward at the edges, a
feature which is often illustrated by Mediaval artists, and is the chief characteristic in the decorative treatment of the Tudor Rose; but as often as not one side only of the partly-divided petal turns in, and this might well be used as a change from the severe and regular turning over we are so accustomed to associate with preconceived ideas of the correct conventional treatment of the Rose.
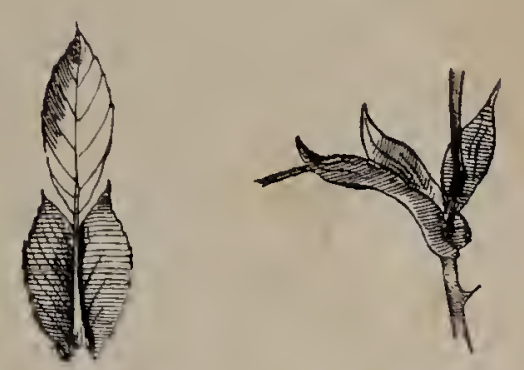

Figs. 8,9 , and 10.-Various forms of stipules.
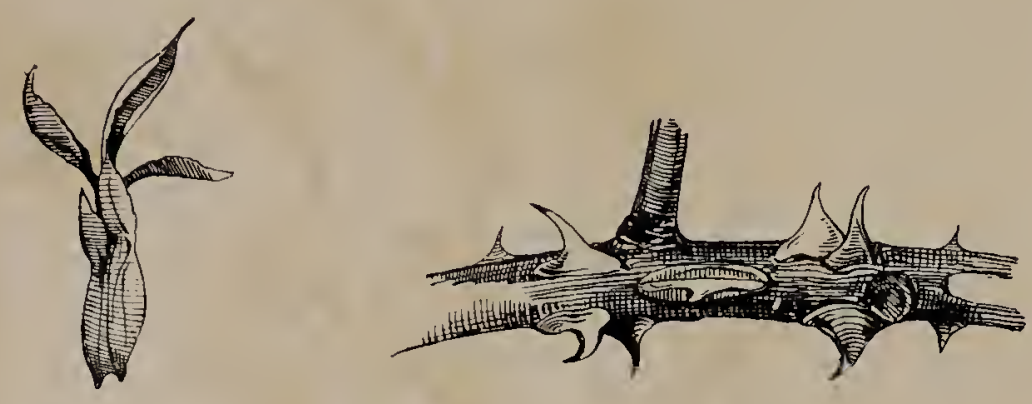

Fig. 11.-Stem-growth.

After the petals have fallen, the stamen (Figs. 2 and 3) remaining on the calyx affords a very pleasing change. The peculiarities of the sepals were commented upon in the description of the Hip of the Wild Rose. Fig. 4 illustrates their construction.

The bud-growth is a very pleasing period. When first opening the folded petals appear as deep pink; these, against the more delicate pink and white of the full-blown blossom, considerably increase the beauty of the plant.

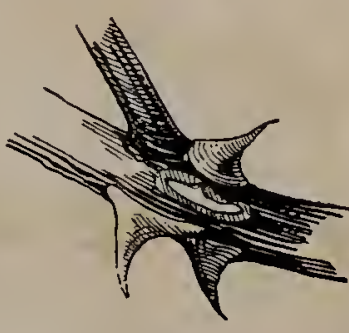

Fig. 12.-Thorn-growth

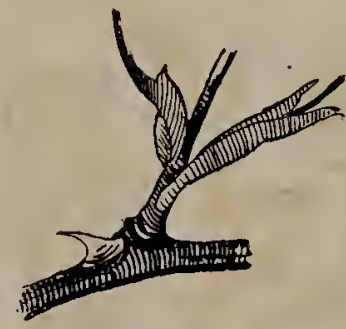

Fig. 13. -Growtli of lateral shoot.

The leaves grow in groups of three, five, or seven, are ovate in form, serrated, and smooth and shining. The leaf at the top of the spray is the longest, the others decreasing in size as they approach the main stem; they are centre-ribbed and delicately veined. At the base of the leaf-spray stipules of various forms fold partly over the stalk (Figs. 8, 9, and ro). The stem (Fig. II) is tough, rounded, and plentifully supplied with strong hooked thorns (Fig. I 2).

A beautiful feature of the young growth is the brilliant crimson colour of its thorns, which contrast most beautifully with the rich yellow-green of the young leaves.

Few flowers have received so much attention as the Rose, both in the past and the present, from the hands of English craftsmen. Nor can we wonder at its popularity; it has the advantage of never seeming out of place wherever used, if the adaptation be at all worthy of notice. The conventional Tudor treatment has been so often repeated that in that form it has become somewhat monotonous, but some of our best ornamentists of the present day have again invested it with a spirit of our own times, without loss of either vigour or grace.

To every purpose and in every medium hitherto mentioned the Rose could be adapted, and the range might be still further extended. 


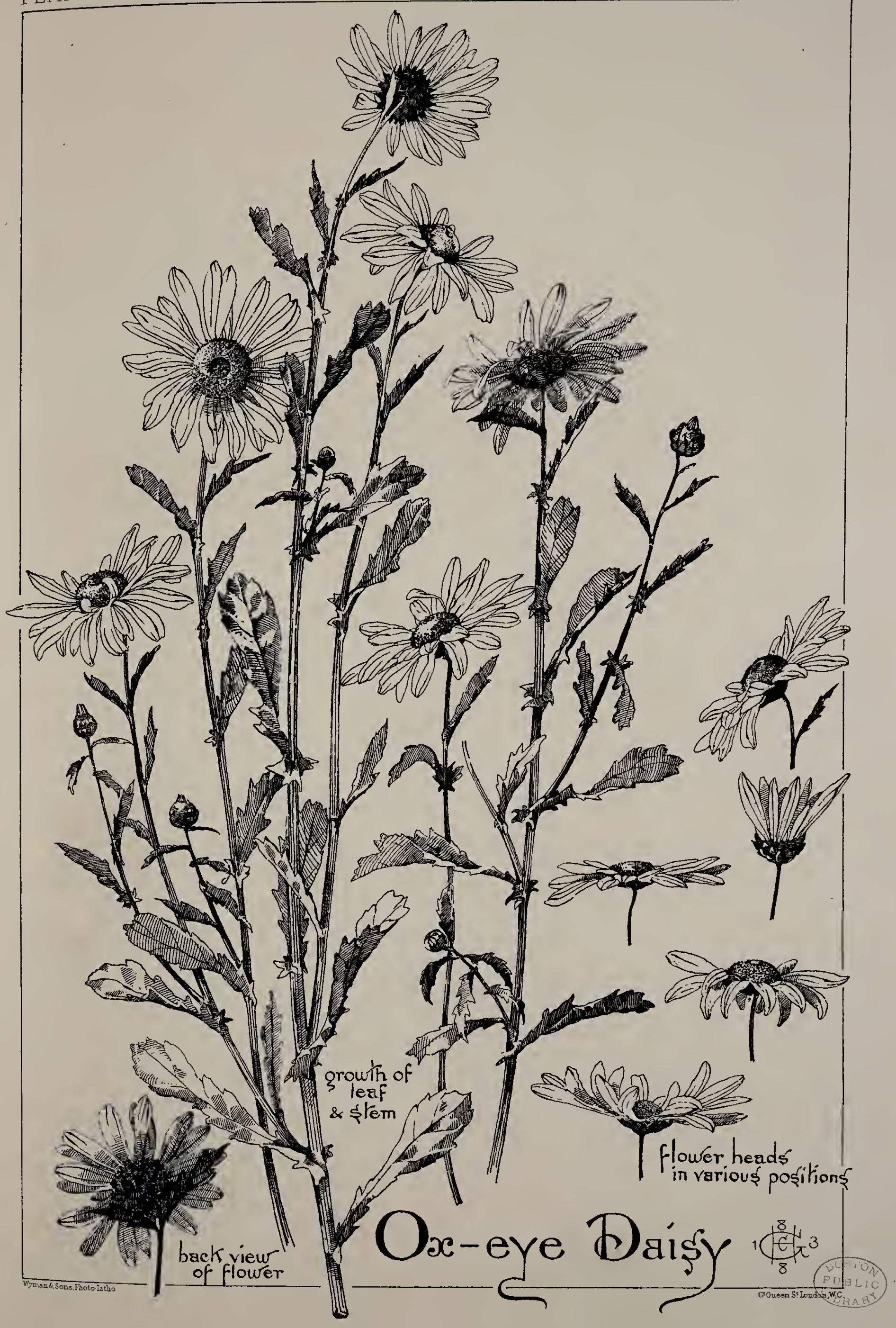





\section{Plate XXV.-THE OX-EYE DAISY.}

$\mathrm{T}$

HE Great Ox-Eye Daisy, which blooms during the months of June and July and the greater part of August, must be a wild flower familiar to every one. It is one of the first flowers which welcome us as we leave the unlovely town for the purer country. We sce it nodding on the banks of the railway-cuttings as we rush past, and find it besieging the villages and lining the lanes with its armies. It seems to reach its perfection though, in the wild state,-in the railway-cuttings and desolate places, where it apparently takes upon itself to renovate and beautify what the hand of man has laid waste in his so-called progress. Though it grows almost everywhere in plenty, yet its natural home is among the

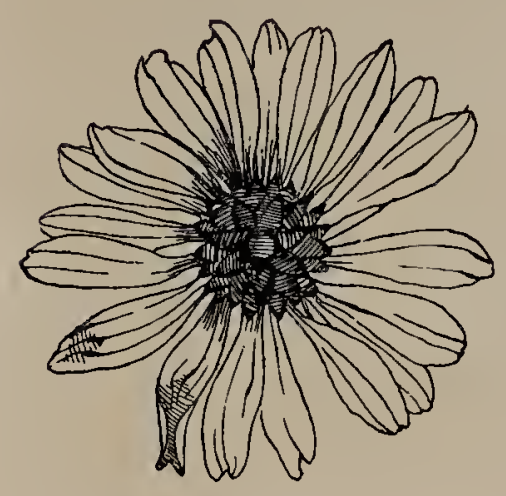

Fig. 1.-Back view of tlower.

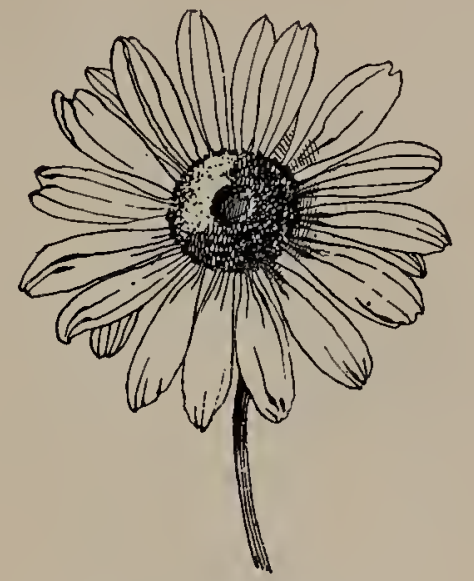

Fig. 2.-Front view of flower.

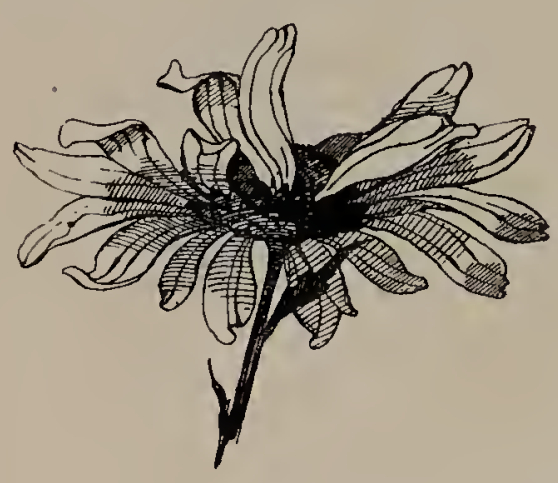

Fig. 3.- Frofile view of Bower.

varied meadow grasses. Here its blossoms diaper the green with golden-eyed rays of milky white, not unlike the multitude of the stars seen on a clear night. Perhaps some such conparison suggested its beautiful rustic name of the "Moon Daisy."

The Ox-Eye Daisy is now cultivated in gardens, as it deserves to be (for this and the Corn Marigold are the only members of the Chrysanthemum family indigenous to England), and thus cultivated it attains gigantic dimensions, both in flower and leaf.

The flowers are solitary, and stand erect on deeply-ribbed stems, which are often to the height of two and three feet, while some of the blossoms measure as much as two inches and a half to three inches in diameter.

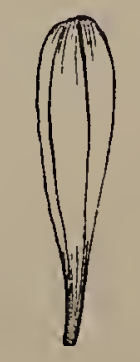

rig. 4.-1'etal.

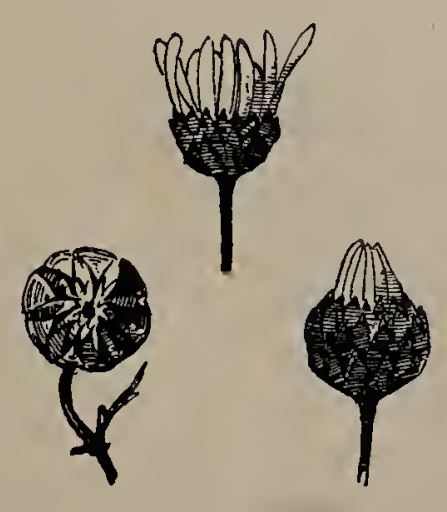

1iig. 5.-Bud-growths.
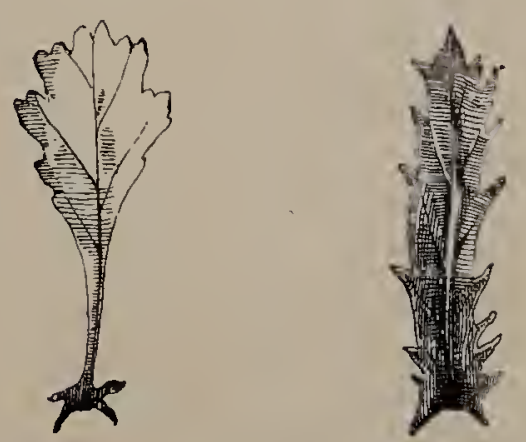

rigs. 6 and $7 .-$ Leaves.

The flower (Figs. I, 2, and 3) is composed of a ray of pure milk-white petals, perpendicularly lined and sometimes serrated at the tips (Fig. 4). These surround a disc of goldenyellow. The flower takes a variety of pleasing forms, of which I have given several illustrations in the Plate. It is firmly supported on a sturdy involucre of small green sheaths, which have a darker line of colour round their edges. The buds (Fig. 5) are full of beauty, from their first appearance on the lateral shoots until they reach maturity. The leaves are oblong, irregularly cut, and jagged; they are winged at the base, and vary very mucl in their forms; two of these, however (Figs. 6 and 7), most frequently occur. They grow alternately from, and partly close round, the stem (Fig. 8). The lateral shoots spring from inside the leaf-joint (Fig. 9), and when developed give the plant a bushy shape. 
The Daisy has lately received much attention from the hands of the designers of wallpapers, fabrics, and repoussé work; it is also particularly adapted for stencilling. The flowerheads can be most effectively used as diapers for fabrics, wall-papers, glass, \&c. For the

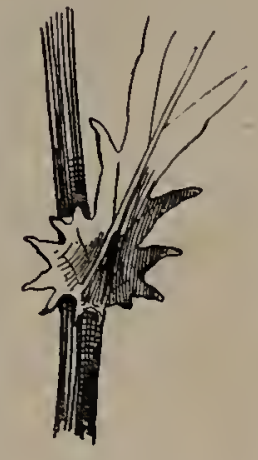

Fig S. - Leal-growth.

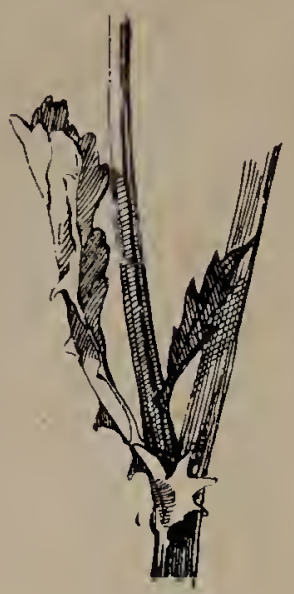

Fig. 9. - Lateral growth

many kinds of needlework so popular at the present time, the Daisy is admirably suited, and it seems to be a general favourite for ornamentation, having the charm of early association, a pleasing familiar appearance, and a connexion with poetry of a pure and simple naturainess.

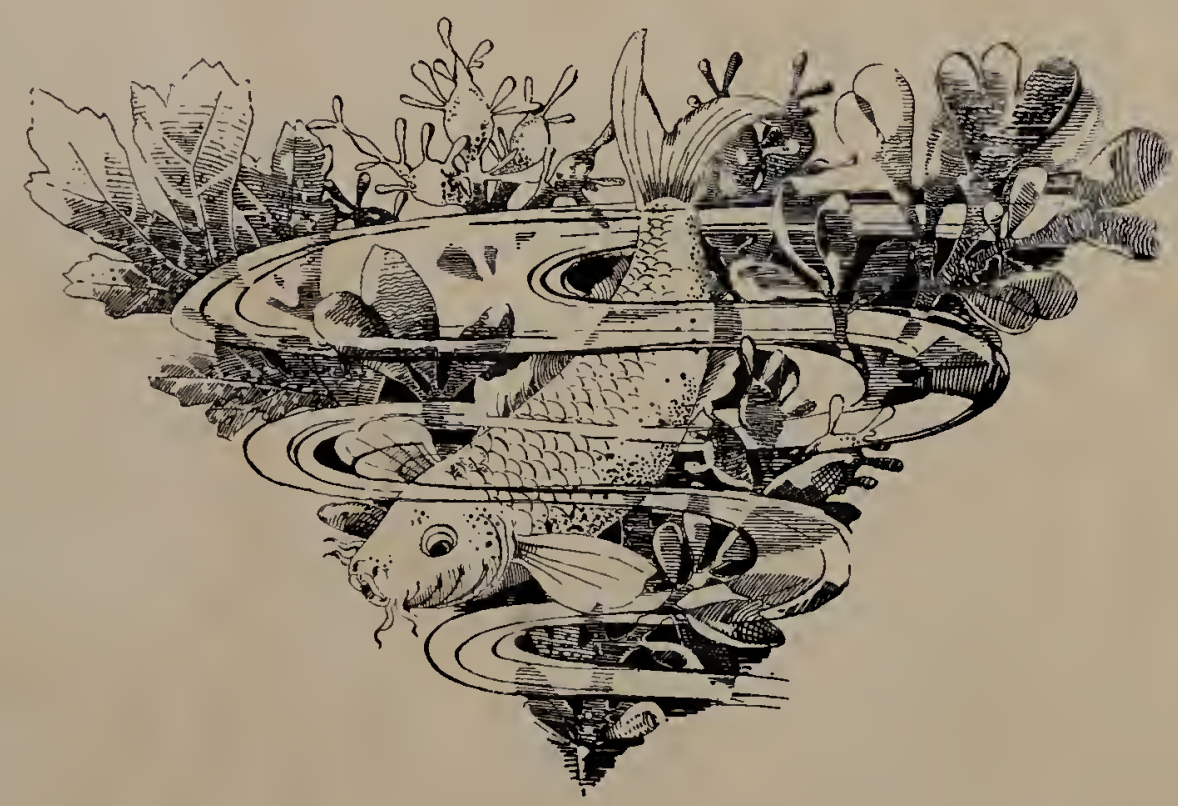




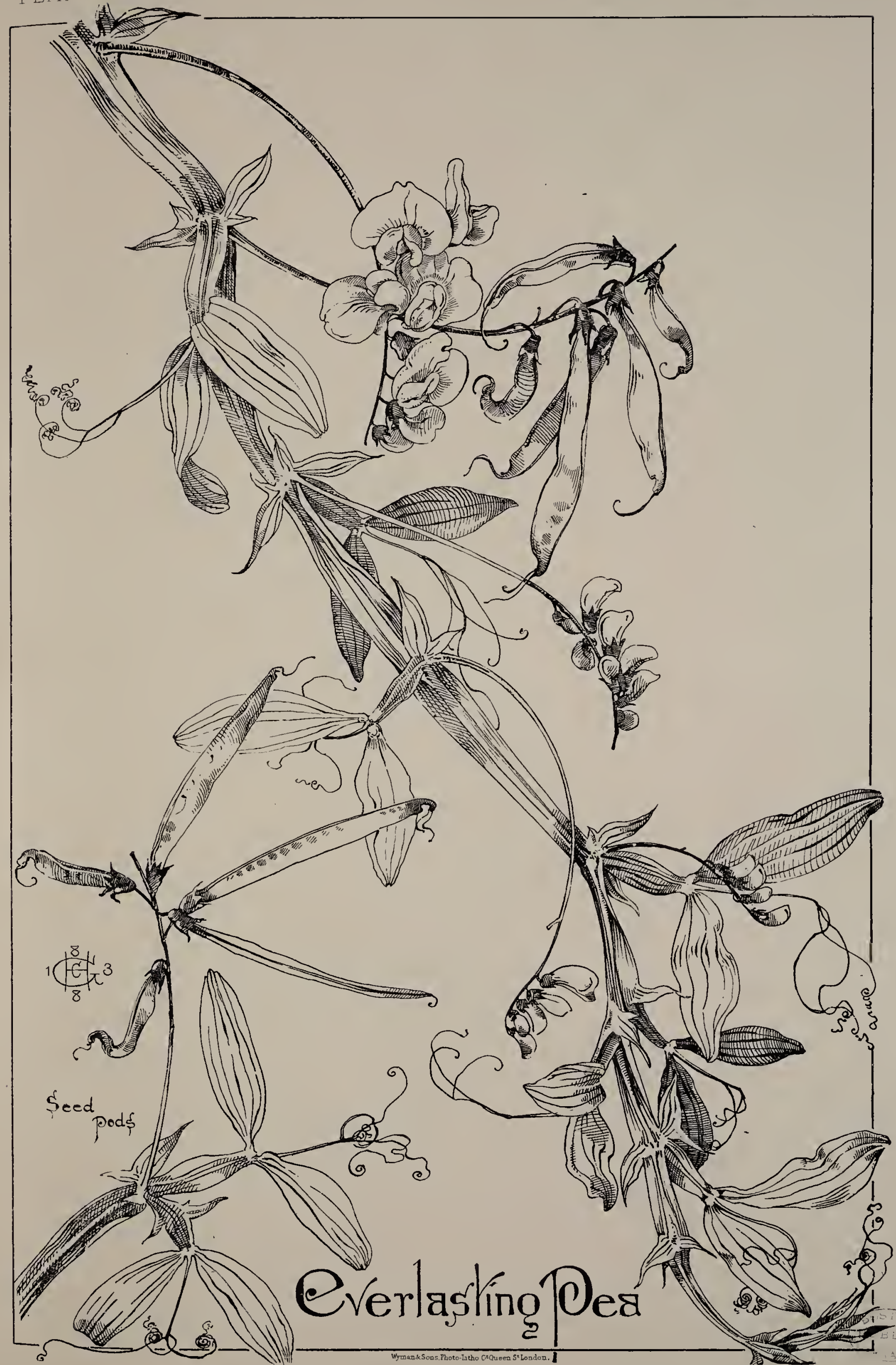





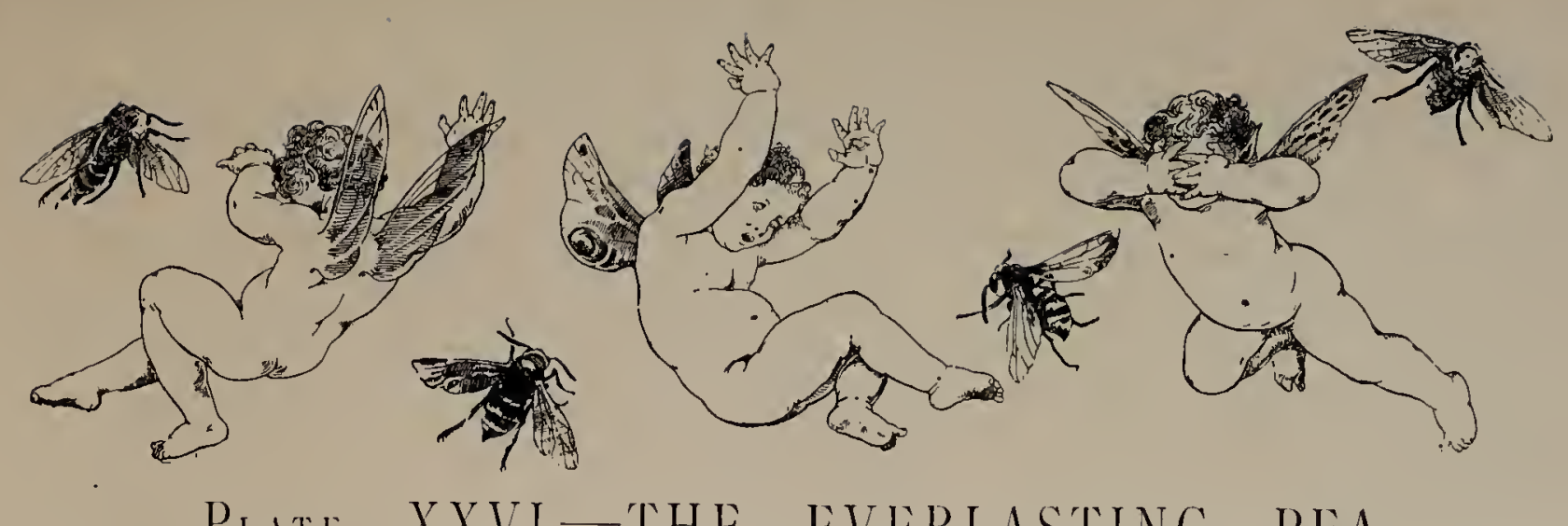

\section{Plate XXVI.-THE EVERLASTING PEA.}

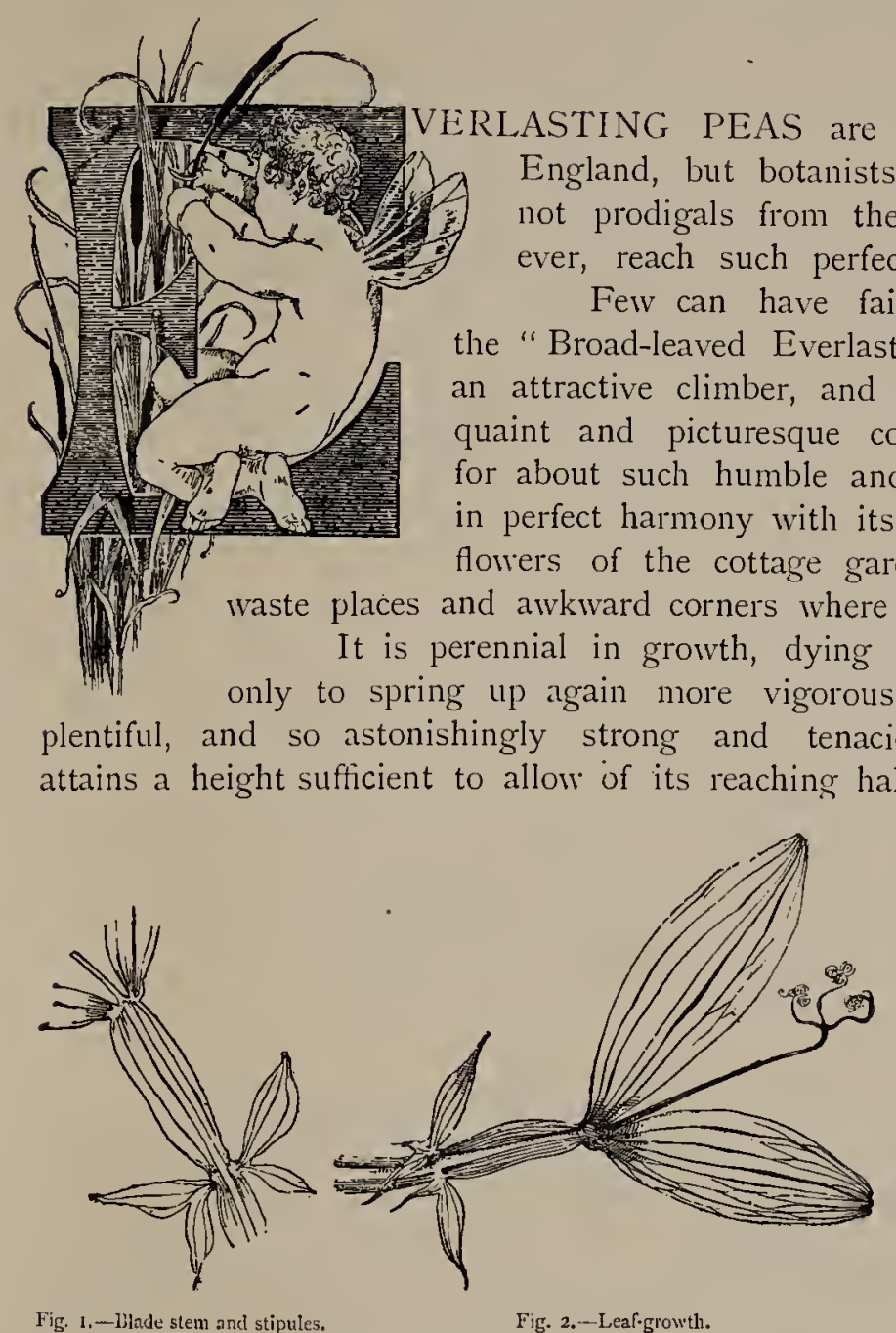

VERLASTING PEAS are to be found growing wild in some parts of thists consider it very doubtful whether they are not prodigals from the garden. In their wild state they rarely, if r, reach such perfection as is seen in the garden species.

Few can have failed to notice the subject of my illustration,-the "Broad-leaved Everlasting Pea," which will be readily recognised as an attractive climber, and possibly associated with memories of many a and picturesque cottage porch and arbour, or low garden wall, and homely structures it thrives best, and seems in perfect harmony with its surroundings. It is one of the most luxuriant flowers of the cottage garden, and generally beautifies those troublesome laces and awkward corners where little else will grow.

th is perennial in growth, dying off as the chilling frosts of winter commence, aid the plant frequently attains a height sufficient to allow of its reaching half over the thatched roof of a wayside cottage.

Fig. 1,-IHade stem and stipules.

Fig. 2.--Leaf.grow'tl.

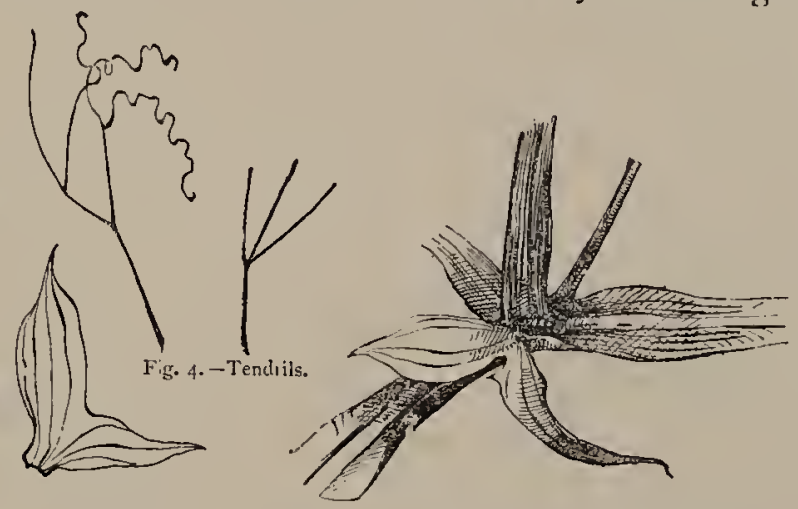

Fig. 3.-Stipule.

Fig. 5.-Growth of lateral shoot and stalk of fluwer.

Its stem is peculiar, bcing winged on both sides (Fig. I), and grows in a zig-zag manner, thus forming angles, from which the lcaflets spring (Fig 2). These leaflets grow in pairs at the end of a lateral stalk, which is also winged, and has at its base stipules of a pcculiar half arrowlike form (Fig 3). The leaflets arc oblong in shape, blunt-pointed and fivc-ribbed. From the fork of the leaflet the tendril grows,-always as a terminal (Fig. 2). Every pair of leaflets is
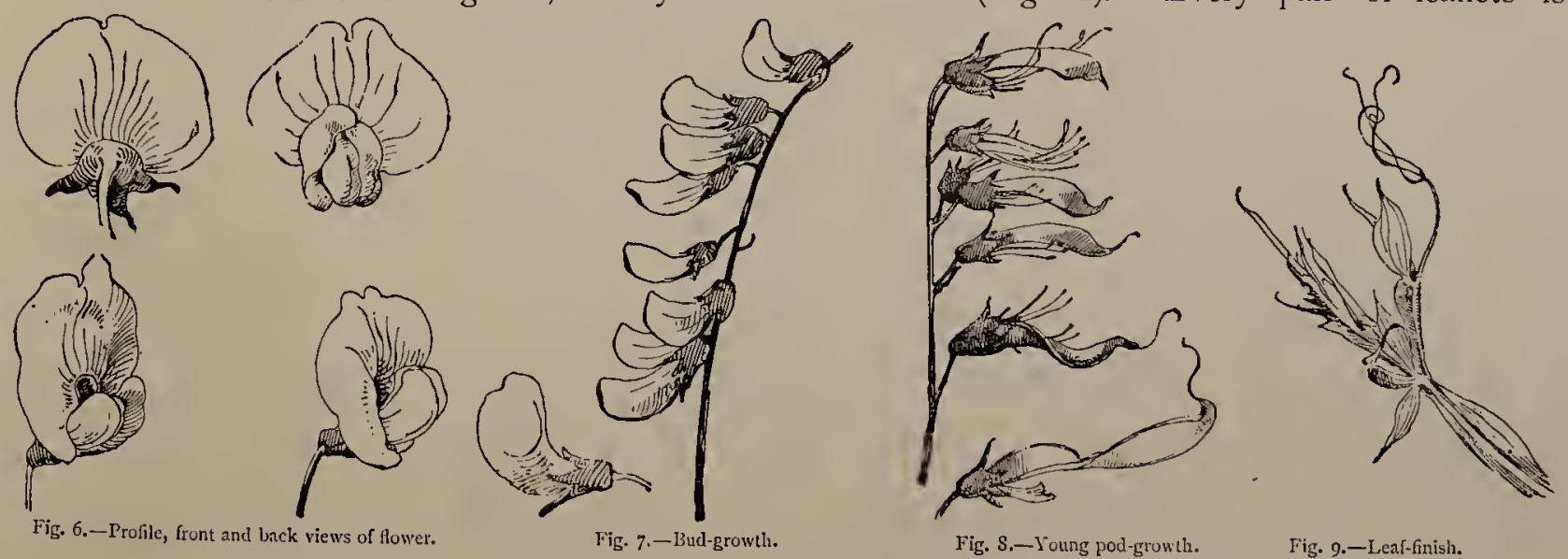

provided with a tendril, which divides itself into two or more (Fig. 4), thus enabling the plant to attach itself to supports, or, failing that, they twist themselves into little tangled knots.

The stem and leaves are of a tender green colour, which is often subdued by a bluishwhite bloom. The lateral shoots spring from inside the leaf stem-joints (Fig. 5), and accurately observe the same order of growth. 
The flowers somewhat resemble a butterfly in shape (Fig. 6), and grow in clusters at the end of long stalks, which also spring from inside the leaflet stem-joint (Fig. 5). They are seen in full blossom and pod at the same time with the fully-developed flower of the lateral shoot. Figure 5 illustrates an instance of this. The young buds take numberless graceful forms, and are of pale yellow's tinged with pink (Fig. 7); these develop into flowers of varied pink and purple hues. As they begin to fade, they undergo peculiar colour-changes, and assume metallic greenish-purple tints, thereby presenting a strong and not unpleasing contrast to the colours of the more rigorous blooms. With the falling of the petals, the pods appear, and from the earliest stage (Fig. 8) to their final development are full of quaint beauties, which add considerably to the general effect of the plant.

There are varieties of the Everlasting Pea with pure white and rose-coloured flowers. All the stages of growth enumerated are to be found on the plant at one and the same time, and from the young leaf-growth (Fig. 9) to the matured seed-pod the changes are as useful to the designer as they are beautiful to the observer of Nature.

My readers will probably recognise the various manufactures and art-productions in which the use of this plant would be judicious or possible, and it is therefore unnecessary for me to individualise. Many of the remarks on the Garden Pea (Part I.) will be applicable in this case, especially those bearing upon metal-work; but the Everlasting Pea offers a wider field to originality, and has the advantage of a more extensive colour-range. If the character of the plant is to be preserved in adaptation, the angular and rigid manner of its growth should be carefully adhered to, and should be as assertive in ornament as it is in its natural state.

\section{Plate XXVII.-ASPARAGUS.}

$\mathrm{T}$

HE word Asparagus is of Greek origin, and was applied by the ancients to the edible species. As a regetable it must be familiar enough; but, among the multitude who have enjoyed and praised its delicacy at table, how many are there acquainted with the beauties of its natural state? When thus seen, its slender columns of feathery leafdecked and berry-laden branches never fail to excite admiration, and frequently astonishment, that so exquisitely-delicate a spray can be the growth of a common vegetable. As in the case of the carrot foliage, few are able to name the leaf they so heartily admire, and thus many of Nature's most beautiful floral works, familiar enough by name, are more foreign to us than plants and growths which require all the fostering care and expense of a conservatory.

The Asparagus is perennial in growth, and, whether indigenous or not, is to be found growing wild on some parts of our south-western coast, and, as it possesses all the distinctive features of our garden species, is without doubt the origin of our cultivated vegetable. When seen in its wild state, beautiful though it is, nothing would seem less likely to give sustenance or to offer so little encouragement to the cultivator.

A little island at Kynance Cove in Cornwall bears the name of Asparagus Isle, owing to the plant's extensive growth there; and it is also found in abundance in some parts of the steppes of Poland and the south of Russia, where it is the characteristic feature of vegetation. The knowledge of the value of the young shoots of the Asparagus as a vegetable must have been handed down from time immemorial, for Pliny mentions that it was cultivated to perfection, praised as a favourite dish, and speaks of shoots so fine that three would suffice to weigh a pound, and also that the berry-decked stems attained the great height of fifteen to twenty feet
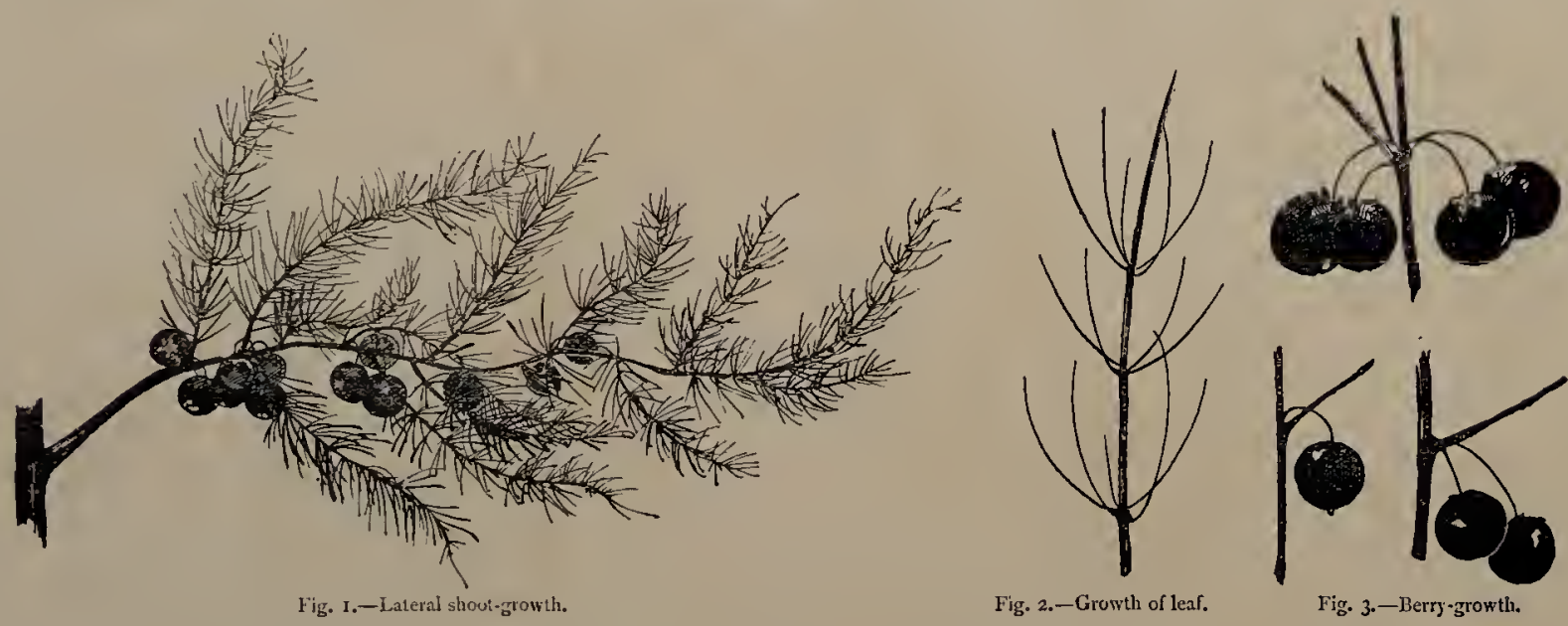

Towards the end of summer, under ordinary cultivation, the stem, if allowed to perfect itself, attains the height of four or five feet, becoming much branched and pyramidal in form. 


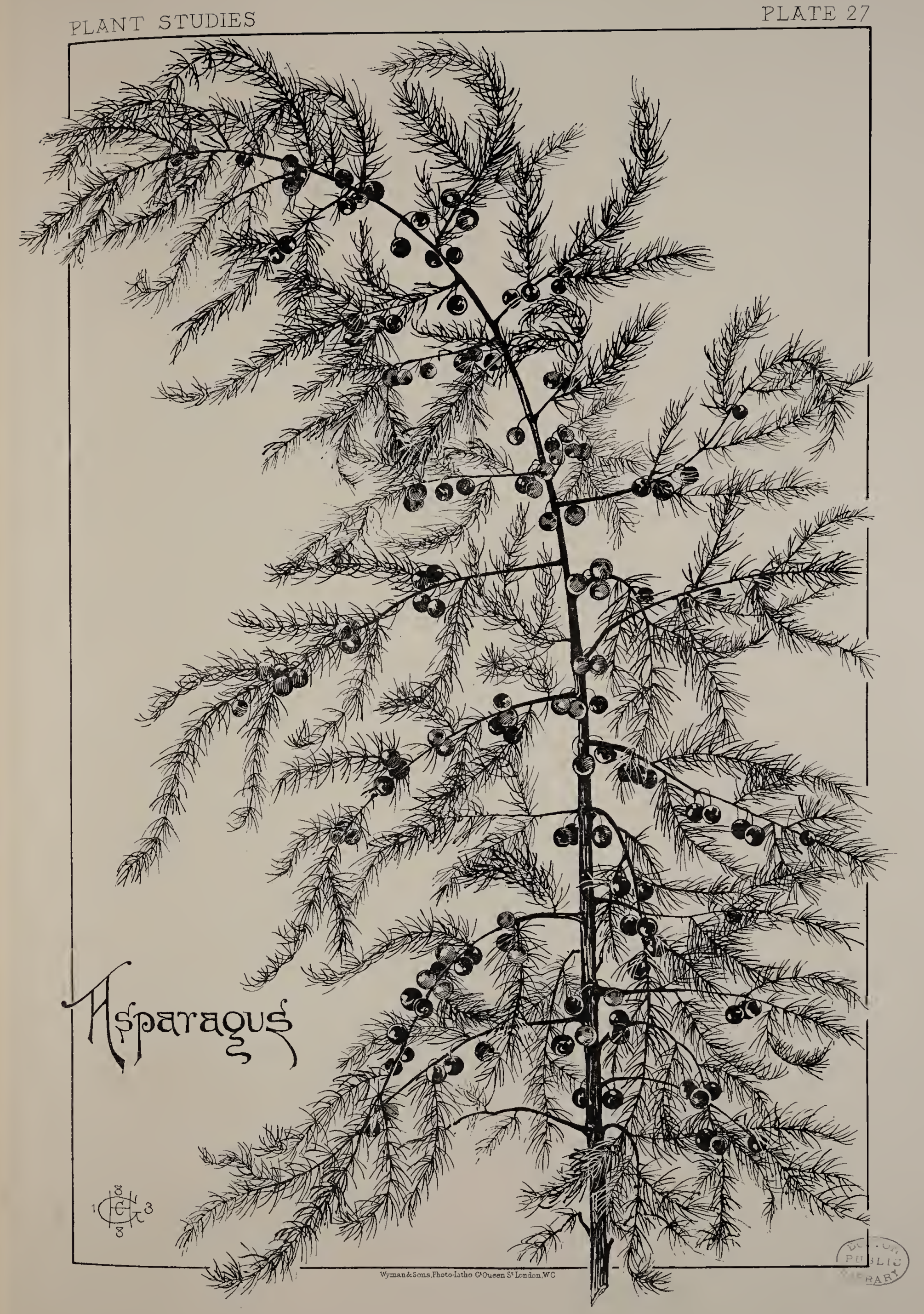





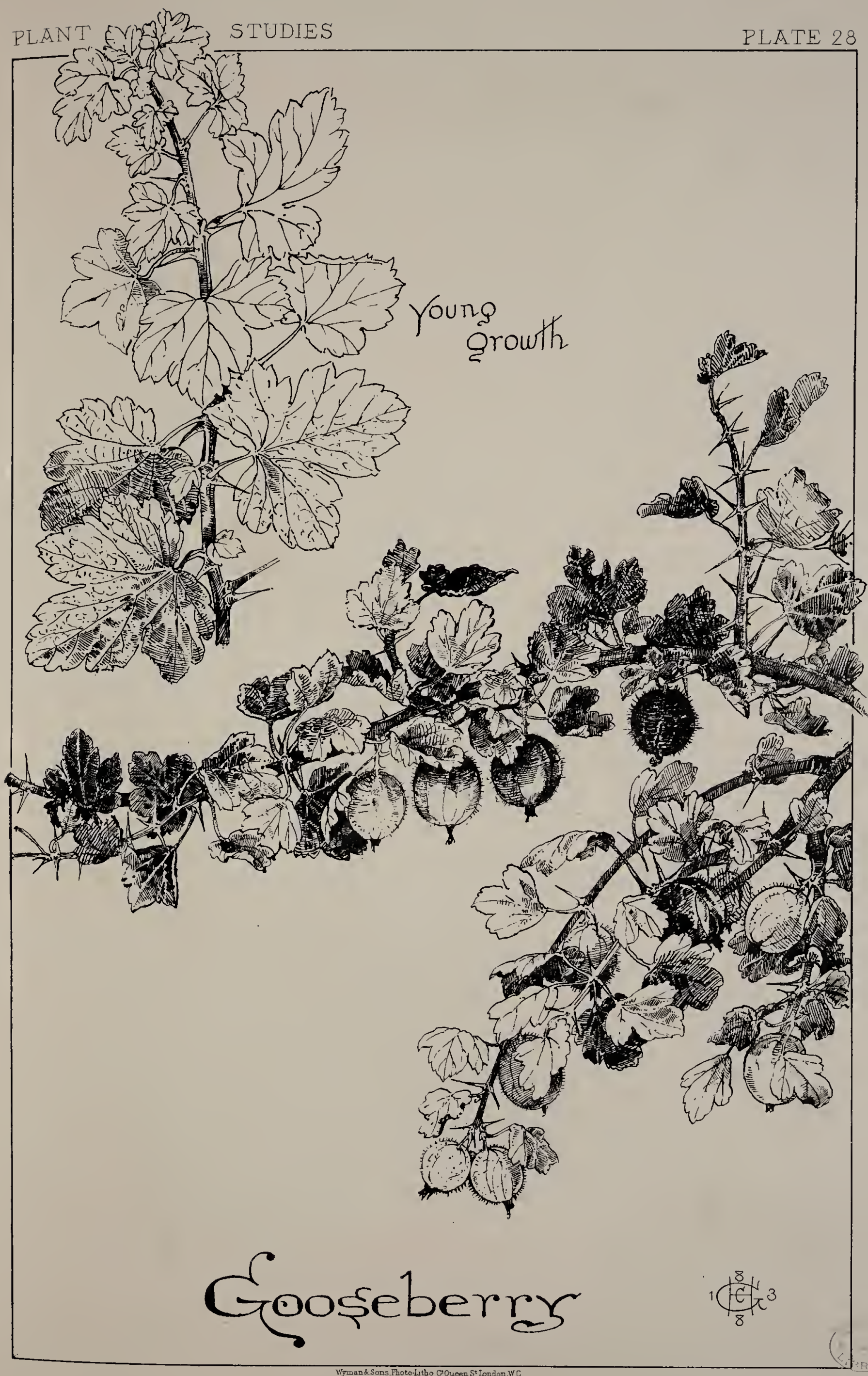



From the lateral branches other smaller branches spring (Fig. 1), from which little flexible, hair-like leaves grow from the same joint, in pairs or bunches of threes and fours (Fig. 2), closely resembling the fir needle in both form and grouth.

The main stem is slightly ribbed, and, in common with the foliage, is of a rich green colour, changing to yellow and brown as the Autumn advances. From June to August the small greenish blossoms appear, and, although insignificant as flowers, ultimately develop into the polished bright-red berries which adorn the autumnal period. There are three distinct colour-stages of the berry-growth-they appear first in rich bluish-green tints, later change to golden bronzes, and finally ripen into rich scarlet; they are the size of a large holly-berry, and grow singly, in pairs, and in clusters of three and four (Fig. 3), hanging from the delicate hair-like stalks, which spring from the joint of the lateral shoot, or independently from the stems.

There are many purposes to which the decorative artist could put this elegant plumous growth. It is particularly suited for delicate needle-work, the leaves being readily represented by singlc stitches, or for the various branches of fancy painting. By itself or grouped with bolder subjects, the Asparagus could scarcely fail to produce a satisfactory result.

\section{Plate XXVIII.-THE GOOSEBERRY.}

$\mathrm{T}$

HE Fruit of the Poor, as the Gooseberry has appropriately been called, is the commonest of our native garden plants, requiring little care, and flourishes under the most unfavourable conditions and surroundings. There are some 700 or more varieties of this homely, wholesome fruit, some being round, others elongated; some having smooth, others hairy skins, through which, in the lighter-coloured berries, the ripening pips show. They range in colour from silvery-whites and yellows to varied greens and the rich juicy reds and marones.

The wood of the old trees is quaint and more rugged than that of the younger shrubs, but the latter usually have finer foliage and fruit. A peculiarity of the plant is its habit of bcaring fruit on the young as well as on the old wood. The leaves vary in form, gradually becoming more regular as they develop, and are divided into three or five lobes (Fig. I), strongly centre-veined, and of a rich shining green in colour. They are attached to the stem by a long stalk, growing alternately on the young wood or in whorls on the small lateral shoot (Fig. 2). The flowers and fruit hang from the inside of this leaf-joint, or from the centre of the whorl (Figs. 3 and 4).
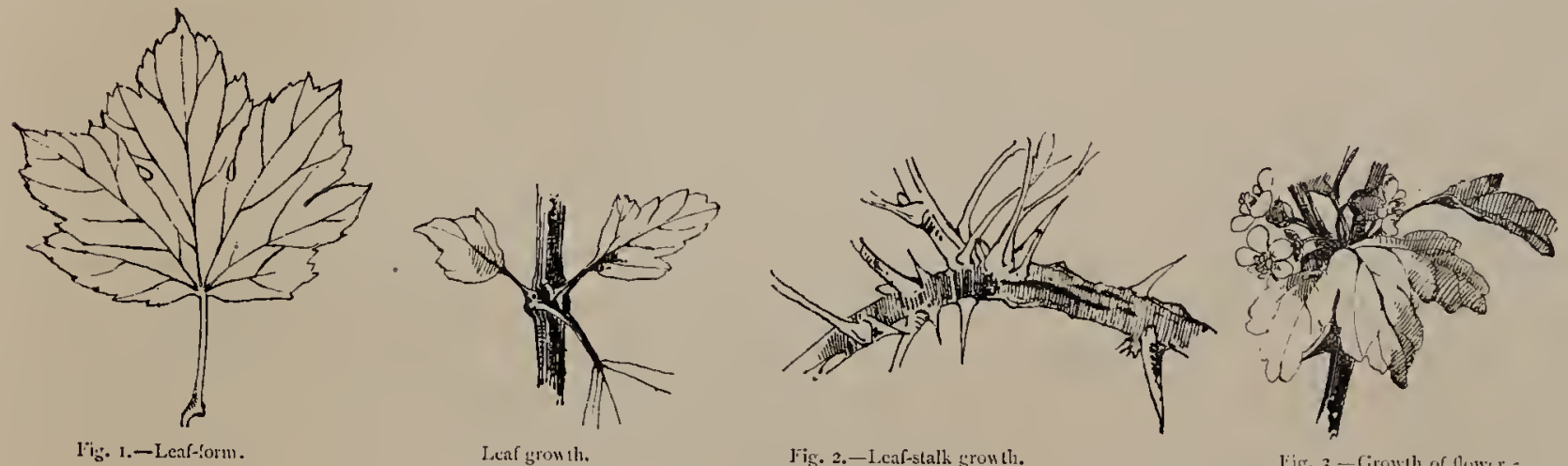

The flowcring period of the plant is interesting, and, although the blossoms are small, measuring but a quarter or at most threc-eighths of an inch long, still the little hanging racemes and solitary blossoms are very effectivc. The flower is formed of a fivc-lobed calyx (Fig. 5), the colour of which is pale green tinged with brownish red, and five petals of a paler greenish white, from the centre of which rises a cleft pistule, surrounded by five two-lobed stamens (Fig. 6).

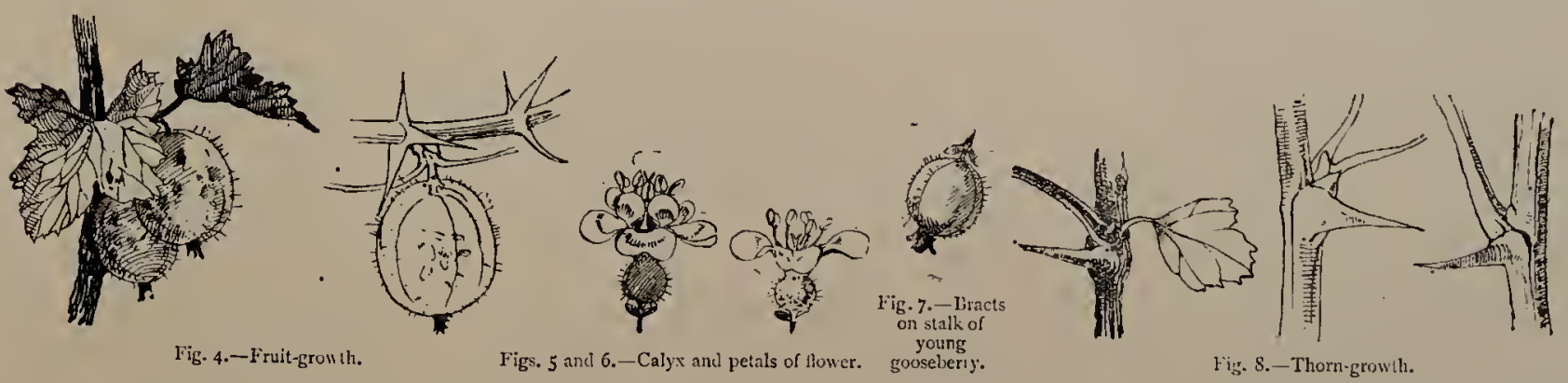

The base of the calyx is the seed-receptacle, which becomes grcatly enlarged, and ultimately forms the fruit (Fig. 4); while beneath are two small bracts, which remain until the berry attains a goodly size (Fig. 7). 
Under the leaf-whorl, and at the base of the leaf-stalk, the thorns (Fig. 8), a well-known appendage of the gooseberry-bush, spring, and grow remarkably sharp and strong, either singly or in couplets and triplets.

Its fruit-bearing period, however, is the nost characteristic and familiar aspect of this plant -the green and red berries peep from beneath the leaves, and are protected by the hidden thorns, which lie in wait for the unwary gatherer. The variety illustrated is that known as the "Warrington," the fruit of which is of medium size, sparsely covered with hairs, and of a deep crimson colour veined with a lighter red.

To the Artist the Gooseberry is one of the most useful of our native fruit-growths. As a motif in decoration and design, it can be used in many ways and materials, and allows so much scope for originality and novelty of treatment that it would be superfluous to enter into details.

\section{Plate XXIX.-THE HAWTHORN.}

$\mathrm{T}$ He Hawthorn, or, as it is more frequently called, the May-tree, is doubtless endeared to us by its association with some of our earliest and purest impressions. In the spring-time of the year, the May puts forth her canopy of white blossoms, and what fond memories of happy childhood are recalled by its clusters of ivoried flowers and sweet refreshing fragrance! In the gloomy months of winter its ruddy berries cheer the dreary scene, and of their abundance give food to our feathered songsters.

Maying is one of the oldest of our English customs, for Chaucer tells of courtiers and others of high and low degree who sallied forth "To fetch the Flowris fresh, and branch and blome," and so through all ages, the May-tree, and the traditions connected with it, will provide a theme for nevcr-ending songs of sentiment and glee.
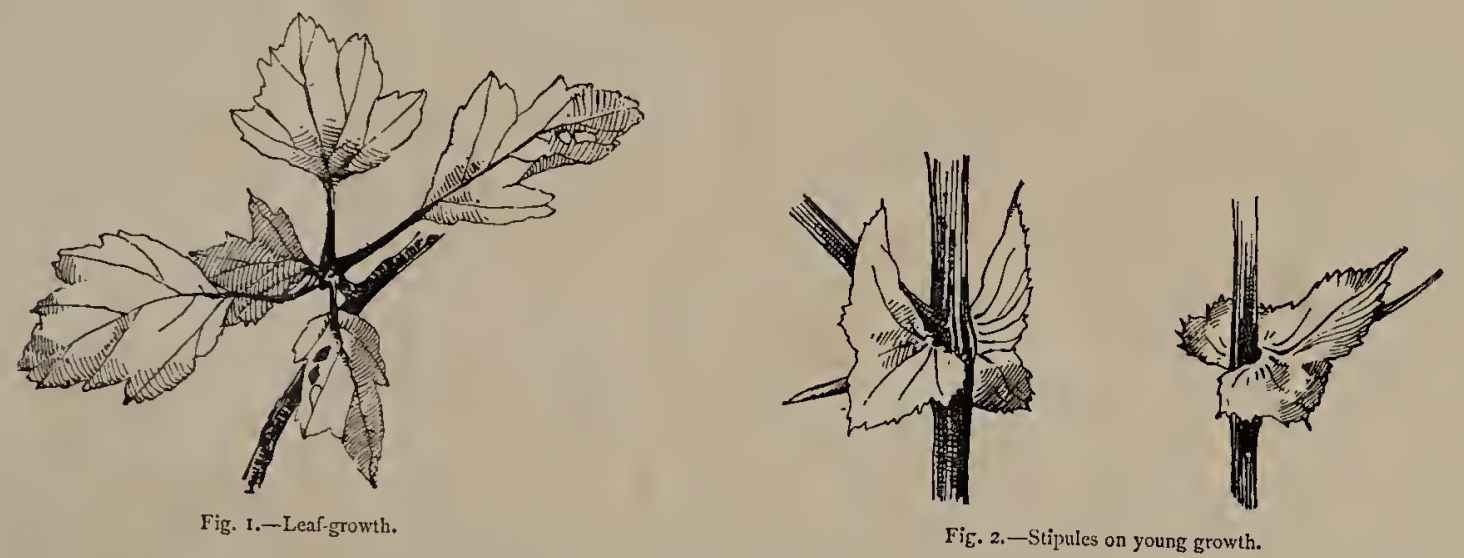

I have selected for illustration a spray of the Pink May, which agrees in all respects with the growth of the common white Hawthorn; there are also pink and scarlet flowered varieties, several of which have been cultivated into double-flowered trees. All are hardy, growing solitary or in clumps, and form one of the chief beauties of the English landscape, adorning alike the lordly park or woody hedgerow.

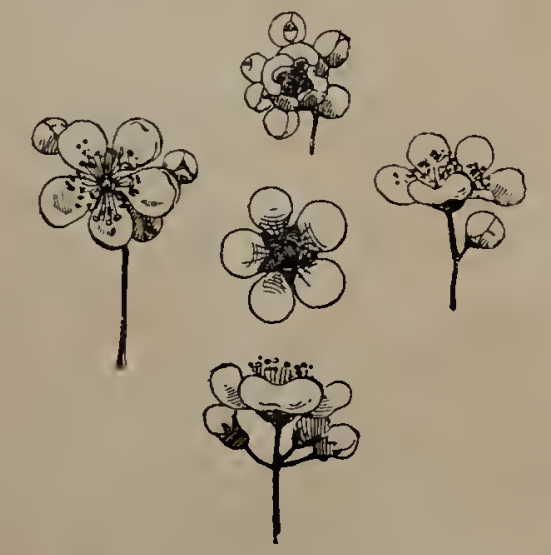

Fig. 3.-Flower and Bud.growth.

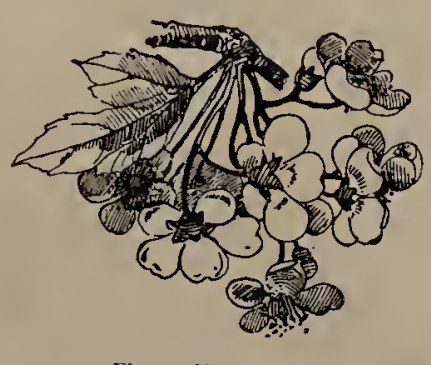

Fig. 4.-Flower-growth.

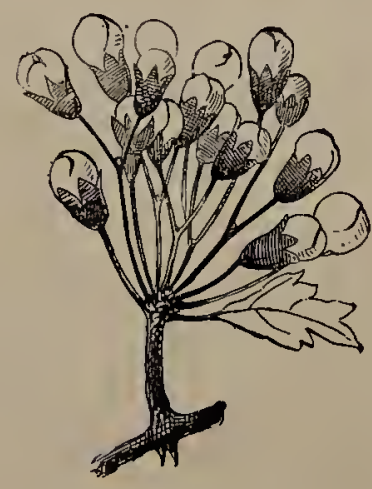

Fig.5.-Flower-stalk and bud-growth.

The tree lives to a great age, vigorous and honoured, and is extensively used in forming thick and impenetrable hedges. In the old growth the wood of the Hawthorn is gnarled and twisted, and frequently covered with lichen, or adorned with ivy, which plant seems to have singled it out as an especial favourite for its embrace. The young wood is of a brownish-purple,
and plentifully supplied with long sharp thorns. 


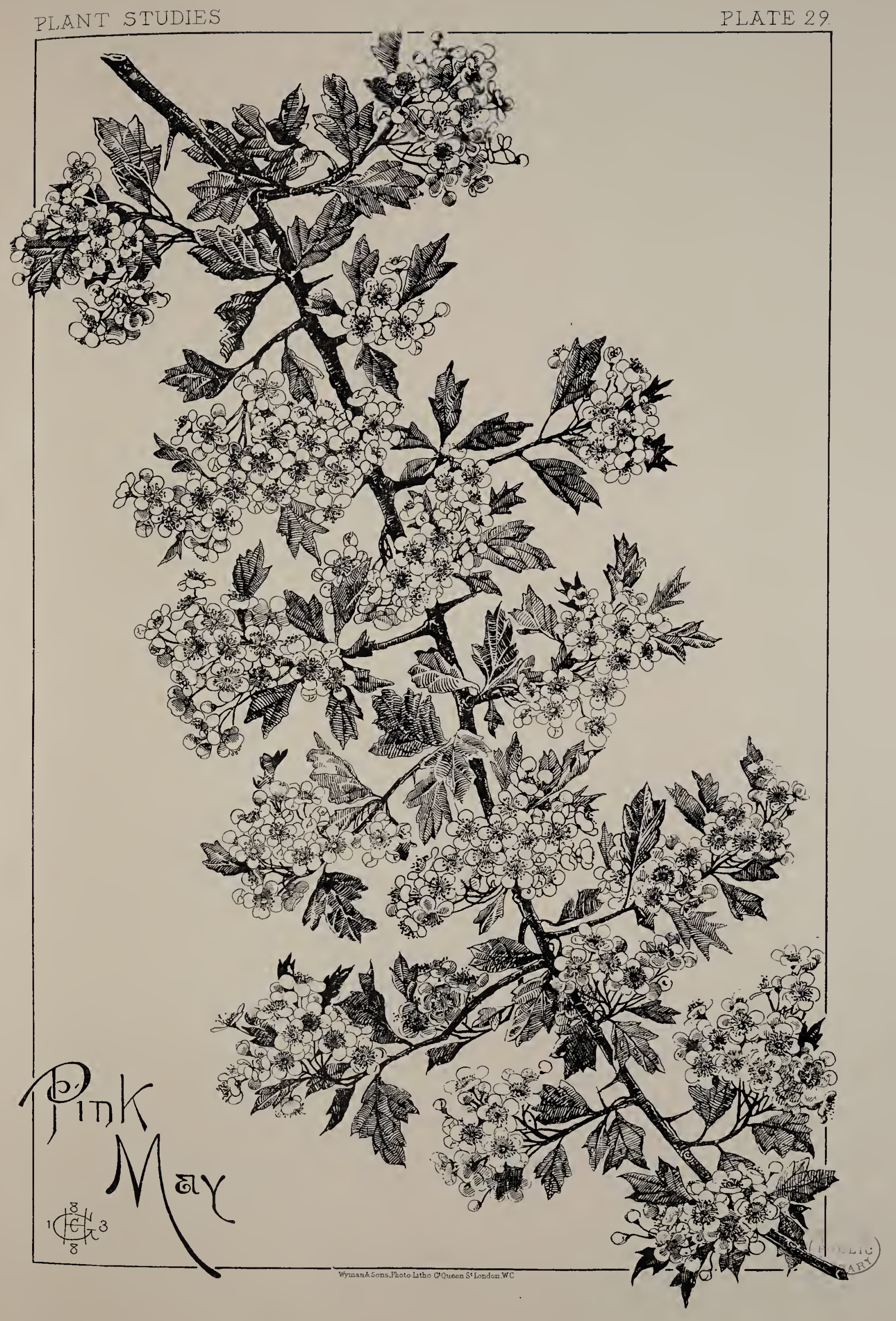





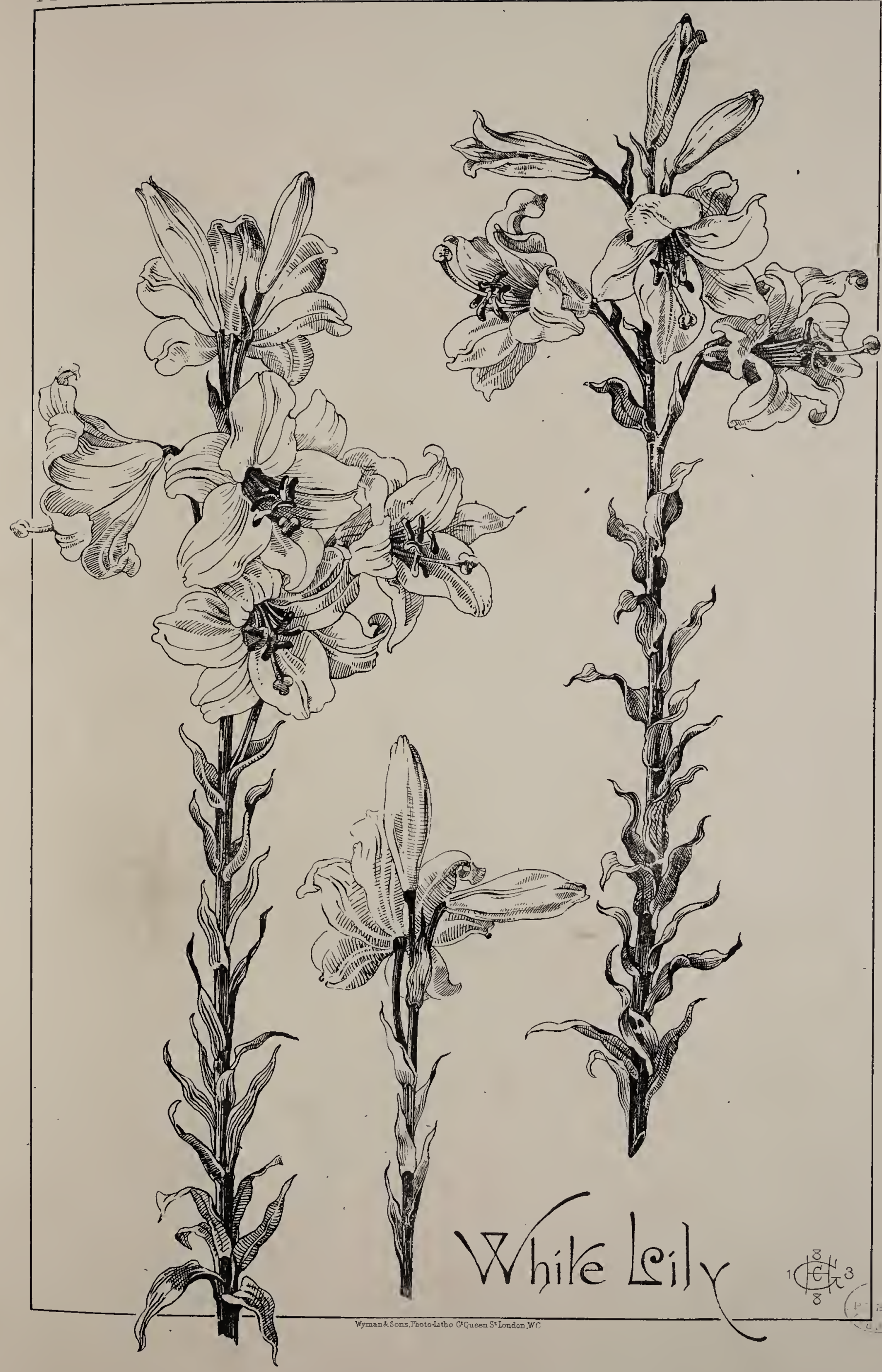



The leaves grow in whorls, on short lateral shoots (Fig. I), or alternately round the young sprigs, are deeply divided, three or five veined, and joined to the stem by a long stalk. They take numerous forms, which I shall describe more fully when illustrating the Haw period of growth. On the young shoots, at the base of the leaf-stalk, bracts form (Fig. 2), and, from beneath the bract, the thorn.

The chief charm of the tree is its blossoms (Fig. 3), which grow in clusters (Fig. 4), on long slender stalks from the centre of the leaf-whorl or at the end of the lateral shoots, and are each composed of five white petals, fixed on a small five-pointed pale-green calyx, which develops into the haw or berry. From the centre of the flower spring an indefinite number of stamens, tipped with a golden yellow or pale salmon colour, which fades into black, and matcrially changes the effect of the flowers when seen in a mass; the clusters of buds (Fig. 5), just bursting from their covering, and surrounded by the rich refreshing green foliage, are beautiful beyond description, and have been compared to ivory-could even ivory look so pure?

The old Cothic craftsmen and masons fully recognised the ornate qualities of the Hawthorn, hence we so frequently see it used in ecclesiastical work, both in stone and wood carving. To most purposes connected with modern ornamentation the Hawthorn, both in its blossom and berry-growths, may be satisfactorily applied.

\section{Plate XXX:-THE WHITE LILY.}

$\mathrm{W}$

ITI its soft and delicate fragrance and its chaste and stately beauty, the Lily is certainly not surpassed, if equalled, by any species of flowering plant; it has been appropriately chosen as the emblem of purity.

Travellers tell us that in Eastern lands the Lily grows in the richest profusion, not only as a cultivated plant, but wild in the field and by the wayside-a fact which renders more comprehensible the comparison in the Song of Solomon (chap. ii. v. 2), of the Church to a "Lily among thorns." Many are the references to it in sacred history,-amongst the best known, those beautiful words of our Lurd : "Consider the lilies of the field, how they grow; they toil not, neither do they spin, and yet I say unto you that even Solomon in all his glory was not arrayed like one of these,"-nust surely be recalled whenever we gaze upon the tender grace of the White Lily, although Christ's words were possibly applied to a different species.

The name Lily is derived from an old Celtic word- $l i$, from which we get the French lis, whiteness; its Hebrew name, "Shushan," meaning "light or splendour," was also the name of the chief city of Persia, whence the plant is supposed to have originally come. This city was probably so named from the fact that the flower grew in great abundance there. The Lily is both common and popular in all parts of England, where it has been cultivated from the earliest times. It is exceptionally hardy, requiring little care, and as content to blossom in the lowliest cottage garden as it is to rear its stately loveliness in the carefully-tended grounds of palaces and mansions.

There are numerous varieties of this plant, many differing greatly from one another, both in form and colour, amongst which may be mentioned a double-flowered variety, one having blossoms striped and spotted with purple, and another, perhaps the most remarkable, although certainly more curious than beautiful, is a species in which the flowers are abortive and replaced by white petaloid bracts.

The height of the blossom-topped stems varies from four to six feet, and they grow either solitary or in groups of twos and threes from the same bulbous roots. The flower-heads sometimes display as many as six or eight full-blown flowers, besides the unopened buds. The
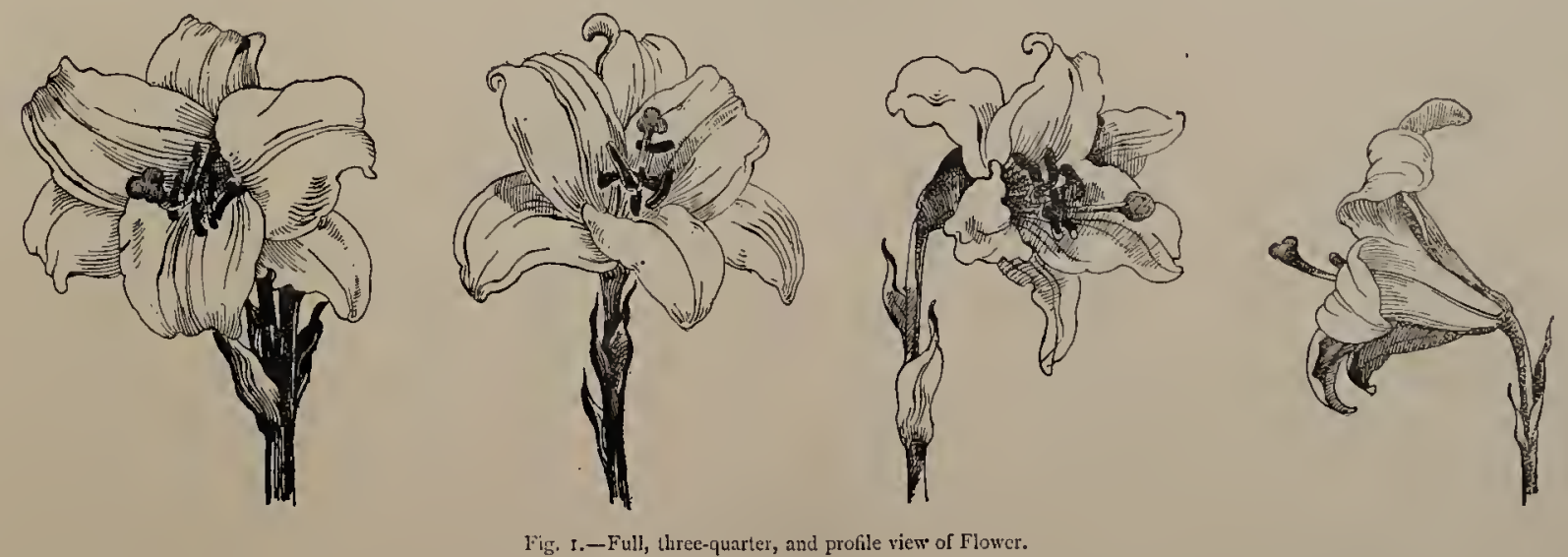

flower (Fig. I) is of a snowy white, but under the varying changes of sunlight and shadow have many of the subtle and transient colours of the opal,- rich and warm, with a soft golden hue; anon, pale and cool with silvery greys and greens. It is composed of six blunt-pointed 
petal-like segments, which have a tendency to curl under, and spring from a triangular base, three forming the inner and three the outer cup. From the centre of the flower rises the delicate green pistil, the head or stigma of which is divided into three portions, and projects beyond the flower; around this cluster six orange-tipped stamens (Fig. 2).

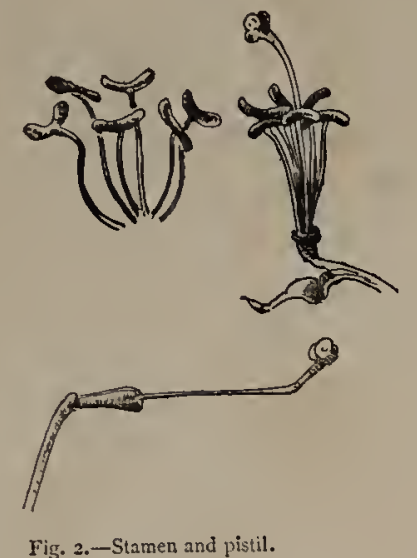

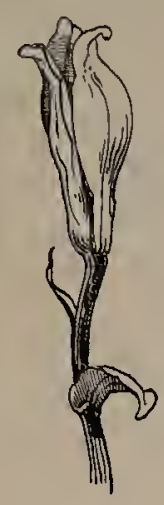

Fig. 3.-Dud.

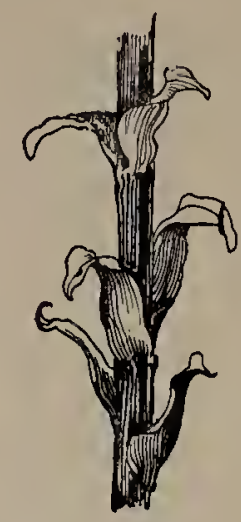

Fig. 4. - Leaf-growth.

The buds (Fig. 3) are almond-shaped, of a greenish-white, the stalks of which grow from inside the leaf-joint. The leaves are long and narrow, tapering towards each end, and veined from tip to base. They grow alternately round the stem, and repeat above the same point at intervals, which become less frequent as they approach the flower-head (Fig. 4).

They are closely and firmly attached to the stem, which is slightly ridged in a triangular form, from which ridges the leaves spring and have a habit of folding over and twisting at the tips. They are of a bright yellow and blue-green colour, and as they begin to fade tinged at the end with a warm brown, ultimately becoming rich golden-brown or copper-hued. This stage of the lily foliage is handsome beyond all word-painting, and presents to the colourist a scheme which his highest inspiration would fail to perfect.

Few plant-forms are more frequently met with in ornament than the White Lily, which, owing to its Biblical association, its refinement of form and purity of colour, is particularly suited for ecclesiastical work, -in the decoration of altar frontals, panels, and windows; while its peculiar elegance and stately beauty must always make it a favourite with both poet and artist, and in domestic decoration it can hardly be too frequently used.

Besides those media mentioned, in reference to its adaptation to ecclesiastical requirements, there remain an endless number of positions and materials in which its use would be judicious, as in the various methods of needlework, painting, stencilling, carving, glass and metal work, \&c. In manufactures it can be used freely in wall-paper, the various kinds of woven fabric, lace, Lincrusta Walton, \&c. Its qualities, however, seem to be well known and largely utilised. Artists and Art-craftsmen have from the earliest times availed themselves of the plant's valuable characteristics and decorative lines, and there is no lack of good examples of old work to prove how thoroughly appreciated as a motif was the White Lily.

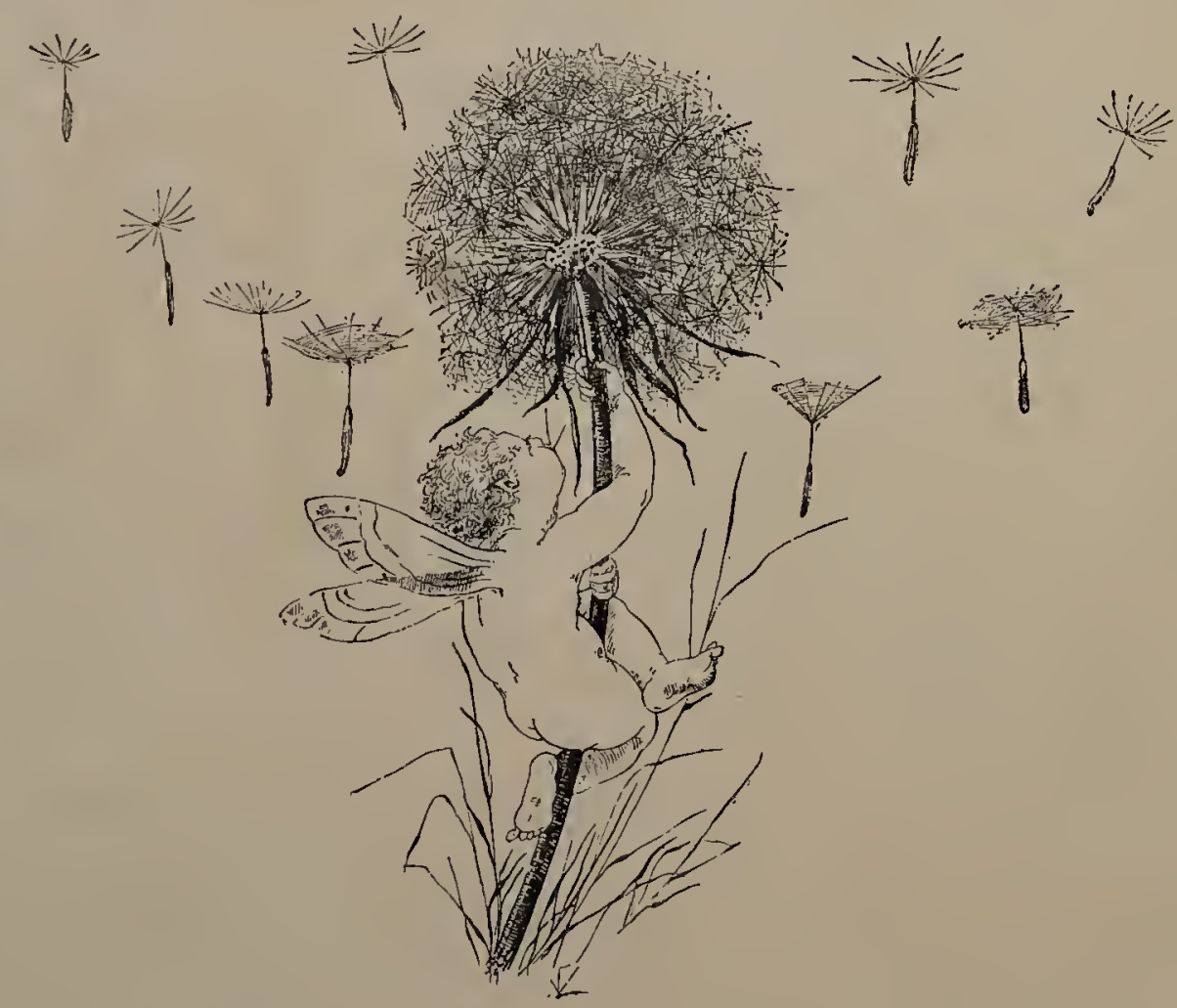




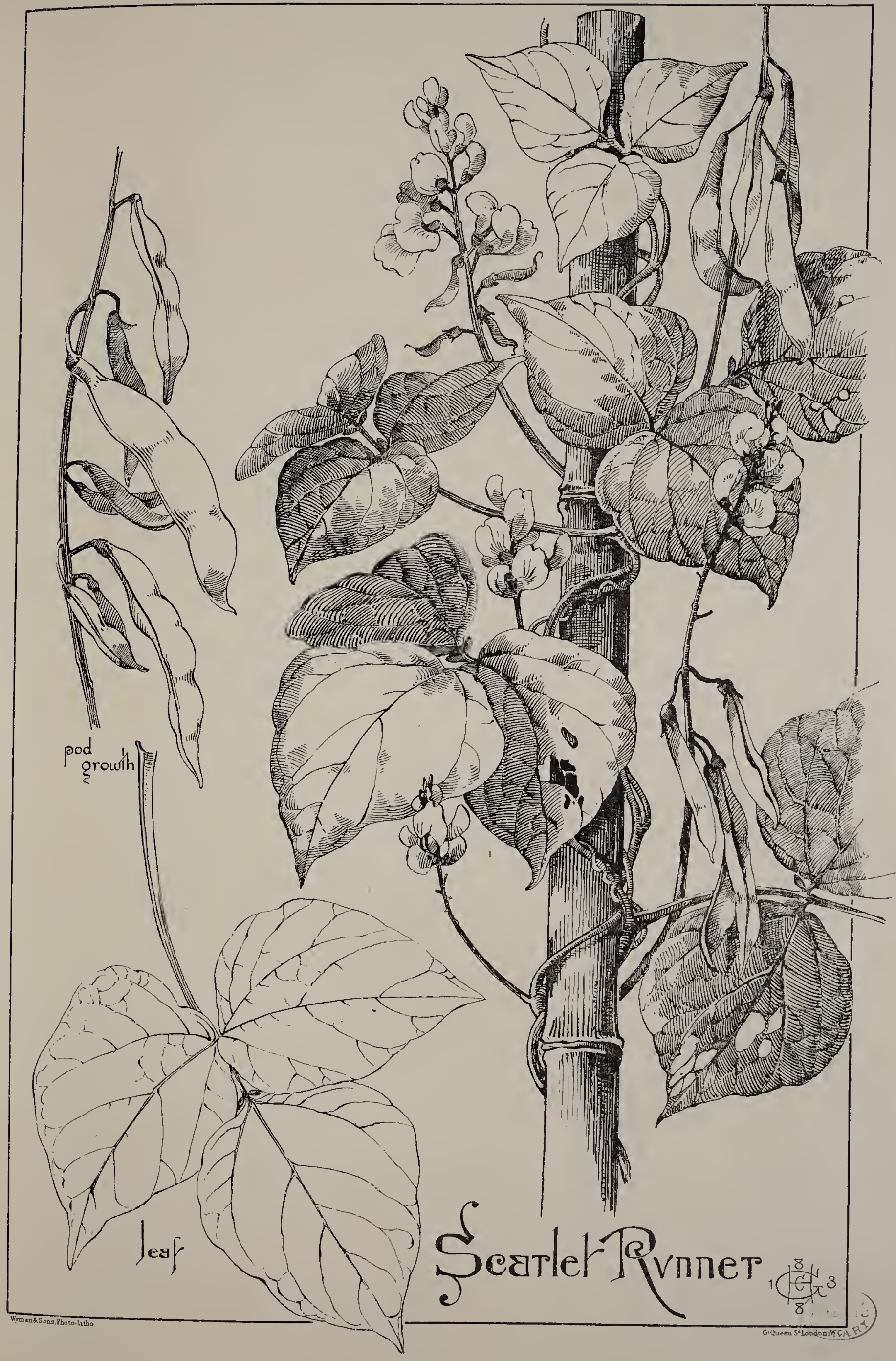





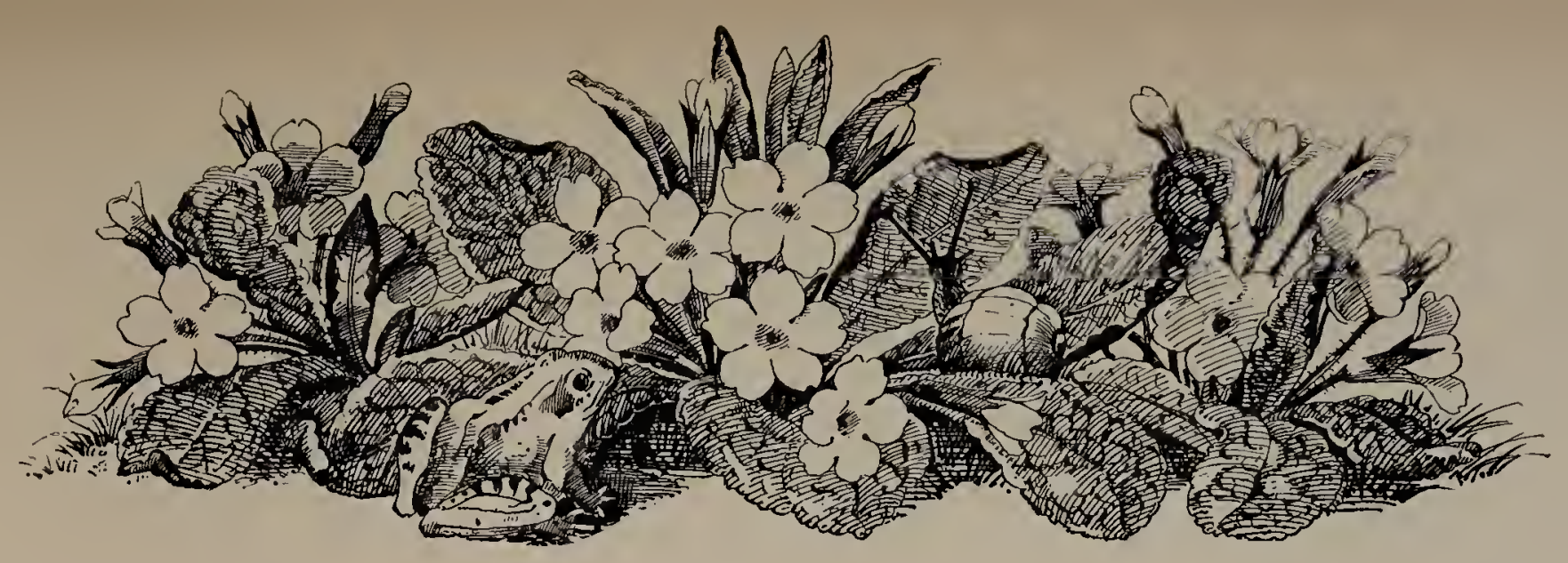

\section{Plate XXXI._THE SCARLET RUNNER.}

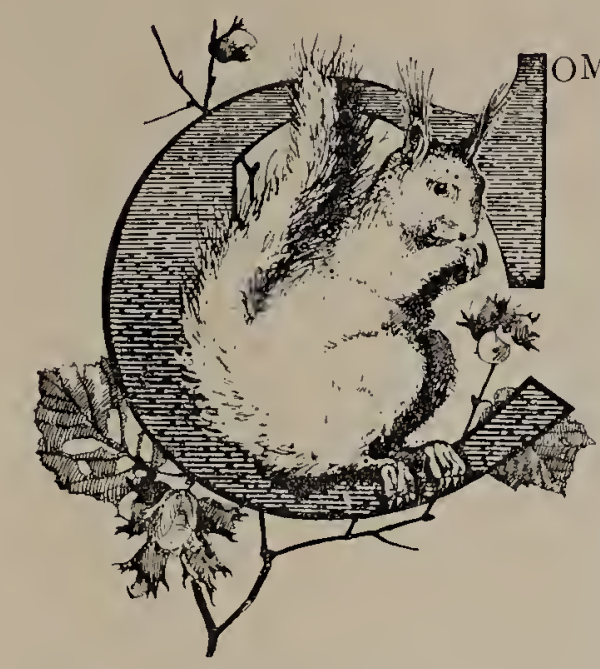

OMMON enough is the Scarlet Runner,-aptly so named from the colour of its flowers. It is one of those useful plants with which familiarity has bred, if not contempt, that which is almost as bad, indifference.

How cherished and admired it would be were it to require great care in cultivation, instead of growing as it does in any humble cottage garden, and providing the poor man with a wholesome and delicious vegetable. It may be seen flourishing even in the smoky atmosphere of towns, where it decorates many a hideous boundary wall with its veil of dark-green leaves and sprays of brilliant scarlet blossoms, chequered here and there with white or dull yellow. Though usually relegated to the kitchen garden, the æsthetic qualities of the Scarlet Runner can scarcely fail to interest the most casual observer, and claim for it an honoured place among those plants which are cultivated for their beauty alone. Burns has sung of the daisy, Shelley of most of our familiar garden flowers: when will the beauties of many a now neglected plant be recognised by some such master-mind?

The Scarlet Runner has no tendrils, but climbs with its stem (Fig. I), which is lined perpendicularly, and is of a soft-green colour, sometimes slightly tinged with a dull reddish-purple. Like most annuals, it grows very rapidly to a great height round a support, or, failing that, twines about its own or other growths in a mass of luxuriant verdure, which is very beautiful when seen with the summer sunlight shining through its glistening leaves, and throwing flickering shadows on the graceful pods that show between.

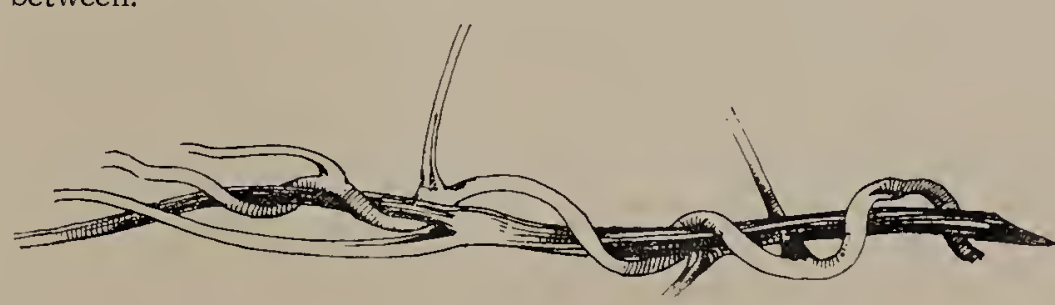

Fig. I.-Method of twining.

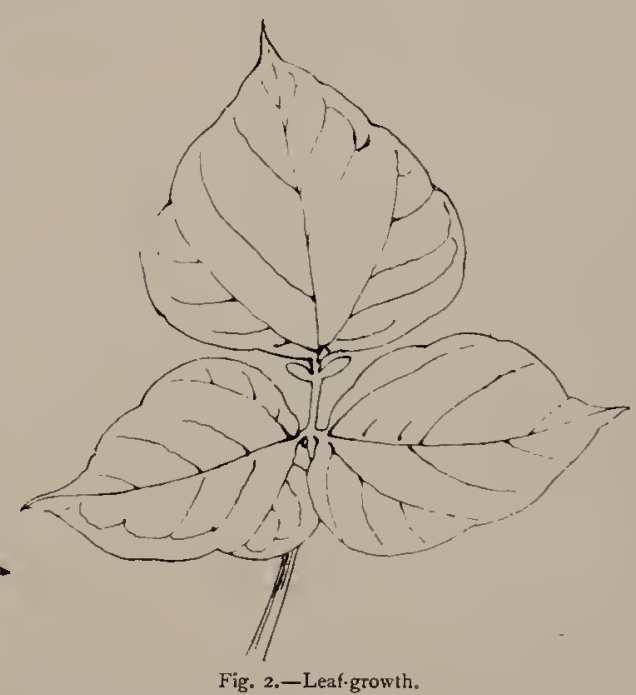

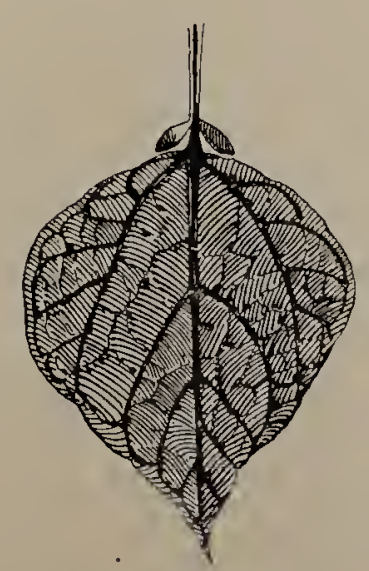

Fig. 3.-Underside of leaf.

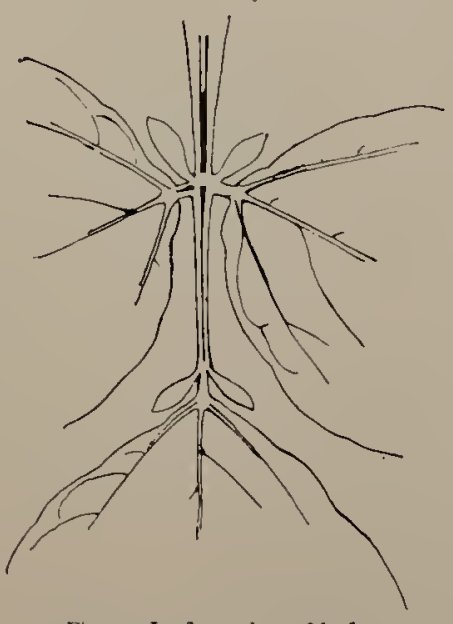

Fig. 4. - Leaflets at base of leaf.

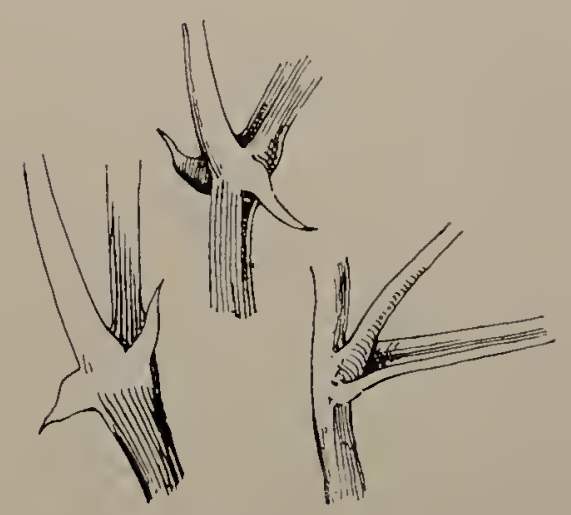

Fig. 5.-Growth of leaf.stalks and bracts at base.

The leaves grow in triplets (Fig. 2), though there are occasional departures from this rule. They are heart-shaped and centre-ribbed to the tips. The body of the leaf is broken up with delicate 
veins, which show more prominently on the under side (Fig. 3). At the base of each leaf grow tiny leaflets (Fig. 4), which form an interesting feature. The leaf-stalks (Fig. 5) are grooved on the inner side, and joined firmly to the stem, round which they grow alternately, or if that is prevented by conditions of growth, on one side only. The lateral shoots and flowers spring from the inner side of the leaf-stalk (Figs. 6 and 7 ).

The buds and flowers (Fig. 8) are shaped like those of the pea, and grow in clusters on long upright stalks. After the petals of the flower fall away, the pods appear, and undergo a series of beautiful changes, until the beans are fully ripe (Fig. 9), when the dry case bursts and allows them to fall to the ground.
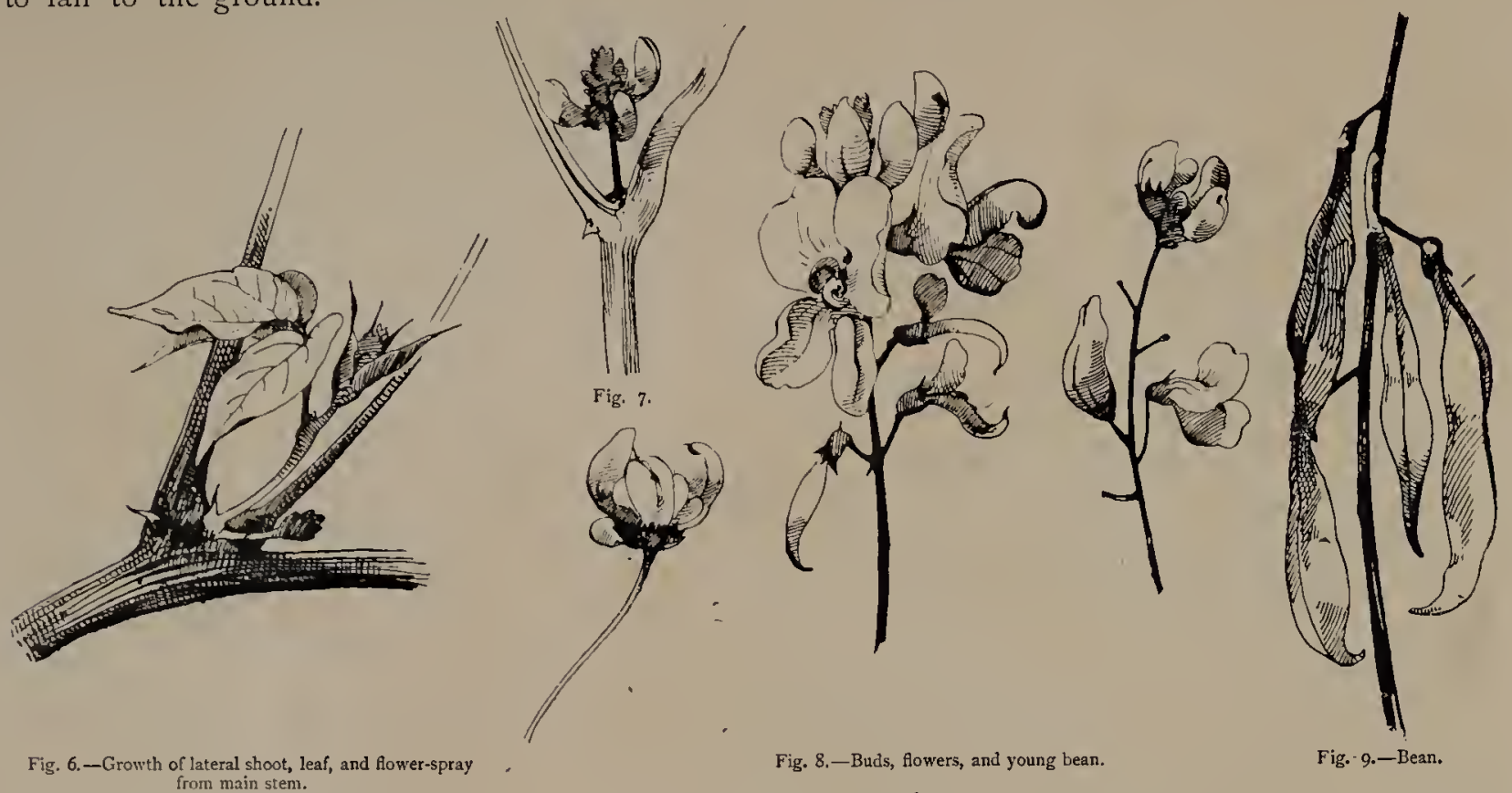

The Scarlet Runner can be utilised in many kinds of decoration, either in a severe conventional form or in its natural spiral growth, which specially recommends it for use in panels, pilasters, or the embellishment of columns, while, as a study for brilliant colouring, the plant is full of instruction. The small leaflets (Fig. 4) which grow at the base of the leaves are capable of forming a striking feature in adaptation.

\section{Plate XXXII.-THE PASSION-FLOWER.}

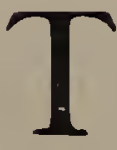

HIS extraordinary plant is said to have been first brought to notice by Roman Catholic priests, who followed up the discovery of America in their desire to win over the Aborigines to the Christian faith. To them the structure of the plant appeared to be miraculous, for on careful analysis the various parts of the flower seemed to represent the instruments used in the Crucifixion of our Blessed Lord: hence they called it by the name Passi flora.
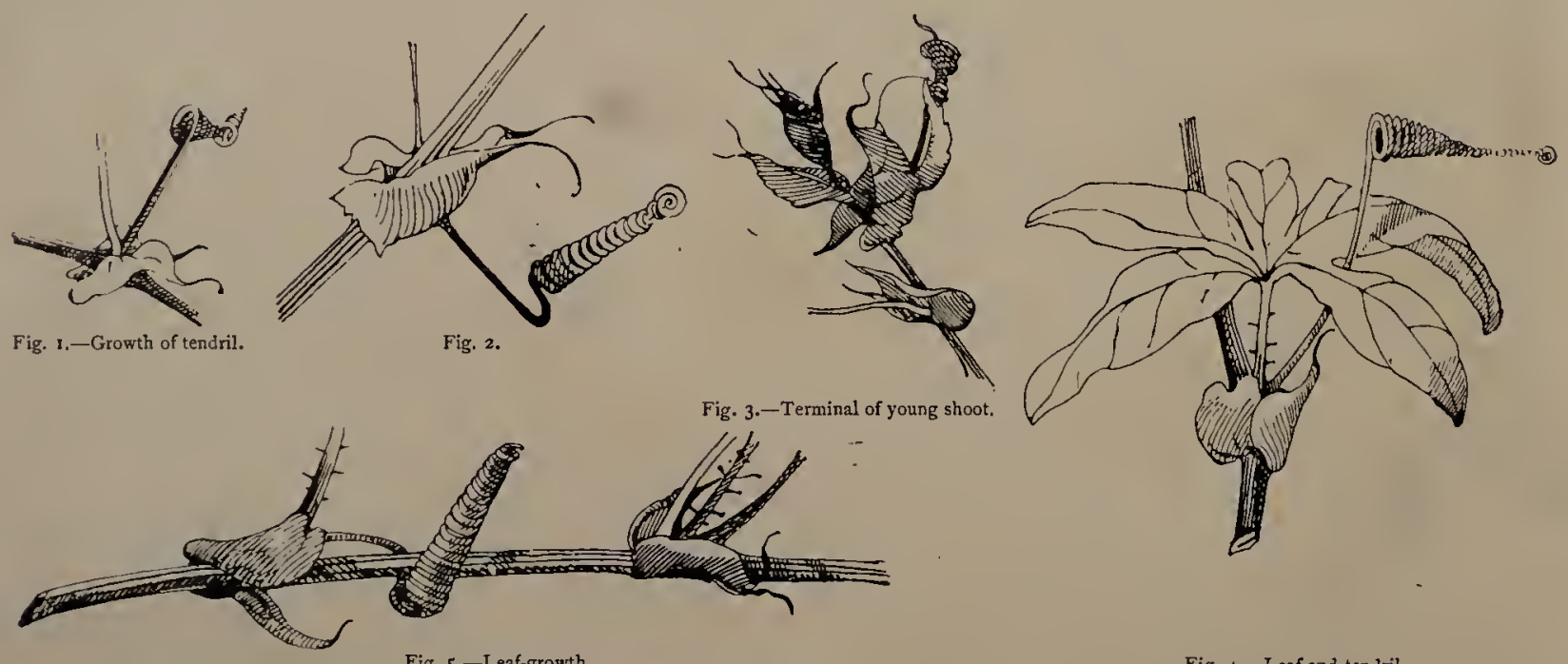

Fig. 5.-Leaf-growth.

Fig: 4. - Leaf and tendril.

The stamens are compared to the five wounds; the three styles more aptly to the nails by which our Saviour was fastened to the cross; the column which elevates the germen to the 


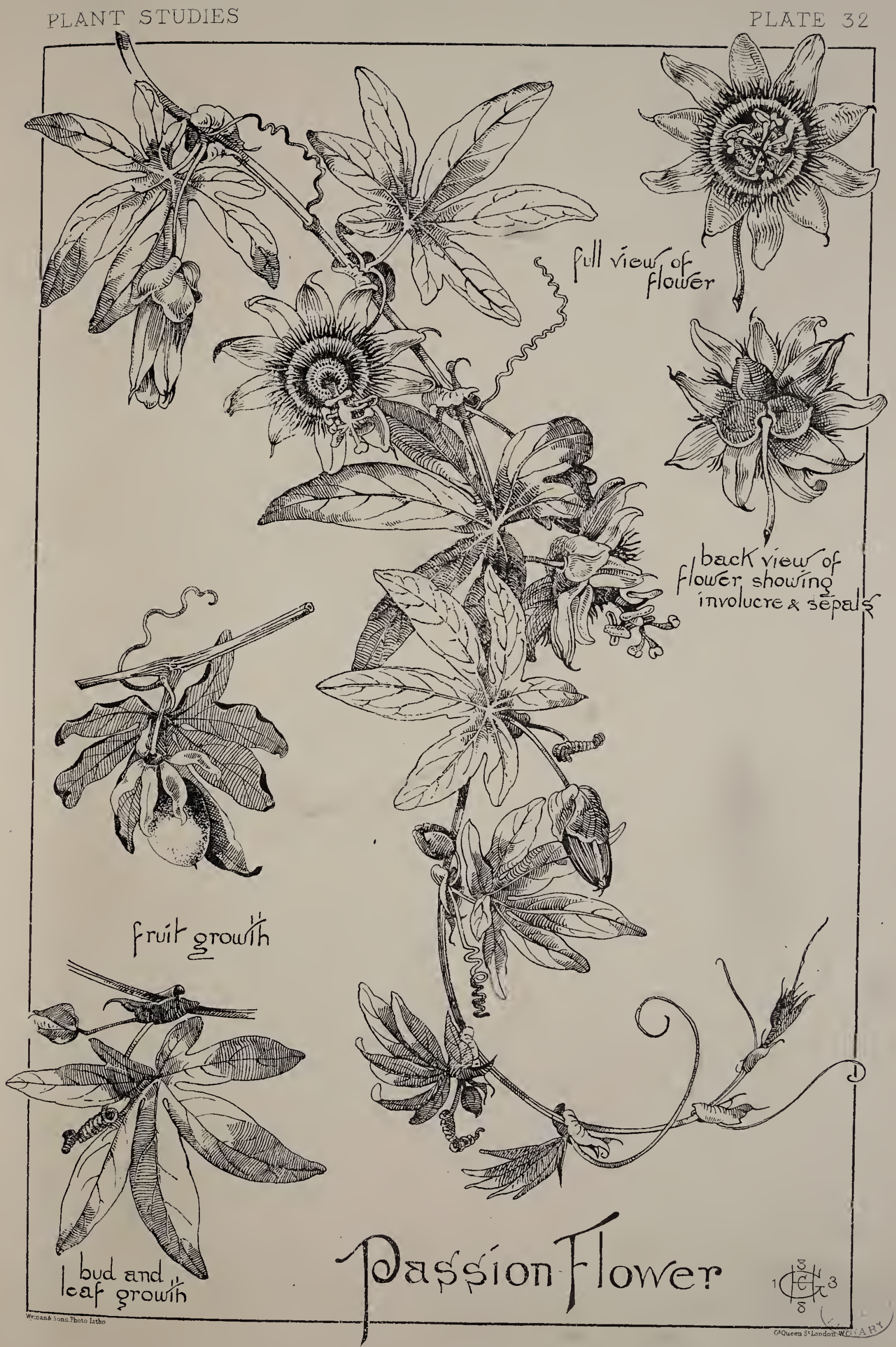



cross itself, or the pillar to which $\mathrm{He}$ was bound; the ray of the nectary to the crown of thorns; the tendrils to the scourges, and the ten petals and sepals to the Apostles, minus the betrayer and denier, \&c. It would not be difficult to carry this simile still further. There are cuts to be seen in old books in which the flower is entirely composed of the objects above enumerated, and it is something more than curious that so many of its parts should bear so close a comparison, for the slightest examination will prove how pardonable are these similes.

In its native home, the Passion-flower climbs to the tops of high trees, and hangs from their branches in thick festoons of foliage and blossoms, or trails over the rocks in rich profusion; while in England, where the cultivation of this beautiful evergreen climber is becoming more common every year, we find it vigorous and flourishing in sheltered positions. It is of rapid growth, and climbs by means of its tendrils, which spring from the side of the leaf-stalk. Their characteristic manner of twisting is shown in Figs. 1 and 2.

The stems are flexible, and of a pale-green colour, shading to reddish-purple in the young shoots (Fig. 3).

The leaves are exceedingly beautiful, divided into five or seven divisions, which are centreveined to the tips (Fig. 4). They grow alternately round the stem on long stalks, which are studded with little nail-like growths (Figs. 5 and 7). From inside the leaf-joint springs the lateral shoot, tendrils, or bud, and sometimes all three (Figs. 6 and 7). At the joint of the leaf-stalk with the stem grow two green sheaths, varying in shape, and terminating in a kind of spur. Fig. 8 gives various examples, and, as this bract-growth adds much to the character of the plant, it deserves careful study and attention.
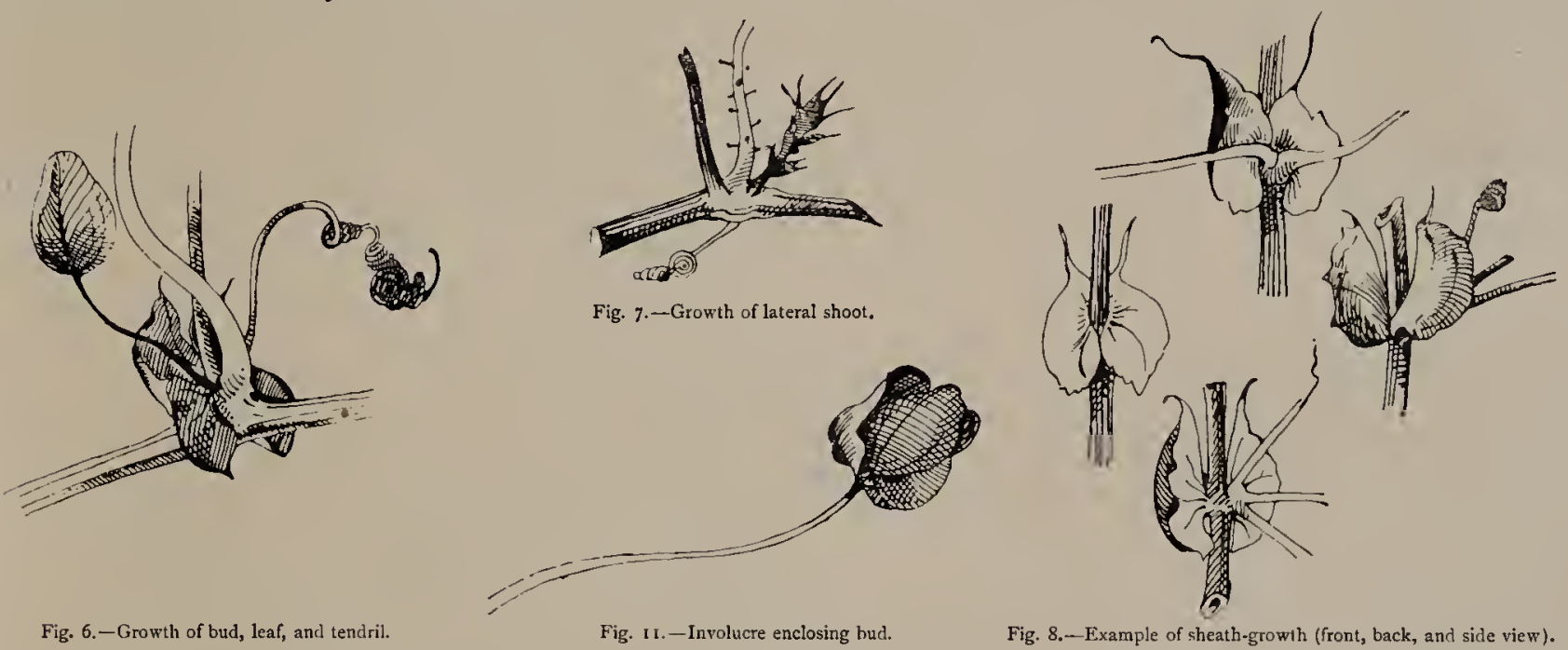

The flower (see plate), owing to its peculiar formation, demands a somewhat lengthened description. It is composed of five white petals and the same number of sepals, though the latter are so large that the blossom has the appearance of being composed of ten petals. The sepals, however, may be readily distinguished, not only by their being of a more greenish-white, but also by the tiny green hook with which their tips are armed (see Fig. I2). From the centre of the flower springs the pistil, which is divided at the top into three dull purple-spotted, greentipped styles, round which cluster the five orange-topped stamens (Fig. 9). Surrounding the base of the pistil grow the rays of the corona in a variegated fringe of red, green, purple, white, and blue circles (Fig. Io). The bud first of all appears encased in a delicate green involucre (Fig. I I) which opens out as the sepals increase in size (Fig. I2).
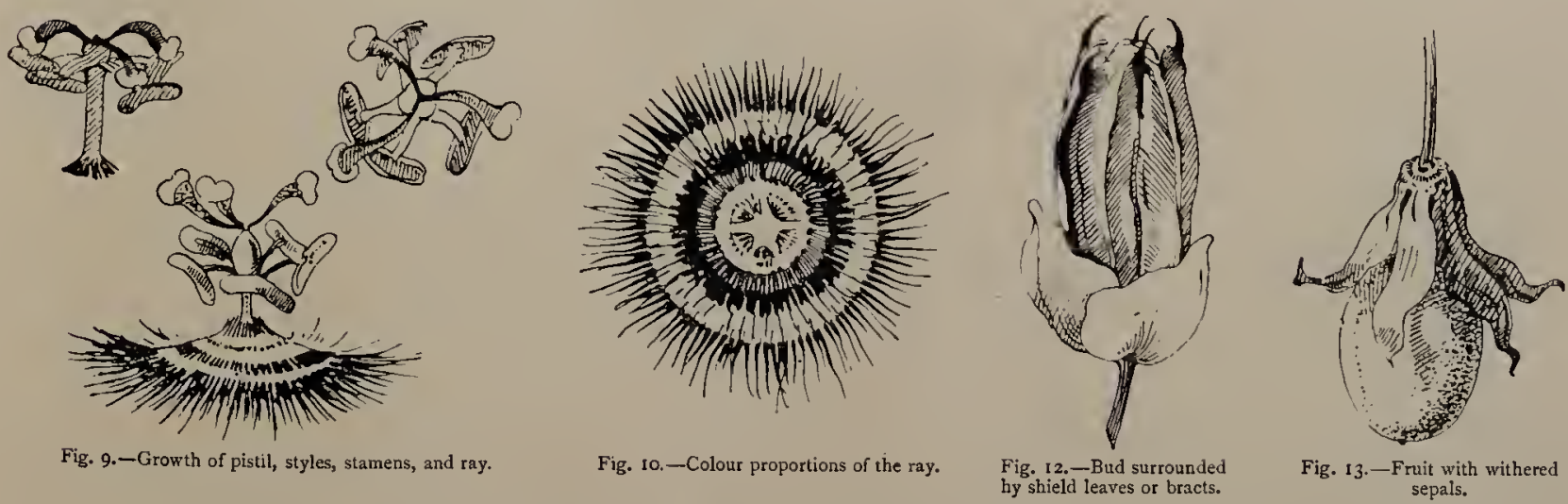

A singular habit of the Cerulea or Blue Passion-flower is that the blossom only remains open for twenty-four hours, dating from its expansion, which may happen in the evening or night; but in any case it closes on the return of that hour, never to open again, and beneath its closed petals fosters the ripening of its golden fruit. Not the least remarkable feature of the plant is seen in the beauty and formation of this golden-orange, egg-shaped fruit (Fig. I3), which appears in all stages 
of development at the same time as the later buds and blossoms, and hanging with its withered sepals and petals still clinging round it, presents a brilliant contrast to the glossy, dark-green leaves.

To carver, smith, or metal-worker, as to designer and painter, the value of this plant can scarcely be over-estimated, for it is rich with beauties of form and colour, equally suited to the severity of the one as to the delicacy of the other. Being peculiarly adapted to ecclesiastical purposes, it can be carved in wood, stone, or brass, upon pulpit, panels, or dados, and stencilled and painted upon stone or flat surfaces, and in needlework can be used for the ornamentation of altar frontals, stoles, and hangings.

\section{Plate XXXIII.-THE HALEL.}

$\mathrm{I}$

all its varying aspects, as the seasons succeed each other, there is no native tree more familiar or pleasing than the Hazel or Common Nut. In winter, when frosts still cover all the earth, the little crimson stigmas of the catkin shine out in brilliancy unequalled by any adjacent object. Then, in sweet spring, when early flowers carpet the ground, over banks and hedges the graceful twigs of the Hazel spread, and the pendant catkins sway in every gentle breeze. Later, when ruddy autumn ripens earth's produce, what wild fruit of our hedgerow and coppice is more acceptable than the nut of the Hazel? Who does not remember the holidays of our happy, idle youth, and the joyous pleasures of the nutting season? Such tempting clusters nestling beneath the broad protecting leaf, and those raised far above our reach, what prize e'er seemed so great for chubby hands to grasp, when once the stately bough had been brought low?

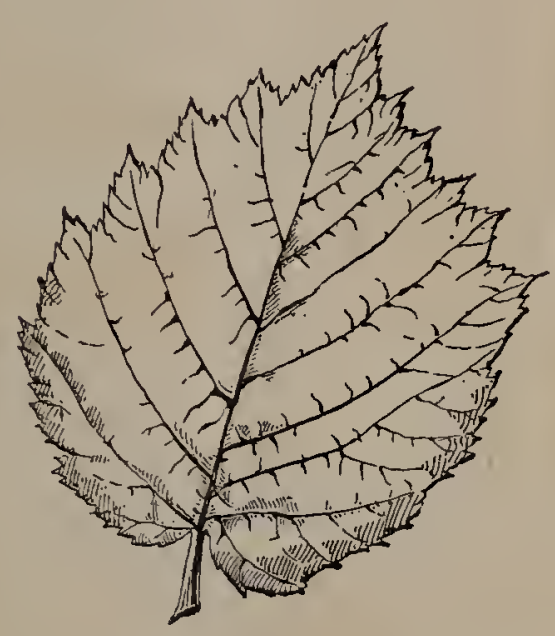

Fig. I.-Leaf.

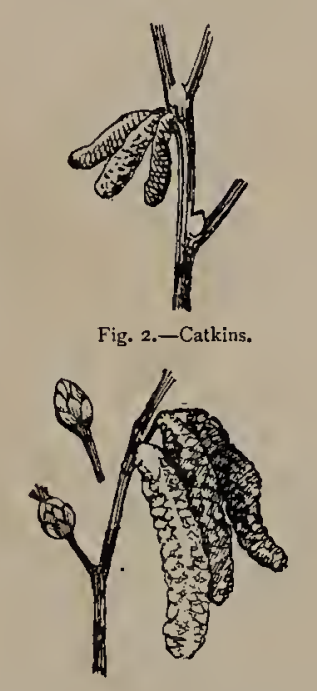

Fig. 4.-Catkin, stigma, and leaf.bud.

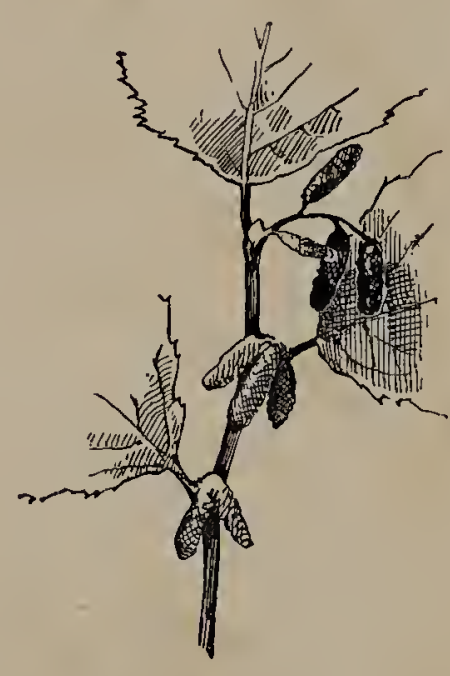

Fig. 3.-Growth of catkin.

The Hazel may be described as a bushy shrub, exceedingly valuable for hedges, and under-growth for covers. If allowed to attain the proportions of a tree, it often reaches a great height, and is of imposing appearance. In some parts of England,-notably Kent, especially in the neighbourhood of Maidstone,-its growth has been so plentiful that many persons, and ancient places, have derived their names from it. It is much associated with early superstitions, one of which still remains in the use of the Hazel divining twig for the discovery of metals. The old wood is ash-coloured and barked; the young wood and branches light brown, spotted with a dull whitish-red. The foliage is of a soft quiet green, though many of the younger terminal leaves, and the extremely large ones, are often dull purplish-red in hue.

The leaves may be called heart-shaped, and are slightly unequal at the base, with their edges finely and doubly serrated (Fig. I). They grow alternately from the stem in a zig-zag manner, and have short thick stalks, which are firmly attached to the twig. They are plentifully and strongly veined, with secondary veins running straight from the mid-rib to the margins. The upper surface of the leaf is rough; the under side,-on which the veins show much more prominently,-is downy, and of an opaque whitish-green. At the base of the young leaf oblong stipules form, enclosing the leaf and fruit-buds.

During the autumnal period the leaves undergo a succession of beautiful colour changes, through russet browns to rich tawny yellows; they cling most tenaciously to the boughs, and only at winter's rapid approach begin to wither and fall.

The male catkins are composed of numerous little scales of a pale yellowish-green, tinged with a suspicion of purple at the tips. They appear during autumn, in clusters of twos and 


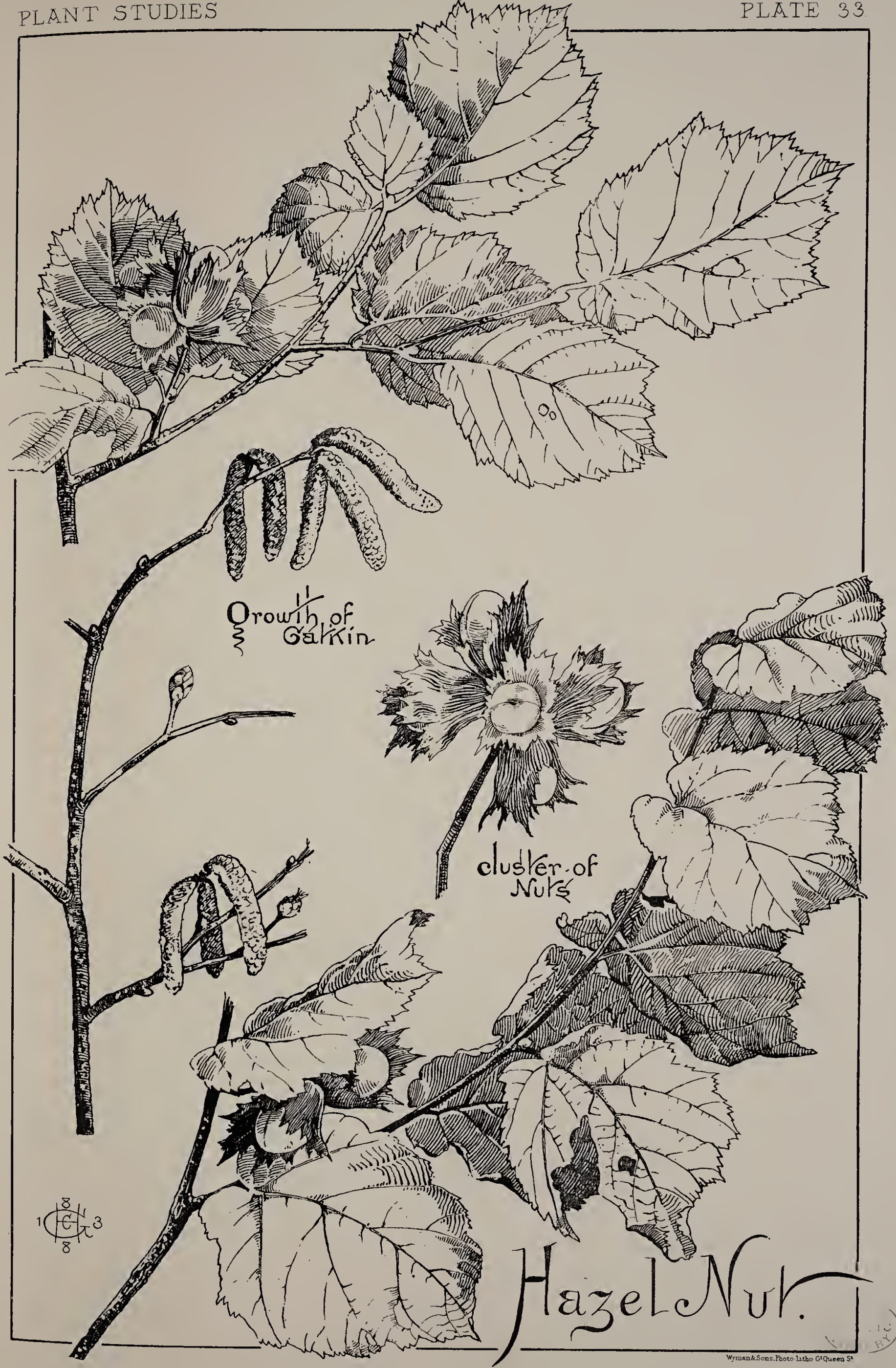





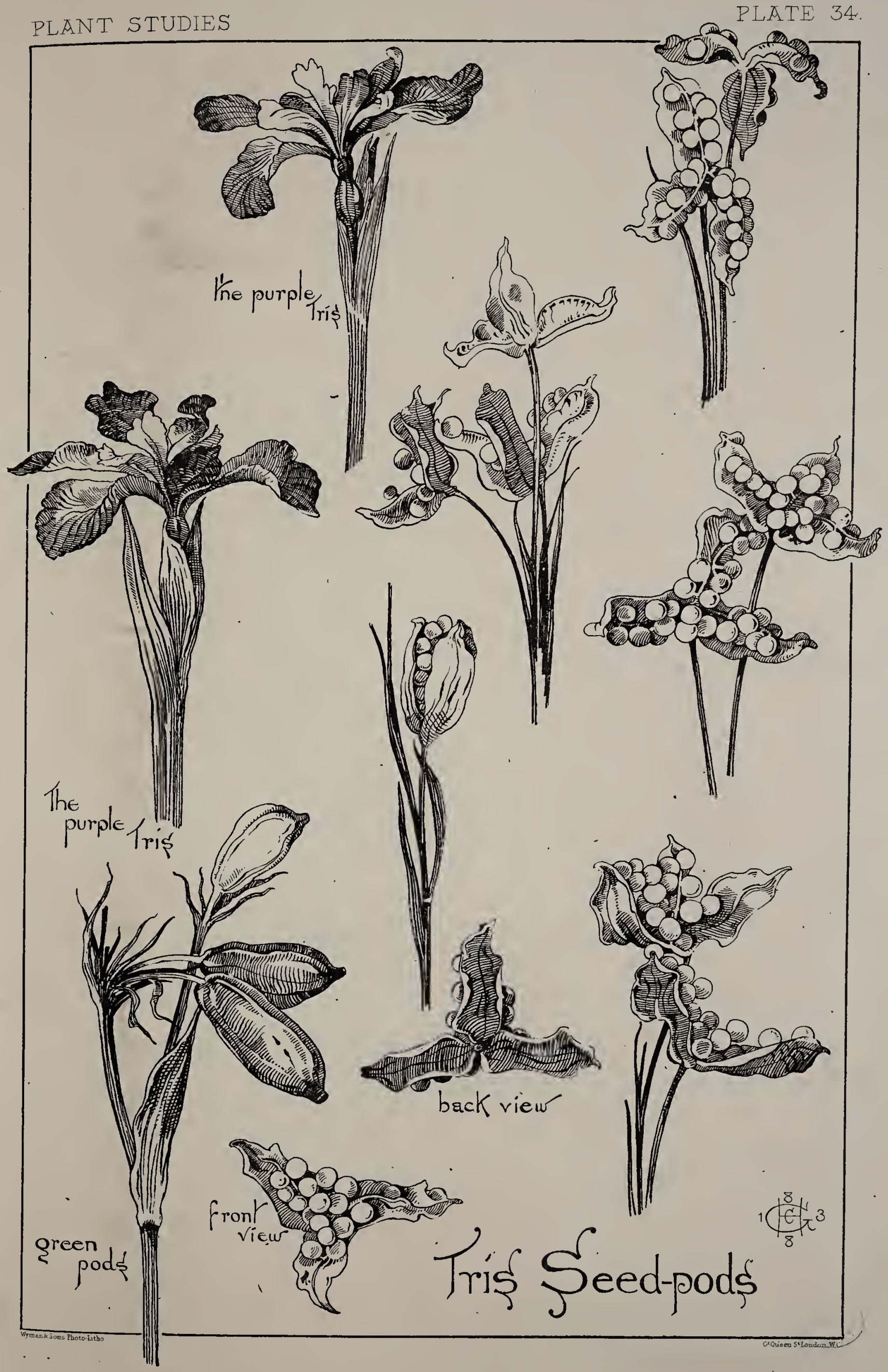



threes (Fig. 2), in the axils of leaves on the young shoots, but do not expand fully until the end of winter. They are pleasing heralds of spring, being, perhaps, the first to awaken from winter's lethargy, and are frequently in full bloom when the hedges are still covered with frost and snow. Their form could scarcely be better described than by the name, "Lambs-tails," so commonly applied by country children.

The fruit-bearing flowers spring from solitary scaly buds (resembling those of the leafbuds, Fig. 3), out of which protrude small crimson stigmas; (Fig. 4), the bare twigs and branches and general absence of colour serving to enhance their brilliancy.

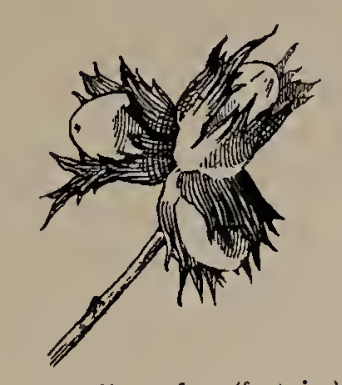

Fig. 5. - Cluster of nuts (front view).

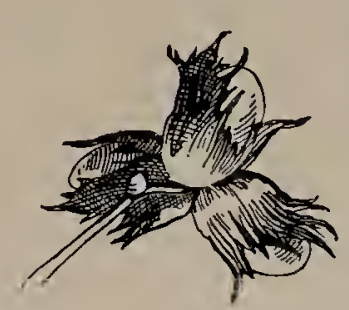

Fig. 6.-Cluster of nuts (back view).

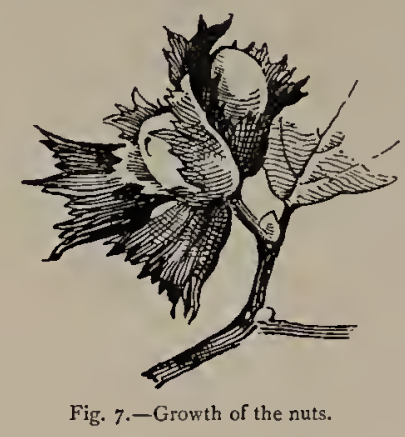

Fig. 7.-Growth of the nuts.

The nuts grow as terminals to short stalks, generally in clusters of two, three, five, and seven (Figs. 5 and 6), though quite as often a single nut is to be found. Each nut is encased in a ragged-edged, cup-shaped involucre, of a soft green colour, which changes into various brown shades under the ripening touch of autumn. That portion of the nut visible between the protecting edges of the involucre is whitish-green, gradually turning to rich bronzy yellows.

The Hazel, in every aspect of its growth, is so full of charming and eminently decorative features, that enumeration is well-nigh impossible. For many purposes of decoration, especially in panel-carving and painting, and the lighter pursuits of needlework and china-painting, where great variety is an advantage, the growth can be used in conjunction with the Squirrel, Dormouse, or Nut-Hatch, for these little creatures make the nut of the Hazel their favourite food.

\section{Plate XXXIV.-IRIS SEED PODS.}

$\mathrm{I}^{\mathrm{N}}$ $\mathrm{N}$ describing the Yellow Iris (Plate XXI.), I mentioned the valuable decorative qualities of the seed-pods, and my intention of illustrating them. I should have explained, however, that this did not refer to seed-pods of the Water Iris only, but more particularly to those of the Wild Purple variety, which is now shown in conjunction with its seed-bearing aspects. The Wild Purple, or Stinking Iris, so called from its unpleasant odour, is found most commonly in thickets and hedgerows in the south-west of England, though it also grows in great profusion in some parts of Wales. The general characteristics of this species agree with those of the Yellow Iris, but its blossoms are not nearly as beautiful; neither is it of such fine growth, seldom exceeding three feet in height.

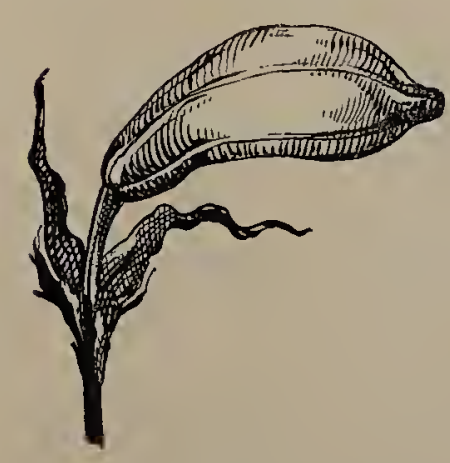

Fig. I.-Seed-pod,

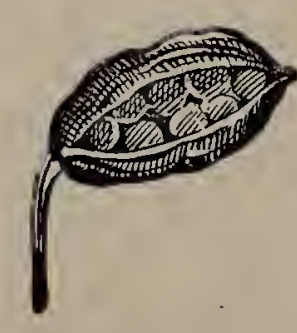

Fig. 2.-Seed-pod opening.

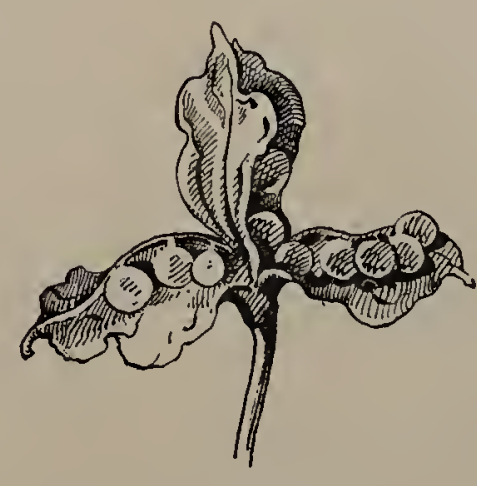

Fig. 3.-Seed-pod open.

The flower is composed of six deep segments, the three outermost reflexed and spreading, and the inner three nearly erect or incurved, all being united at the base into a narrow tube immediately above the seed receptacle. The colour of the flower at the tips of petals is bluishpurple, merging into purplish-reds and yellows towards the base, all being marked with pale-green and brown veinings. Owing to its varied hues, this, probably, is the flower which suggested the name Iris. 
The seed capsules are so heavy, that a less sturdy plant would be unable to bear their weight. They are oblong (Fig. I), and formed by three cells and three valves, the former closely packed with double rows (Fig. 2) of brilliant orange-coloured berries, attached to the ridge of the valve dividing each cell. In late autumn or early winter, when the capsules shrivel and burst, (Fig. 3), the seeds are displayed in all their lustrous beauty, enlivening many a bare and cheerless spot.

Although this seed-period of the Iris growth is of singularly ornamental appearance, I cannot call to mind any instance of its application. To the stone or wood-carver, for instance, it should be of great service, and, owing to its novelty, much could be done with it in the lighter and more fanciful branches of art, as for plaques, tiles, and fan-painting.

\section{Plate XXXV.-THE FOXGLOVE.}

$\mathrm{T}$

HE name of this genus of plant is derived from the Latin digitus, a finger, and the origin of the common name, Folks-glove or Foxglove, has given rise to many curious and interesting conjectures. The name Folks-glove is of great antiquity, being said to exist in a list of plants in the time of Edward III.

The "folks" of our ancestors' were undoubtedly the "fairies," and what fancy more quaint and poetic than that the pretty coloured bells should be their homes and lurking places.

The Purple Foxglove is the species best known. It is very abundant about hills and borders of fields and woods in many parts of England, and in most places where it occurs is called by some name having reference to its bell, or finger-like blossoms.

The flower-stem of the Foxglove is round and stout (Fig. I), and often rises to the height of six feet; generally erect and solitary, but in some cases slightly branched. The leaves at the base of the plant are of great size and beauty, but they gradually diminish, and are shorter in the stalk the higher they are placed on the stem, until the highest become quite narrow and straight. They are downy, and of a beautiful grayish-green in colour, with the undersides of a steel-like gray. Both the upper and under surface of the leaf is broken up into a multitude of small forms by the numerous veinings, giving to the foliage a characteristic and beautiful texture.

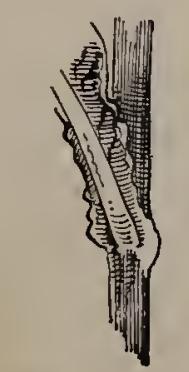

Fig, s. - Flower-stem
and Leaf-joint.

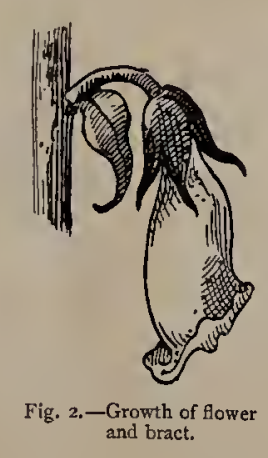

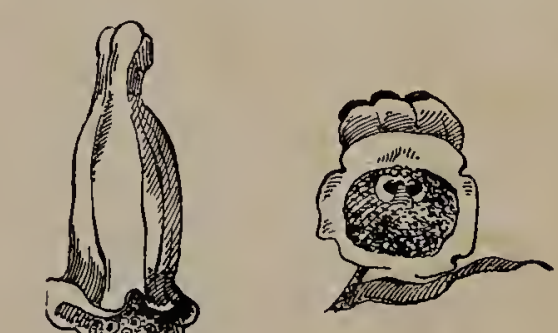

Fig. 3.-Shape of flower.

Fig. 4.-Full view of flower.

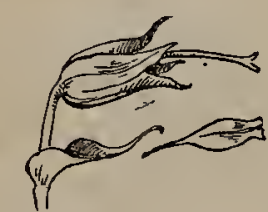

Fig. 5. - Segments,

The flowers are from one and a half to two inches in length; are very numerous, and, clustering round the stem, form an elegant pyramid of pendent, bell-like blossoms. At the base of each flower-stalk grow bract-like leaves (Fig. 2). Each flower is composed of one petal (Figs. 3 and 4), fixed upon a rich green calyx of five permanent segments divided to the base (Figs. 5 and 6 ), which protects or encases the seed-capsule (Figs. 7 and 8). No stigma or stamens are visible on general observation.

In the cultivated species, the flowers vary considerably in colour, some being white, others pink or crimson; but those of the common Wild Foxglove (see Illustration) are purplish-crimson
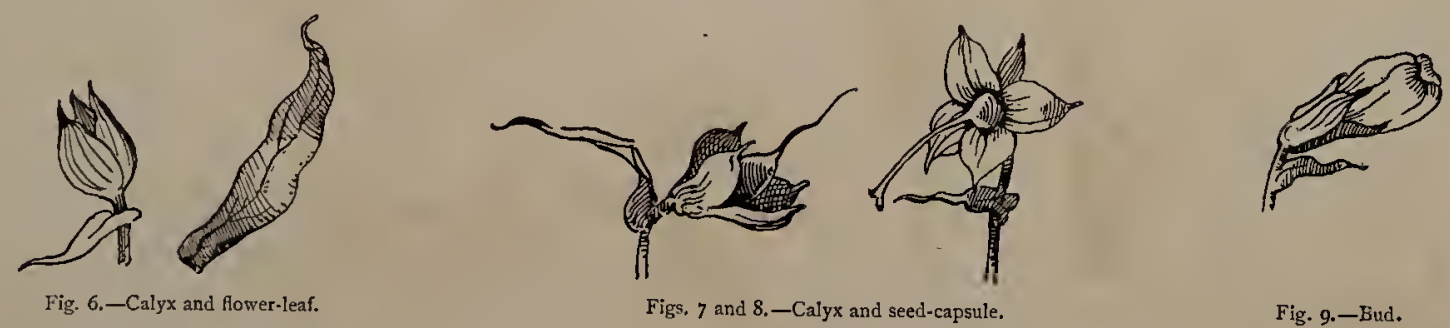

above, somewhat paler beneath, gradually merging into pale pink or greenish-white at the base of each blossom. The inner parts of the flowers are splendidly marked with dark purple spots, 


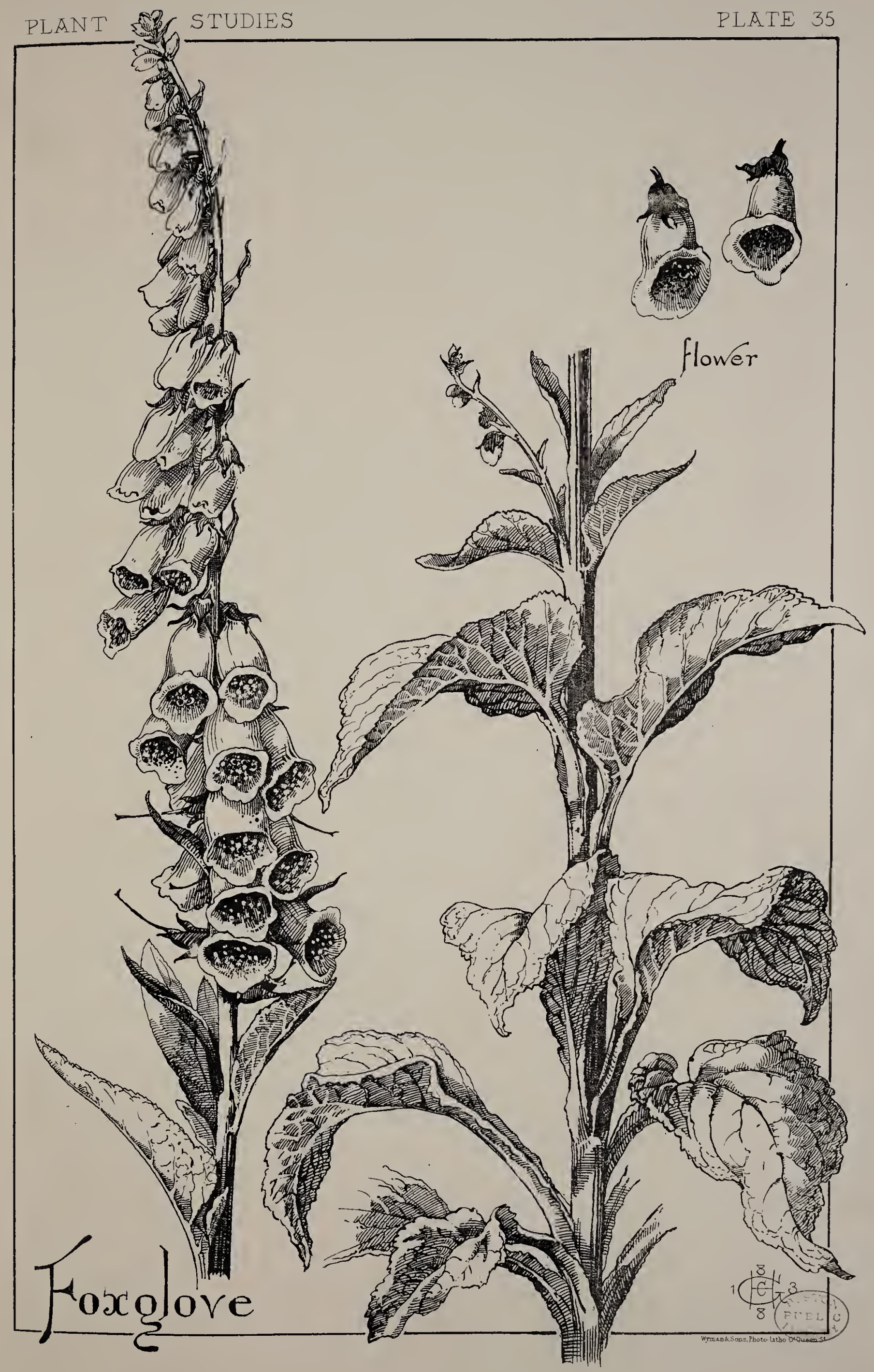



which are less frequent, or less conspicuous, on the outer surfaces. The buds are generally lighter in colour, some being of quite a pale buff (Fig. 9).

The blossoms, while apparently in full bloom, have a habit of falling off one by one, commencing at the lowest, gradually ascending to the highest. Owing to this characteristic, the flower column usually presents to view the seed-capsules, fully-open blossoms, and terminating buds at one and the same time.

The Foxglove is so thoroughly an English plant of the wood and roadside that it will always have a claim to the attention of the ornamentist. It can hardly be said to have suffered neglect, but, as a motif in decoration, it is doubtless often selected more for its associations than for its adaptability. However, in such upright positions as screens, panels, portières, or stainedglass windows, it may be judiciously used; and the plant being a favourite resting-place with the butterfly and the bumble-bee-who is generally to be seen busily exploring the deep recesses of its tube-shaped blossoms,- the introduction of these pretty insects would be characteristic of the Foxglove, and might be represented in connexion with it.

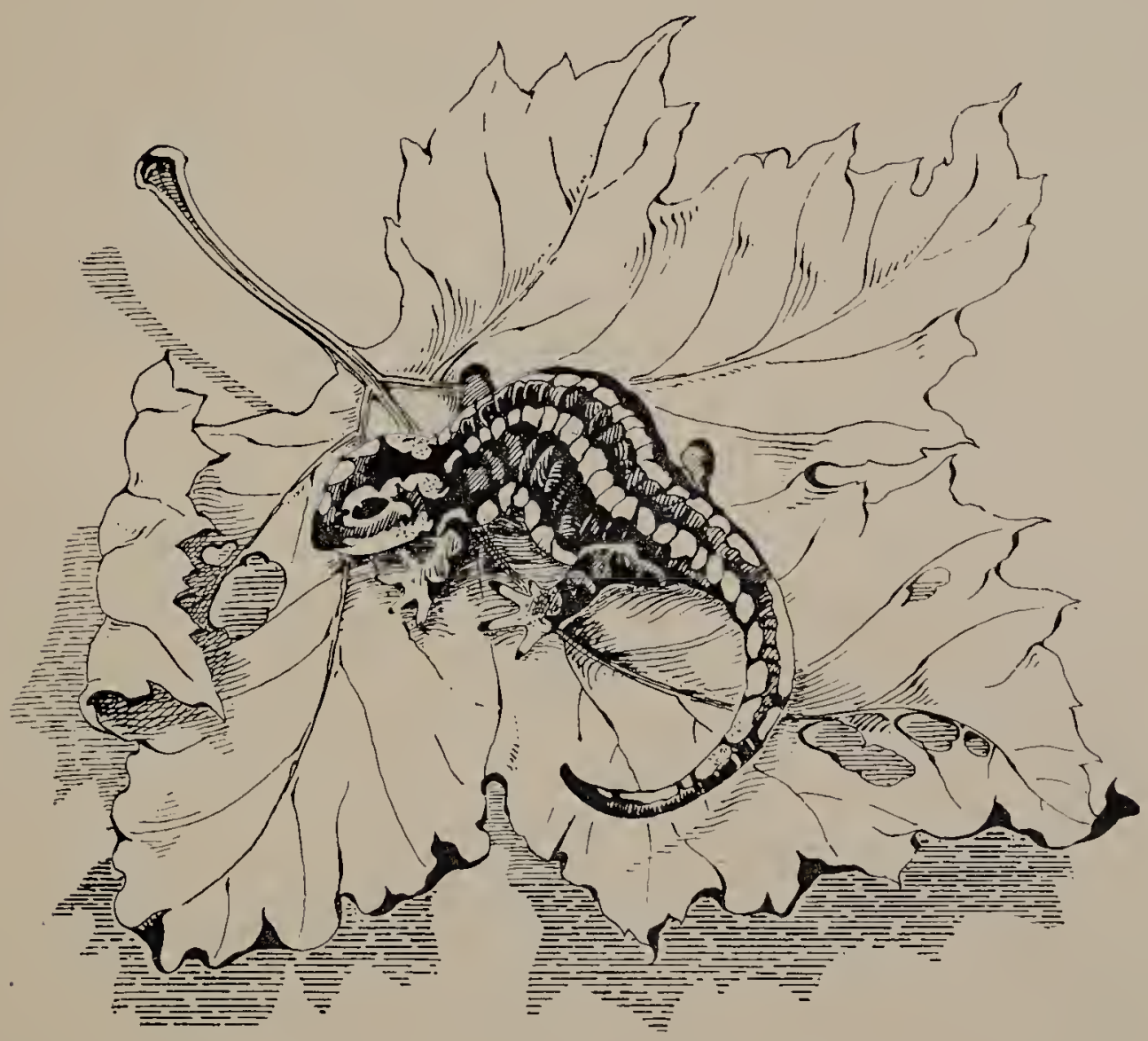



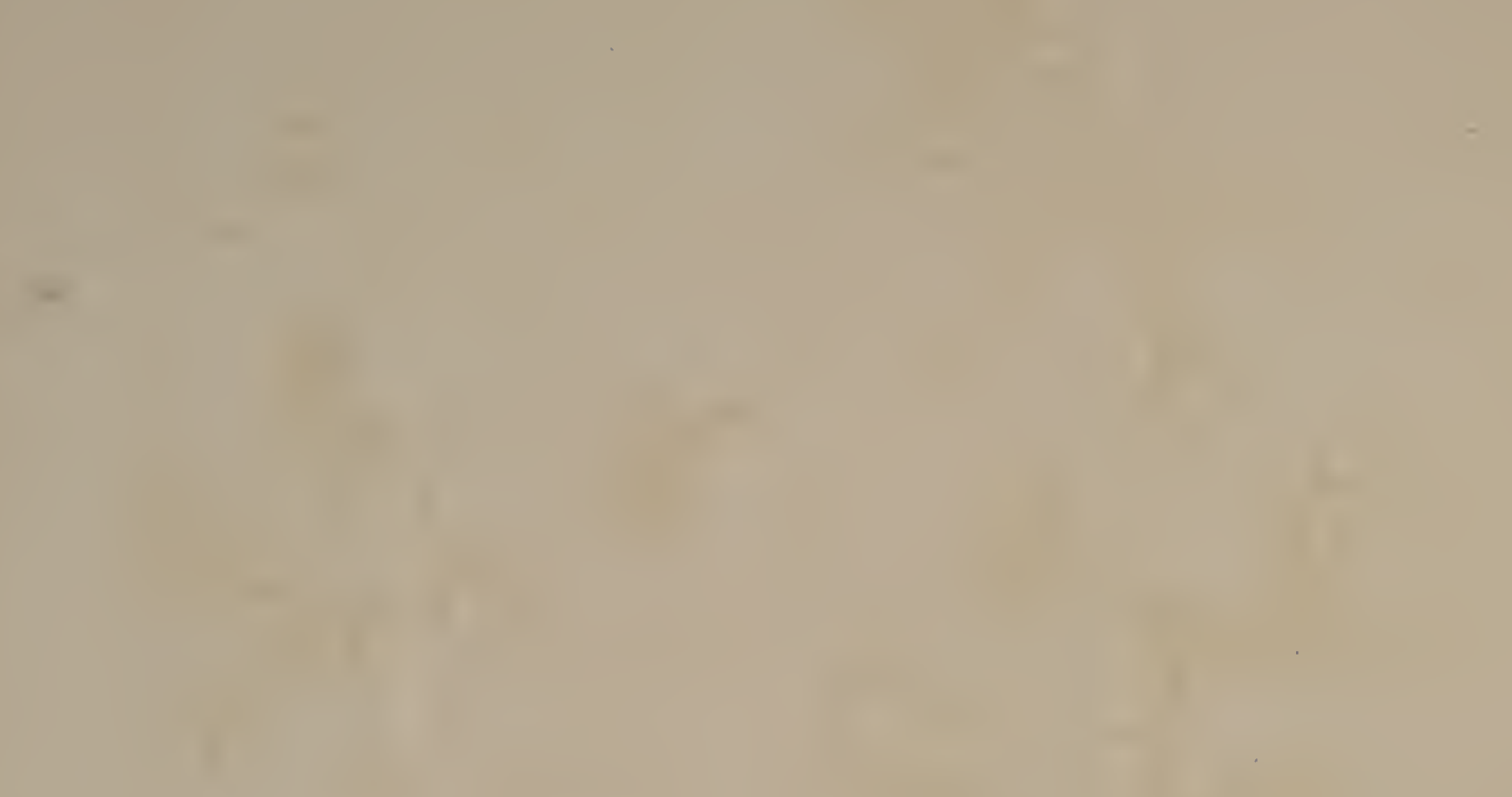

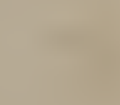
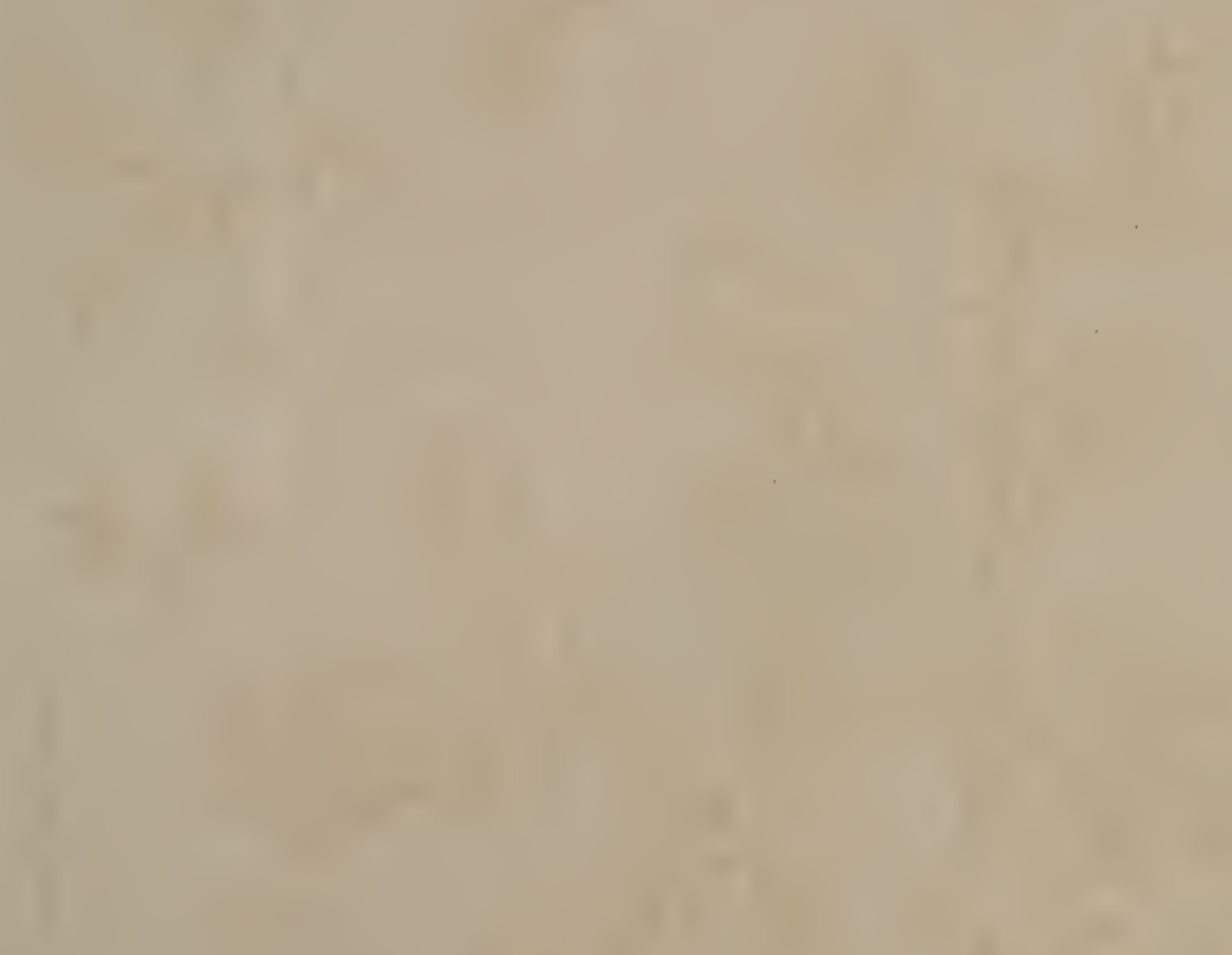

n

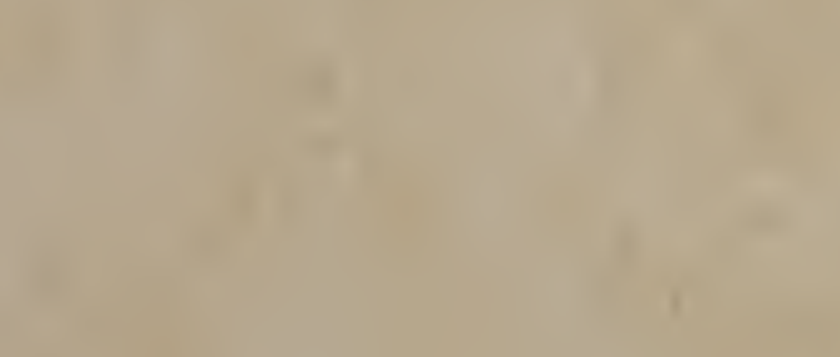

$x^{2}$

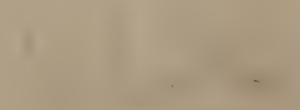



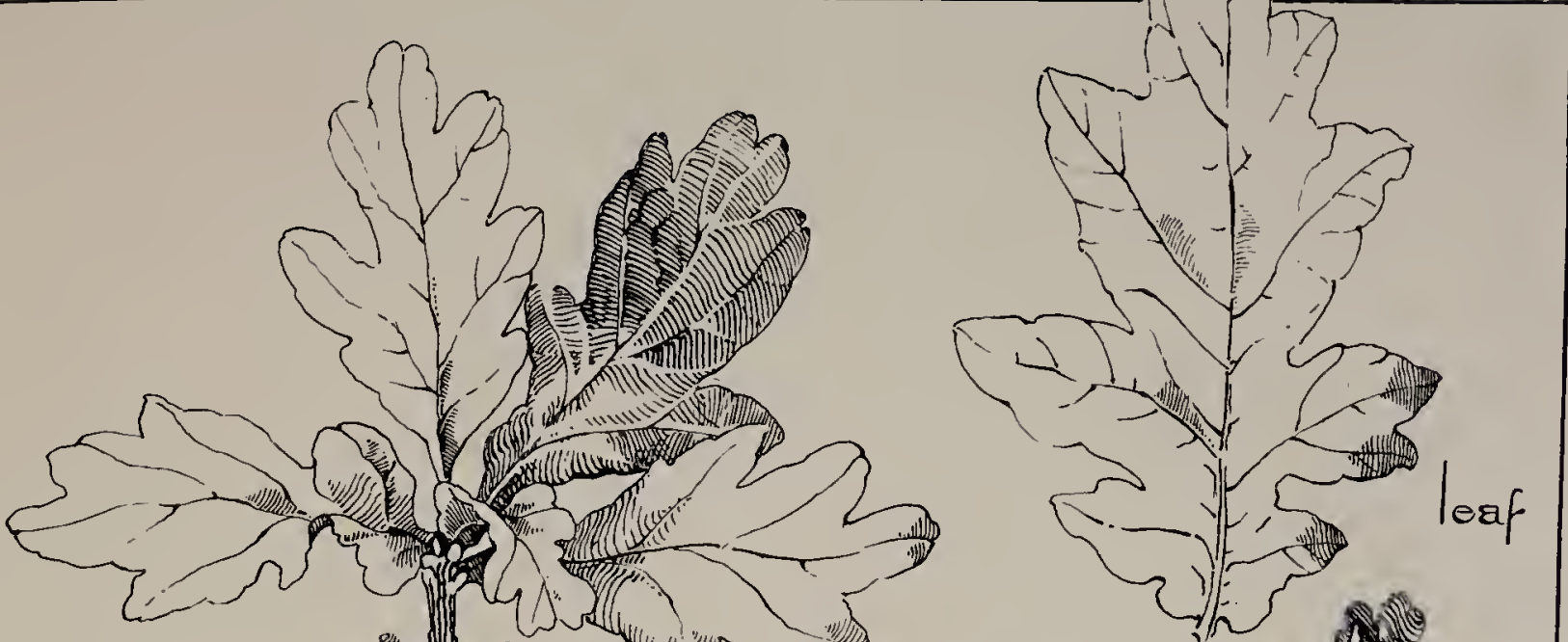

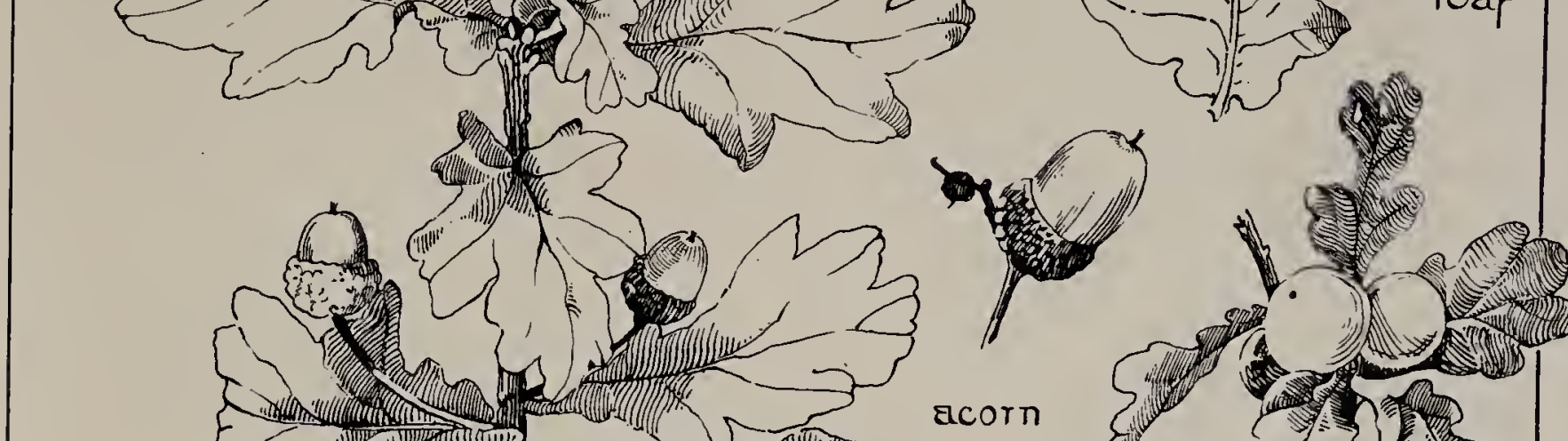

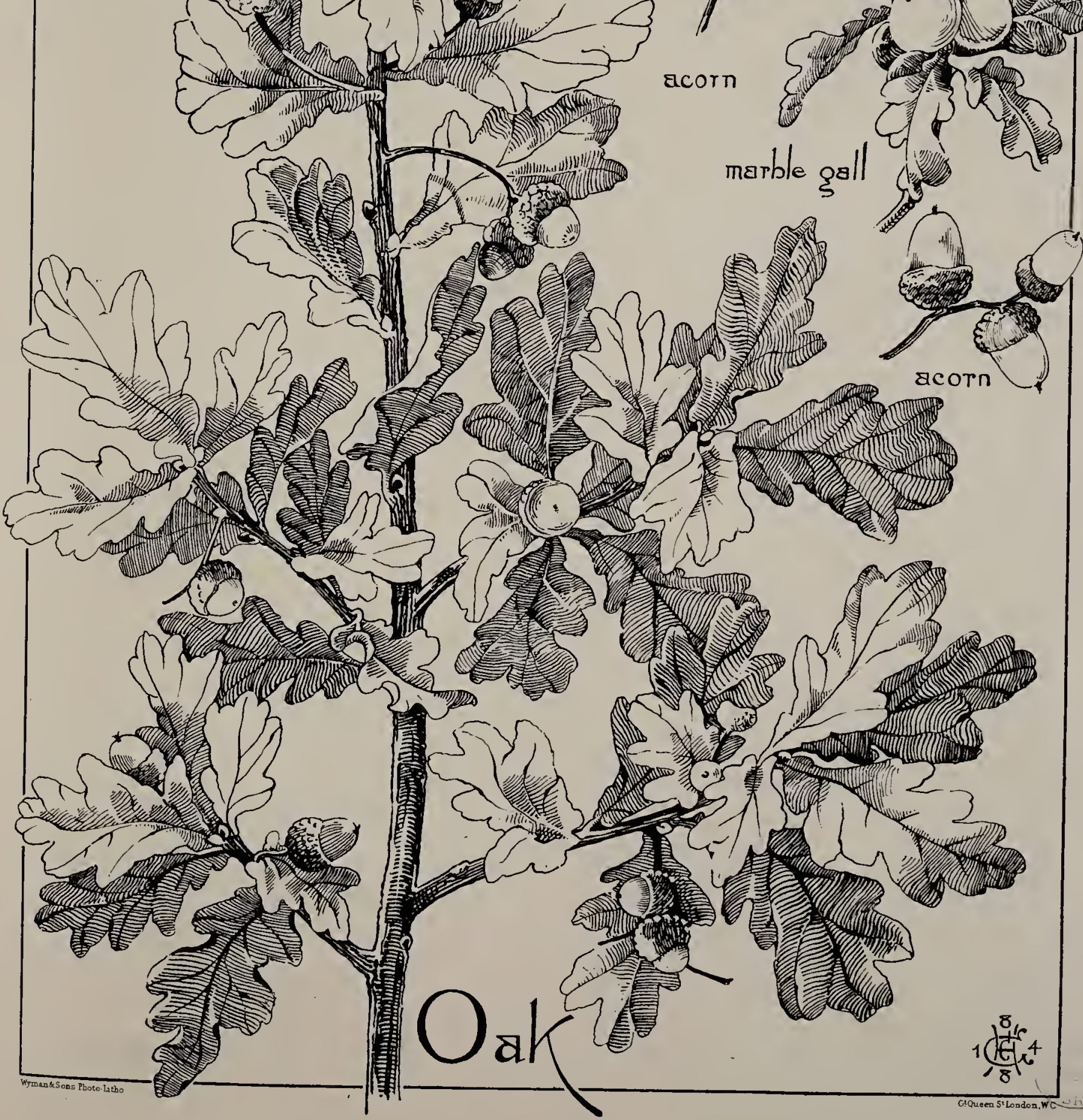





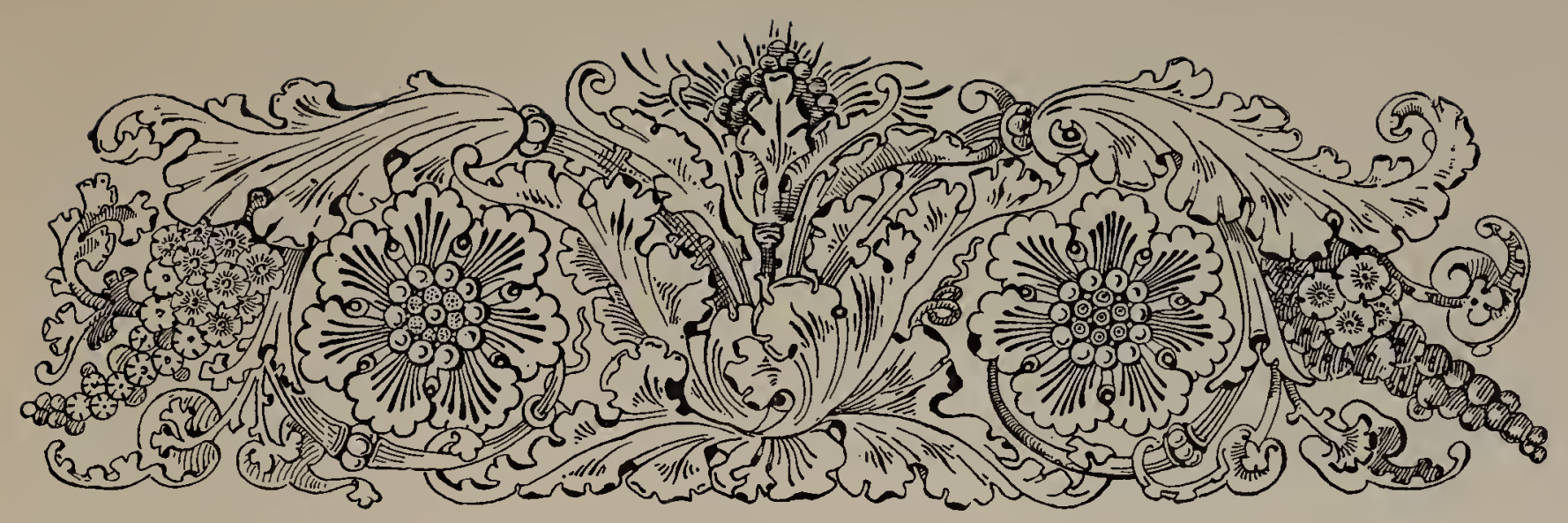

\section{Plate XXXVI.-THE OAK.}

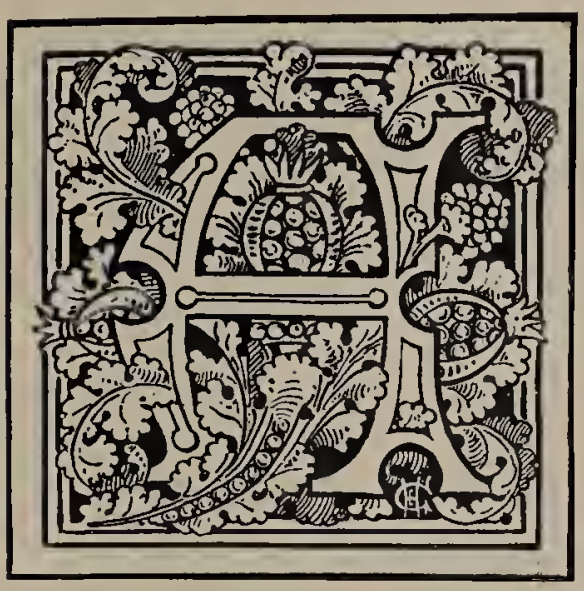

RIGHT royal tree is the sturdy Oak, and fittingly crowned the "Monarch of the Forest." It is pre-eminently a British tree, and is universally considered characteristic of our island, although it may be found in almost every part of the globe; -in some countries growing in tall, straight, and graceful forms, a striking contrast to the spreading and rugged branches we are so familiar with. Irrespective of its great beauty, it is one of the most valuable of trees. The numerous purposes for which its timber is employed must be well known, and there is, perhaps, no tree growing that has had so large a share in influencing the destiny of man. It would be difficult to say anything in praise of the Oak which has not already been well said; for all ages it has been alike an object of admiration and superstitious respect, and has borne an important part in many religious rites and ceremonies.

There are two distinct species of this tree indigenous to Britain: the variety selected for illustration is the Common Oak, which may be known by its long fruit-stalks and almost sessile leaves.
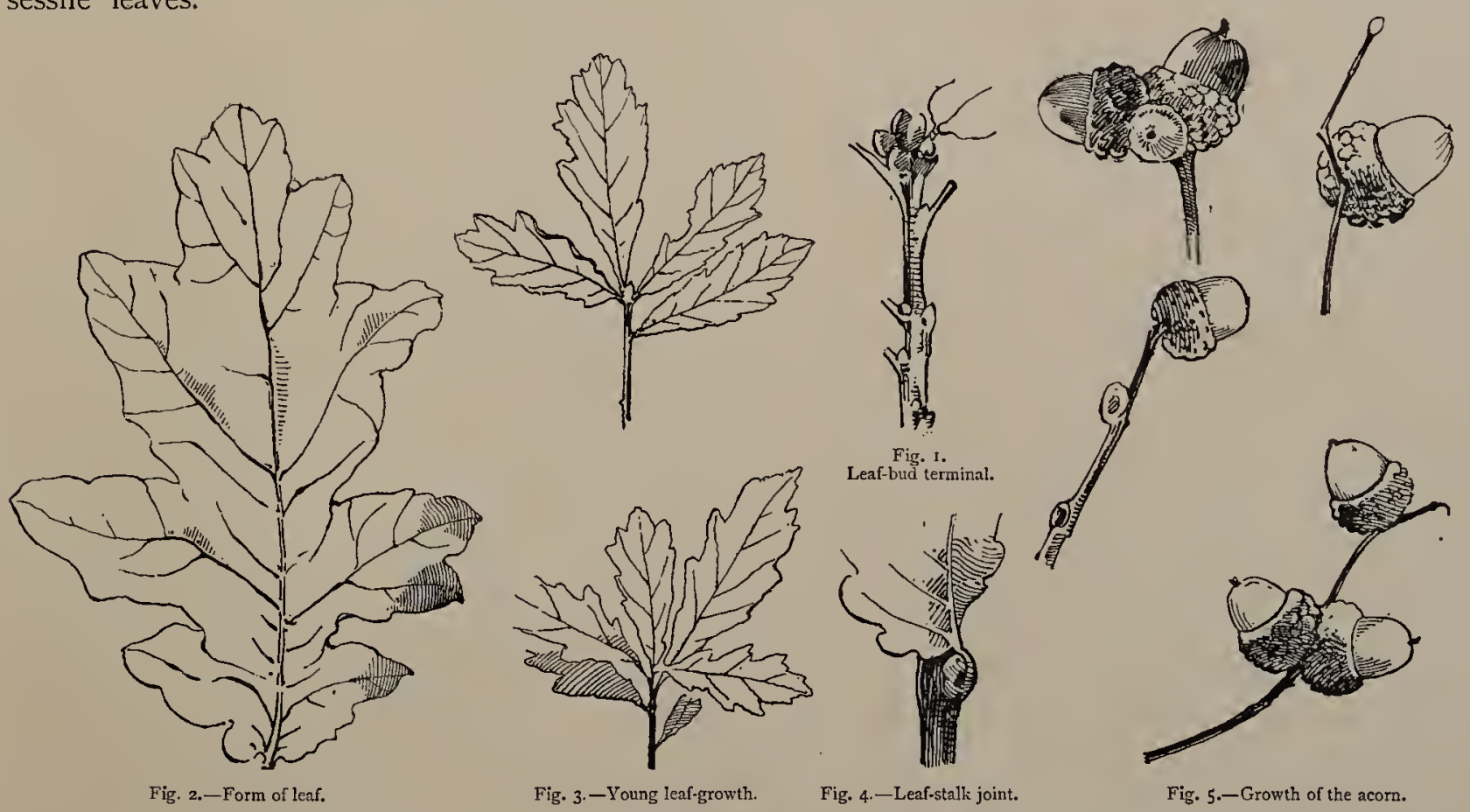

The wood of the Oak is ashy gray or brown in colour; is roughly barked and furrowed, and angular in its habit of growth. The young shoots are ribbed and of a bronzy green. The lateral shoots grow alternately round the branch, upon which the leaves grow singly, and more closely in a cluster round the terminal buds (Fig. I). 
The leaves are firmly attached to the stem by very short stalks; are centre-ribbed, and veined to the lobed edges (Fig. 2). They are oblong in form, widening towards the extremity, and grow to a goodly size; a fully-grown leaf may often be found to measure from six to eight inches in length. In the young leaves (Fig. 3) the edges are sharply toothed and deeply cut, but as they increase in size become more rounded at the edges, with obtuse lobes, commonly divided half-way down to the mid-rib. In the early growths the leaves are of rich citron-green hues, which gradually deepen and finally fade off into yellows and russet browns.

From the inside of the base of the leaf-stalk terminal buds, lateral shoots, or fruit-stalks spring; the buds (Fig. 4) are often tinged with crimson. The fruit-stalk is long and of a reddish-green; upon this acorns form, either singly or in couplets and triplets (Fig. 5).

The acorn or nut is smooth and oval in form, and is partly encased and firmly held in a rough scaly cupula. Both cupula and acorn are pale green, the latter ripening into golden brown, and during that period of growth, owing to the contraction of its surface (Fig. 6), very frequently falls, exposing the smooth cavity of the cupula (Fig. 7).

On examining the Oak, we cannot fail to notice the number of unnatural parasitical appendages to which it is subject. These peculiar growths, or galls, are caused by insects, and among the most conspicuous are those known as the Spangle, the Marble, the Currant, the Artichoke, and Oak-apple Galls.

The Spangle Gall (Fig. 8) is a small, greenish yellow, circular scale, slightly raised in the centre, and marked either with dots or a series of rings; these are to be found besprinkling the leaves, sometimes in great abundance.

The Marble Gall (Fig. 9) is, as its name implies, a round ball, varying in size, and may be found either solitary or in clusters attached to the terminal branches. They are green in their early stages of growth, and of a rich brown when dry, each having a little hole in its surface, punctured by the imprisoned insect in making its exit. This gall is probably the most familiar characteristic of the Oak, and is not unfrequently thought to be a fruit of the tree.

The Currant Gall (Fig. Io) is doubtless so called from its close resemblance to a bunch of currants. They are of a delicate green, semi-transparent, and often speckled with red.

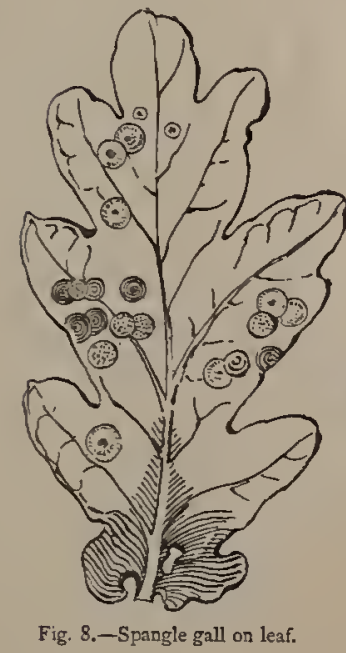

Fig. 8. - Spangle gall on lear.
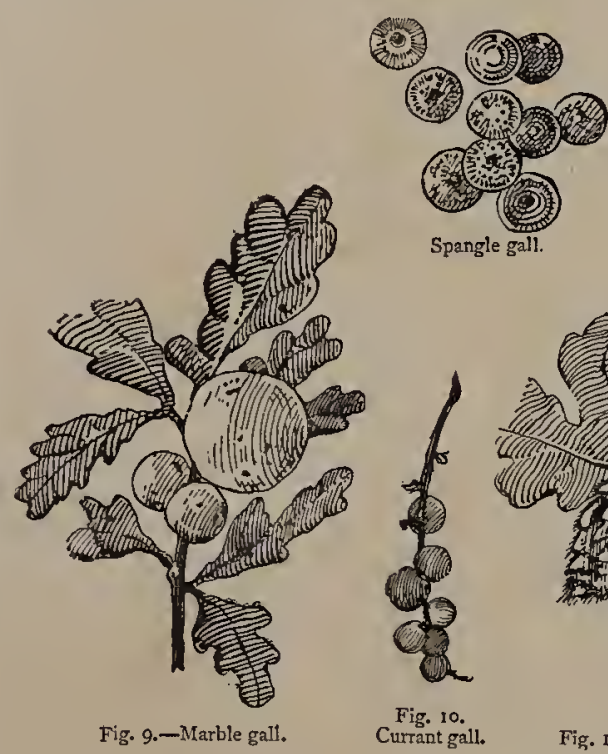

Spangle gall.
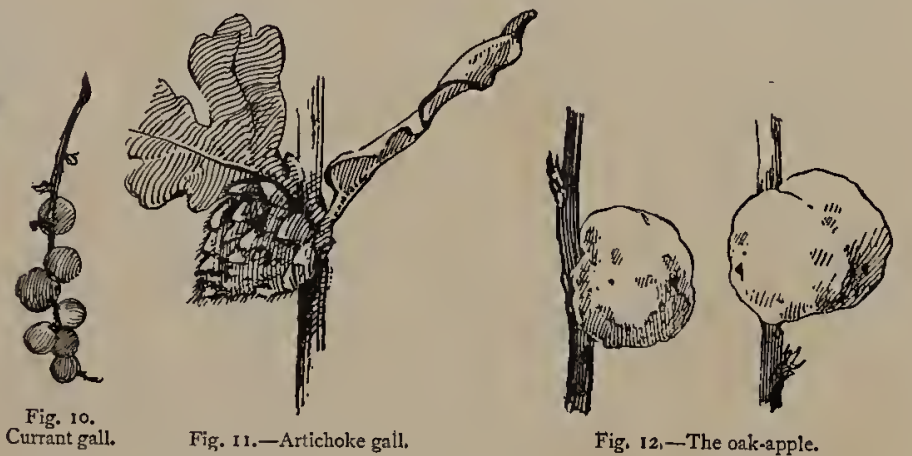

But perhaps the most beautiful of all these parasites, both in form and colour, is that known as the Artichoke Gall (Fig. II), which might as appropriately be called the Oak-cone. It greatly resembles the Fir-cone in shape, and is composed of a number of hairy-edged sheaths or scales of rich green, blending into reddish-brown shades. It is exceedingly common, sometimes all the buds on the branches of young Oak trees being transformed into these cones.

The Oak-apple (Fig. 12), which appears in conjunction with the young growth of the Oak, is undefined in form, of a soft leathery substance, and pale whitish-brown in colour, speckled and marked with deeper browns or brilliant crimson.

The foliage and fruit of the Oak have always been extensively used by the artist-so commonly, in fact, that the most casual observer cannot fail to recall numerous instances of their application in decorative work. It may, however, be worth while to point out to the ornamentist the great value of the galls as a means of investing the Oak-growths with new characteristics and greater interest. The Spangle Gall could be used as a diaper upon the leaves; and much might be made out of the Artichoke Gall, especially if more decided colours than the greens of the foliage were required. In the early periods of the Oak's growth, the Oak-apples offer opportunities for pleasing variations in representation, while the Marble and Currant Galls, in conjunction with the Acorn, might be satisfactorily adapted. 


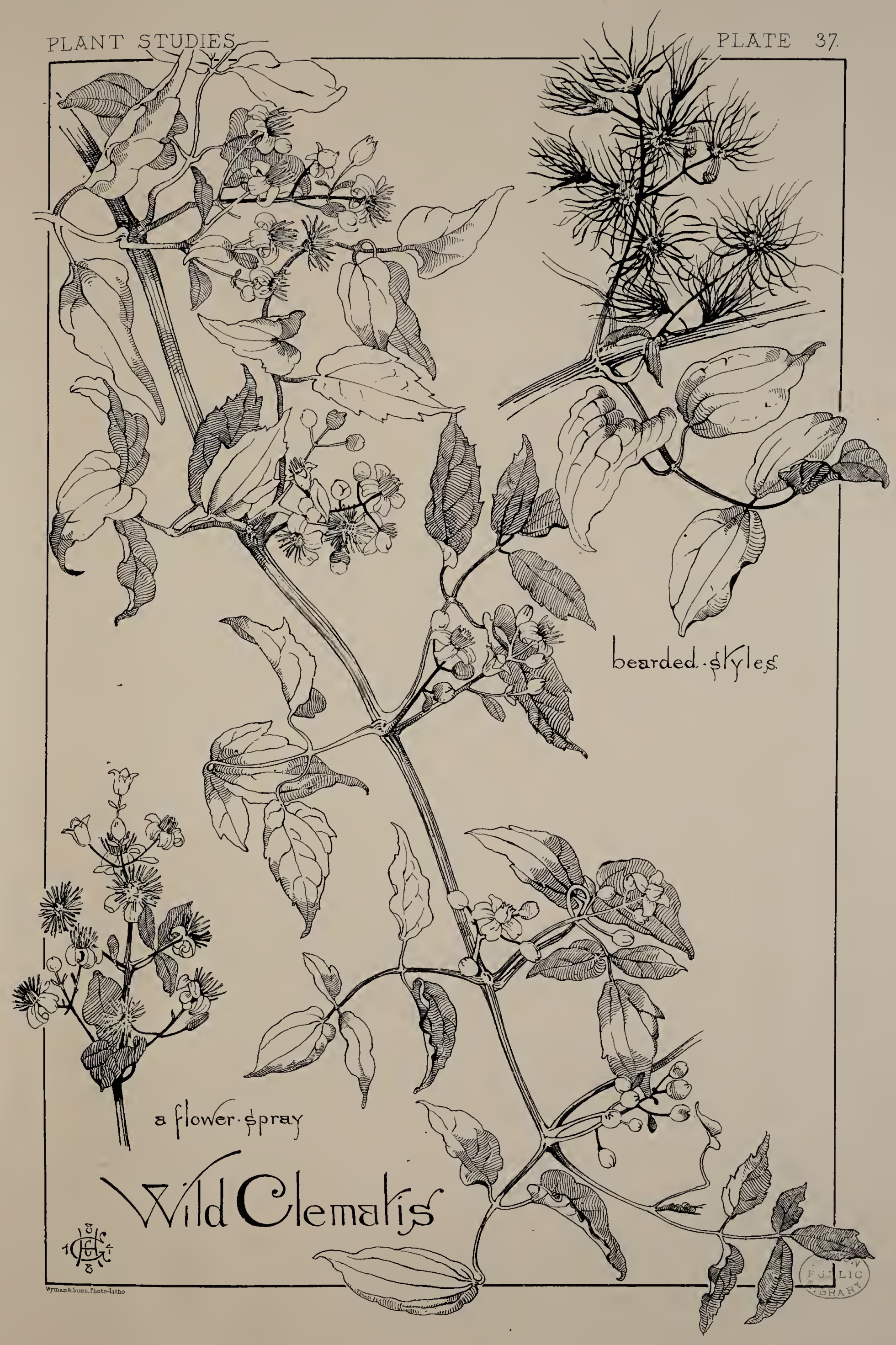





\section{Plate XXXVII.-THE WILD CLEMATIS.}

I N Wales and the south of England the Wild Clematis grows in such profusion as to form quite a feature of the country, and is one of the most beautiful of the hedge-growths. It is a persistent climber, often mounting to the tops of hedges, rocks, and high trees, and falling down in such profusion of leaves and star-like flowers as to completely hide its support, forming the most delightful shade, made more refreshing still by the sweet odour of its blossoms. These pleasing characteristics gave rise to one of the many names by which the Clematis is known, "Virgin's Bower"; this however, has never been so closely associated with the plant as that of "Traveller's Joy," or the even more familiar "Old Man's Beard," a title suggested, without doubt, by the autumnal aspect of the plant. After a very brief summer life the flower sepals and stamens fall, and the numerous styles increase in length, becoming silvery and shimmering in hue, making the Clematis in its seed period even more lovely than in its earlier stages of growth, and appearing to greater advantage by contrast when mingling with the ripening fruit of the blackberry, the nut and its foliage of downy green, the brilliant wax-like berries of the bryony, and the chequered berry clusters of the guelder rose and dog-wood.

Although a climber, the Clematis has no tendrils, but clings by means of its tough, yet pliant, twigs and stems. The branches, however, attach themselves to surrounding objects by a kind of curling clasped cirri (Fig. I), which are never found upon the young shoots, being, in fact, the permanent stalks of fallen leaves. The stem is woody and twisted in appearance, having lateral branches springing from every joint, thus giving the thick, bushy appearance to the plant which it would otherwise lack, as the leaves grow at some distance apart. These are attached to long stalks in threes and fives on either side of the stem (Fig: 2), and have three or five principal veins. The edges of the leaves are usually coarsely serrated and even lobed (Figs. 3 and 4), but are occasionally to be found entire (Fig. 5); indeed, a considerable deviation in the leaf-form is to be observed upon one plant.

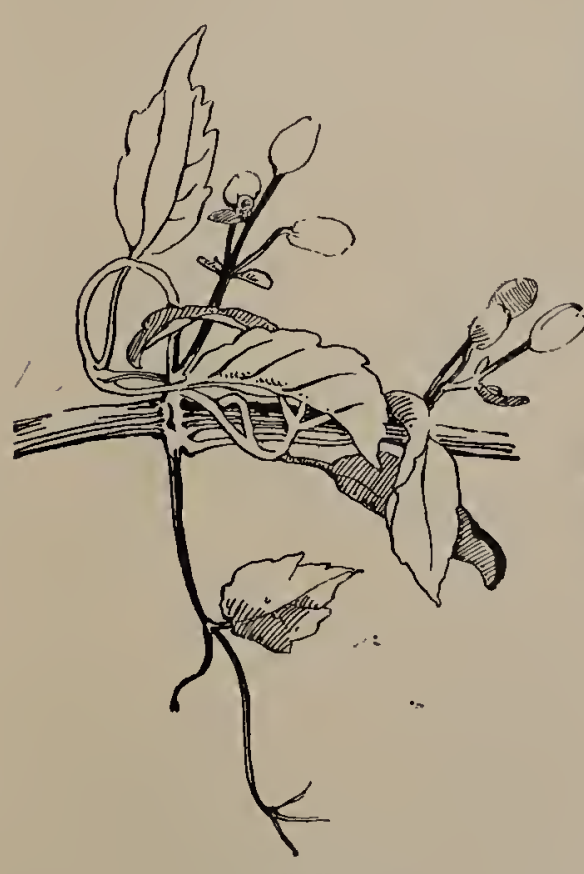

Fig. 1.-Twisted petioles.

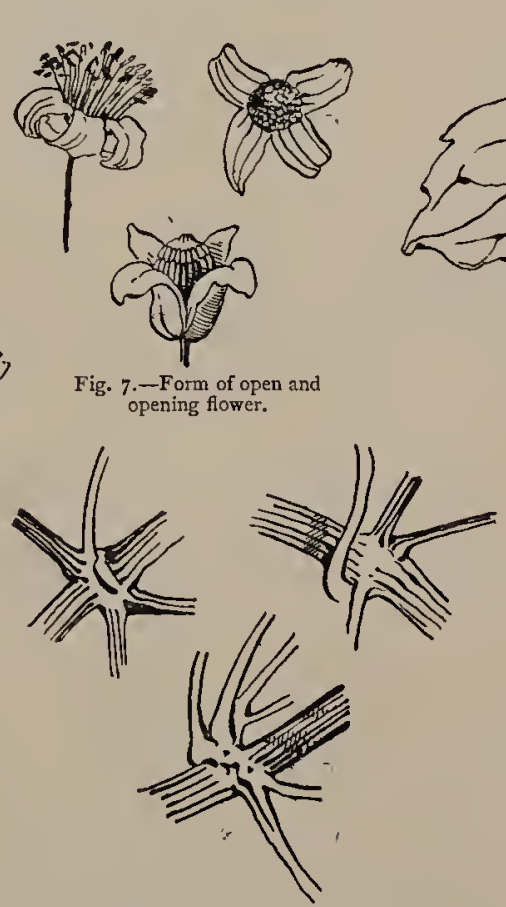

Fig. 2.-Flower and leaf-stalk growths.

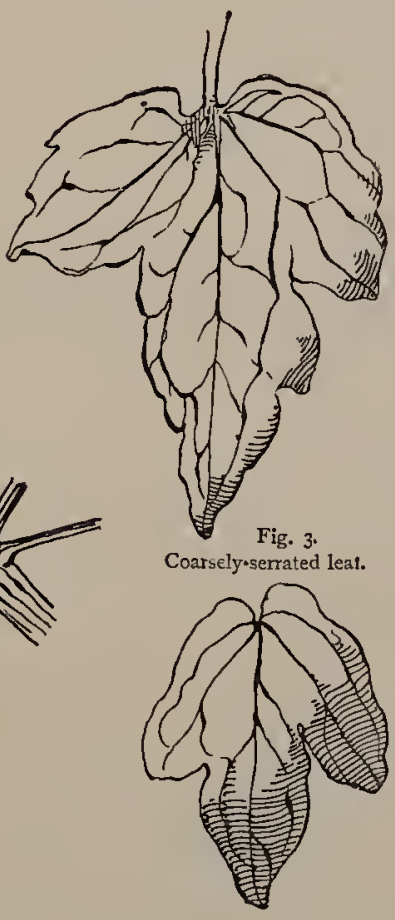

Fig. 4.-Lobed.

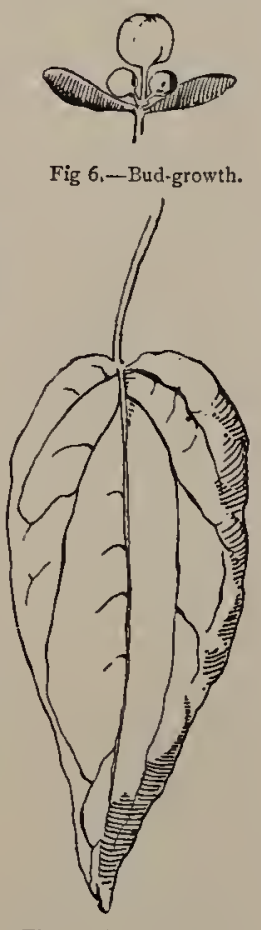

Fig. 5.-Leaf entire

The leaves on the old branches and woody part of the stem are long and oval in shape, irregularly toothed, and somewhat resembling the leaf of the pear-tree. Those on the young shoots are usually ternate; they have a smooth and shining surface, and in their early growth are bright fresh green in colour, which becomes more sober as the season advances.

The buds (Fig. 6) are round in form, and pale greenish-white in colour, having no petals, although the sepals when opened much resemble them. At the base of the bud-stem small leaflets grow in pairs, slightly increasing in size as the bud develops. The flowers grow in loose panicles at the ends of short axillary or terminal branches on long upright stalks, which spring from beside the leaf-stalks on either side of the stem. They are each composed 
of four thick opaque-white sepals (though departures from this rule occur, and five, six, or even eight are to be seen), which are lined from tip to base, and surround numerous stamens (Fig. 7), from the centre of which springs a cluster of closely-packed persistent styles, that finally expand into long feathery awns, and give the flower its bearded appearance.

The Clematis has not been used as a motif in decoration so freely as its suggestive growth and beauties would appear to recommend. The flower in its early stages, when the styles and stamen are unexpanded (Fig. 7), is particularly decorative and capable of conventionalism.

The neglect may probably arise from the fact that the plant is somewhat difficult to adapt, for the single spray might appear weak and weedy unless treated in a vigorous and masterly manner. Still, on a careful study of the Clematis, the very difficulties it at first presents will be found in the end to assist and suggest the solution of the problem of adaptation; for, as its successful treatment might in a measure depend upon its association with other plants, it would surely not be difficult to make a choice from so large and varied a selection of growths round which it may commonly be found entwined.

\section{Plate XXXVIII.-THE ALMOND.}

$\mathrm{I}$ $S$ it possible for mind to conceive or brush of painter to create a more delicately beautiful object than a spray of almond blossom? Fragile though it appears to be, it is almost the first blossom to brave the biting winds and late frosts of winter, and the peculiar habit of the tree in putting forth blossoms whilst its twigs are yet bare of leaves, makes it a conspicuous object and pleasing omen of Nature about to awaken from her lethargic sleep. It is by no means an uncommon sight, even when the snow is lying thickly on the ground, to see the branches of the Almond tree profusely decked with the most delicate pink and white shell-like flowers. In Arabia and the south of Europe, enormous orchards of this tree are in cultivation for the sake of its fruit, but in England it is grown for its ornamental appearance, as the fruit rarely matures. Under favourable circumstances, the Almond attains to all the dignity of a tree, often growing to the height of twenty to thirty feet. Its branch growth is somewhat angular and straight, the
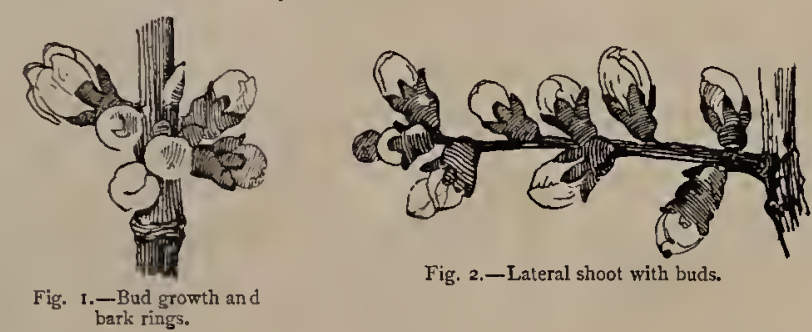

Fig, 2.-Lateral shoot with buds.

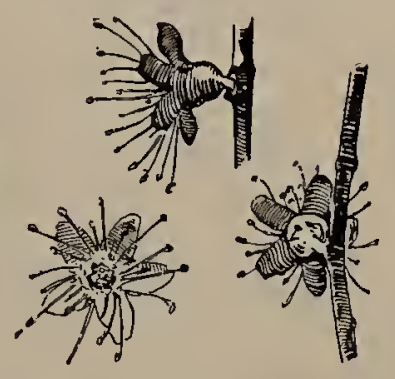

Fig. 4.-Front, back, and profile view of calyx.

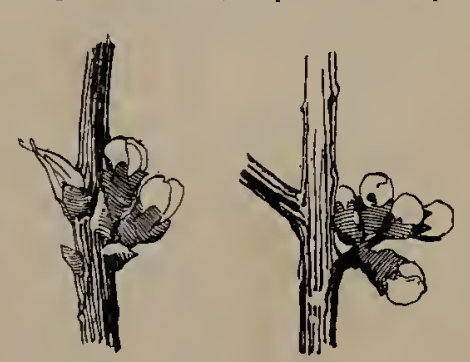

Bud growths.

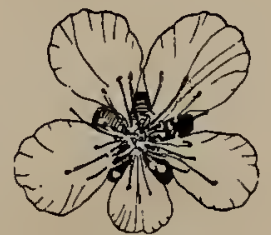

Fig. 5 . Front view of flower.
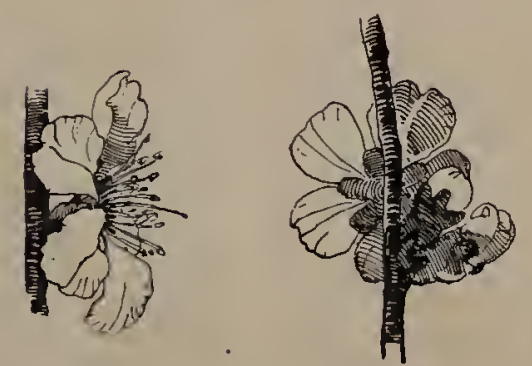

Profile of Elower on stem, Back view of flower on stem.
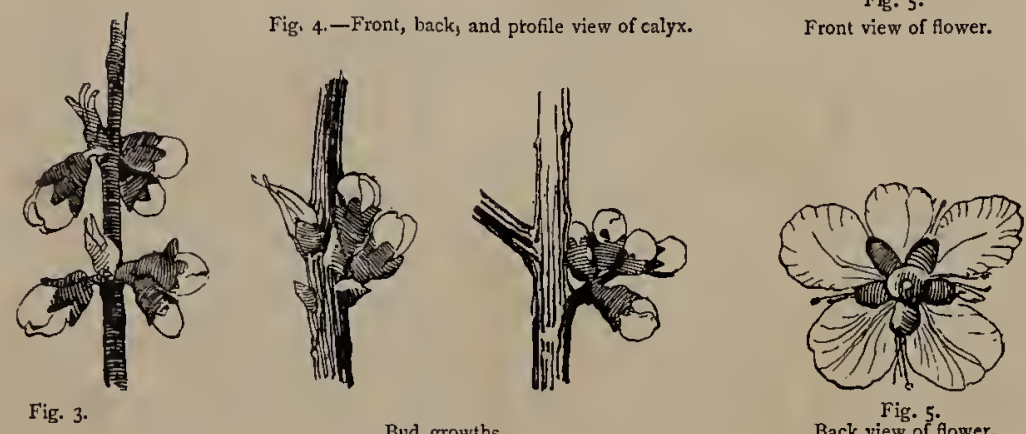

Fig. 5 .
Back view of Hower.

young shoots being green, and at their junction with the darker wood of the preceding year are encircled with rings of brown (Fig. I).

The buds appear long before the leaves expand (Fig. 2), although a succession of later buds and flowers mature when the foliage is fairly well developed, but the true characteristics of the tree are seen when the bare branches are laden with the fragile and unprotected blossoms. The young opening buds are of the most brilliant pink and red hues, and present a very striking contrast to the more delicate colours of the open blossoms; they grow on very short pedicels-in fact, may almost be called sessile-and cluster close to the stem (Fig. 3). The flower is supported upon 


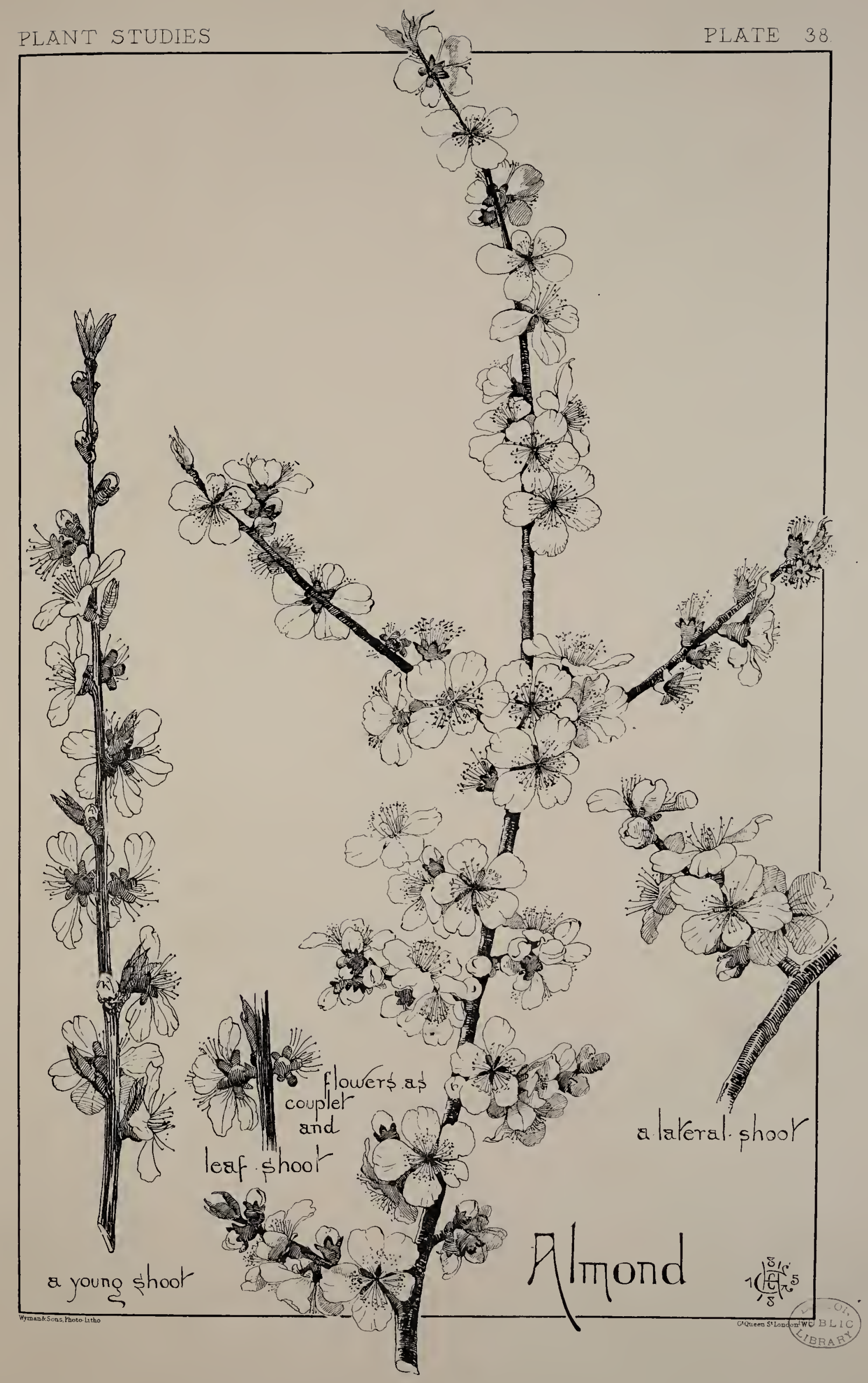





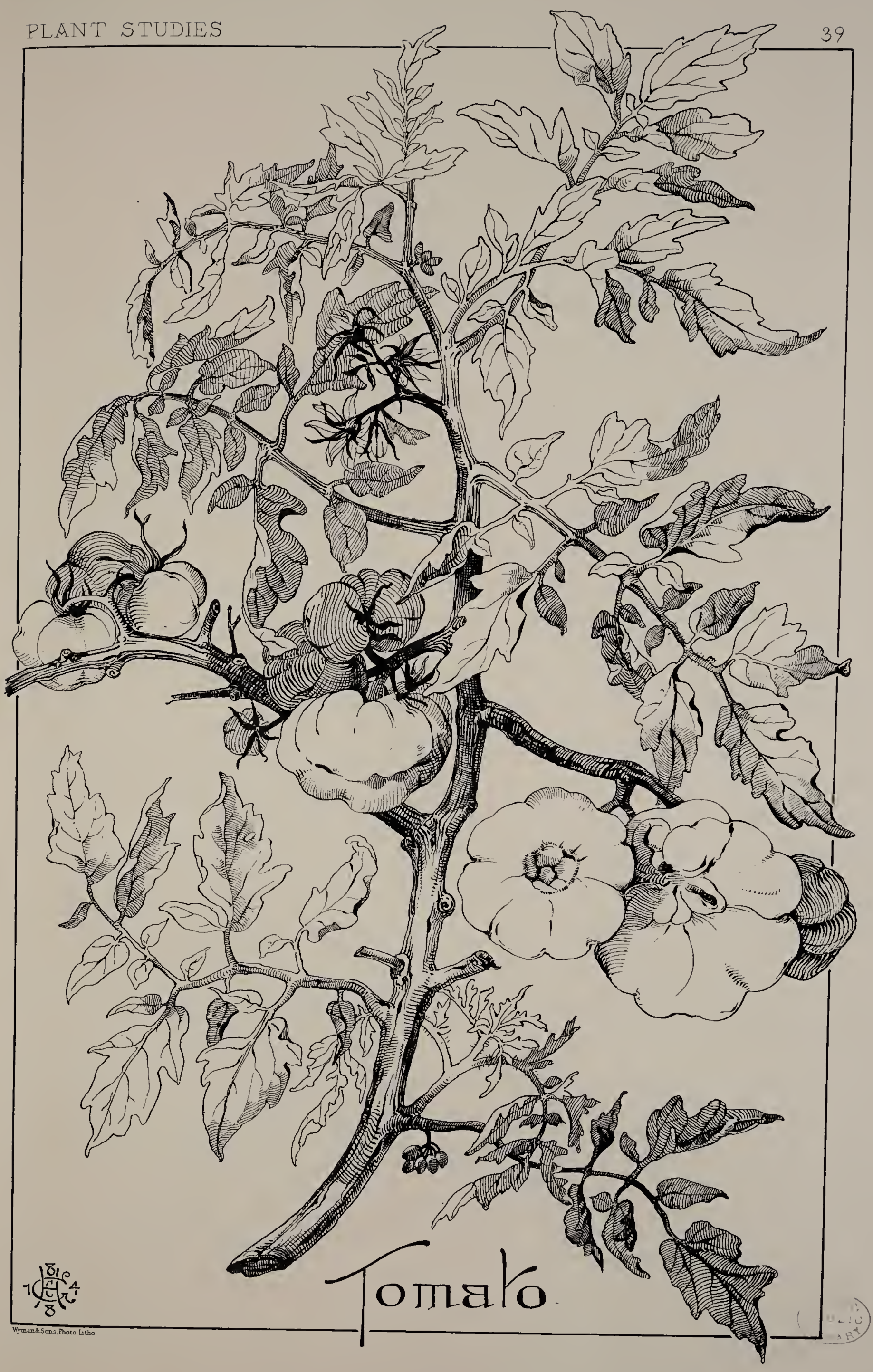



a five-pointed calyx (Fig. 4), and is composed of five petals, varying in size, three being large, one medium size, and the other small (Fig. 5); this inequality gives the flower rather an oblong shape. Fig. 6 gives an example of a flower in which the disproportion of petals is strikingly apparent; they are all slightly cleft and crinkled at their edges, and are of the most delicate pink imaginable, but as they expand, gradually lose their colour and become pale pink or almost white. From the centre of the flower springs an indefinite number of orange-tipped stamens, which are arranged in a circle within the calyx, and from their midst the fruit is developed, and as it grows assumes the form of two pendulous ovules. The flowers rise from their scaly buds either singly or in couplets, and cluster alternately round the stems of the lateral shoots or young wood terminal. After the petals have fallen, the calyx and dried stamens remain (Fig. 7), presenting a very pleasing contrast to the other branches still covered with the opening flowers.

From the axil of the flower-buds with the stem, the foliage springs in a radiating cluster of oval-shaped, finely serrated leaves, which form either a lateral shoot or terminal (Fig. 8); but ere they reach their full development the blossoms have faded and fallen. There are

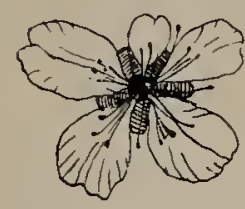

Fig. 6. - Flower showing

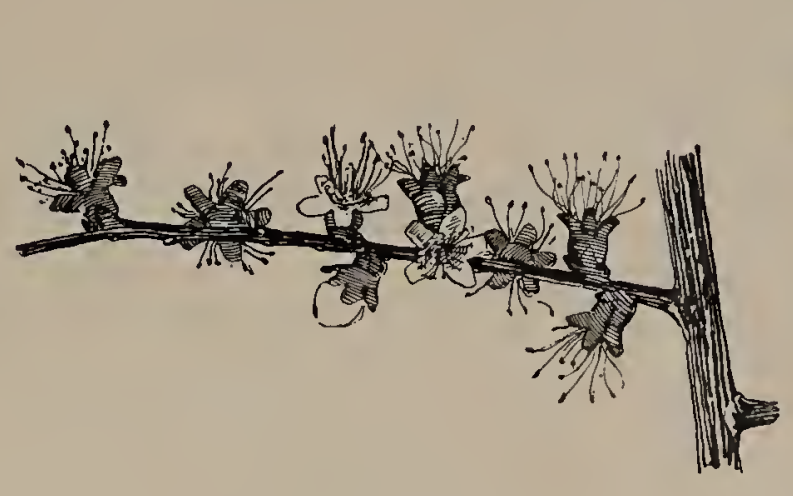

Calyx and stamen remaining on lateral shoot.

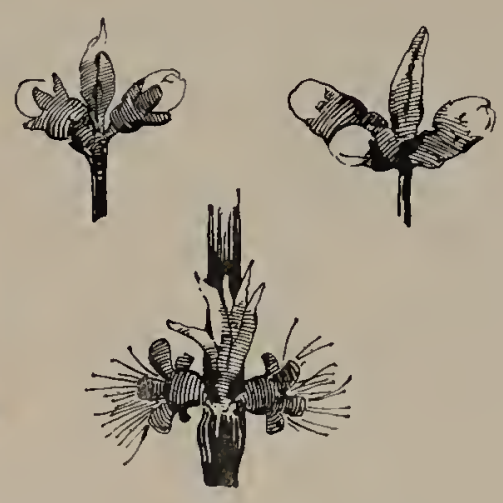

Fig. 8 .
Leaf-shoot growths, as terminal or lateral growths.

numerous varieties of this beautiful tree, including a pink, deep red, and double-flowered species. It would be difficult to suggest, as an incentive to decoration, a plant more lovely than the Almond. Its method of growth, form, and general characteristics allow of a ready and satisfactory conventionalism, and under such treatment the Almond is suitable for the embellishment of a great variety of materials. For panels and all the endless geometrical forms it may be readily applied, as it can be made vigorous and strong even to severity, or light and elegant as a treatment more suited to such purposes as fan decoration, china painting or fancy work; but, to realise the results possible from skilful adaptation of the Almond, we cannot do better than examine the best Japanese work in lacquer, bronze, carving, and printing.

\section{Plate XXIX.-THE TOMATO.}

$\mathrm{T}$

HE Tomato or "Love-Apple," with its abundance of brilliantly-coloured fruit, is one of the most ornamental of the plants relegated to our kitchen gardens. It is naturally of such vigorous habit, or rank in growth, that it becomes necessary to mutilate the plant by continual cutting, to prevent it making all wood and producing small and insignificant fruit. From this cause it is difficult to procure a study at once natural in growth and with finely-developed fruit. The peculiarities in the leaf and fruit forms of the Tomato are so marked as to render the plant almost grotesque in appearance, but it, nevertheless, possesses varied and striking beauties, and is surpassingly rich in colour.

It attains to a considerable height, is much branched, and has a deeply-scored juicy stem, from which lateral shoots, leaf, and fruit-stalks spring, without any apparent order of growth (Fig. I). On either side of the leaf-stalk spring unequally pinnate leaflets-differing greatly in shape-with incised segments, a leaf forming the terminal (Fig. 2). The leaves are certainly more quaint than beautiful, and seem to form under individual caprice. 
The flowers grow in clusters on a stalk springing independently from the stem (Fig. 3). They are dull yellow in colour, with deeper yellow centres, and are supported upon a five-parted dark green calyx (Fig. 4), the regularity of which, like the leaf, is not to be depended upon, as three, five, six, or more divisions are often to be found. Two of the sepals of the calyx are generally cleft at the tips (Fig. 5). The flower petals also vary in number, as five, six, and even seven are not at all uncommon.

The fruit, which is the chief beauty and value of the plant, hangs in clusters (Fig. 6), varying greatly in form, colour, and number. In the early period of its growth it is rich green in colour, which changes through orange to the brilliant scarlets of the fully-ripe fruit. The form of the fruit may be described as round, but, owing to its many seed divisions, the surface is contracted, which forms a broken and crinkled outline and depression at the centre. There are varieties of the Tomato in which the fruit presents unbroken and rounded forms, but the
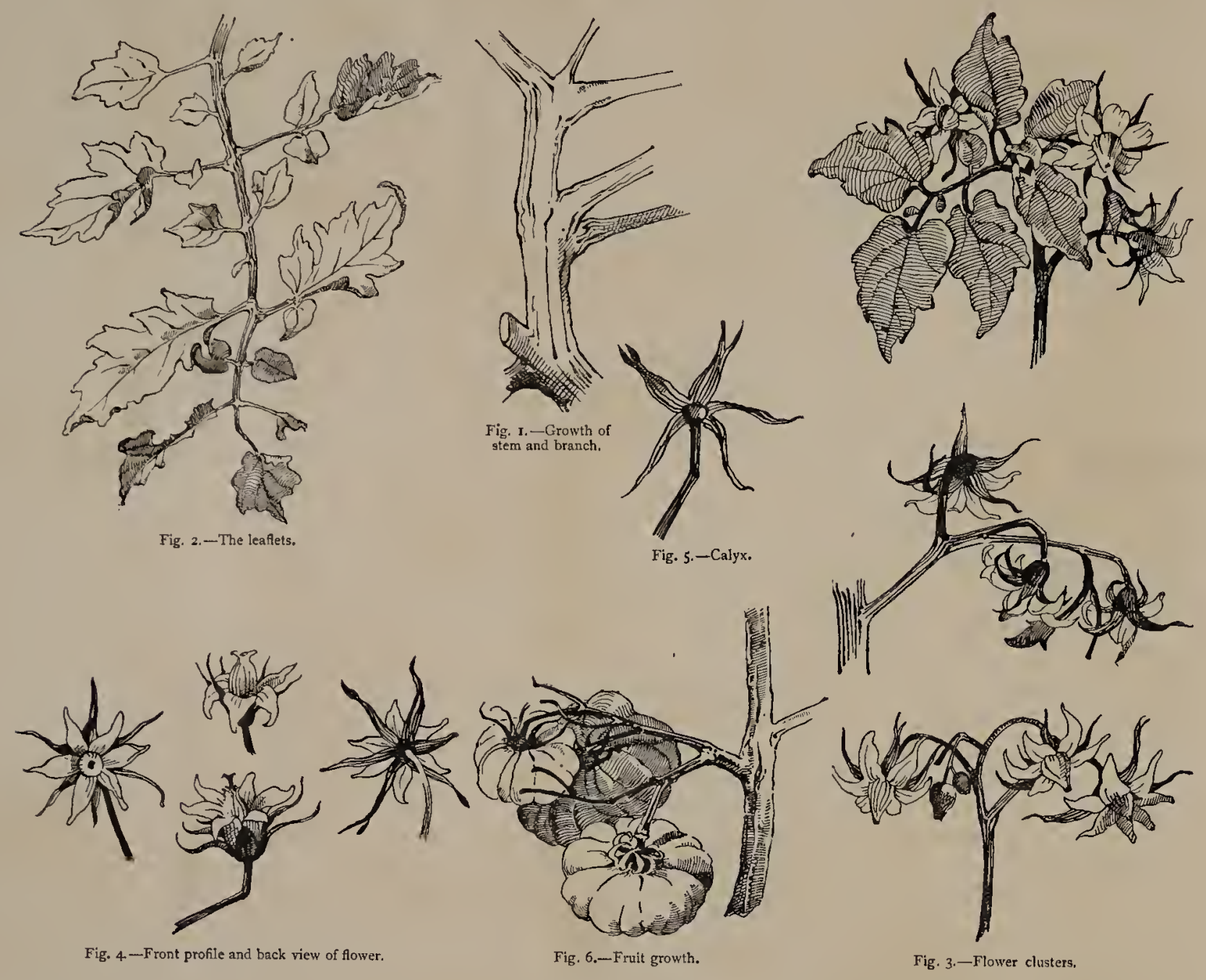

general aspect is not so quaint as that of the common kind, in which the shape of the fruit is so uncertain.

I cannot recall any application of the Tomato as a motif for ornamentation of any material, and it occurs to me that this is again an instance of undeserved neglect, arising, possibly, from the lack of attention to its growth and beauties. There are few plants that would give such ample return for selection and adaptation; its singularly unrestricted method of growth and apparent disdain of all regularity, affords the ornamentist opportunities of following his own inclination in its treatment, which would not be justifiable in adaptation of many other plant forms. 


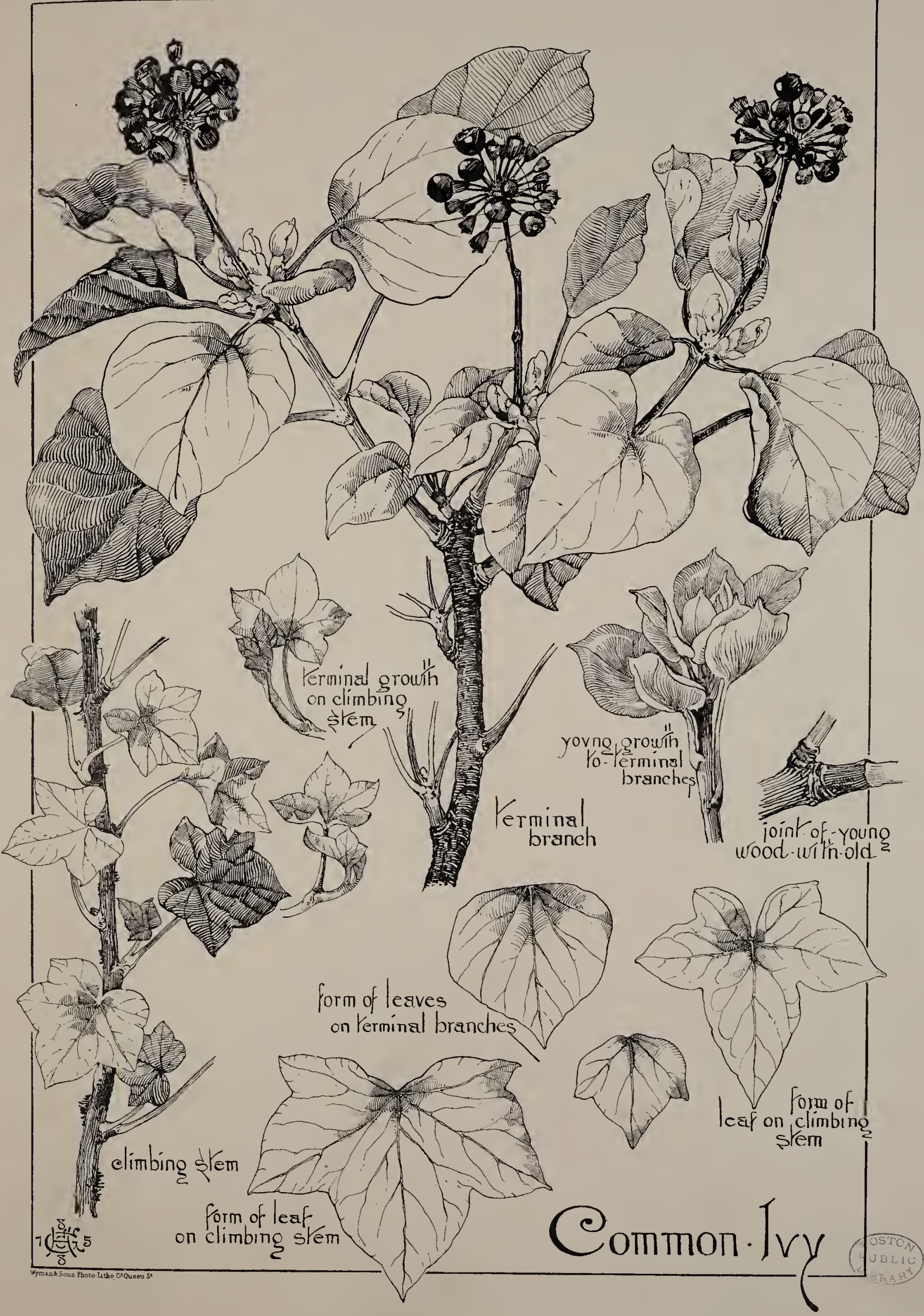





\section{Plate XL.-THE IVY.}

$\mathrm{M}$ ANY an interesting ruin of castle or abbey is strengthened and made beautiful by the graceful verdure of the clinging Ivy, and so commonly do we find it in such positions, that it has become inseparably associated with picturesque ruin and decay. Not only does it form a lustrous drapery to wall and tower, bridge or tottering roof, but over rocks and round the boles of many trees it creeps and twines. In all ages the Ivy has been honoured in scng and legend; there are, perhaps, more superstitions and legends based upon, or associated with it, than any other plant; and at one time there was a strong prejudice against its use in our church decorations, to which allusion may be found in some of the ancient carols.

The Ivy is an evergreen and long-lived, for many rugged trunks or stems that must have been the growth of centuries are frequently to be found. It is a persistent climber, but trails over the ground when there is no support available. In such condition the leaves are small, very deeply lobed, and veined with white, and the plant never flowers, proving its natural habit to be a climber. In all its most vigorous growths, the shoots will be found throwing upwards, and on reaching the limits of the support to which they have attached themselves, large bushy heads of foliage and flowers form. It is interesting to note that in these terminal growths (Fig. I), neither rooting fibres nor creeping stems are to be found, and the leaves change their characteristic forms, becoming oval or narrow in shape, completely losing their lobed edges.

The Ivy blossoms during the months of November and December, but the clusters of small yellowish flowers are too insignificant to be made useful unless individually enlarged.

The stem of the Ivy is stout and exceedingly tough; and the old wood is much gnarled and crooked. It adheres to its support by means of numerous radicular fibres (Fig. 2), which

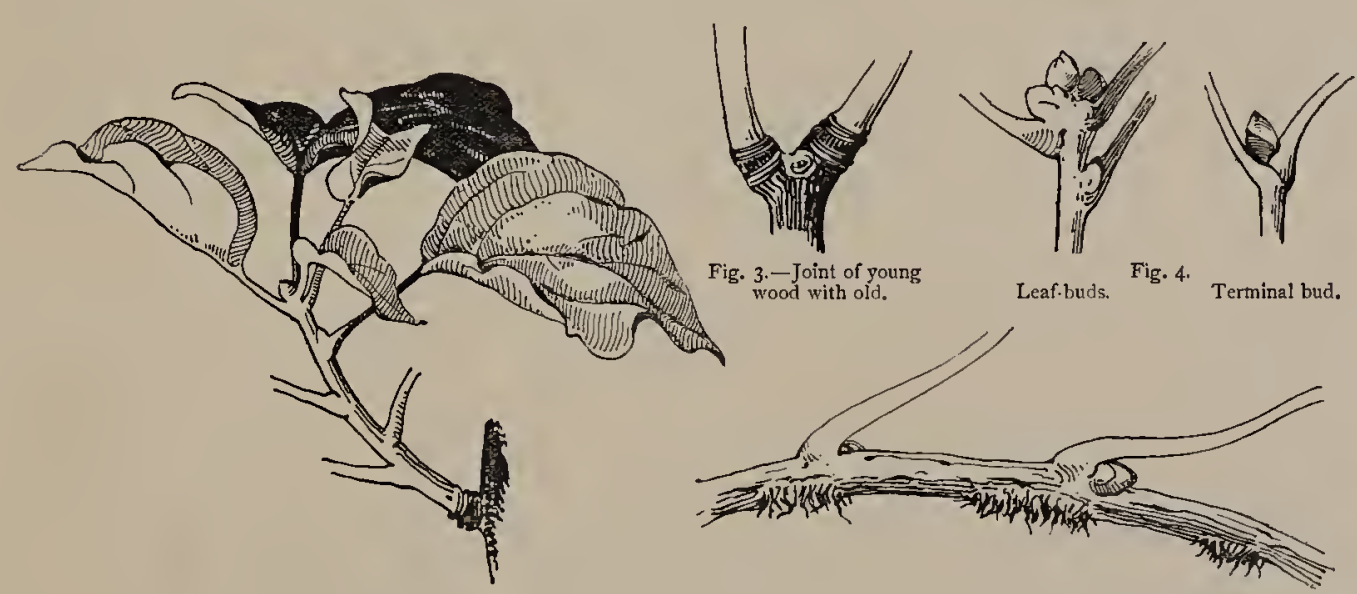

Fig. I. - Lateral shoot to terminal branch.

Fig. 2. - Stem with fibres,

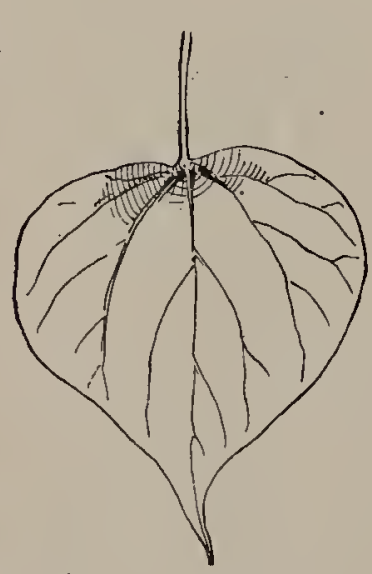

Fig. 6. - Form of terminal leaf.
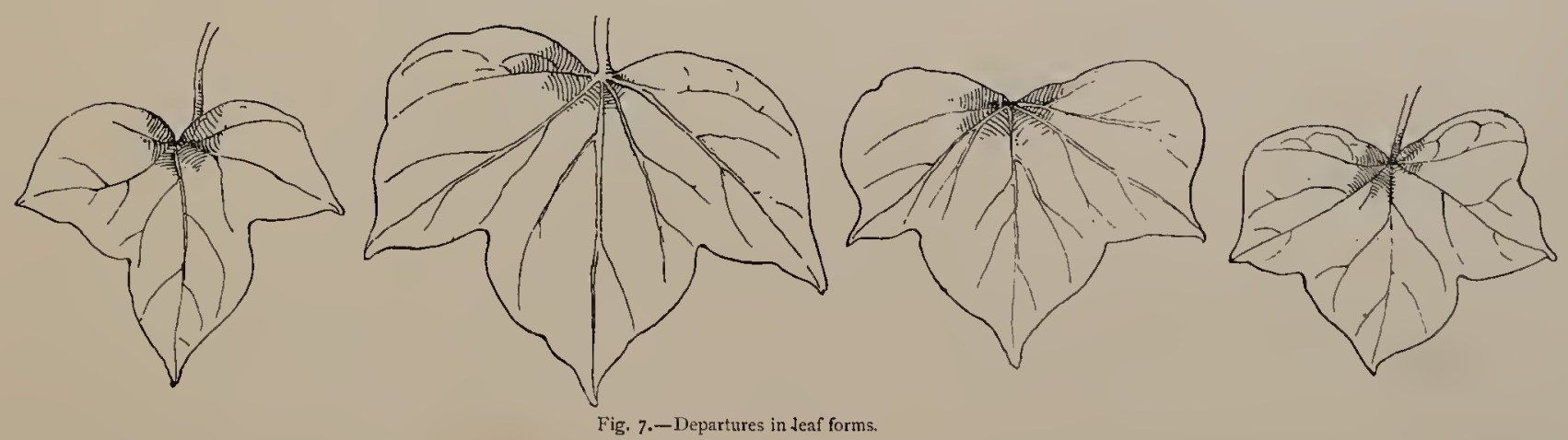

frequently embed themselves into the bark or wood of trees. The young shoots are bright green in colour, and are separated from the old wood by rings of bark (Fig. 3). The terminal of each lateral shoot or spray is formed by a leaf-bud, or flower-spray (Fig. 4).

The leaf of the Ivy is of a rich and lustrous green, exceedingly beautiful, but differs considerably in form. On the same plant may be found surprising variations, from the deeply lobed growths on the lower branches (Fig. 5), to the plain and ovate leaves of the terminal shoots (Fig. 6). Departures from these two characteristic forms are very frequent (Fig. 7). The 
veins are lighter in colour than the body of the leaf, and in the normal growths are either five or three. The leaves grow solitary and alternately round the stem (Fig. 8), which is scarred on the places whence the leaves have fallen (Fig. 9).

The berries of this beautiful plant ripen in the spring. They grow in bunches or clusters (Fig. IO), from a radiating centre, at the ends of rather long stalks, which are slightly

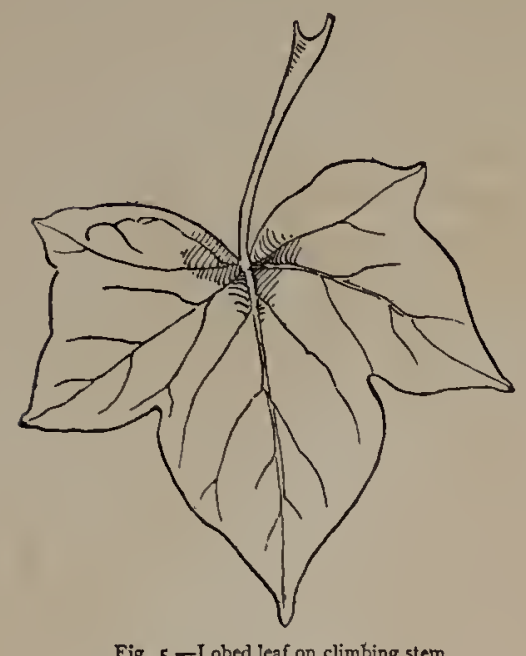

Fig. 5.-Lobed leaf on climbing stem.

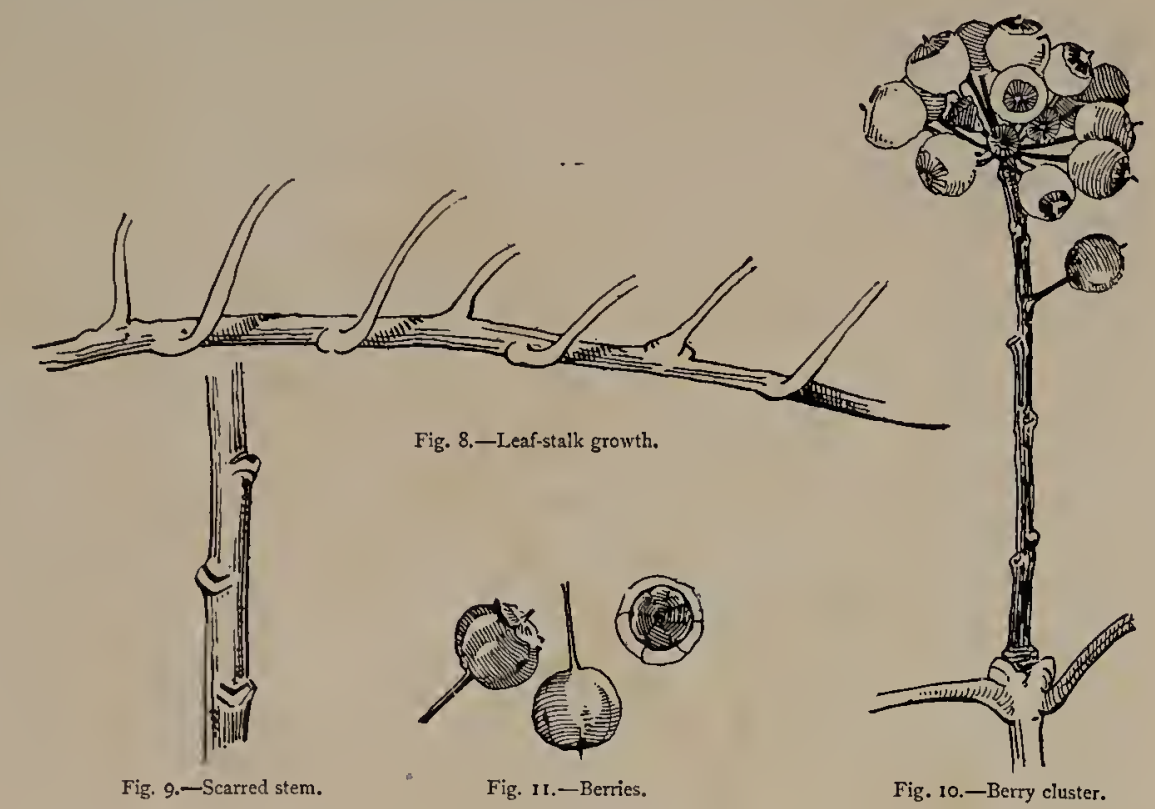

tinged with a reddish-purple. The berries are about the size of large peas (Fig. I I); bright glossy green in their young stages, becoming dull bluish-purple when fully matured. They are somewhat peculiar in shape, being rather more angular than round, and depressed at the top, over which falls a kind of cap slightly raised in the centre.

In all ages the Ivy has been as great an incentive to the fancy and skill of the artist as to the verse of the poet. It has figured upon the pottery of classic Greece, and the sturdy Saxons carved its image in wood and stone. Innumerable are the illustrations of its use in the best Gothic periods, and whether severely conventionalised, or naturalesque in treatment, it always presents a satisfactory result; its beauties, like its nature, being evergreen.

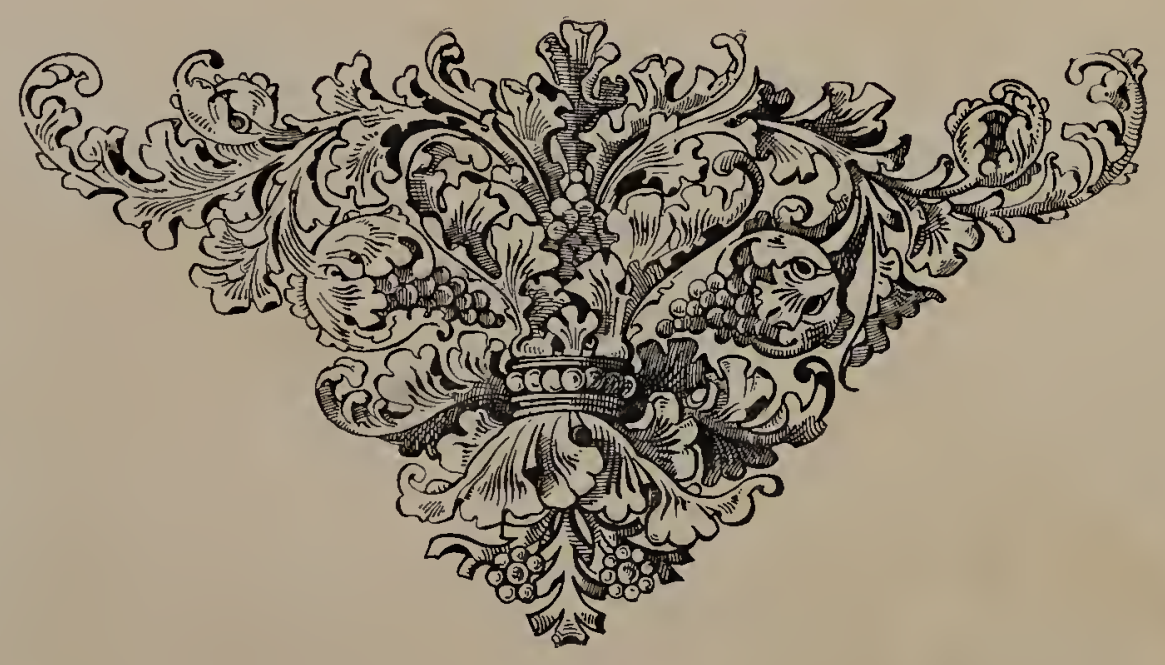




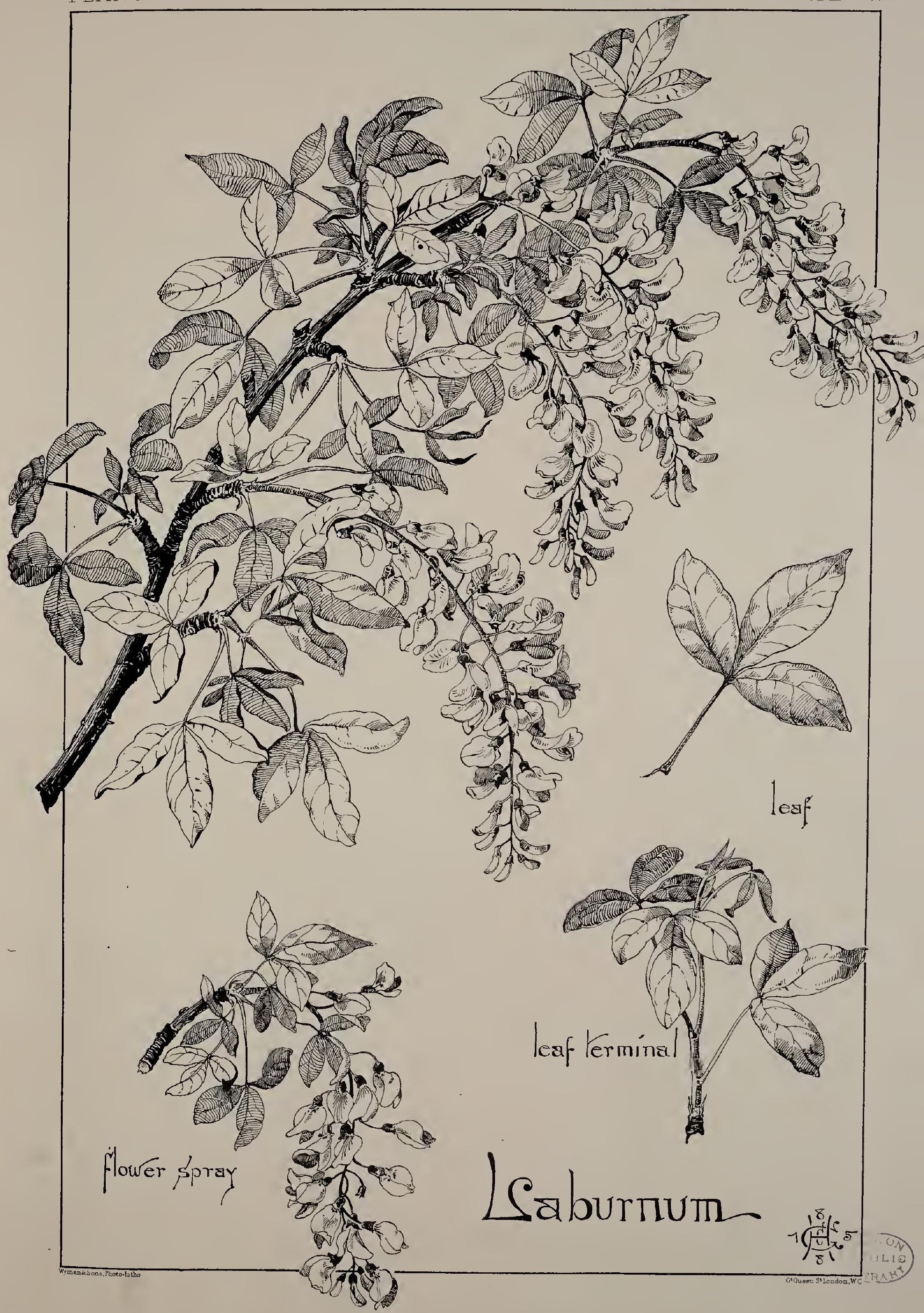





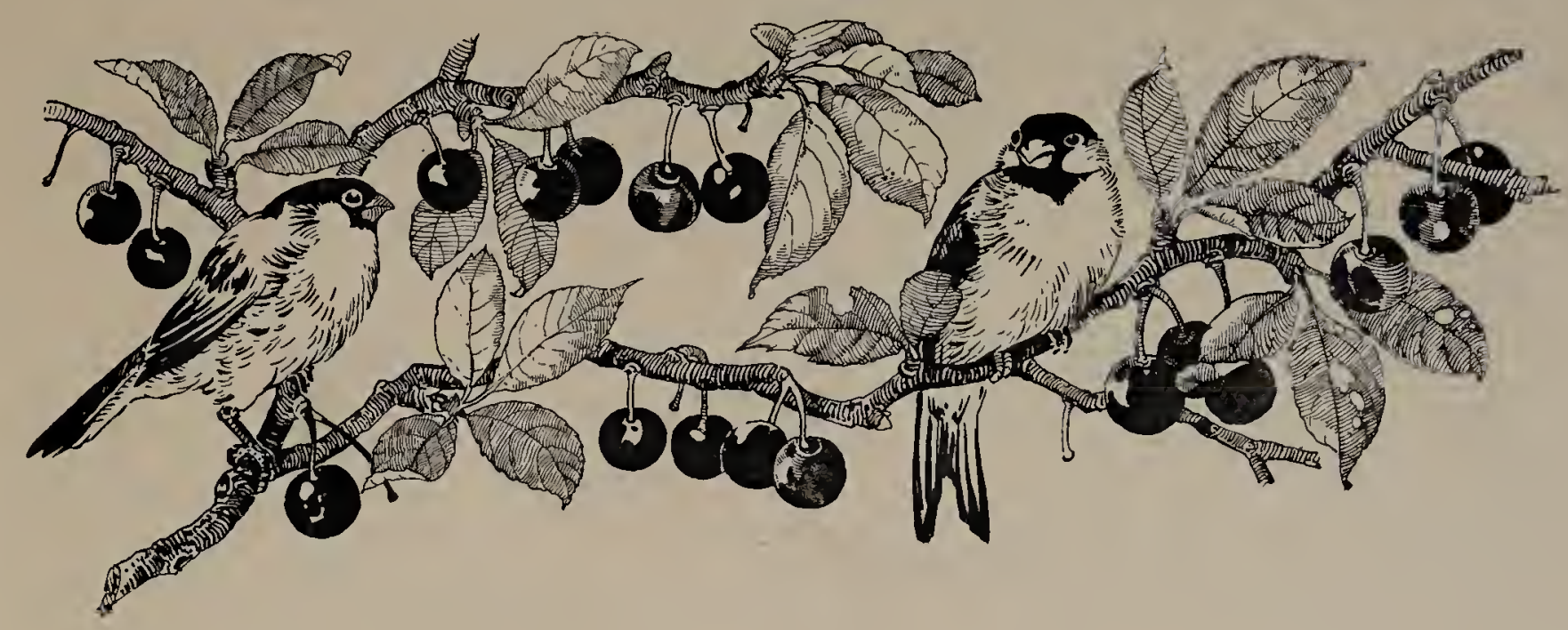

\section{Plate XLI.-THE LABURNUM.}

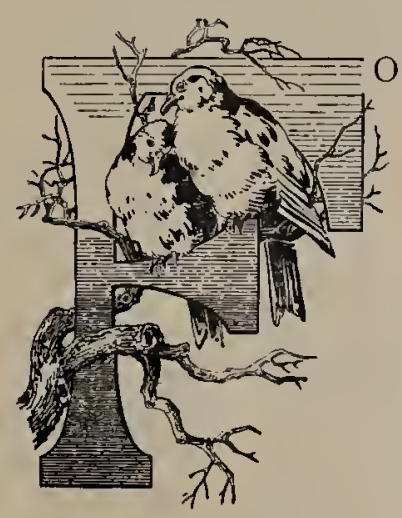

REMOST among those trees cultivated for their ornamental appearance must be ranked the Laburnum, or "Golden chain," a fanciful and appropriate name it is often called by. It is a native of Europe, and is said to have been introduced into England in or about the year 1596 . It is now quite common in many of our parks, and is rarely absent from our gardens and shrubberies, where it may be seen during May and June in full bloom side by side with the delicately-tinted and sweetscented Lilac, the soft shell-like pink of the Almond blossoms, and the pale white or rich red of the Hawthorn. Under such conditions, and with a sunny sky overhead, the Laburnum, with its delicate green foliage "rich with streaming gold," as Cowper so eloquently describes its shower of yellow blossoms, is indeed a picturesque object, and presents a most exquisite contrast of colour. There are several varieties of the tree under cultivation, and they differ from the common kind in bearing finer blossoms and more developed foliage.

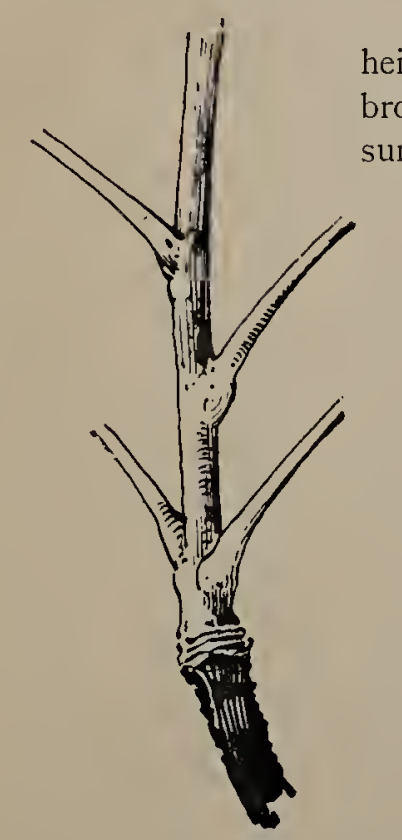

Fig. 1. - Joint of young wood with old.

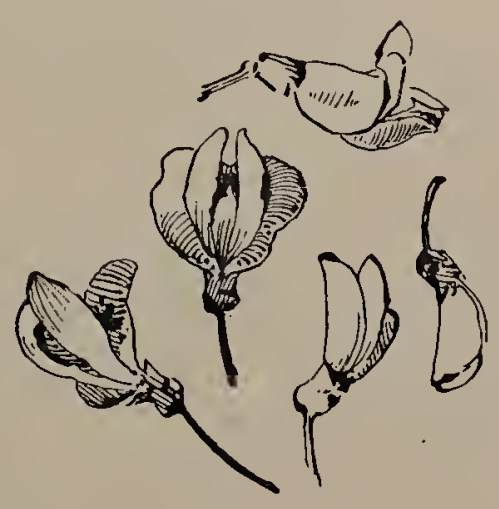

Fig. 2. - Bud and fowers.

Its growth is woody and branching, and the tree often attains to the height of twenty feet and upwards. The wood is barked, and of a warm brown colour; the younger shoots are smooth and of a pale green, and are urrounded by rings of bark at their joints with the older wood (Fig. I).

The flowers are bright saffron yellow in colour, with rich reddish-brown markings (Fig. 2). They grow on long stalks in pendulous racemes, at the ends of small lateral shoots; and a number of flowers are attached to delicate stalks, and spring spirally round the main stem. The leaves are three-parted, each acute oblong in form; mid-ribbed, and veined from the centre to the edges. They grow in clusters on long stalks around short lateral spurs (Fig. 3), or alternately 
round the young shoots (see Fig. I). Their surface is smooth and shining, and in colour they are bright green, which becomes much darker when the flower-bearing period is passed.

The interesting growth of the Laburnum could be made very useful and effective for many purposes of decoration; notably in needlework, or in designs for woven silk and other fabrics. In many hand-painted decorations its selection would prove judicious. For instance, in fan-painting, its growth is very suggestive of the shape to which it would be applied; and the pendulous flower-clusters suggest their suitability for the embellishment of spaces that taper towards the base. It is also eminently adapted for bold stencil work.

\section{Plate XLII.-HONESTY.}

$\mathrm{T}$

HIS plant, commonly known as Honesty or Satin-flower, is the Lunaria, so named by the older botanists on account of the silvery semi-transparent aspect and broad orbicular shape of its seed-vessels. It grows from two to four feet high, and is in blossom from May to July. There are two varieties, a white and purple-flowered; but neither are conspicuous for beauty of form or colour. During its seed period, however, the plant is at once both beautiful and quaint, particularly when the sprays are quite dried, looking like so many discs of pearl tissue, on which the encased seeds, supported by slender thread-like stalks, may be plainly seen; these bear so close a resemblance to some of the signs used in musical notation, that it might not inaptly be termed the musical plant.

The stem of the Honesty is solitary, much branched and leafy. The leaves, which may be described as heart-shape (Fig. I), are dull green in colour, and rather bluntly serrated. They

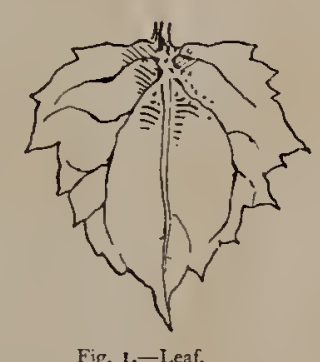

Fig. 1.-Leaf.

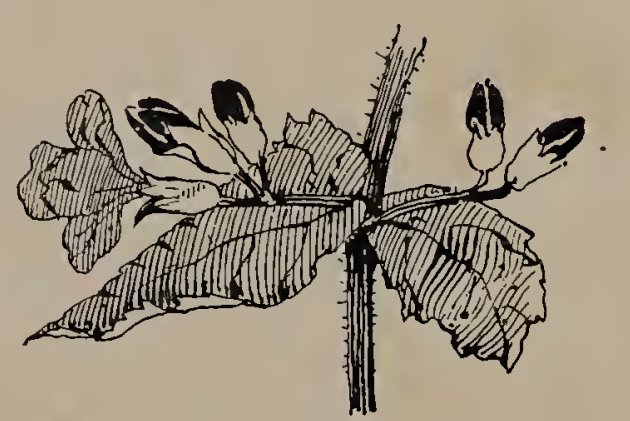

Fig. 2.-Flower and leaf-growth.

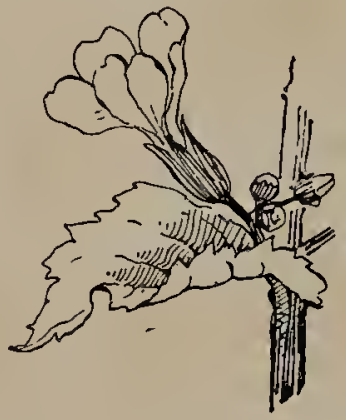
have long stalks, and grow opposite on the lower part of the stem and alternate on the upper part.
There are occasional irregularities in their growth, for amid the flower sprays they may be found solitary and almost sessile. The lateral shoots spring from inside the leaf-stalk joint.
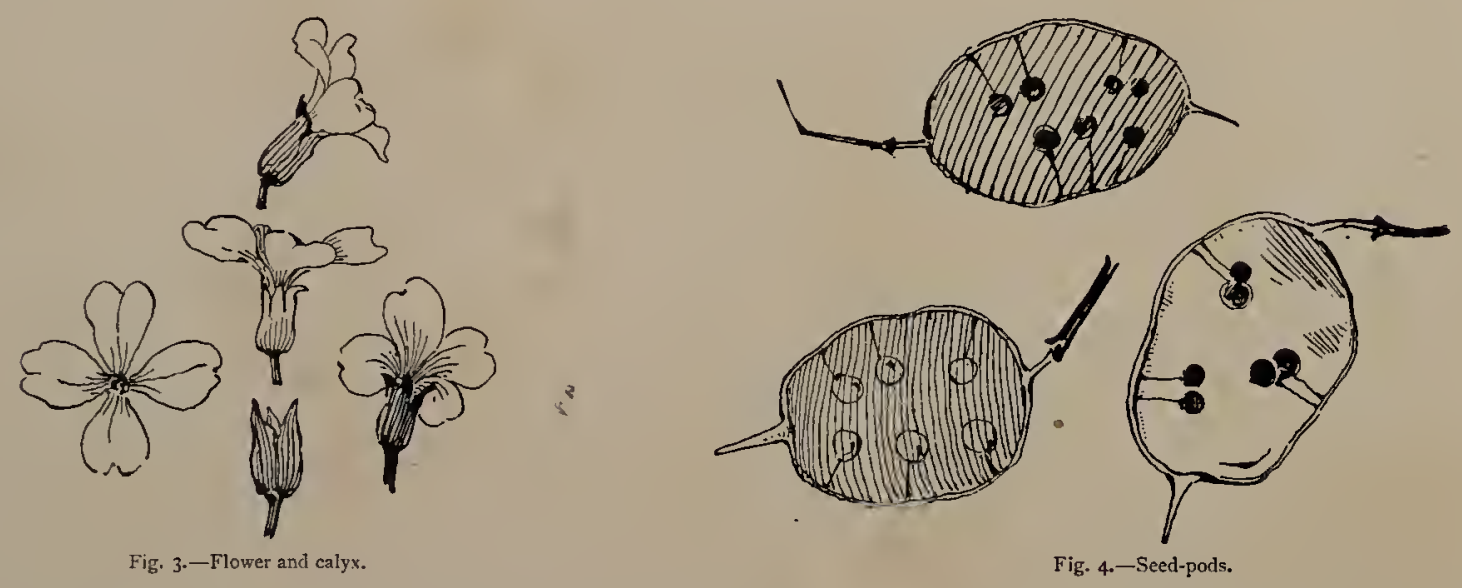

The flowers are numerous, and grow solitary or in clusters as terminals, or from inside where the leaf joins with the stem (Fig. 2). They are composed of four equal petals, each tapering down into the calyx, which is oblong in shape and consists of four obtuse coherent leaves, of which the opposite ones are convex at the base (Fig. 3). The seed-pod, which is the most remarkable feature of the plant, is pale green in its early period, and when fully ripe widens out and becomes of a silvery shimmering hue, with the seeds distinctly visible, projecting towards the middle on delicate thread-like stalks (Fig. 4). 


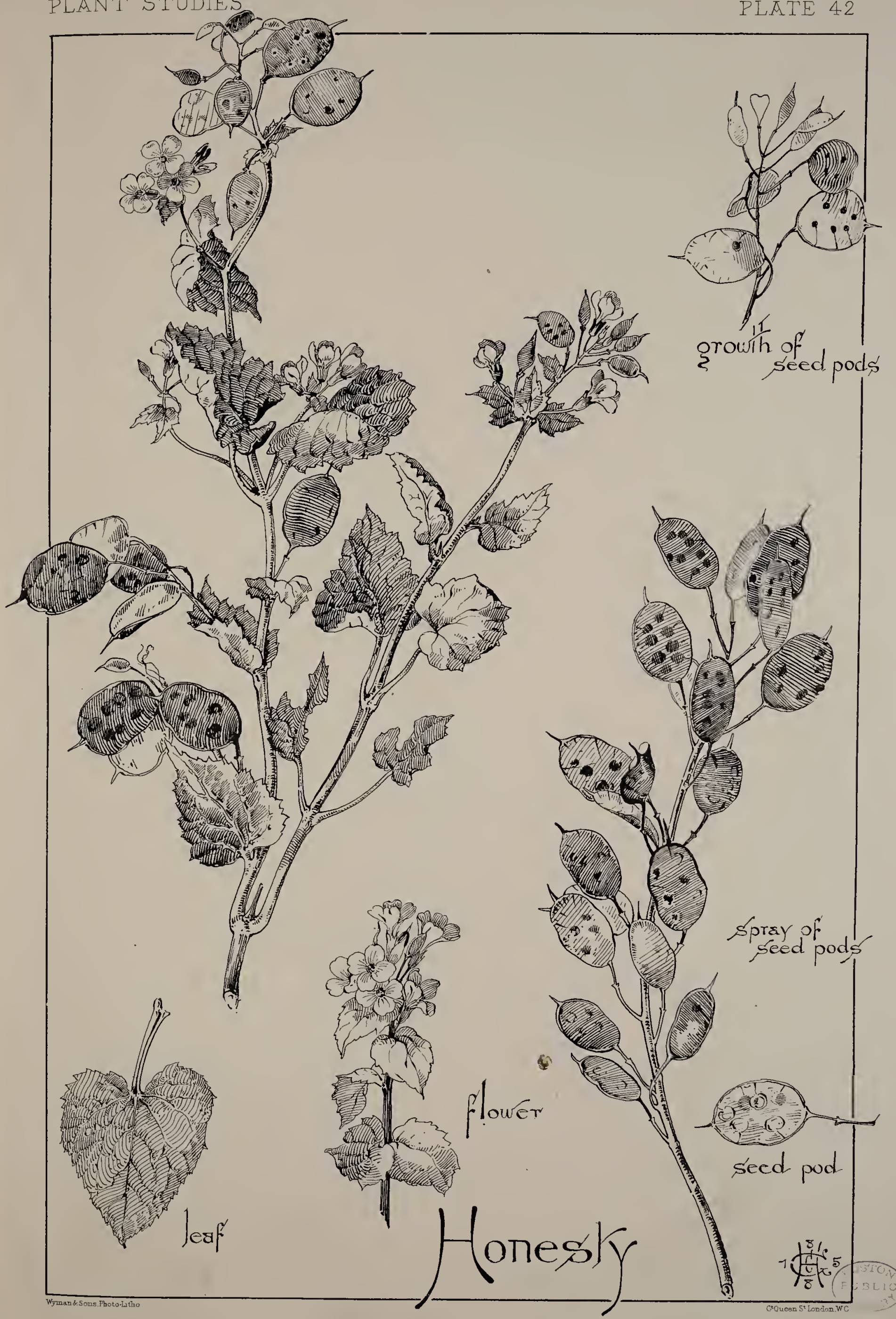





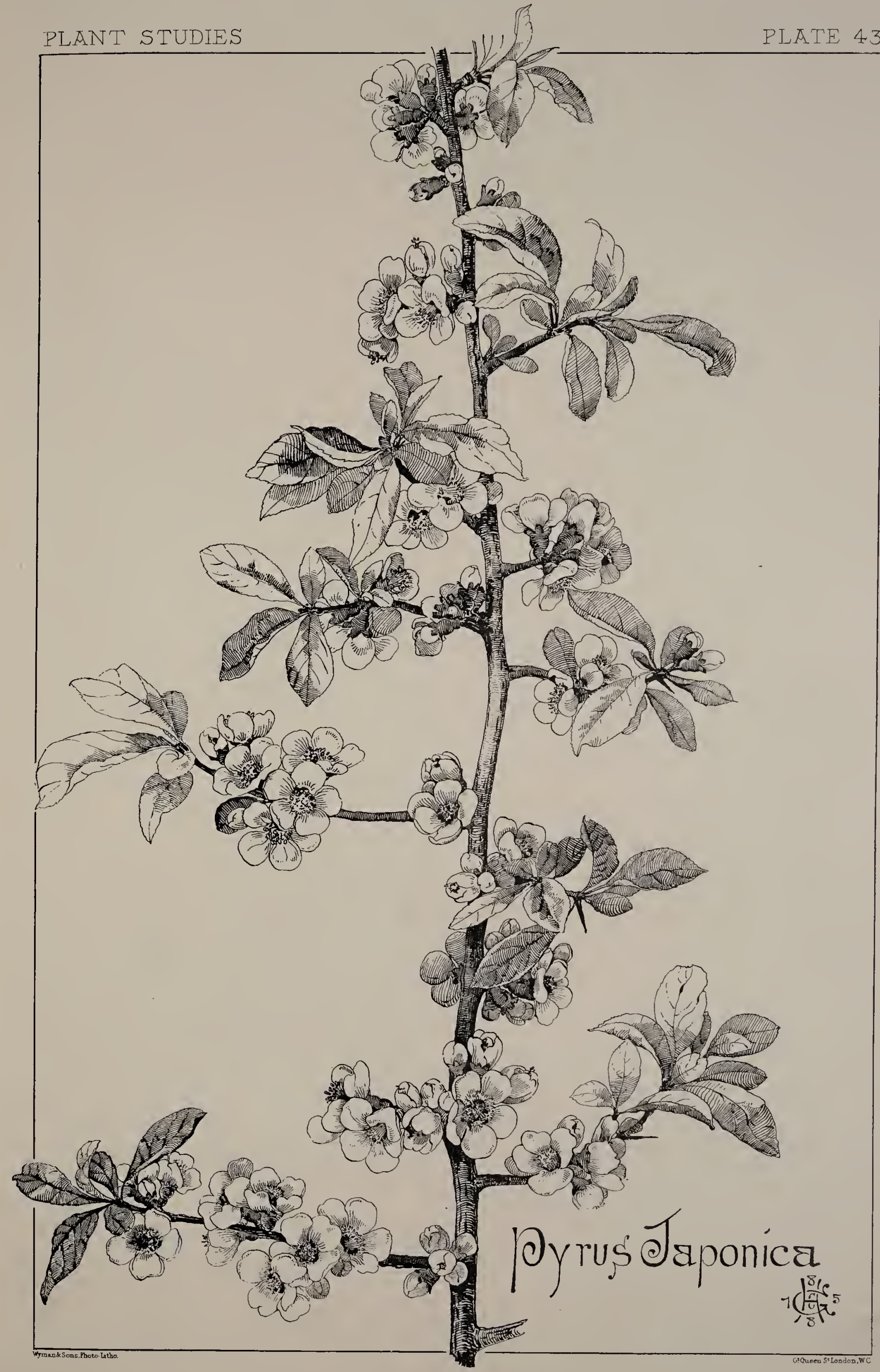



The dried branches of the Honesty might be made serviceable to the designer in any decoration representing or typifying music; for instance, in its suggested emblematical character, it might be used for the leading motive of a design in needlework or painting, for a piano-back or music-case. But quite apart from this quaint similitude, the plant should offer great attractions to the ornamentist, more especially as the peculiar seed-growth may be used in conjunction with the bud and flower aspect, thus allowing a greater variety than would be possible if the seed matured only when the flower and leaves had fallen. Not only are the green pods to be seen during the flowering period, but also the dried and silvery sprays.

\section{Plate XLIII.-THE PYRUS JAPONICA.}

A

CCORDING to some authorities, the Japonica, or Japan Quince tree, was only introduced into England as recently as 18 I5. It it hardy and vigorous, and in its natural state forms a large and thickly-branched shrub, but is often to be seen pruned and trained as a covering to wall or fence. There are several varieties of this most ornamental plant; some bearing white or flesh-coloured flowers, others, red flowers tinged with white. There is also a variety with semi-double flowers, but the common kind, with its beautiful opaquelooking scarlet flowers, is the most effective.

The Japonica blossoms during February and March, sometimes before its leaves appear; thus, like the Almond, braving the biting winds of the early spring. In sheltered situations it not unfrequently blossoms twice during the year, and the beauty of its flowers is then enhanced by the rich blue-green of the fully formed foliage.

Its habit of growth is angular and straggling. The wood is round and smooth-barked, and of a rich reddish-brown shade, inclining to green surrounded by rings of bark at their joint with

The lateral shoots grow alternately from strong sharp spines form (Fig. I).

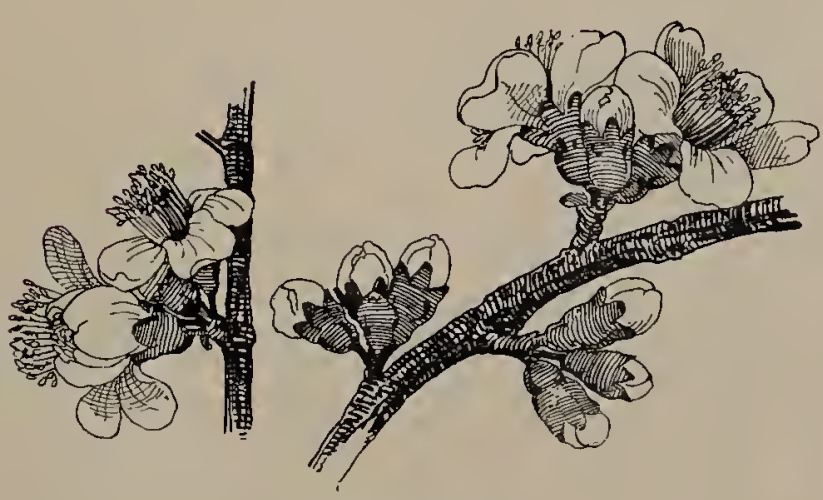

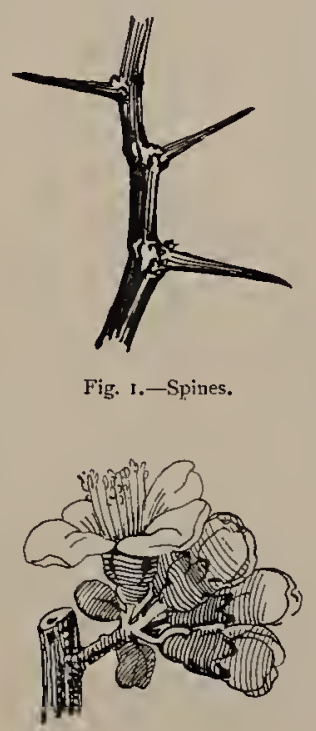

Fig. 3.-Bracts. in the young shoots, which are the old wood.

and around the stem, on which

Fig. 2.-Flower-clusters.

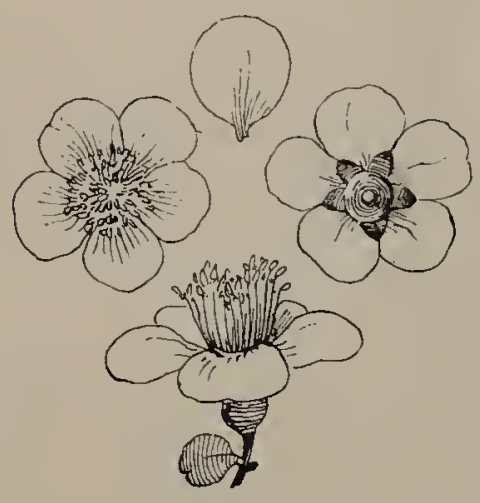

Fig. 4.-Front, back, and profile view of flower.

The flowers are almost sessile, and grow in clusters of two, three, or more (very rarely solitary), at the end of short spurs, which form spirally round the stem (Fig. 2). At the base of the flower-stalks small round bracts or leaflets often form (Fig. 3). The flower is composed of five short and thick, rounded petals, which partly overlay each other (Fig. 4). They are brilliant scarlet in colour, and have the appearance of being covered with a bloom, that gives the flower its opacous effect. From the centre rises an indefinite number of pale yellow-tipped stamens set in two rows. The calyx is five-pointed; and short and sturdy in appearance; it is pale green in colour, but is often partly or wholly tinged with crimson.

The leaves grow in clusters round the ends of the lateral shoots and spurs. They are attached to short stalks, at the base of which oval-shaped stipules often form, and are of an elongated oval shape, smooth on both sides, and very finely toothed and delicately veined. In the early growths they appear half folded, and are of a glossy golden-green colour, that becomes deeper or more bluish as the leaves expand. 
The shrub bears a fragrant but non-edible fruit, green in colour, and shaped somewhat like an elongated apple.

The vigorous growth of the Japonica, and its simple and well-defined bud and flower forms, make it a valuable plant to the designer, to whom it should be full of suggestions. Its decorative merits appear to be recognised by art-workers, for it is often to be seen in use as the leading motif in modern ornament. Among many of the purposes to which it can be readily and appropriately applied would be in designs for wall-papers, friezes, and borders; for needlework of all descriptions; painted panels or tiles; and particularly for stained glass, in which the calyx, so frequently tinged with crimson, would admit of the entire flower bunches being leaded-up in ruby glass.

\section{Plate XLIV.-THE HOP.}

$\mathrm{T}$

HE Hop was not cultivated in this country till about the year 1524 , but it might be said to have now become to England what the vine is to other countries. Large quantities are grown in many of the southern counties, while the finest kinds come chiefly from Kent, and a small district around Farnham in Surrey. Under cultivation, the Hop is familiar to most of us, but as a wild plant of the hedge-row it is not so well known, though it is to be found in many localities, and is always a pleasing object. The genus consists of a single species, although we have many cultivated varieties. If we look carefully, we cannot fail to notice two very different kinds of blossoms on the Hop; one growing in a loose panicle of small yellowish-green flowers, and the other in a cluster or bunch of globular heads or spikes. These are the male and female flowers, which are produced on separate plants; both are very beautiful in their form of growth, although the latter only is considered of any value for brewing.

The Hop has no tendrils, but its stem twists around any support, and climbs with great facility, always turning from right to left with the sun.
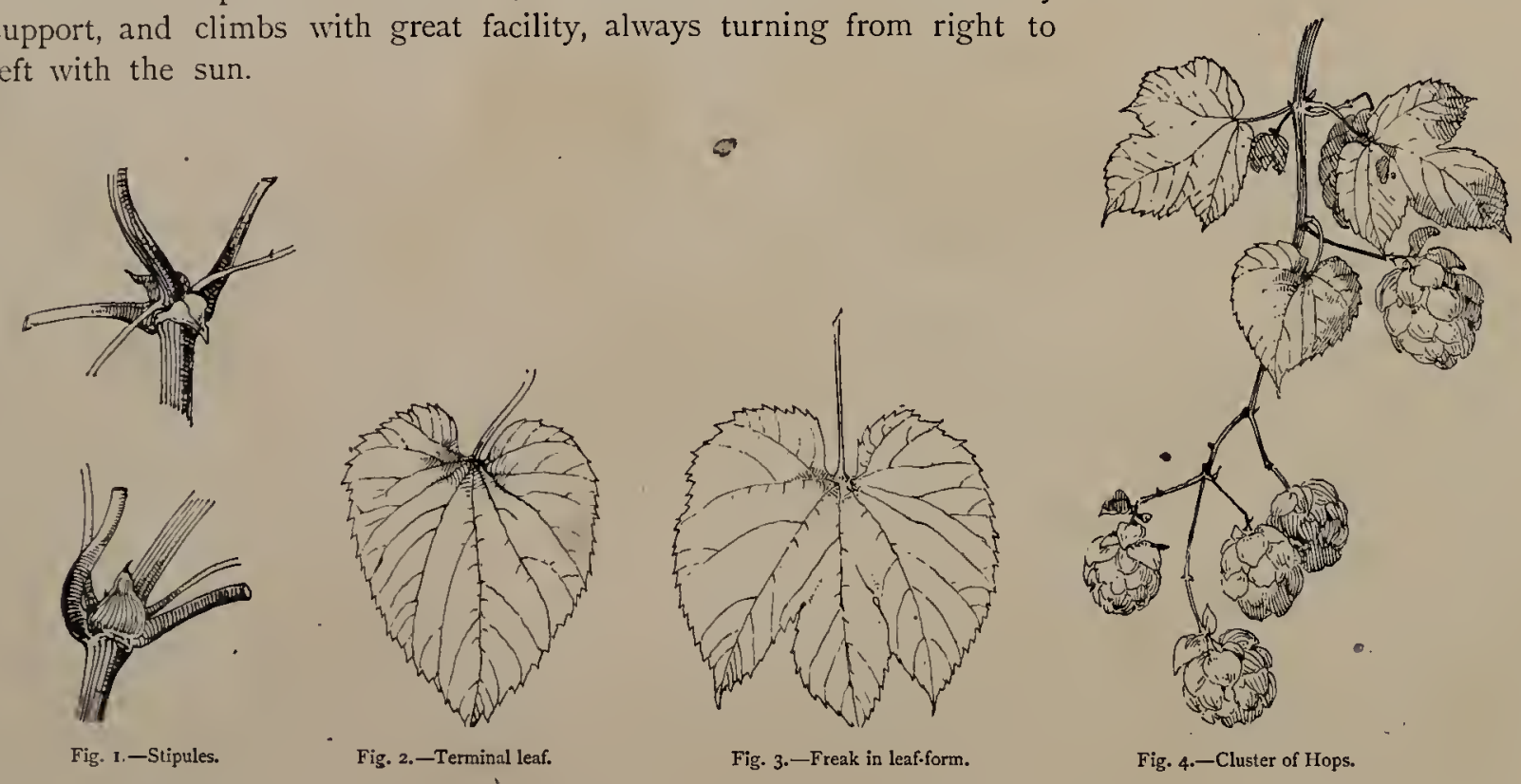

The leaves are deep green in colour, and palmately veined, with the veins most prominent on the under sides. They grow opposite each other on long stalks, at the base of which small united stipules form (Fig. I). At the ends of the shoots, and amid the hops, the leaves are inclined to be heart-shape (Fig. 2), but they are commonly three or five-lobed, with the lobes divided about half-way down, and the edges rather coarsely serrated. In the older growths seven-lobed leaves may be seen, and freaks or departures from the true forms are very frequent (Fig. 3).

The female flowers, as mentioned above, grow inside the small spikes of green scales; they have no true petals, and are almost unnoticeable. As the seed matures, the overlapping scales become 


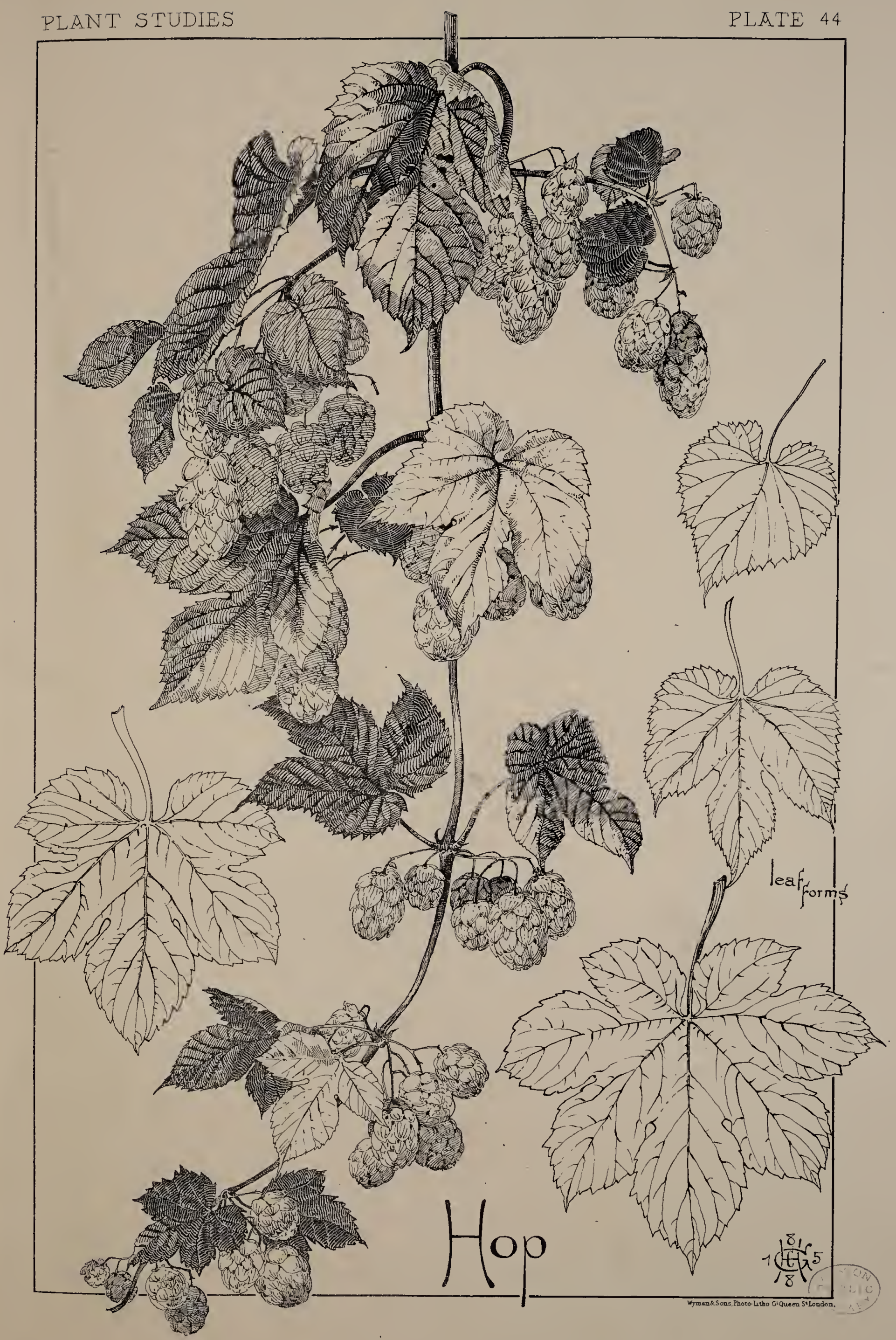





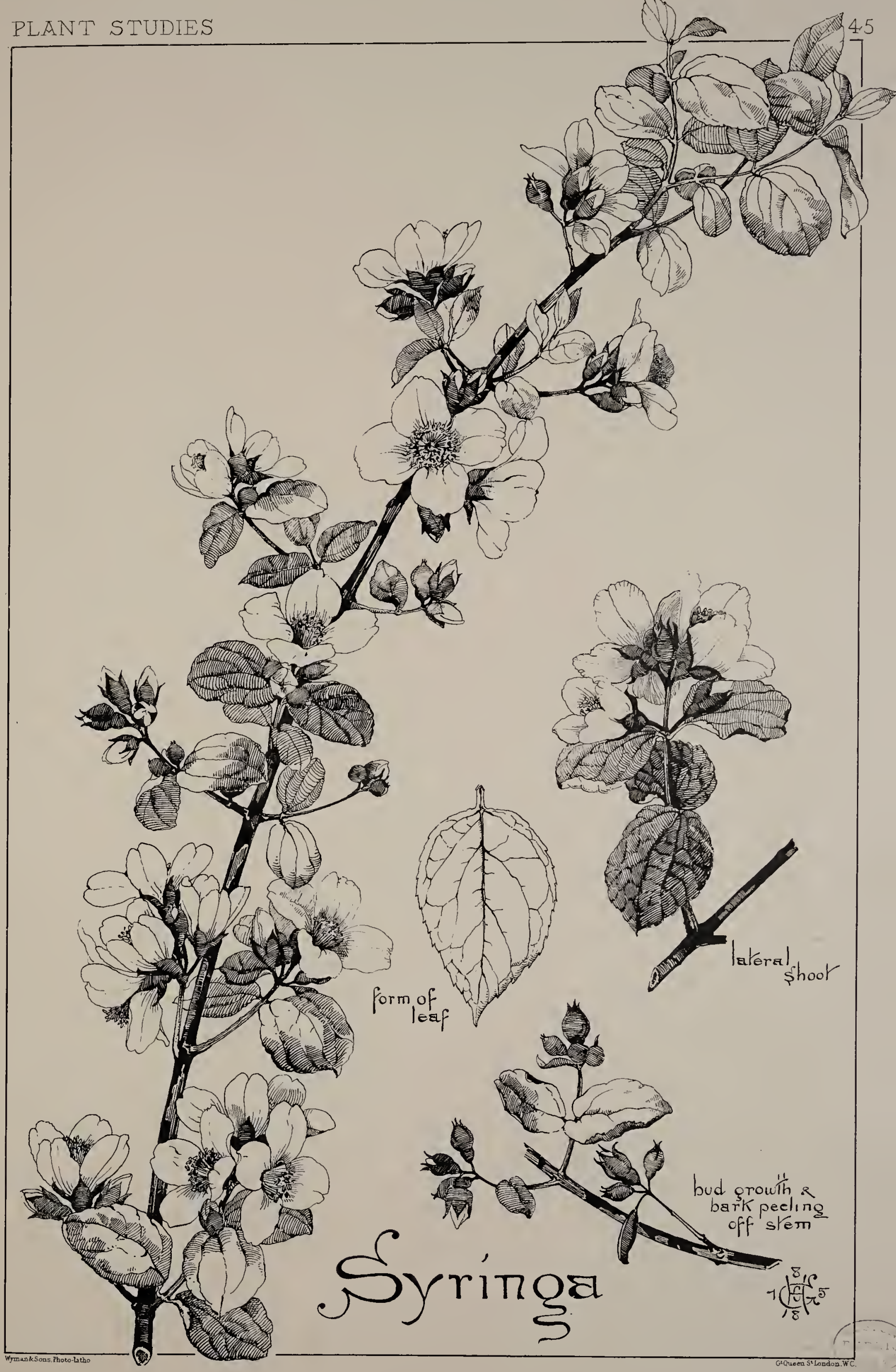



greatly enlarged, and the spike increases to a large cone-like catkin of a delicate yellowish-green colour. These catkins or hops are either ovate or round in form, and hang in graceful pendent clusters (Fig. 4). At this period of its growth the plant may be said to be in its supreme beauty; and a glimpse of a Kentish Hop garden, with the masses of exquisitely delicate hops clustering among the dark rich verdure of the bind, cannot fail to create a lasting impression upon the most indifferent observer.

To those at all familiar with the appearance and growth of the Hop it is superfluous to draw attention to its value as a plant suitable in many ways for ornamental purposes, or to point out what satisfactory results may be attained by selecting it for conventional embellishment.

\section{Plate XLV.-THE SYRINGA.}

$\mathrm{T}$

HE Syringa, or Mock Orange, is said to be a native of South Europe, and to have been introduced into England about three centuries ago. It is a tall bushy shrub, flowering in May and June, and is much cultivated in our gardens and shrubberies for its fragrant and showy white flowers, which, by their powerful odour, resembling that of orange blossoms, often betrays its presence even when the flower-laden branches are hidden from view. There are several varieties of the Syringa in which the flowers differ considerably in size (those of the plant illustrated being exceedingly fine), and in some species they are quite inodorous.

The Syringa is upright in growth, having a woody and somewhat angular stem. The joint of the young wood with the old is well defined (Fig. I). The bark, which is pale brown, peels off, and exposes in places the tender green of the inner stem, and thus presents a pleasing colour contrast and robs the wood of any monotony.

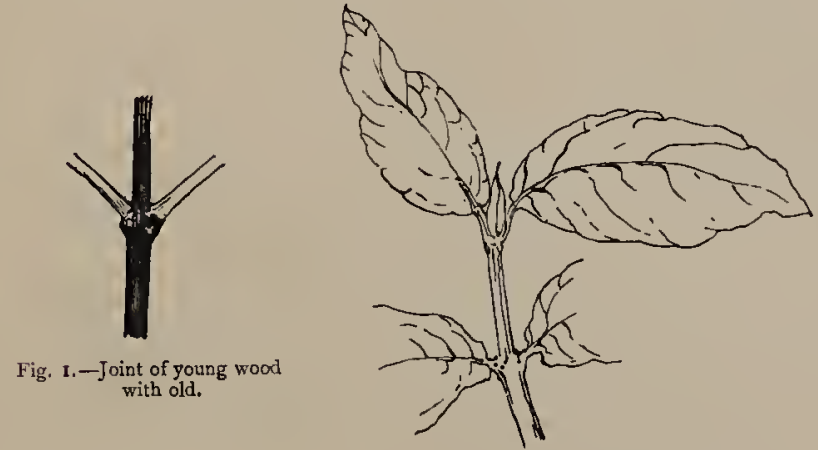

Fig. 2.-Leaf-spray.

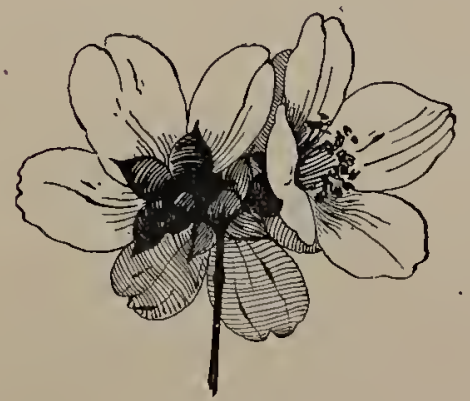

Fig. 4.-Flowers

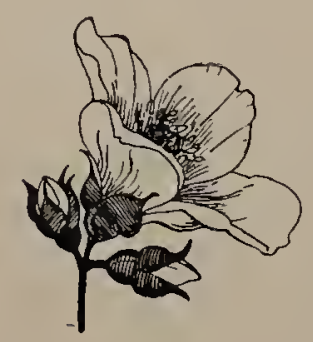

Fig. 4.
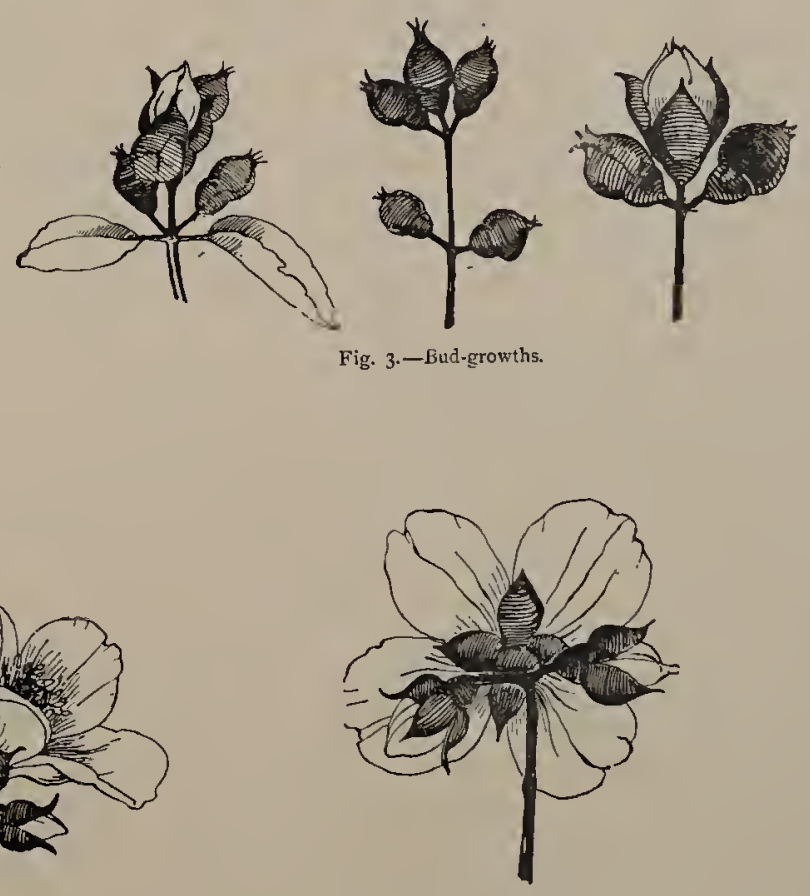

Fig. 4.-Back view of flower.

The leaves are attached to very short stalks, and grow opposite each other in sprays of two, four, or six, and occasionally form leaf terminals (Fig. 2). They are a dark smoky-green in colour, broadly ovate in shape, with the edges slightly serrated and the surface raised by irregular veins. 
The buds are set within a four-pointed spreading calyx of pale green. They grow in upright terminal clusters of three or five, the latter number being the most general, but three always form the terminal (Fig. 3). The flower is composed of four slightly-cleft, semi-transparent white petals, which are roundish-ovate in form, and spreading (Fig. 4). From the centre an indefinite number of yellow-tipped stamens rise in a cluster, and from their midst springs a four-cleft pistil.

The Syringa is a plant that needs little recommendation to the artist. Its bud and flower growth is particularly pleasing, and as there are few departures from the characteristic laws, it may be selected when regularity of form and arrangement is needed. Moreover, its bud, flower, and leaf are reducible to the simplest of modifications, and would lend themselves readily to a two-colour treatment for decoration of flat surfaces.

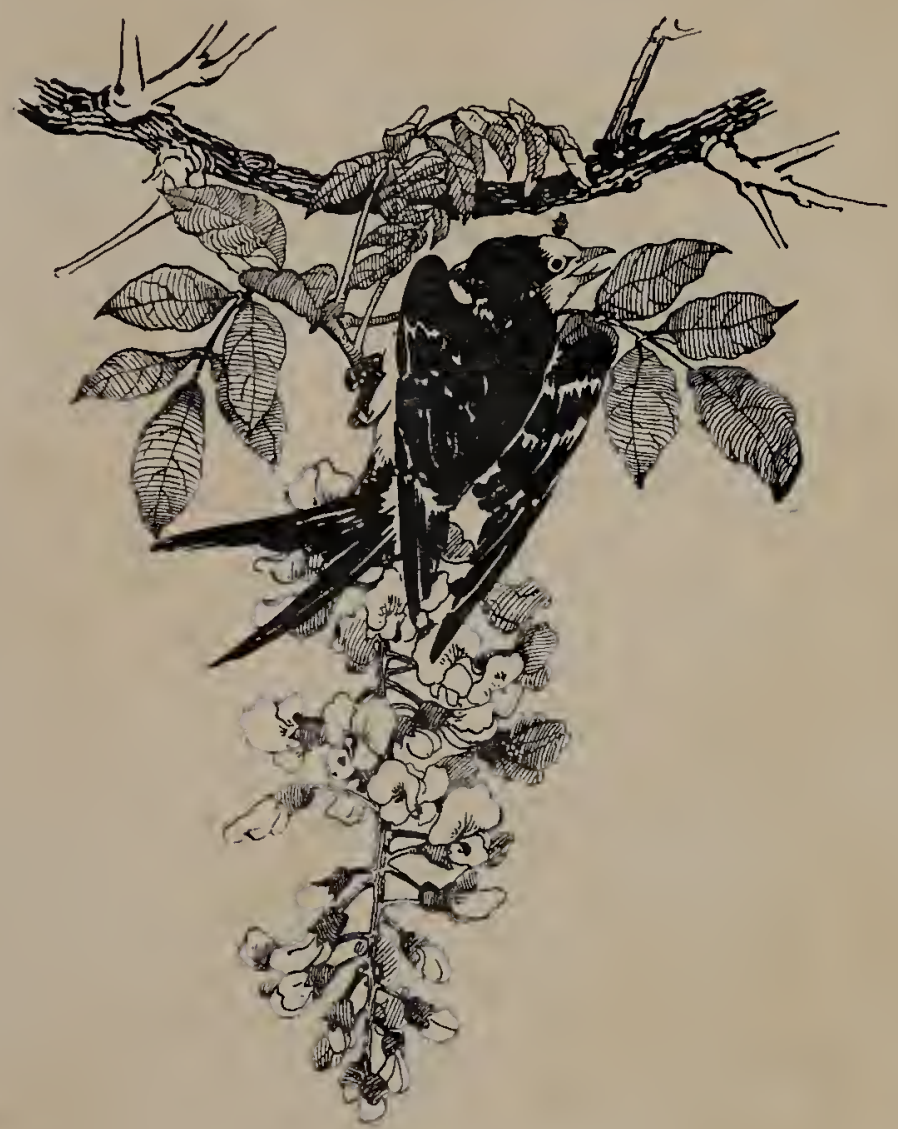




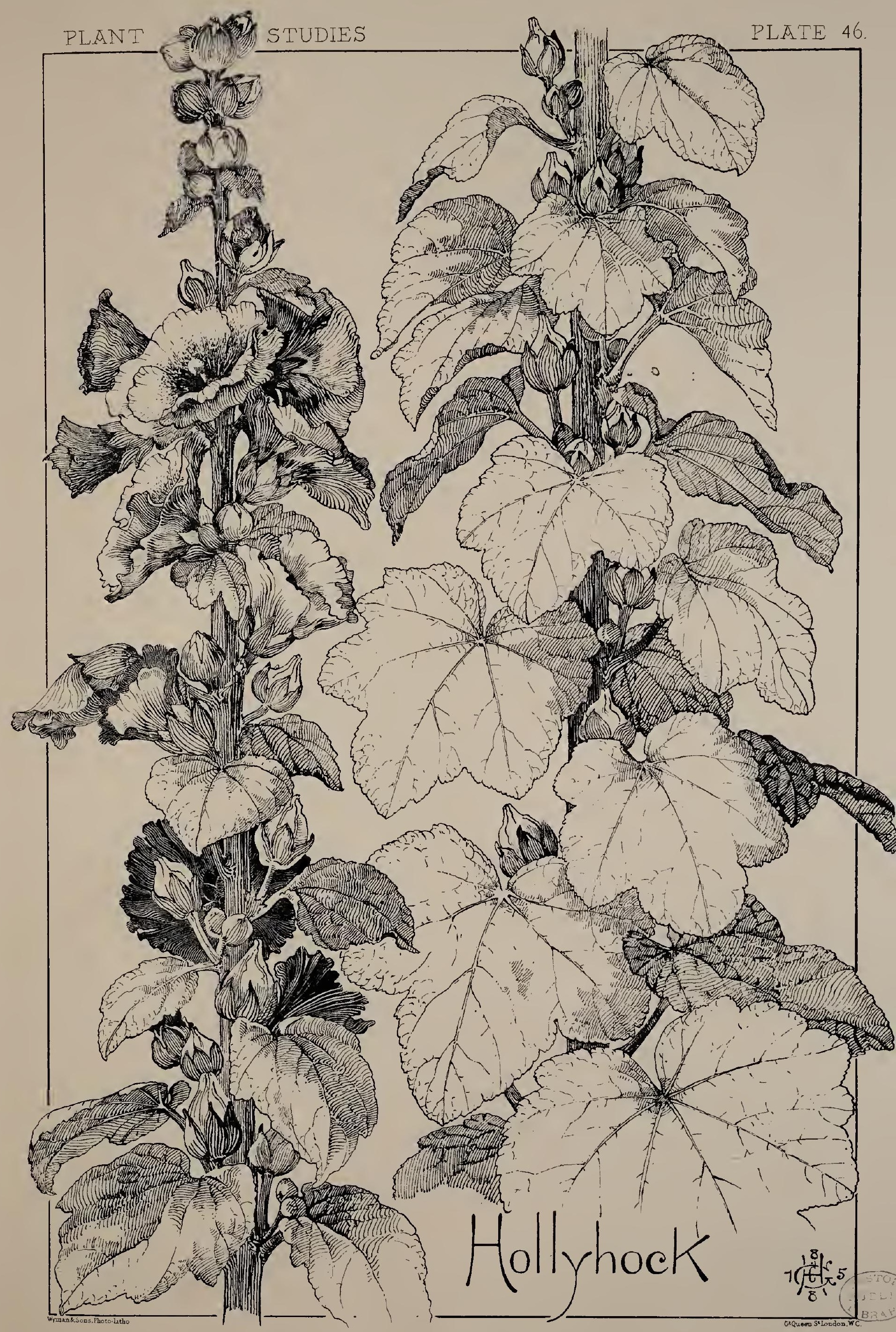




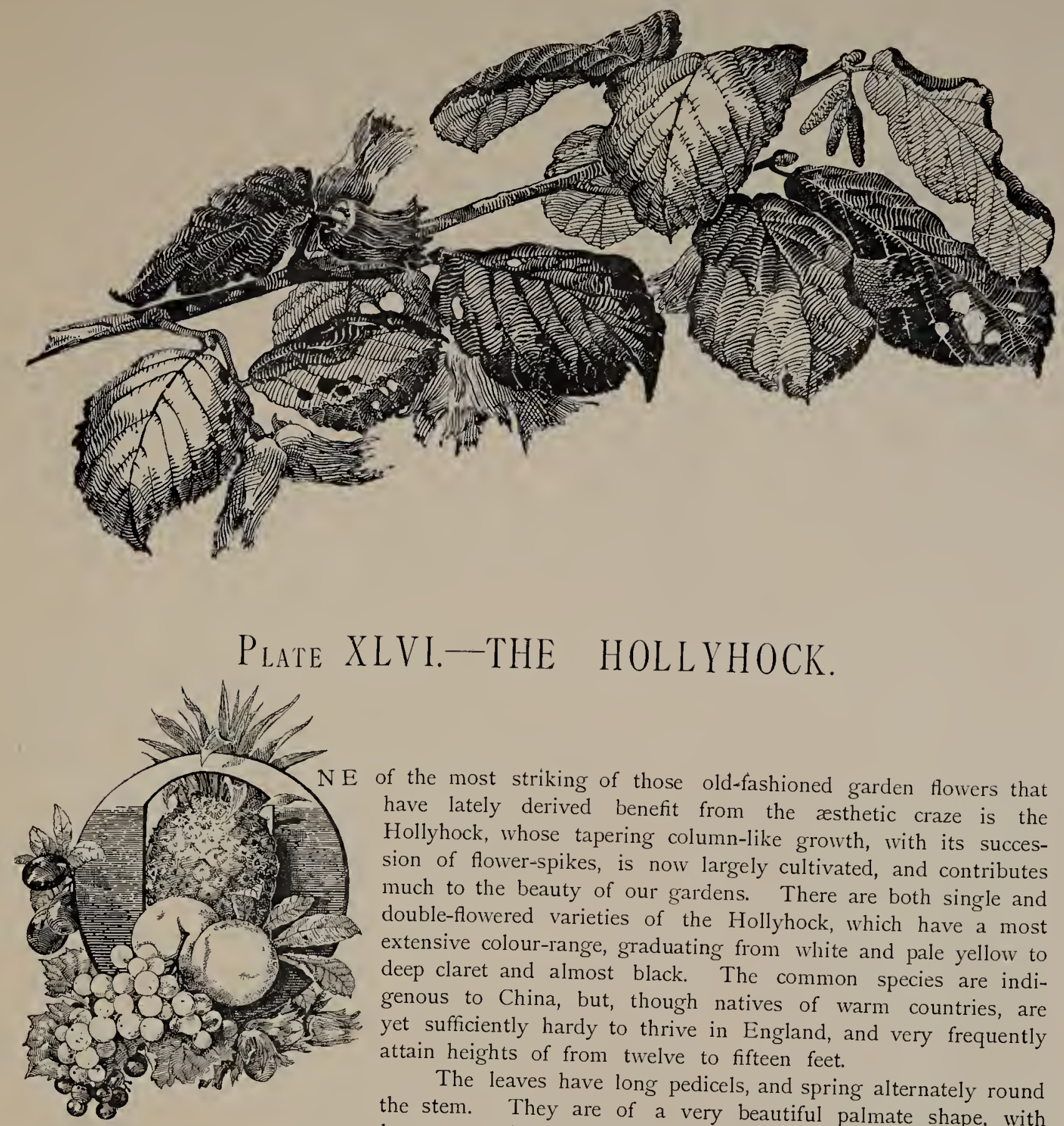

of the most striking of those old-fashioned garden flowers that have lately derived benefit from the rsthetic craze is the Hollyhock, whose tapering column-like growth, with its succession of flower-spikes, is now largely cultivated, and contributes much to the beauty of our gardens. There are both single and double-flowered varieties of the Hollyhock, which have a most extensive colour-range, graduating from white and pale yellow to deep claret and almost black. The common species are indigenous to China, but, though natives of warm countries, are yet sufficiently hardy to thrive in England, and very frequently attain heights of from twelve to fifteen feet.

The leaves have long pedicels, and spring alternately round the stem. They are of a very beautiful palmate shape, with large serrated angular lobes. There are seven or nine principal veins, and the body of the leaf is broken up into numberless spaces by a multitude of smaller veins, forming a reticulated surface. Although the leaf-form varies considerably, the five and sevenlobed may be considered distinct, the latter being the most characteristic (Fig. I). At the base of the leaf-stalk there are large and well-developed stipules, which fade off as the leaf matures (Fig. 2).

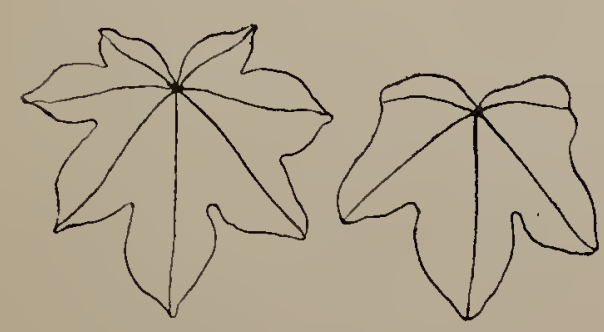

Fig. I.-Leaf-forms.

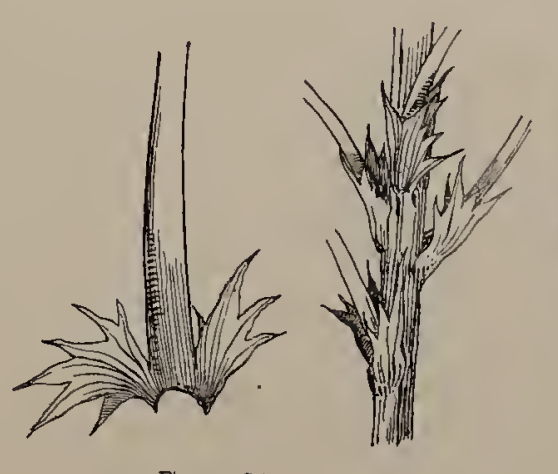

Fig. 2.-Stipules.

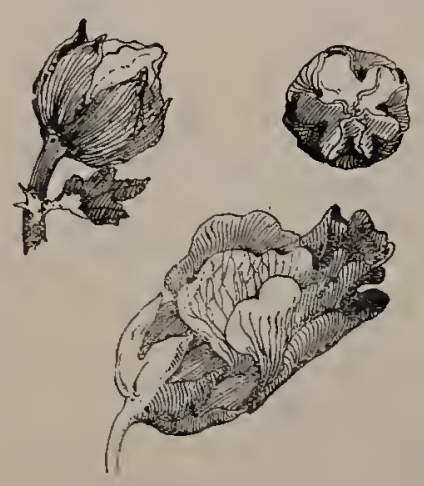

Fig. 4.-Double calyx.

The buds spring from the axils of the leaves, either solitary or in clusters of two and three (Fig. 3). The calyx is double, the outer part usually being divided half way down into six parts, persistent and very spreading; the inner cut half way into five parts, larger, and also persistent (Fig. 4). Occasionally a divergence from these numbers occurs, for seven and even nine divisions may be found in the calyx. 
The corolla consists of five spreading petals, with waved and crinkled edges, having towards the base markings of a deeper colour. The petals are streaked with a lighter local colour, and raised, causing a somewhat rough texture. From the centre of the flower rises the cylindricalshaped pale yellow pistil, surrounded by numerous twisted stamens of the same length (Fig. 5).
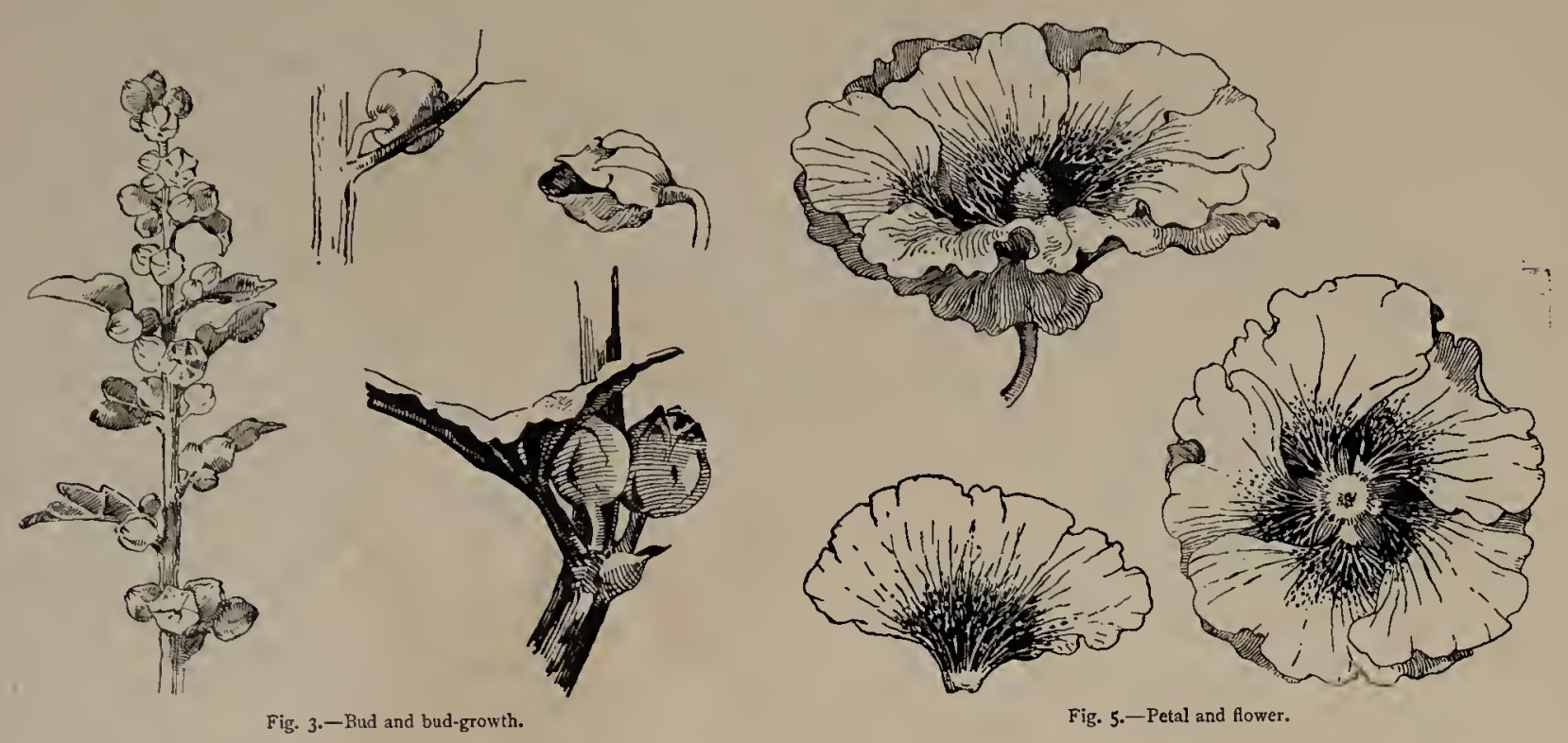

The habit of the Hollyhock restricts its application to those positions where upright growths are possible and judicious. It is essentially a flower adapted for the embellishment of long and narrow upright panels or screens, etc., and when properly treated in such positions looks, as it really is, far more suitable than the weak distribution of such growths as the honeysuckle, clematis, or spray of virginia creeper, which are so commonly used, and not unfrequently made to run out at the sides, suggesting that the ornament had been cut from a larger piece. These objects are readily adaptable for the covering of large and irregular spaces, but the Hollyhock, Foxglove, Canterbury Bell, and many other upright growths, are necessarily of restricted application; therefore it would seem more fitting to select positions in harmony with their forms.

\section{Plate XlVII.-THE GUEldER ROSE.}

$\mathrm{T}$

HE Snow-ball or Guelder Rose of our gardens is a cultivated species of this plant, but with all its cultivation it cannot be compared in beauty to the denizen of the woods, which, prominent among the varied growths, may be seen during the months of June and July in full blossom, its pale white flower discs peeping above or between the foliage of young oak tree, alder, or hazel bush. Lovely as the Guelder Rose is during the summer or flowering aspect, it is even more beautiful in the autumn, when, notwithstanding the many-tinted foliage surrounding it, it is conspicuous for richness of colour. The leaves are tinged with varied shades of red, purple, and bronzy green hues; and the glistening semi-transparent berries, as they hang in drooping clusters, have not inaptly been compared to garnets. The berries cling to their stems long after the last lingering leaves have fallen, and in the grey days of approaching winter enhance with brilliant touches of colour the bare branches of the underwood.

The plant attains to a goodly height, and is of straight and woody growth, with lateral shoots forming almost at right angles. The bark of the old wood is of an ashen grey colour, with well-defined brown markings separating it from the young shoots (Fig. I), which are of a tender green hue tinged with red.

The leaves are large and pleasing in shape, with three or five angular, unequally-serrated lobes (Fig. 2); are centre-ribbed and delicately veined, the leading veins showing more prominently on the under sides, which are grey-green in colour, offering a pleasing contrast to the richer green of the leaf's surface, and the milky white tints of the flower clusters. Though inclining to palmate, there are frequent departures in the leaf-forms, those of the terminals being generally without lobes and quite oval in shape (Fig. 3). They are attached to stalks of medium length, 


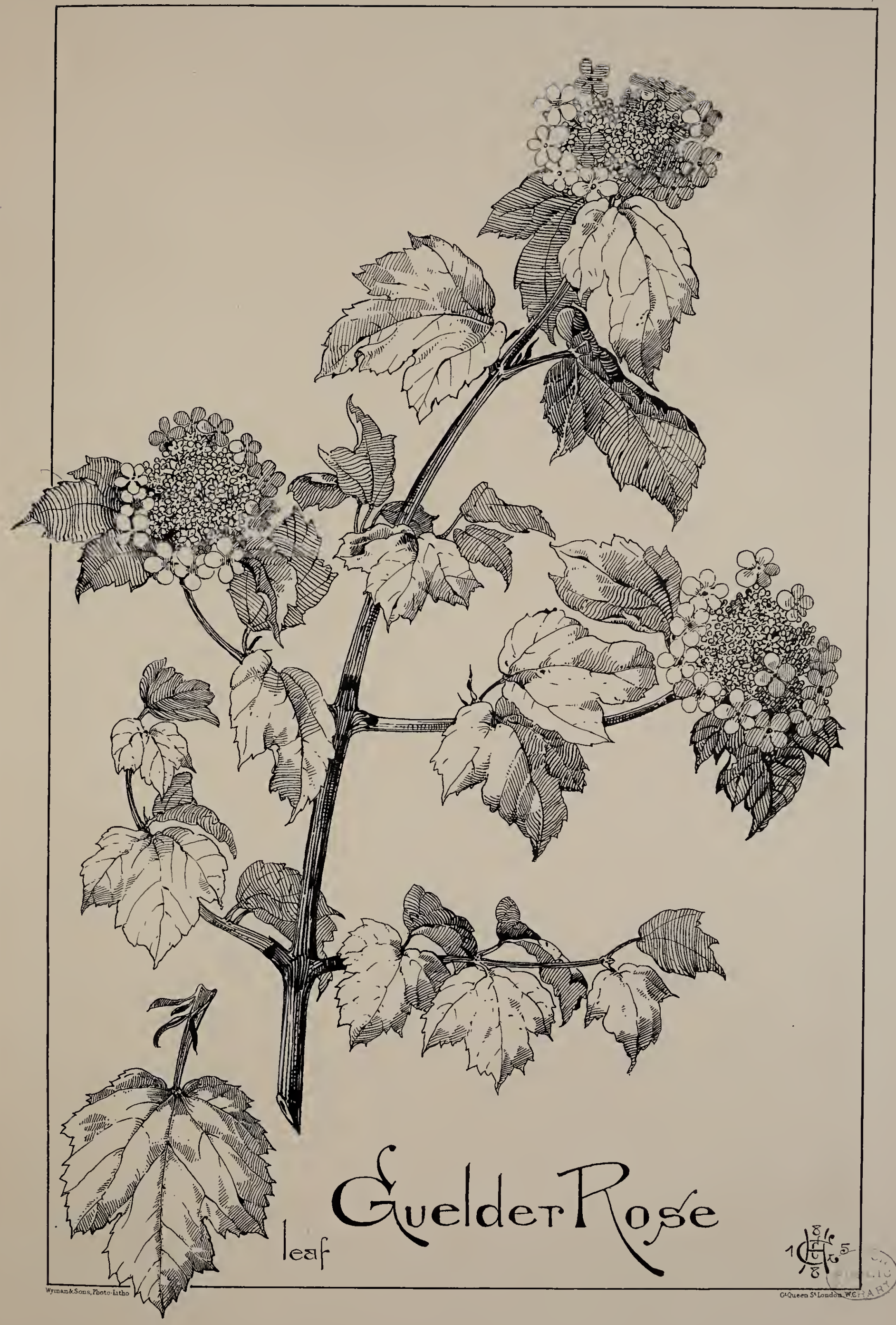





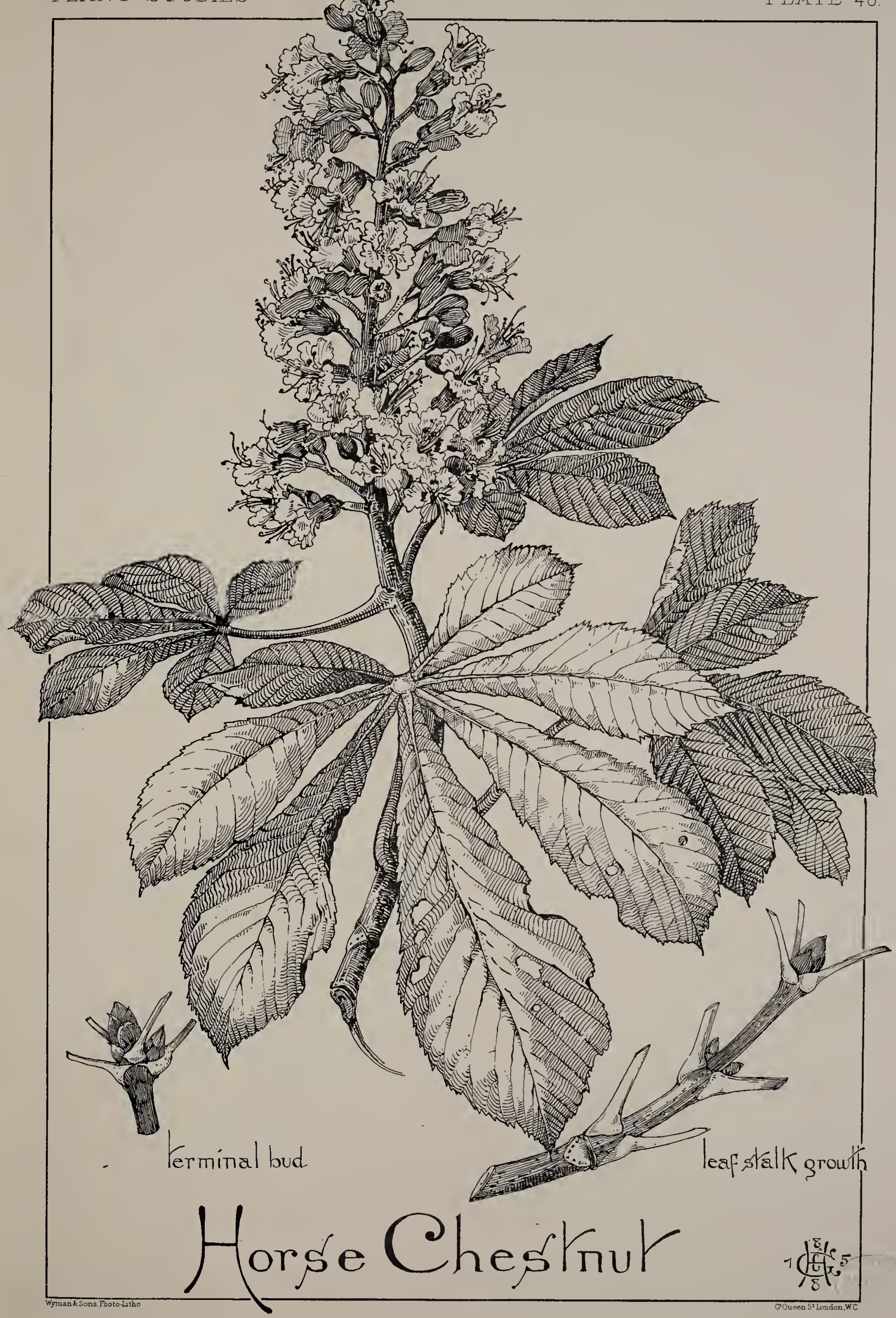



and grow opposite each other (Fig. 4), having at the base of the leaf-stalks long tapering leaflets or stipules, which add equally to the beauty and character of the leaf-growth (Fig. 5).

The flowers grow in hemispherical clusters at the end of the main stem or lateral shoots, and are composed of irregular circles of small blossoms, divided into two distinct forms and sizes. The centre of the cluster is composed of minute dull pale yellow flowers, which are five-petalled and have a corresponding numbcr of stamens; the outer edge or rim is formed by the larger milk-white flowers, which consist of a corolla only, partially cleft into five irregular
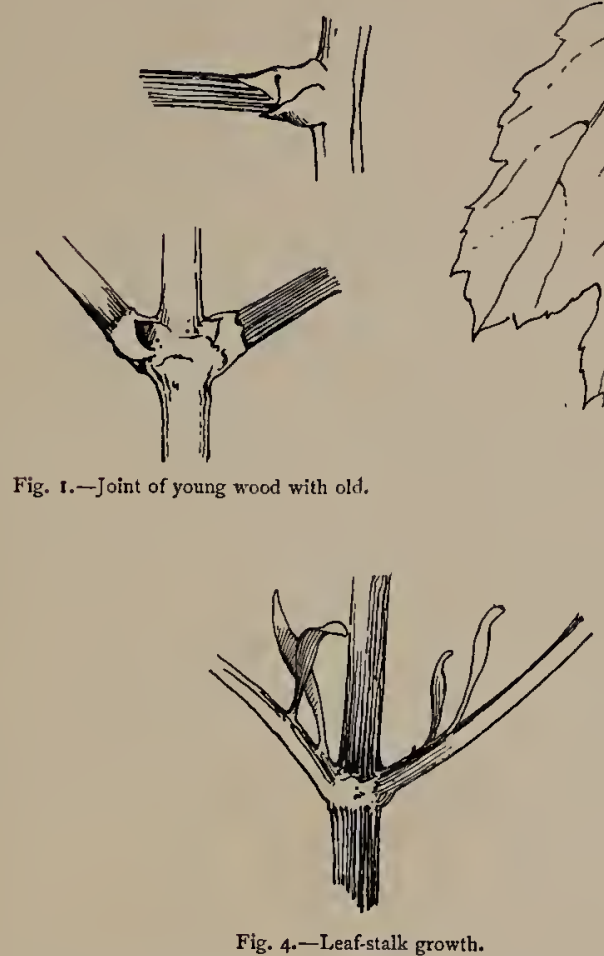
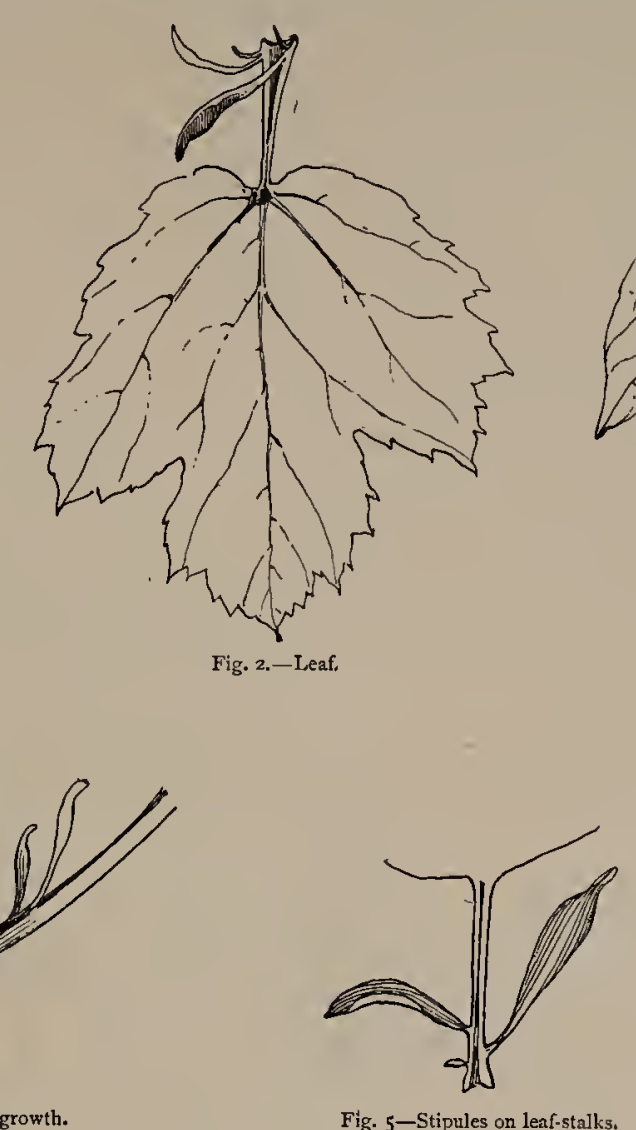
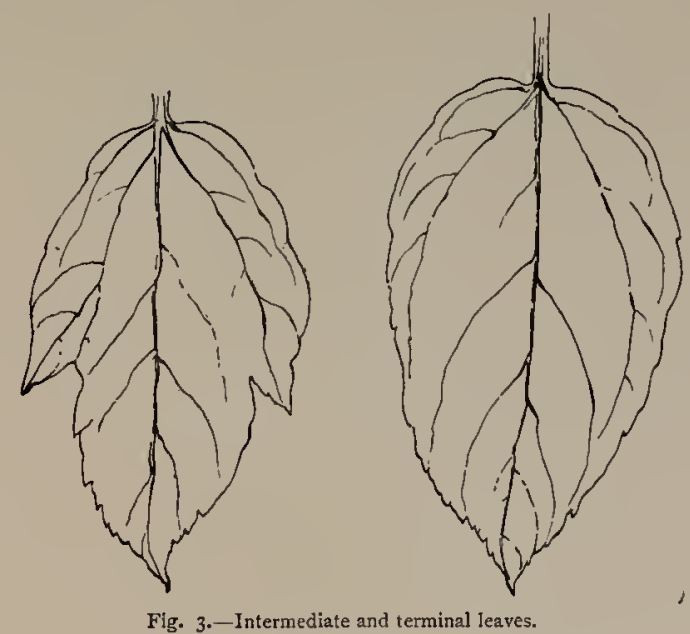

Centre flowers

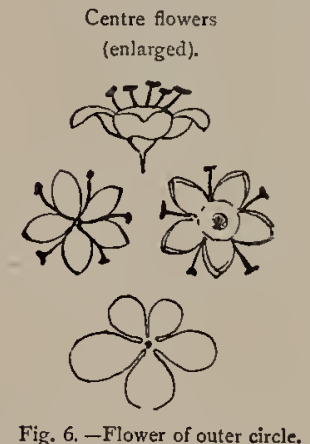

divisions (Fig. 6). These florets are attached to branching pedicels, all springing from one stalk, resembling when seen from behind the construction of an umbrella.

In autumn the berries become fully matured, ripening into a rich, semi-transparent blood-red colour; and, as they remain for some considerable time after the boughs are quite destitute of foliage, this aspect of the plant might with advantage be utilised by the ornamentist. The general beauty of the Guelder Rose, and its great scope for variety both in form and colour, places it foremost among those growths which are readily adaptable to the innumerable purposes of artistic work.

\section{Plate XlVIII._THE HORSE Chestnut.}

I Hemsley's work on hardy trees it is said, "this highly ornamental tree needs no description," and so our very familiarity with it might lead us to think; but, if the simple question of why it bears the name of Horse Chestnut be raised, we shall find that few outside the students of botany will be able to answer. In some parts of the world the nuts are ground and given to horses, and that fact is supposed by many to account for its name; but few people, although familiar from their earliest days with this stately tree, have noticed (or are even aware of what may be considered its most curious feature, and from which it is much more likely to have taken its name. There are multitudes of almost perfect representations of miniature horse-hoofs and shoes to be found on the branches of the Horse Chestnut, and all the points are directed towards the bole of the tree. It will be interesting, for those who have not observed this strange freak of nature, to examine the boughs of the tree for themselves, and they will be astonished to find, in most cases, how close is the resemblance.

The tree is said to be a native of Asia, and to have been introduced into Europe some three centuries ago; but on the latter point authorities differ considerably. It has most readily naturalised itself, for we have examples all over England, forming a leading feature of our meadows and parks. It has also been extensively used for avenues, of which the finest is probably that 
at Bushey Park, so justly considered one of the sights of the neighbourhood of London ; thousands of persons flock to view it in the spring of the year, when the trees are to be seen in all their glory, studded over with graceful pyramids of siveet-scented blossoms. The Horse Chestnut is interesting and beautiful in all its stages of growth, from the first formation of the bud-shoots enclosed in their gummy scales, which the bees lay under such heavy contribution for their wax in cell-making, to the early appearance of the drooping palmate leaves and the exquisite flowers. As the leaves arrive at perfection, they begin to lie out flat and spreading. After the blossoms have fallen the clusters of nuts commence to form, and about September, when fully ripe, their prickly green casings burst, and the glorious brown nut falls to the ground; yet the tree is still an object of admiration through the golden and brown autumnal tints of the foliage until the winds of chill November sweep its branches bare.
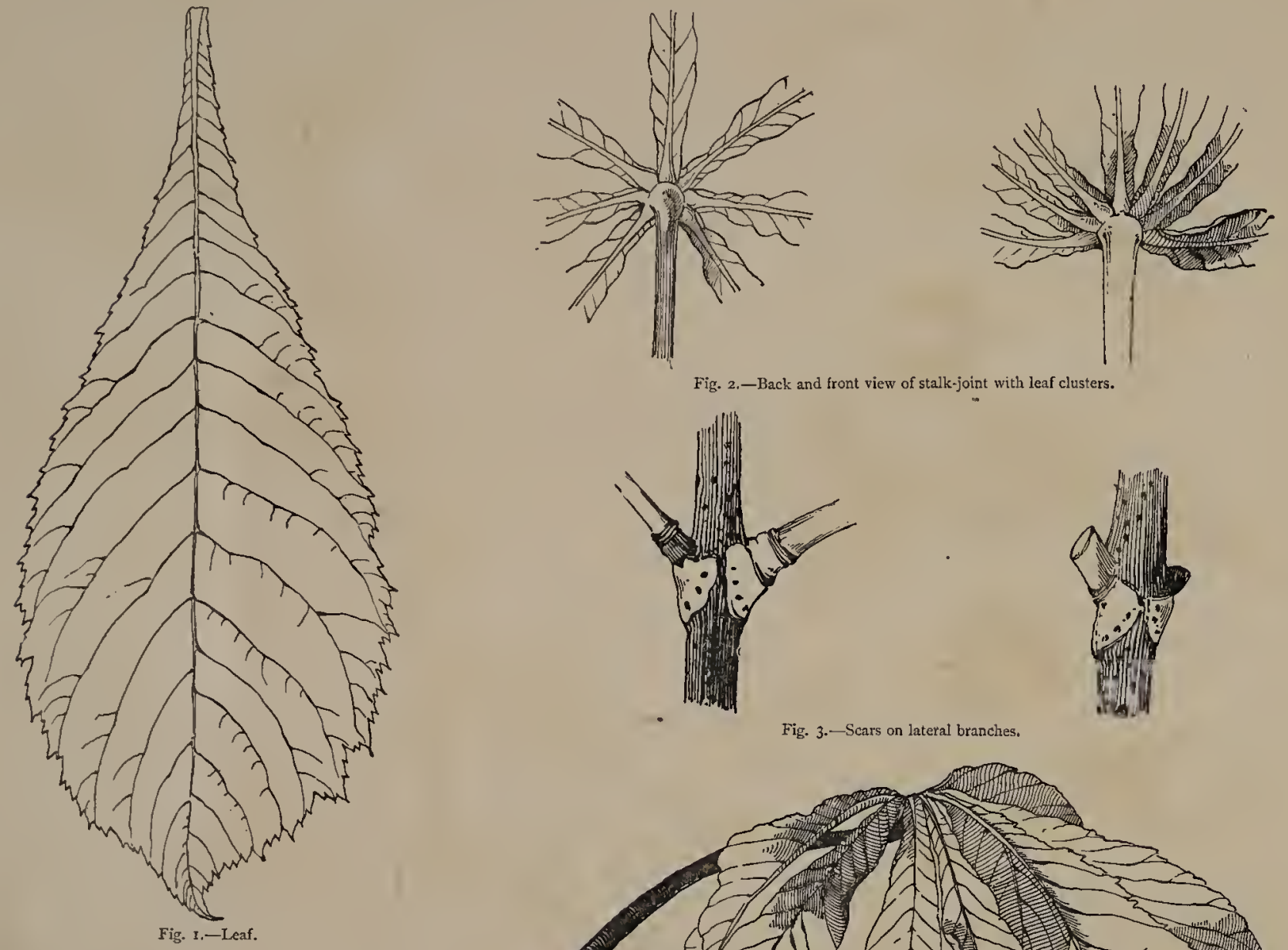

Fig. 2.-Back and front view of stalk-joint with leaf clusters.
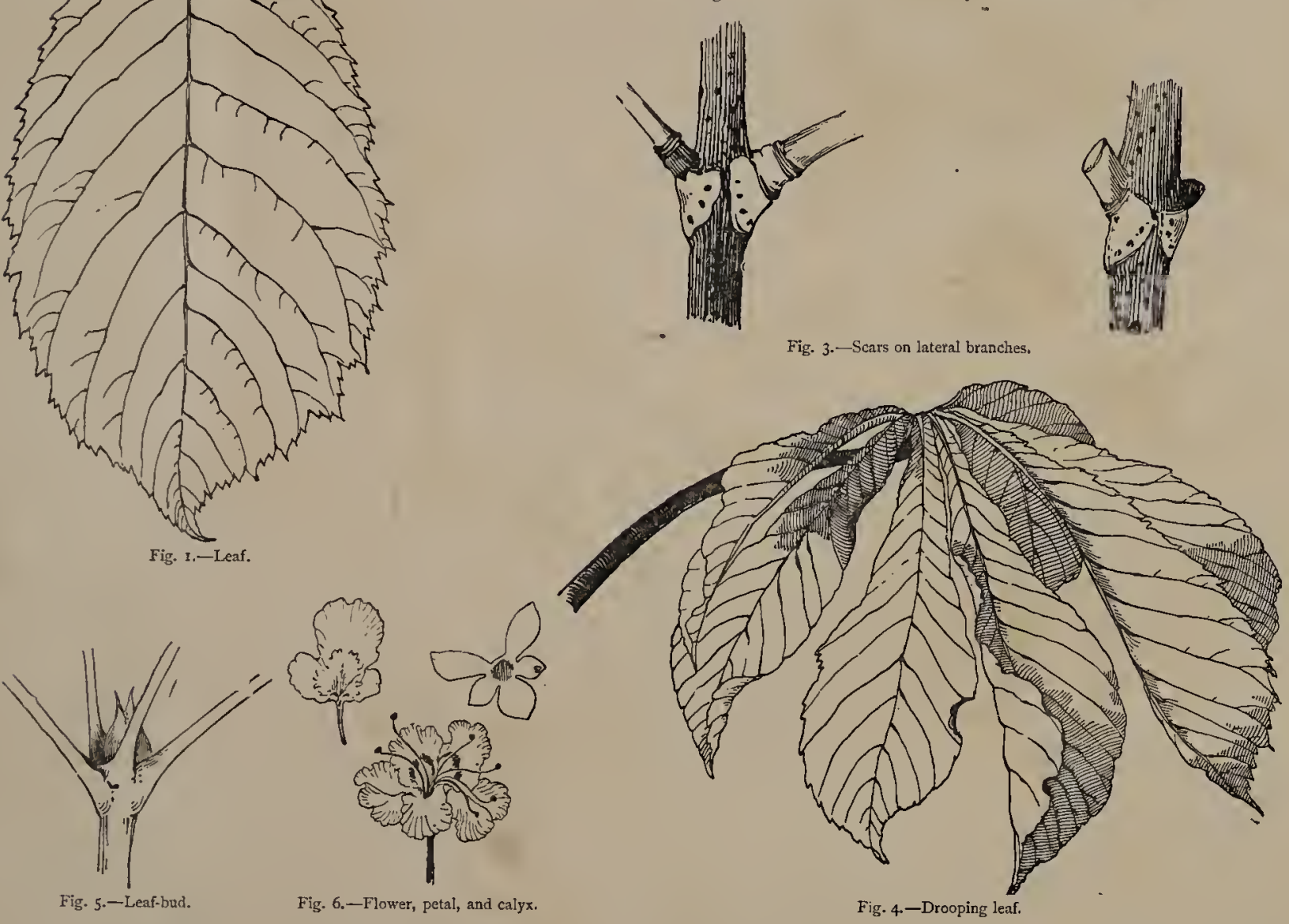

The cluster of leaves is formed by four, five, or seven leaflets (the latter number being the most general and characteristic), which are elongate in form, widening towards the tips, slightly toothed, and finely serrated; centre ribbed; and veined in straight lines to their edges, the veins being most prominent on the under sides (Fig. 1). They are firmly fixed at the end of long and strong stalks (Fig. 2), that grow opposite each other alternately about the lateral or terminal shoot. The stalks on falling off leave a scar, which forms the suggested resemblance to a horse-shoe (Fig. 3). In their early stages the leaflets droop from the end of the stalk (Fig. 4), gradually spreading until they assume a horizontal position.

The lateral shoots grow, like the leaves, opposite and from inside the leaf-stalk joint, terminating either with a flower-spray or leaf-bud (Fig. 5).

The flower-spray grows as a terminal, the stalk being always upright, with the blossoms springing from it in a pyramidal form. Each flower is composed of five crinkled petals (Fig. 6), of a pale yellowish white, having on the two upper petals a brightly-coloured centre, the colour of 


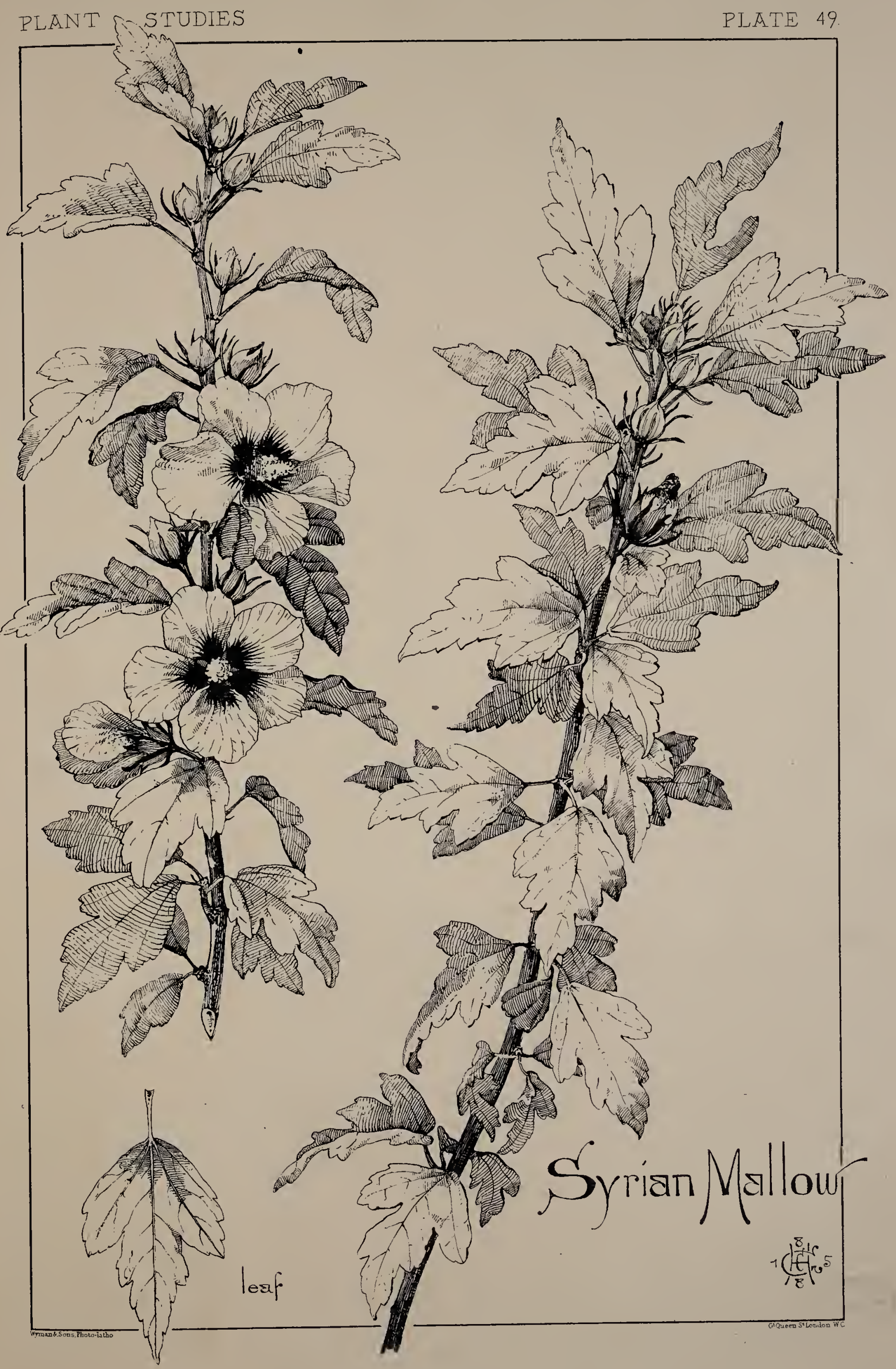



which varies considerably, some being yellow or orange, delicate rose-pink or brilliant red, and others all shades of salmon, dull yellows and browns. The pistil and stamens are white, tipped with a yellow or deep orange colour.

When we consider the variety of purposes and objects to which this beautiful growth could be applied in ornamental embellishment, it appears more than singular that we so seldom see it used in decorative work. The leaf and branch-growths offer little if any difficulty in adaptation, a remark also applying to the upright spray of prickly nuts; but it must be admitted that the quaintlyformed flower needs considerable modification and simplification to be made serviceable for artistic work intended for reproduetion and repetition.

\section{Plate XliX.-THE SYRIAN MALLOW.}

$\mathrm{T}$

H IS beautiful shrub is of the Hibiscus, or Mallow family. It is very hardy, and possesses an elegantly-shaped leaf, most striking bud and flower forms, and an extensive colour range, comprising bright purple blossoms marked with black; white with purple; pale yellow with intermediate shades, besides double-flowered varieties which have variegated foliage. Attractive and ornamental though this shrub is, it appears to be little known. Yet its hardy habit and easy culture should recommend it as a showy and welcome addition to our gardens and shrubberies,

The branch illustrated was taken from a shrub that was about six feet in height: woody, much branched and leafy, and bright with numerous blossoms of a delicate mauve colour, marked

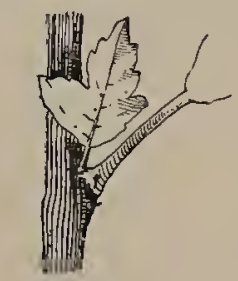

Fig. 1.-Leaflets.

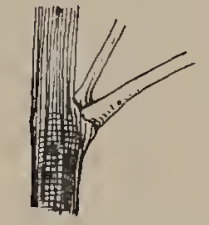

Fig. 2.-Flower and learstalks.

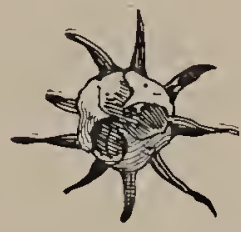

Fig. 3.-Calyx.

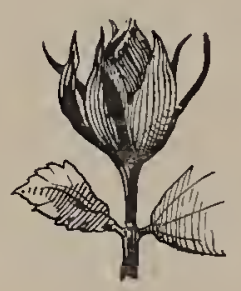

Fig. 3 .

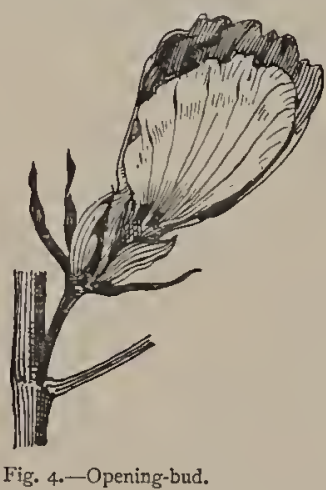

Fig. 4. - Opening-bud.

at their base with fringed spots of rich carmine. The old wood of the Syrian Mallow is grey green, leading into brown hues, and the young wood is of a more decided green.

The leaves are rich green in colour, veined with a lighter shade. They are of a regular threelobed form, with serrated and rounded edges, and grow alternately from the stem, or in clusters of three and four around short lateral shoots. At the base of the leaf-stalks narrow stipules spring, and small leaflets also are frequently to be found (Fig. I).
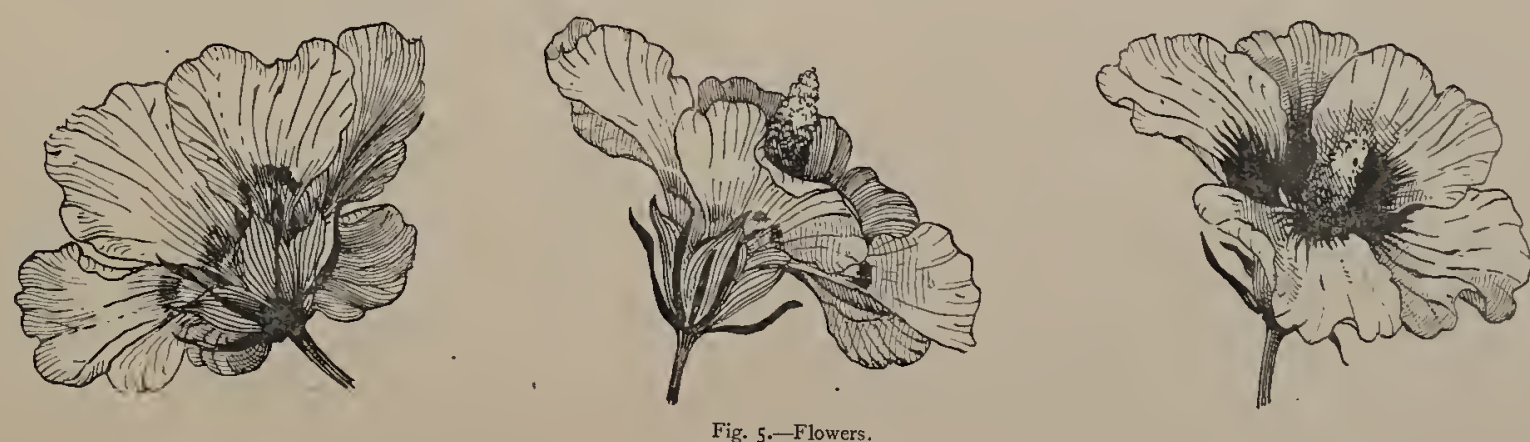

The flowers grow singly on axillary stalks (Fig. 2), or as terminals. In their early stages they are enveloped in a double calyx, the outer part of which is composed of an unequal number of dark green, narrow and persistent leaves, divided down to (very rarely united at) the base. The inner part is composed of one pale-green cup-shaped leaf, either five-cleft half-ivay down or with five teeth only and deciduous (Fig. 3). In the opening buds the petals are disclosed tightly packed, and much crinkled (Figs. 3 \& 4). During development they take many pleasing forms, adding greatly to the general characteristic effect of the plant. 
The corolla of the flower is composed of five delicate mauve, spreading petals, veined, and marked towards their base by blotches of deep carmine colour. The stamens are dull yellow, numerous, and connected to a cylindrical-shaped pistil which rises from the centre of the flower (Fig. 5).

The flower of the Syrian Mallow somewhat resembles that of the Single Hollyhock (which is also a member of the same genus), but there is a marked difference in thc calyx. The resemblance, however, might prove useful in flat surface decoration where the growth of the Mallow could be easily adapted, and that of the Hollyhock would be difficult, if not impossible. As a plant suited for, and readily subservient to, the most exacting of decorative requirements, the Syrian Mallow has everything to recommend it, and to many purposes of art needle-work it could be readily applied.

\section{Plate L.-THE RED BRYONY.}

$\mathrm{T}$

HE Red Bryony, or IVild Vine, as it is sometimes called, is one of the most conspicuous of our berried climbers. In early spring its long soft grey shoots, covered with silvery hairs, and the unfolding leaves, are very attractive; later, as the months advance, the expansion of the leaves into beautiful palmate forms, and the appearance of the flowers, succeeded by the brilliant berry-clusters, are full of interest. It is plentifully supplied with
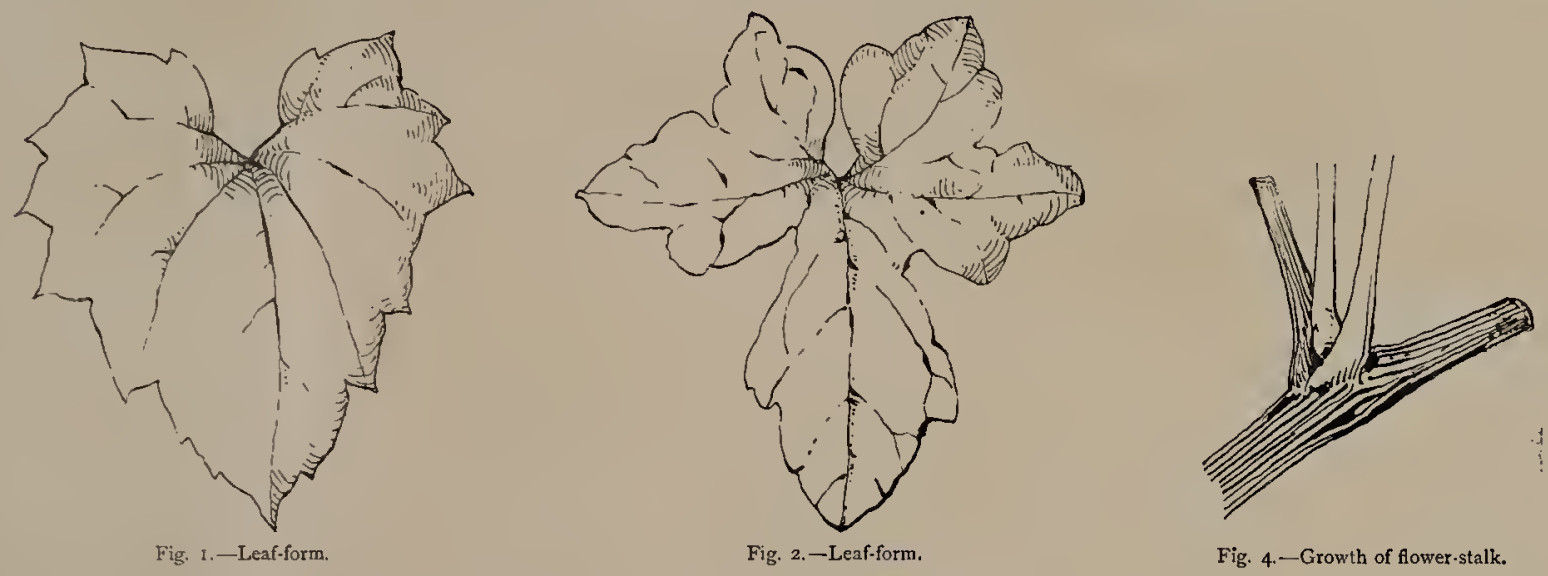

tendrils, by which it attaches itself to surrounding objects, and twining in and out in all directions intermingles with the multitude of other growths that adorn our hedgerows.

In the young growth the leaves are of a rich yellowish green, and become deeper in hue as
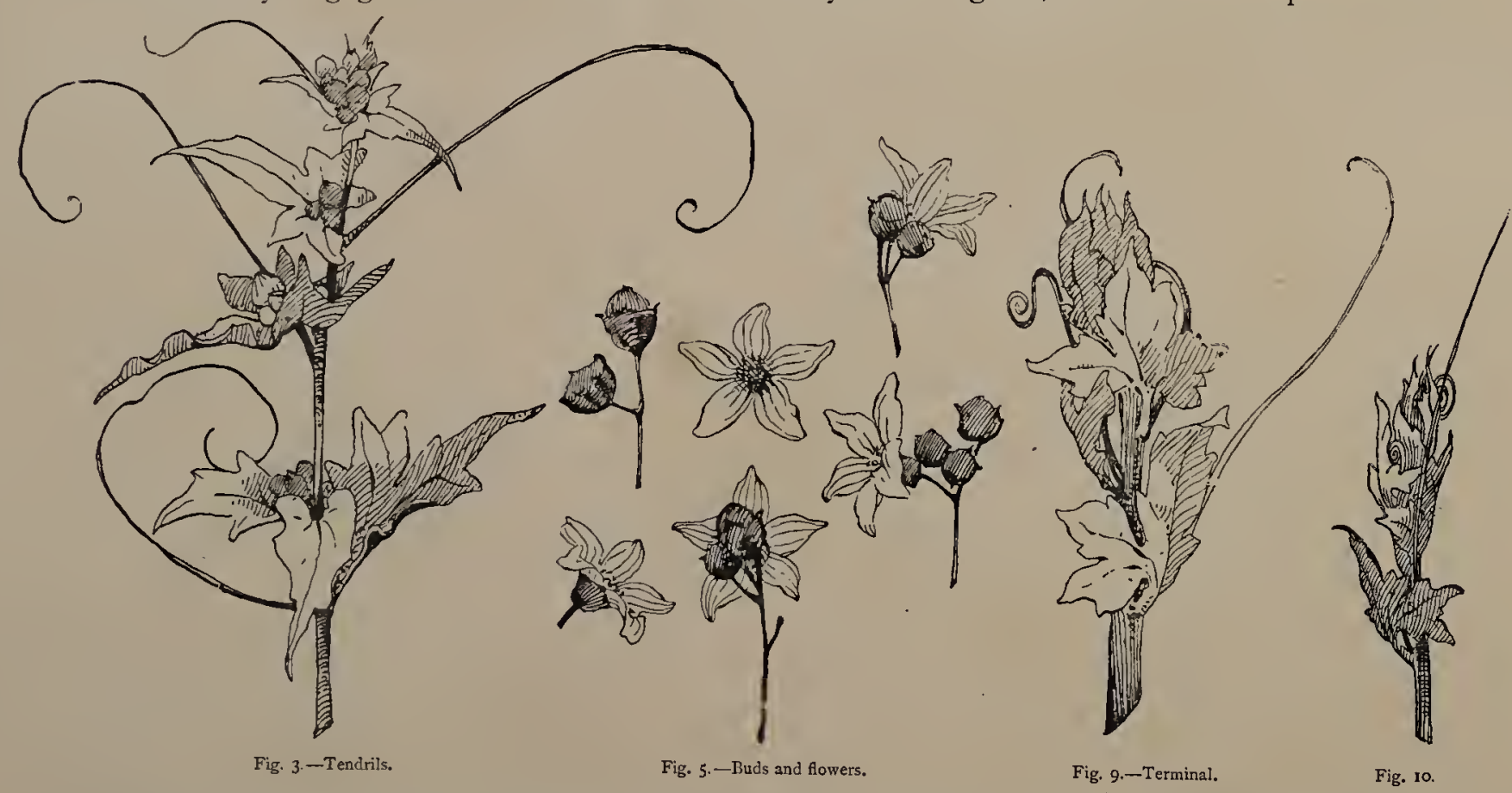

they develope. They grow on stalks of medium length, either opposite one another or set alternately round the stem; are of elegant palmate forms, with five or seven principal veins, and rough on both sides, being covered with thick bristly hairs. The plant may be said to create for itself two distinct 


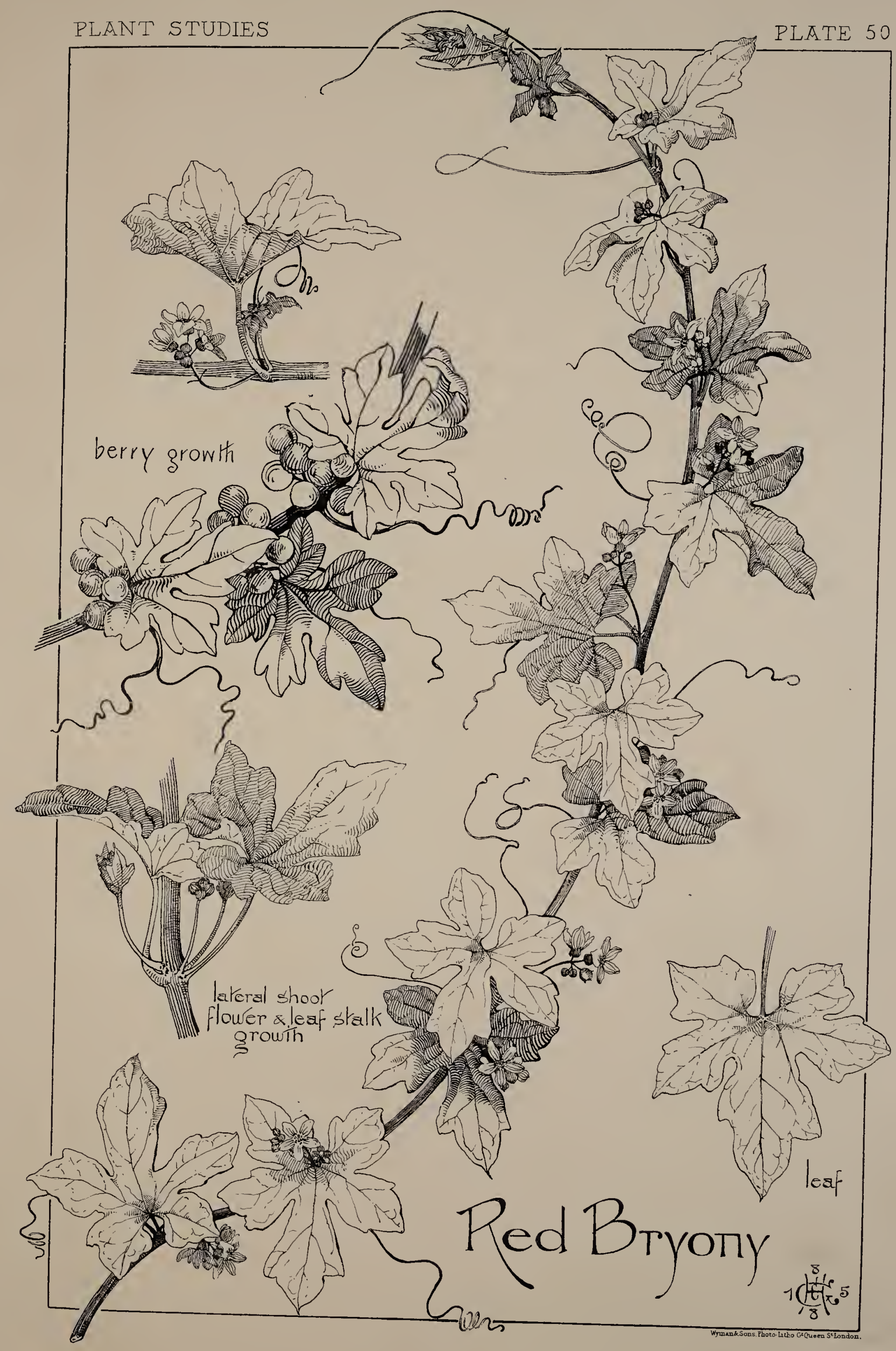



leaf-forms (Figs. I and 2), although departures from these are not infrequent. In the younger or terminal growths it is common to find the leaves like Fig. I, but the older leaf (Fig. 2) is more characteristic of the plant.

From the side of the leaf-stalk, where it joins the stem, spring the long twining tendrils (Fig. 3), which add so much to the graceful appearance of this vigorous climber.

There are two distinct forms of flowers, the male and the female, which grow on separate plants. The male flowers are the largest, and grow several together on a long stalk, which springs from inside the leaf-joint (Fig. 4). The female, or berry-bearing flowers grow on short stalks and cluster close to the stem. The male flower is composed of five greenish white petals veined with green, set within a bell-shaped calyx of a somewhat darker shade of green than the under part of the flower; and in the centre rise four small pale yellow stamens (Fig. 5).
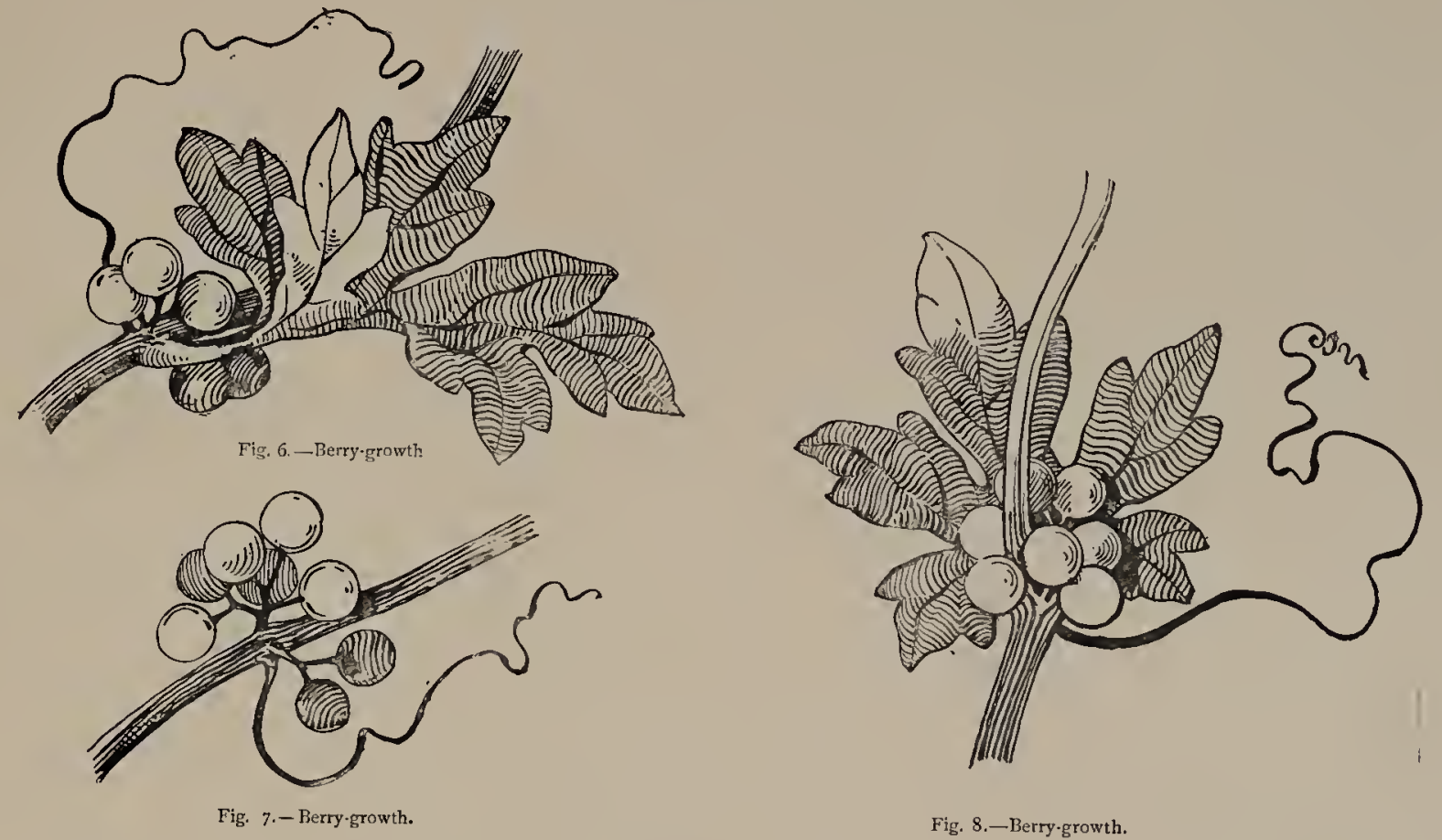

The berries attain maturity during August or September, and are then about the size of large peas (Figs. 6, 7, \& 8), and comprise every imaginable shade between yellow, green, and red.

The use of this plant is so frequent in old work,-especially in the embellishment of wood and stone,-that it has evidently been a favourite growth. It is also constantly used by modern art-workers, but is, unfortunately, too often robbed of its true character, and made to climb and twist by its stem in the manner of the Black Bryony, with which it has doubtless been confounded. If the two plants be compared, a little reflection will show how much more suited is the rounded leaf of the Black Bryony to the spiral grace of its growth, than the palmated and more determined leaf-forms of the Red Bryony, which, if its true growth be retained, is suggestive of a severe gothic treatment. This gothic feeling, so to speak, is particularly noticeable in its beautiful leaf-terminals (Figs. 9 and ro).
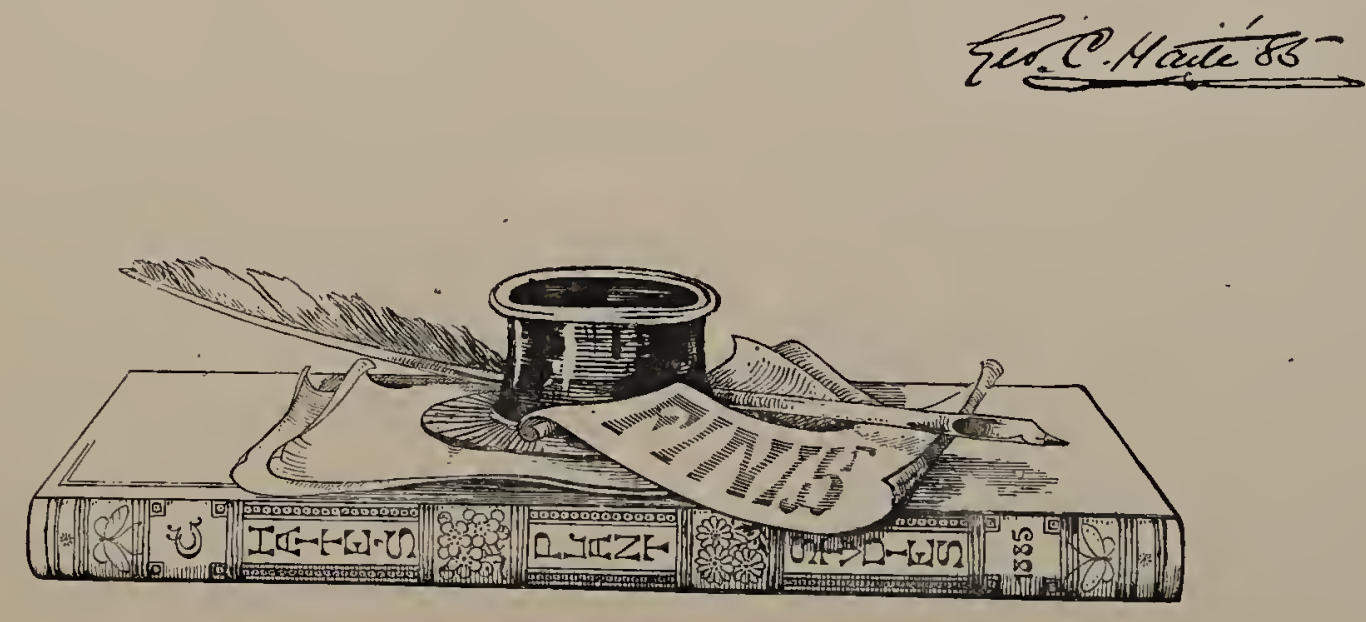


